JOSIANE PALMA LIMA

\title{
MODELO DE DECISÃO PARA A PRIORIZAÇÃO DE VIAS CANDIDATAS ÀS ATIVIDADES DE MANUTENÇÃO E REABILITAÇÃO DE PAVIMENTOS
}

Tese apresentada à Escola de
Engenharia de São Carlos da
Universidade de São Paulo para
obtenção do título de Doutor em
Engenharia Civil com ênfase em
Transportes.

Orientador: Prof. Dr. José Leomar Fernandes Júnior

São Carlos 
AUTORIZO A REPRODUÇÃO E DIVULGAÇÃO TOTAL OU PARCIAL DESTE TRABALHO, POR QUALQUER MEIO CONVENCIONAL OU ELETRÔNICO, PARA FINS DE ESTUDO E PESQUISA, DESDE QUE CITADA A FONTE.

Ficha catalográfica preparada pela Seção de Tratamento da Informação do Serviço de Biblioteca - EESC/USP

Lima, Josiane Palma
Modelo de decisão para a priorização de vias
candidatas às atividades de manutença e reabilitação de
pavimentos / Josiane Palma Lima ; orientador José Leomar
Fernandes Júnior. -- São Carlos, 2007 .
Tese (Doutorado-Programa de Pós-Graduação e Área de
Concentração em Engenharia de Transportes) -- Escola de
Engenharia de São Carlos da Universidade de São Paulo,
2007.
1. Gerência de pavimentos. 2. Priorização de vias
pavimentadas. 3. Análise multicritério de decisão.
S. Sistema de informação geográfica. I. Título.


Dedico este trabalho à minha filha Mariana, pela alegria incessante em todos os momentos

e, principalmente, ao meu marido Renato pelo constante incentivo e valioso amor dedicado. 



\section{AGRADECIMENTOS}

Ao orientador, Prof. Dr. José Leomar Fernandes Júnior, pela confiança, orientação, amizade e pela oportunidade de realizar este trabalho.

Ao Prof. Dr. Rui António Rodrigues Ramos, pela co-orientação, conhecimentos compartilhados e, principalmente, pela amizade durante o estágio realizado na Universidade do Minho e durante todo o período de doutorado.

Aos professores do STT pela convivência e conhecimentos transmitidos ao longo desses anos.

Aos meus pais e irmãos, pelo otimismo e apoio sempre transmitidos nos momentos de alegria e dificuldades.

Às amigas Nívea e Adriana, que compartilharam todos os momentos vividos em São Carlos e, principalmente, pela amizade fortalecida durante esse período de convivência e inabalável para o resto da vida.

Aos amigos do STT, em especial, Ana, Marcela, Alexandre, Everton, Célio, Deda, Gisele, Juliana, Rômulo, Marcão, Ricardinho, Manuel, Cida, Rafael, Adriane e a todos os outros pelos momentos de alegria e convivência.

Aos amigos da Universidade do Minho: José Mendes, Lígia, Daniel, Tojó, André, Paula Nunes, Rui Miguel, Sampaio Duarte e Anabela, pela amizade e todo o apoio dado no período de estada em Portugal.

Aos funcionários do STT: Heloisa, Beth, Magali, Sueli, Alex e Carlos, pela cooperação e incentivo.

À CAPES, pelo apoio financeiro concedido nos três primeiros anos de doutorado. 



\section{RESUMO}

LIMA, J. P. (2007). Modelo de decisão para a priorização de vias candidatas às atividades de manutenção e reabilitação de pavimentos. 170 p. Tese (Doutorado). Escola de Engenharia de São Carlos, Universidade de São Paulo, São Carlos, 2007.

Desenvolver programas de conservação, a partir do conhecimento prévio do estado dos pavimentos, possibilita obter determinados níveis de qualidade em toda a rede viária. No entanto, num cenário de carência financeira, manter esses níveis de qualidade só é possível se as decisões forem tomadas considerando as seções mais prioritárias às atividades de Manutenção e Reabilitação (M\&R) dos pavimentos. O objetivo geral deste trabalho é propor um modelo de priorização de vias, baseado na Metodologia de Análise Multicritério agregada a um Sistema de Informação Geográfica (SIG), considerando critérios objetivos e subjetivos no apoio à tomada de decisão. Fez parte deste trabalho uma pesquisa sobre a situação atual referente aos procedimentos de gerência da conservação de pavimentos utilizados em cidades médias brasileiras. Foi realizado um estudo de caso, na cidade de São Carlos - SP, utilizando um levantamento preliminar da condição do pavimento e de suas características físicas e geométricas, no que se refere às seções de vias urbanas, que são de responsabilidade da prefeitura. O modelo desenvolvido neste trabalho, que utiliza AHP (Analytic Hierarchy Process) e SIG, é adequado à realidade das cidades médias brasileiras, mas mantém a viabilidade de aplicação em cidades de outras dimensões, desde que as particularidades dessas cidades sejam consideradas. É destinado a auxiliar administradores de órgãos governamentais que têm a função de avaliar e planejar as intervenções de conservação em vias urbanas pavimentadas.

Palavras-chave: Gerência de pavimentos; Priorização de vias pavimentadas; Análise Multicritério de Decisão; Sistema de Informação Geográfica. 



\begin{abstract}
LIMA, J. P. (2007). Decision model for prioritization of urban roadways candidate to pavement maintenance and rehabilitation activities. 170 p. Ph.D. Thesis. São Carlos Engineering School, University of São Paulo, São Carlos, 2007.

The development of conservation programs, starting from the previous knowledge of pavements condition, makes possible to maintain certain quality levels in the roadway system. However, in a lack of budget scenario, to achieve those quality levels the decisions have to be taken considering a pavement Maintenance and Rehabilitation (M\&R) prioritization program. The general objective of this work is to propose urban roadways prioritization model based on Multicriteria Decision Analysis aggregated to Geographical Information System (GIS), considering objective and subjective criteria in the decision support. A case study was performed at the city of São Carlos, State of São Paulo, Brazil, using a preliminary study of pavement condition and physical and geometric characteristics. It was also performed a research about the current situation regarding the procedures for pavement maintenance and rehabilitation management in Brazilian medium-sized cities. The model developed in this work, that uses AHP (Analytic Hierarchy Process) and GIS is adapted to the reality of the Brazilian medium-sized cities, but it maintains the application viability in cities of other dimensions, since the particularities of those cities are considered. It is dedicated to help administrators of government agency responsible for the evaluation of urban roads and pavement conservation planning.
\end{abstract}

Keywords: Management of pavements; Prioritization of roads; Multicriteria Decision Analysis ;. Geographical Information System 



\section{LISTA DE FIGURAS}

Figura 2.1: Níveis de decisão na gerência de pavimentos (VISCONTI, 2000) ............................................... 11

Figura 2.2- Etapas na implantação de um SGPU ............................................................................................ 14

Figura 3.1: Etapas de programas de prioridades (Adaptada de Haas et al., 1994) ....................................... 41

Figura 3.2: Cálculo do Índice de Prioridade segundo Chen et al. (1993)..........................................................51

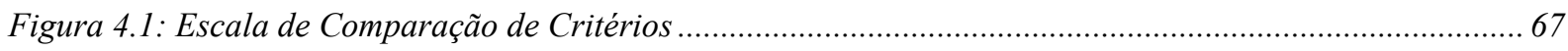

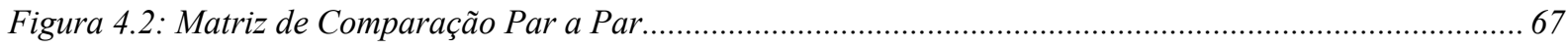

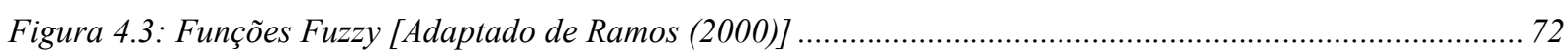

Figura 4.4: Espaço estratégico de decisão - OWA [Adaptado de Ramos (2000)] ....................................... 76

Figura 4.5: Exemplo de banco de dados em SIG - ArcView .................................................................... 83

Figura 4.6: Exemplo de sobreposição de temas de linhas e pontos no ArcView ................................................83

Figura 5.1: Modelo de avaliação multicritério de prioridades de $M \& R$ em ambiente SIG............................. 89

Figura 5.2: Modelagem utilizada para a obtenção do mapa final de prioridades.............................................. 89

Figura 5.3: Estrutura hierárquica do modelo de priorização de seções de vias pavimentadas ......................... 101

Figura 6.1: Localização da cidade de São Carlos- SP ............................................................................. 103

Figura 6.2: Planilha para coleta de dados de inventário. ............................................................................. 105

Figura 6.3: Planilha para avaliação de defeitos no pavimento. ............................................................... 107

Figura 6.4: Estrutura hierárquica reorganizada para o estudo de caso ................................................... 112

Figura 6.5: Fator A1 - mapas não normalizado e normalizado...................................................................... 113

Figura 6.6: Fator B2 - mapas não normalizado e normalizado........................................................ 114

Figura 6.7: Mapa com scores normalizados do fator A1 ............................................................................ 118

Figura 6.8: Mapa com scores normalizados do fator A2 ............................................................... 118

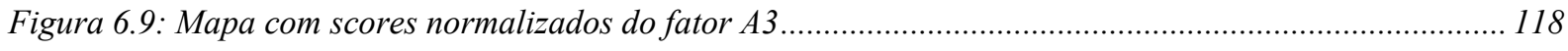

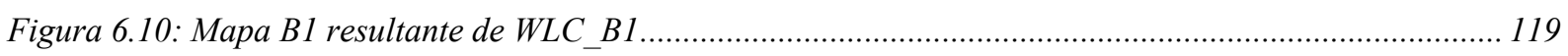

Figura 6.11: Mapa B2 com scores normalizados ............................................................................ 119

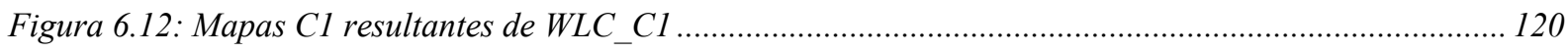

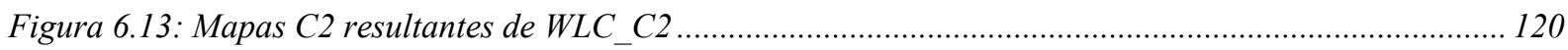

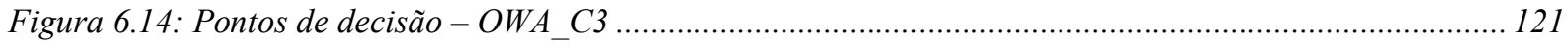

Figura 6.15: Combinação OWA_C3 em SIG-ARCView ................................................................................ 122

Figura 6.16. Cenários do procedimento OWA_C3 no ARCView ............................................................. 123

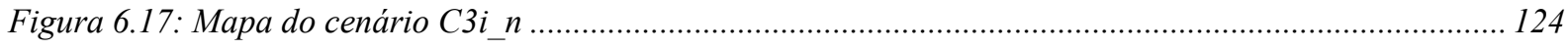

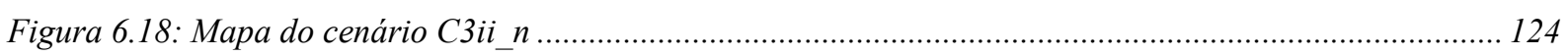

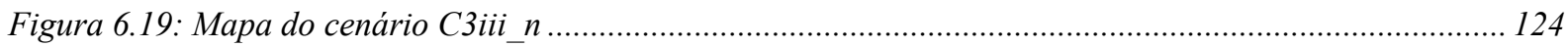





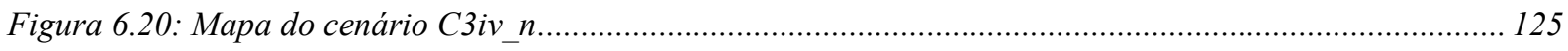

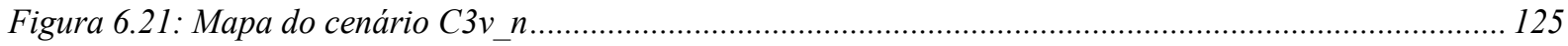

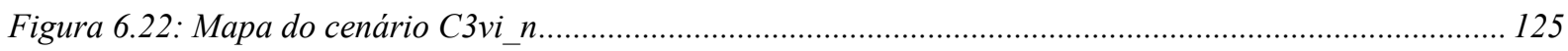

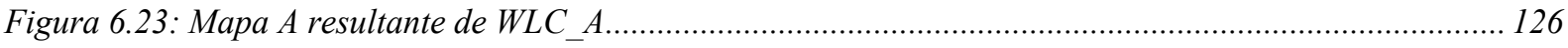

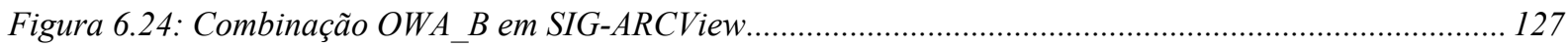

Figura 6.25: Mapas resultantes do procedimento OWA_B........................................................................... 128

Figura 6.26: Mapas resultantes da primeira etapa do procedimento $O W A_{-} C$............................................. 130

Figura 6.27: Mapas resultantes da segunda etapa do procedimento OWA_C .............................................. 131

Figura 6.28: Mapa com scores normalizados do grupo D............................................................... 132

Figura 6.29: Primeira etapa da combinação OWA_G em SIG-ARCView ................................................... 134

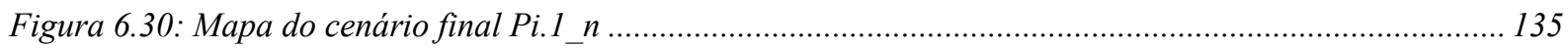

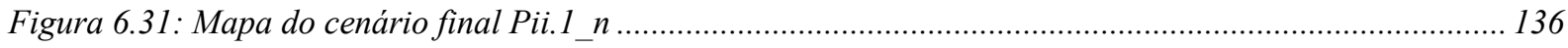

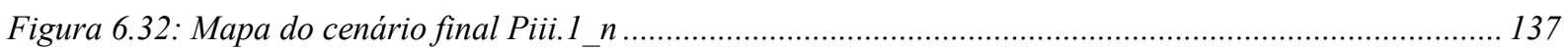

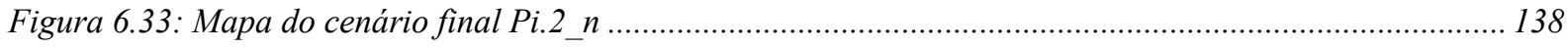

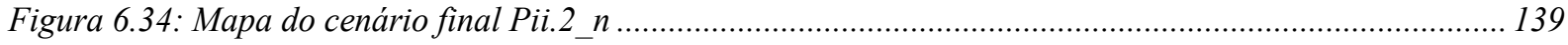

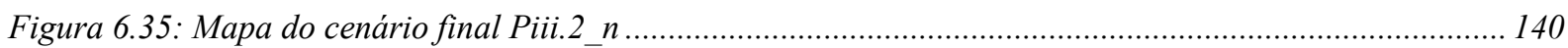

Figura 7.1: Mapa de algumas das principais vias urbanas de São Carlos - SP ....................................... 142

Figura 7.2: Seções de vias urbanas com orçamento limitado .................................................................... 151 



\section{LISTA DE TABELAS}

Tabela 2.1: Freqüencia dos levantamentos de campo e avaliações do pavimento ............................................2 23

Tabela 2.2 : Procedimentos para gestão das atividades de $M \& R$ dos pavimentos .............................................. 23

Tabela 3.1: Índice da Condição de Superfície de Pavimentos Flexíveis (DNIT, 2005a) .................................. 30

Tabela 3.2: Índice do Estado da Superficie do pavimento (DNIT 008/2003-PRO) ........................................... 30

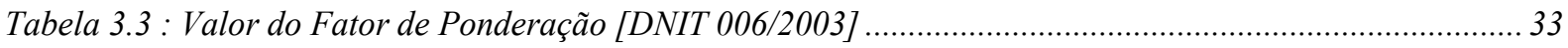

Tabela 3.4: Classes de métodos de programas de prioridades (HAAS et al., 1994)...................................... 43

Tabela 3.5: Prática de seleção de projetos (NCHRP Syntheses 222) ............................................................. 45

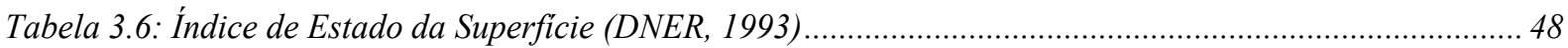

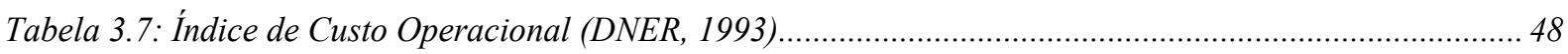

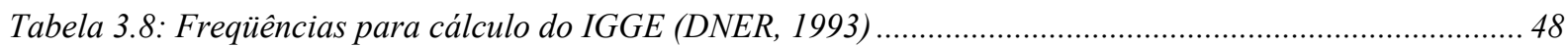

Tabela 4.1: Escala de Comparação de Critérios Segundo Saaty (1980) ........................................................67

Tabela 4.2: Índice de Aleatoriedade (RI) [Adaptada de Saaty (1980)] .............................................................69

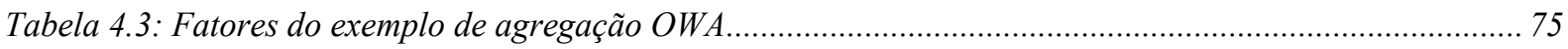

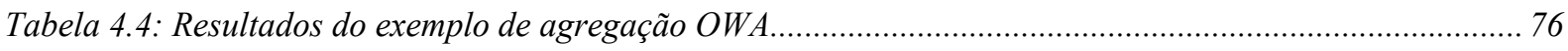

Tabela 5.1:Pesos dos fatores associados à hierarquia viária ......................................................................... 93

Tabela 5.2: Pesos e funções fuzzy dos atributos de necessidade técnica por intervenção ................................. 94

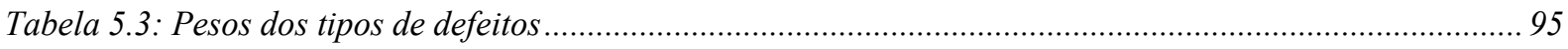

Tabela 5.4: Pesos e funções fuzzy dos fatores associados às questões técnicas e operacionais......................... 96

Tabela 5.5: Pesos e funções fuzzy dos atributos associados à proximidade a Infra-estrutura de Transportes.... 97

Tabela 5.6: Pesos e funções fuzzy dos atributos associados à proximidade a equipamentos e prédios

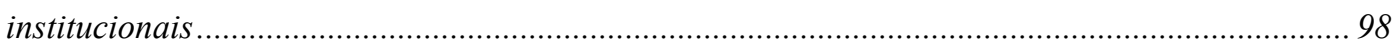

Tabela 5.7: Pesos e funções fuzzy dos atributos associados à preferências pessoais e administrativas............. 98

Tabela 5.8: Pesos dos fatores associados à localização de seções de pavimento.............................................. 99

Tabela 5.9: Pesos e funções fuzzy dos atributos associados aos custos de usuários ....................................... 99

Tabela 5.10: Pesos e funções fuzzy dos fatores associados aos custos ............................................................. 99

Tabela 5.11: Pesos dos grupos de fatores de priorização de seções de pavimentos.......................................... 100

Tabela 5.12: Modelo de priorização - Fatores e grupos de fatores .............................................................. 101

Tabela 6.1: Fatores, pesos e desvio padrão considerados no estudo de caso..................................................... 110

Tabela 6.2: Custos unitários adotados para estratégias de $M \& R$ de pavimentos......................................... 111

Tabela 6.3: Procedimentos adotados para a combinação de critérios ........................................................ 116

Tabela 6.4: Cenários de avaliação empregados para gerar os mapas do fator C3......................................... 122

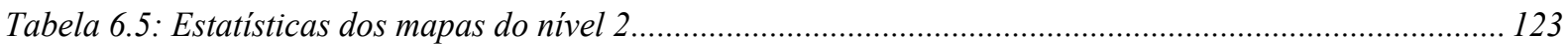



Tabela 6.6: Cenários de avaliação empregados para gerar o mapas do fator $B$

Tabela 6.7: Cenários de avaliação empregados para gerar os mapas do fator C........................................... 129

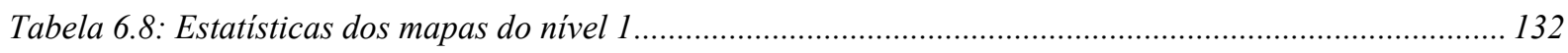

Tabela 6.9: Cenários de avaliação empregados para gerar os mapas finais de priorização............................. 134

Tabela 6.10: Estatísticas dos mapas finais de priorização ........................................................................... 134

Tabela 7.1: Orçamento para o cenário Pi.2_n............................................................................................... 150 



\section{LISTA DE ABREVIATURAS E SIGLAS}

\begin{tabular}{|c|c|}
\hline AASHO & American Association of State Highway Officials \\
\hline AGs & Algoritmos Genéticos \\
\hline AHP & Analytic Hierarchy Process \\
\hline $\mathrm{CO}$ & Custo de Operação dos Veículos \\
\hline DNER & Departamento Nacional de Estradas de Rodagem \\
\hline DNIT & Departamento Nacional de Infra-estrutura de Transportes \\
\hline EBM & Expenditure Budgetary Model \\
\hline ELECTRE & Elimination and Choice Translating Algorithm \\
\hline ES & Expert Systems \\
\hline HDM & Highway Design and Maintenance Standards Model \\
\hline $\mathrm{ICPF}$ & Índice de Condição dos Pavimentos Flexíveis \\
\hline IES & Índice do Estado de Superfície \\
\hline IGG & Índice de Gravidade Global \\
\hline IGGE & Índice de Gravidade Global Expedito \\
\hline IGI & Índice de Gravidade Individual \\
\hline IP & Índice de Prioridade \\
\hline IRI & International Roughness Index \\
\hline IS & Índice de Suficiência \\
\hline LVC & Levantamento Visual Contínuo \\
\hline$M \& R$ & Manutenção e Reabilitação \\
\hline MAUT & Multiple Attribute Utility Function \\
\hline MCDA & Multicriteria Decision Analysis \\
\hline MCDM & Multicriteria Decision Making \\
\hline OWA & Ordered Weighted Average \\
\hline PO & Pesquisa Operacional \\
\hline PROMETHEE & Preference Ranking Method for Enrichment Evaluation \\
\hline PSI & Present Serviceability Index \\
\hline RNA & Redes Neurais Artificiais \\
\hline
\end{tabular}



SAAE

SAD

SADE

SGP

SGPU

SHRP

SIG

TRRL

URMS

VDM

VSA

WLC
Serviço Autônomo de Água e Esgoto

Sistemas de Apoio à Decisão

Sistemas de Apoio à Decisão Espacial

Sistema de Gerência de Pavimentos

Sistema de Gerência de Pavimentos Urbanos

Strategic Highway Research Program

Sistema de Informação Geográfica

Transport and Road Research Laboratory of Technology

Urban Roadway Management System

Volume Diário Médio

Valor de Serventia Atual

Weighted Linear Combination 



\section{SUMÁRIO}

1 INTRODUÇÃO

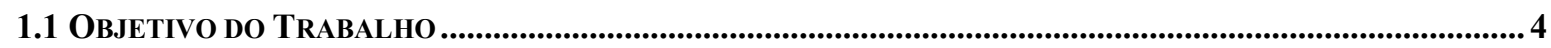

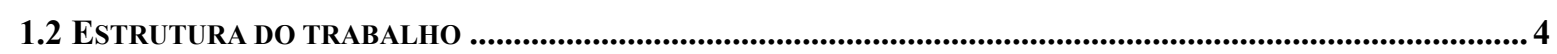

2 GERÊNCIA DA CONSERVAÇÃO DE PAVIMENTOS........................................................................

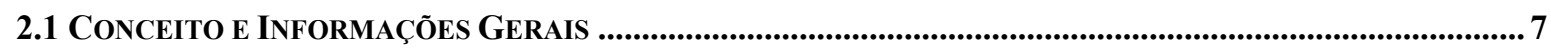

2.2 Sistemas de GERÊnCIA de PaVIMENTos URBanos (SGPU) ............................................................ 13

2.3 Critérios de Decisão na GerênCIA de PaVimentos...................................................................... 17

2.4 GerênCIA de PaVimentos EM Cidades Médias BrasileIRAS............................................................ 20

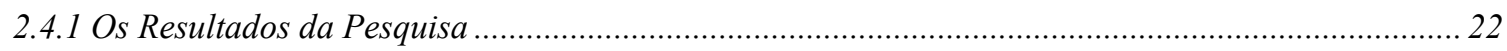

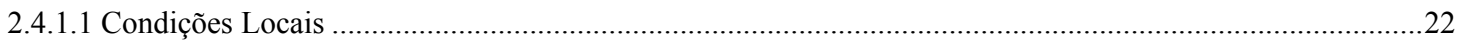

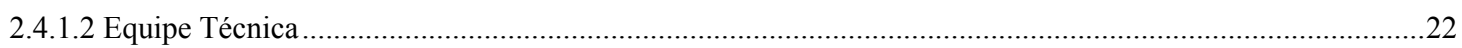

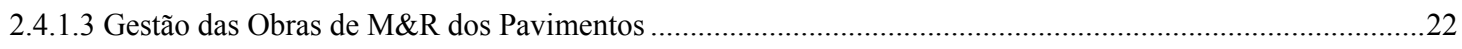

2.4.1.4 Procedimentos Associados à Priorização de Seções....................................................................................23

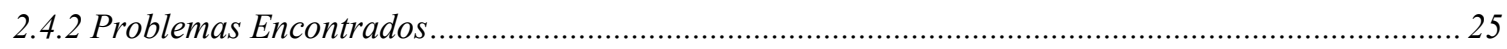

3 DEFINIÇÃO DE PRIORIDADES DE MANUTENÇÃO E REABILITAÇÃO DE PAVIMENTOS 27

3.1 Fatores E ParâMetros AsSociados À DeFinição de Prioridades ...................................................2 27

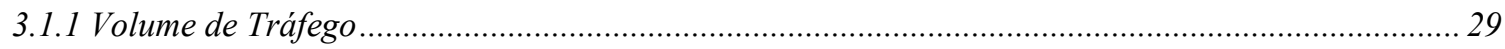

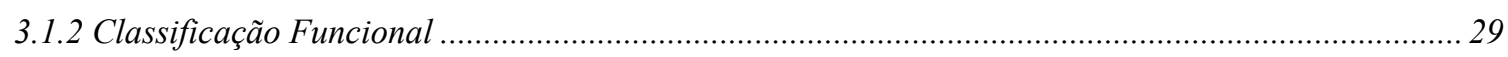

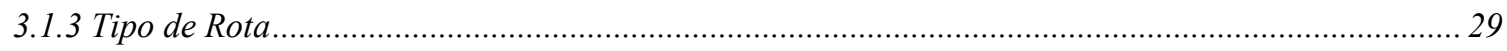

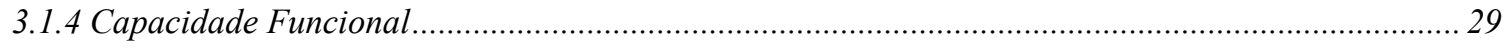

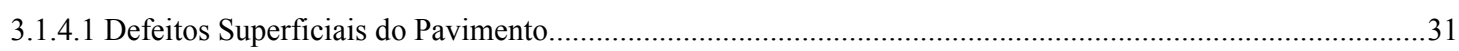

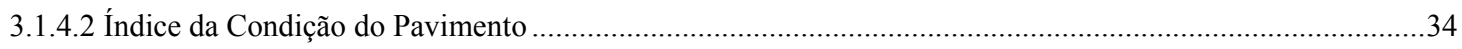

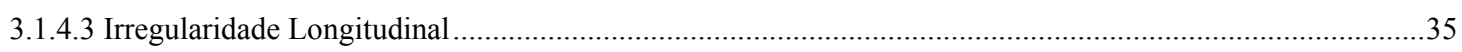

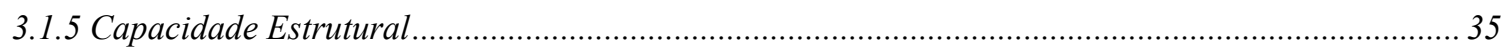

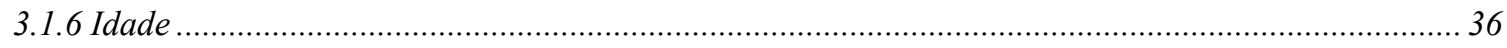

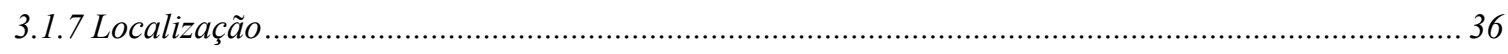

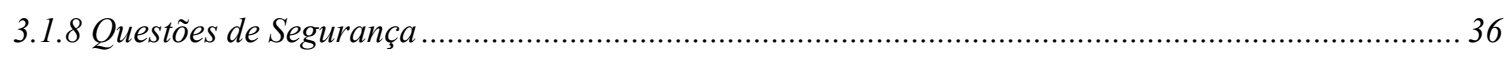

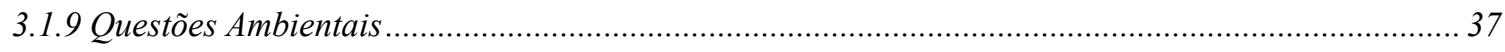

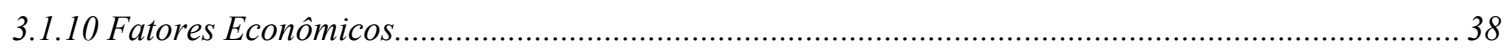

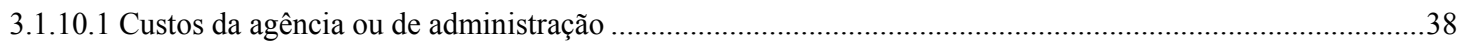

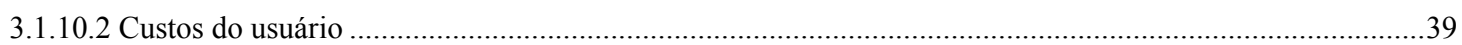





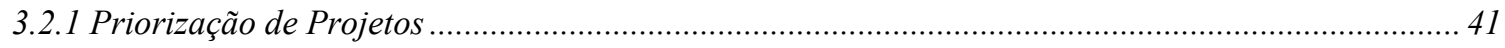

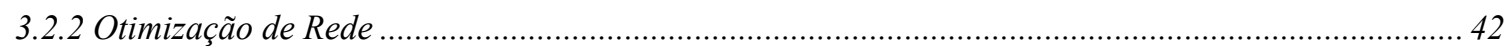

3.2.3 Comparação entre Priorização e Otimização .............................................................................. 43

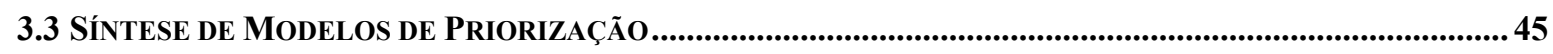

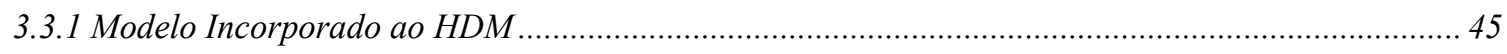

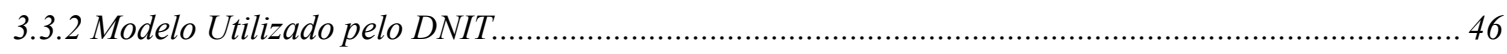

3.3.3 Modelos de Seleção de Seções de Pavimentos Urbanos....................................................................... 49

4 O APOIO À DECISÃO NA GERÊNCIA DE PAVIMENTOS ..................................................53

4.1 A Gerência de Pavimentos e o Apoio À decisão.......................................................................56

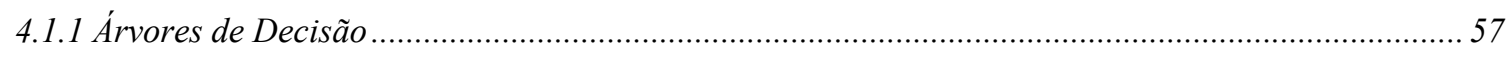

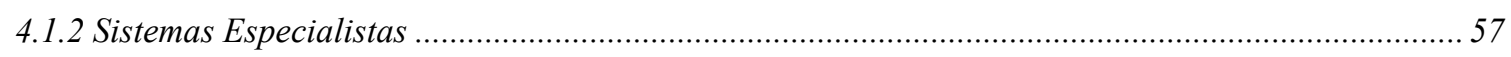

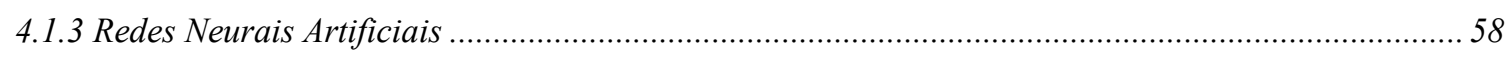

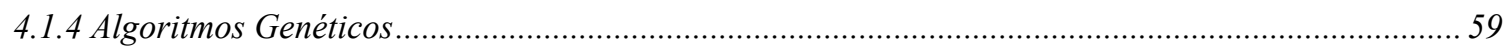

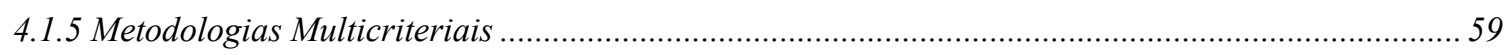

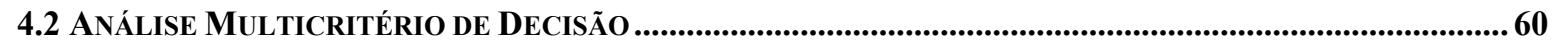

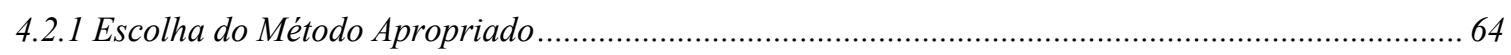

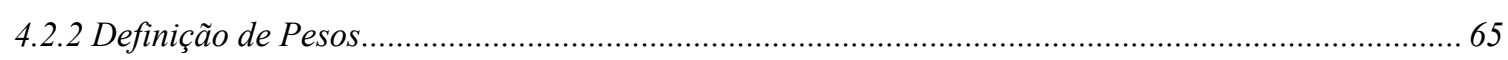

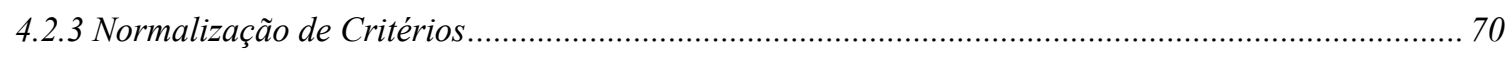

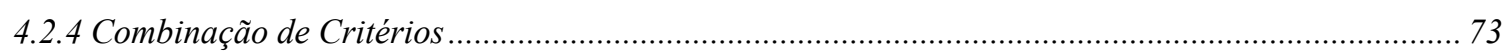

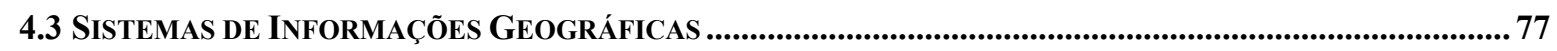

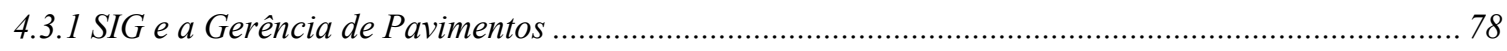

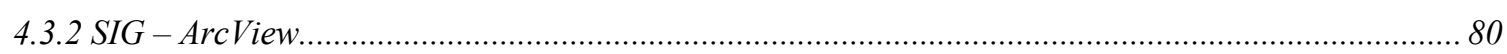

5 O MODELO DE PRIORIZAÇÃO DE SEÇÕES DE PAVIMENTOS PARA CIDADES MÉDIAS

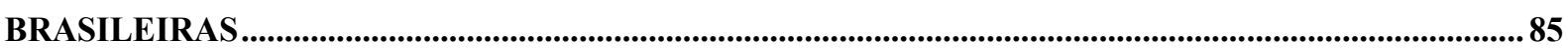

5.1 DEFINIÇÃO DE TÉCNICA E DA IMPLEMENTAÇÃO EM AMBIENTE SIG ................................................85

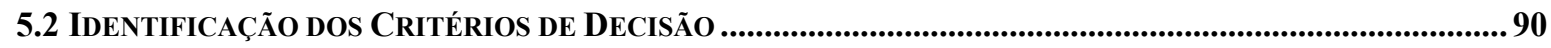

5.3 DEFINIÇÃo dos PESOS E dAS FUNÇÕES FUZZY ASSOCIADAS AOS CRITÉRIOS ...........................................91

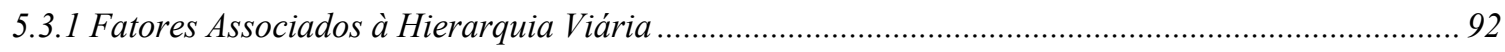

5.3.2 Fatores Associados às Questões Técnicas e Operacionais............................................................ 93

5.3.3 Fatores Associados à Localização das Seções de Pavimento............................................................96

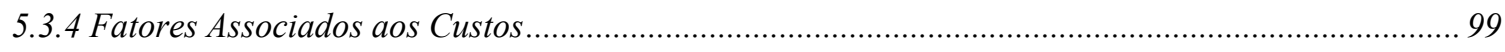

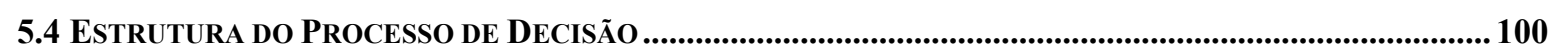

6 APLICAÇÃO DO MODELO DE PRIORIZAÇÃO: ESTUDO DE CASO PARA A CIDADE DE

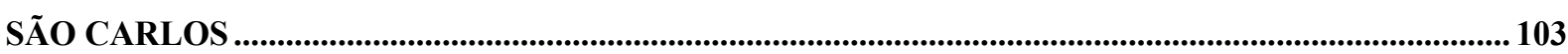

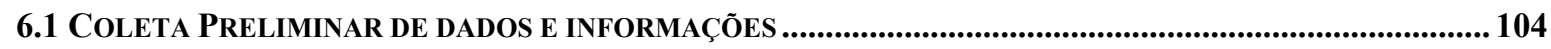

6.1.1 Levantamento de campo sobre as vias urbanas da cidade de São Carlos.................................... 104 

6.1.2 Localização de equipamentos públicos, infra-estruturas de transportes e outras instalações

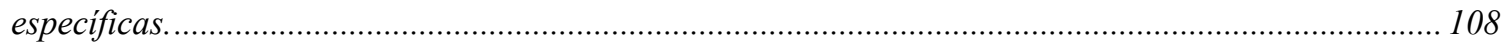

6.2 IDENTIFICAÇÃO DOS FATORES CONSIDERADOS NO ESTUDO DE CASO ..............................................109

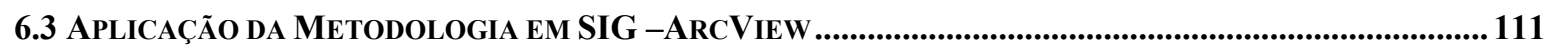

6.3.1 Desenvolvimento de mapas com scores normalizados............................................................ 113

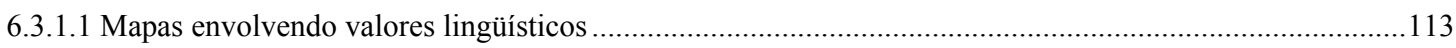

6.3.1.2 Mapas envolvendo valores numéricos..............................................................................................114

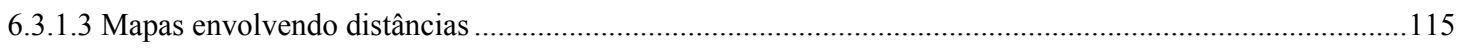

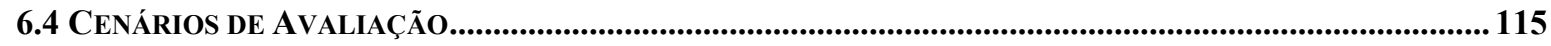

6.4.1 Processo de Combinação WLC - Nível 3 .................................................................................. 117

6.4.2 Processo de Combinação OWA - Nível 3...................................................................................... 121

6.4.3 Processo de Combinação WLC - Nível 2 ............................................................................ 126

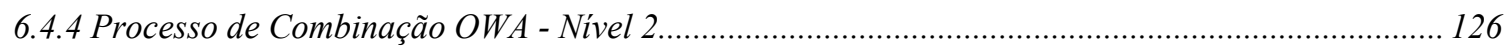

6.4.5 Processo de Combinação OWA - Nivel 1................................................................................ 133

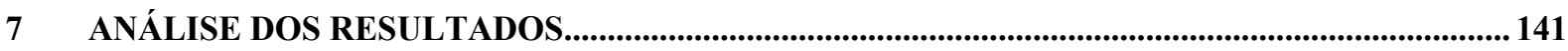

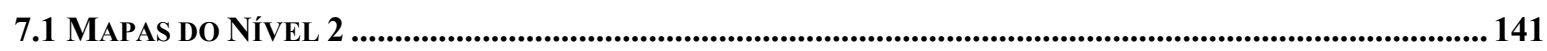

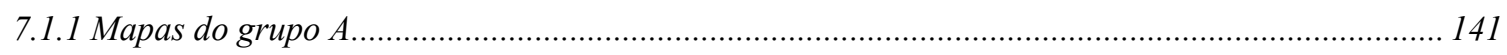

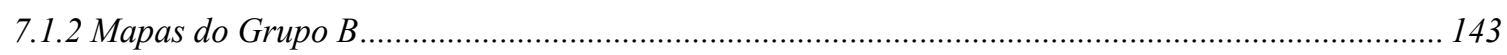

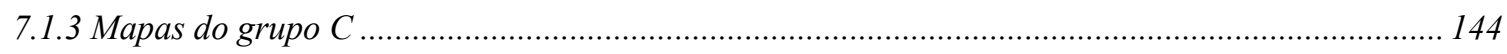

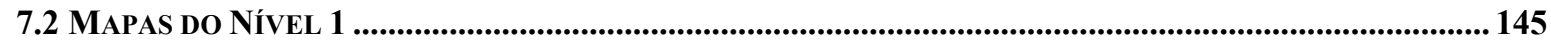

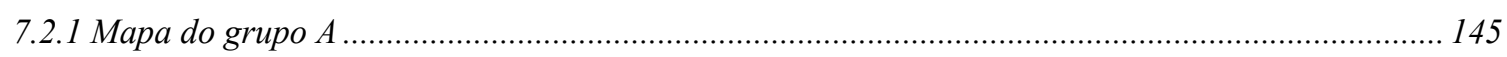

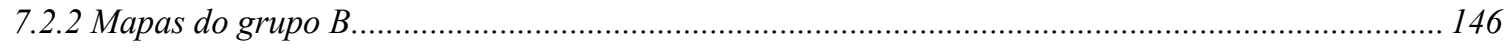

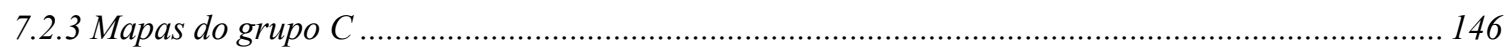

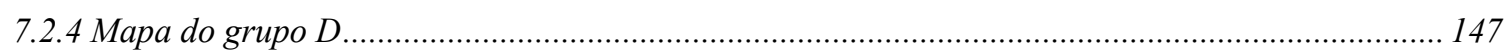

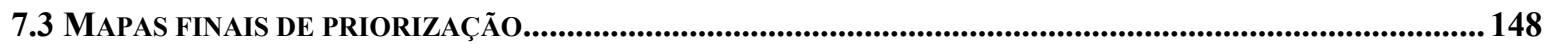

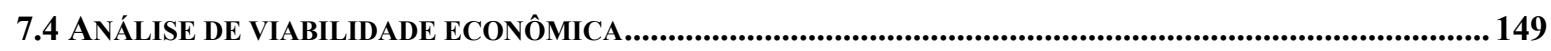

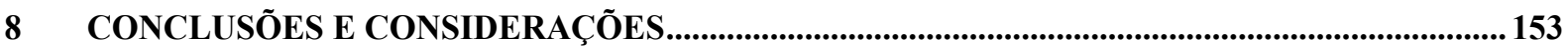

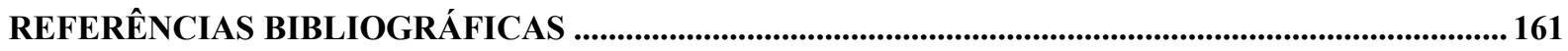

ANEXOS

ANEXO A: Questionário distribuído para as prefeituras de cidades médias brasileiras

ANEXO B: Critérios de priorização de seções

ANEXO C: Avaliação de critérios pelo painel de especialistas

ANEXO D: Mapas e tabelas de localização utilizadas no estudo de caso para São Carlos - SP

ANEXO E: Valores ou fuções fuzzy adotadas e mapas de fatores antes e após a normalização, utilizados no estudo de caso 



\section{INTRODUÇÃO}

O desenvolvimento econômico e o crescimento acelerado das cidades brasileiras no início do século XX tiveram como conseqüência o aumento da malha rodoviária e urbana. Naquela época o assunto conservação de vias ainda não era discutido e o que estava em questão era a construção de novas rodovias para atender o desenvolvimento sócio-econômico estabelecido nas grandes cidades. Com o passar dos anos, o crescimento do número de pessoas vivendo nas cidades e a contínua sobrecarga nos recursos tornou-se insustentável diante da deterioração da infra-estrutura e instalações urbanas. Os problemas relacionados ao uso e conservação das vias urbanas acabam por agravar ainda mais a situação. A ineficiência das vias de acesso, a falta de manutenção dos pavimentos e da drenagem e, principalmente, a realização de serviços com uso de recursos sem programação prévia é o ponto de partida para este trabalho, que tem como objetivo principal propor um modelo de priorização de vias, que auxilie os administradores no planejamento dos serviços de conservação sobre o pavimento.

O crescimento da rede urbana e rodoviária e a necessidade de conservação da malha existente têm incentivado, desde a década de 60, a promoção de estudos envolvendo vários temas relacionados aos Sistemas de Gerência de Pavimentos. Portanto, percebeu-se a necessidade de se desenvolver ferramentas para monitorar desde a construção, a conservação até a reconstrução dos pavimentos. Várias propostas, incluindo a criação de programas computacionais, foram desenvolvidas até o presente momento, no intuito de gerenciar as atividades de manutenção e reabilitação dos pavimentos.

Entretanto, existe dificuldade ao se tentar identificar critérios específicos para as questões relacionadas à seleção dos locais onde essas atividades devem ser empregadas. Critérios técnicos e quantitativos são geralmente pré-estabelecidos dentro de sistemas complexos, mas não há, ainda, procedimentos simplificados que agreguem quesitos cada vez mais importantes para a sociedade moderna, como aspectos econômicos, operacionais, de segurança de tráfego e ainda os aspectos sócio-ambientais. 
No Brasil os serviços de conservação de rodovias são realizados pelos órgãos públicos (Departamentos de Estradas de Rodagem) ou órgãos privados (concessionárias), e as secretarias de obras das prefeituras municipais cuidam da conservação das vias urbanas. Apesar de alguns estados e cidades do país já terem implementado algum tipo de sistema especialista em gerenciar as atividades de conservação em pavimentos urbanos e rodoviários, ainda há muito a ser feito em relação a essa questão.

Por vezes, a falta de gerenciamento e de uso de recomendações técnicas nos serviços de Manutenção e Reabilitação (M\&R) de pavimentos faz com que as atividades sejam executadas sem orientação e de forma desorganizada, produzindo serviços de baixa qualidade e sem retorno técnico-econômico para os investimentos. A realização de um planejamento de seções prioritárias, da melhor época para os serviços de manutenção e de seleção da atividade mais indicada é a base para se tomar uma decisão antes de qualquer atitude em relação a seções de vias.

O presente trabalho fundamenta-se em uma pesquisa realizada com a participação de prefeituras de cidades de médio porte brasileiras, que teve como objetivo maior avaliar a situação atual da prática de gestão dos pavimentos urbanos. A partir daí, foram identificados os procedimentos utilizados para planejar as intervenções nos pavimentos e alocar os recursos disponíveis, além dos critérios adotados para desenvolver essas atividades. As informações agregadas à revisão da literatura pertinente ao trabalho, permitiram a elaboração de um conjunto de critérios relevantes para a tomada de decisão.

A falta de informações, por parte dos responsáveis pelos projetos e manutenção de vias urbanas, em relação às novas técnicas de conservação do pavimento desenvolvidas nos últimos anos e, também, a falta de recursos, são problemas constantes nas administrações públicas do país. Diante dessas constatações, este trabalho se insere no contexto da necessidade de propor novos métodos e tecnologias, agregados à gerência de pavimentos, que se adaptem à realidade brasileira e que permitam o planejamento de procedimentos envolvidos no processo de priorização das atividades de $M \& R$ de pavimentos.

A utilização de ferramentas de apoio à decisão no processo de gerência de qualquer tipo de serviço, pode ser fundamental para análises econômicas, políticas e sociais. No intuito de contribuir para a gerência de pavimentos, utiliza-se, neste trabalho, a Metodologia de Análise Multicritério de decisão (com o modelo utilizando AHP, Analytic Hierarchy Process) associada a um Sistema de Informação Geográfica (SIG). Essa associação proporciona 
subsídios para estabelecer vários cenários comparativos, onde se busca estabelecer as melhores alternativas de decisão.

Uma aplicação prática foi desenvolvida através de um estudo de caso conduzido na cidade de São Carlos (SP), tendo por base dados sobre inventário e avaliação da condição do pavimento e dados obtidos junto à Secretaria de Obras da Prefeitura Municipal de São Carlos.

A contribuição para o conhecimento, que se buscou atingir com o presente trabalho, é a abordagem inovadora à questão da priorização de seções de vias. Utilizaram-se componentes espaciais de análise (com o uso de SIG) e o estudo de critérios de decisão, muitos deles subjetivos (com as técnicas de decisão multicritério), propondo um novo modelo entre os já existentes.

Os critérios podem ser traduzidos na forma de variáveis relevantes ao problema: hierarquia viária caracterizada pelo volume de tráfego, tipo de rota de veículos e classificação funcional; condição do pavimento; questões de segurança, localização das vias analisadas, custos associados às estratégias de intervenção, questões ambientais etc.

A análise espacial dos dados é uma importante aliada para esse tipo de decisão e os SIGs permitem que as informações do mundo real sejam retratadas de forma muito próxima da realidade, através da localização geográfica. O Sistema de Informação Geográfica utilizado neste trabalho é o ArcView, que trabalha com modelos matricial (raster) e vetorial, atendendo às necessidades para o desenvolvimentos de todas as etapas deste trabalho.

O modelo utilizando Análise de Decisão Multicritério e SIG é adequado à realidade das cidades médias brasileiras, mas mantém a viabilidade de aplicação a cidades de outras dimensões, desde que as particularidades dessas cidades sejam consideradas. O foco do trabalho concentra-se em cidades brasileiras de médio porte, uma vez que se presume que as grandes cidades contam, em geral, com sistemas especializados para tratar os problemas de gerenciamento da conservação de pavimentos, enquanto que as pequenas cidades, na maioria das vezes, não possuem rede extensa de ruas pavimentadas.

Espera-se que o resultado final deste trabalho possa servir como ferramenta de planejamento, auxiliando os administradores de órgãos governamentais na avaliação e seleção das intervenções de conservação em vias urbanas pavimentadas. Dessa forma, os orçamentos disponíveis seriam alocados da maneira mais eficaz, além de melhorar os níveis de serviços oferecidos à sociedade. 


\subsection{Objetivo do Trabalho}

O objetivo geral deste trabalho é propor um modelo de priorização de vias, candidatas às atividades de manutenção e reabilitação de pavimentos. O modelo se apóia na Metodologia de Análise Multicritério agregada ao Sistema de Informação Geográfica, considerando critérios objetivos e subjetivos no apoio à tomada de decisão.

Os objetivos específicos do trabalho são:

- Estudar os procedimentos de priorização relacionados com a gerência de pavimentos urbanos e desenvolver diretrizes de apoio à decisão que considerem critérios objetivos e subjetivos na seleção de seções candidatas às atividades de $M \& R$ de pavimentos;

- Desenvolver uma seqüência de passos e seleção sistemática utilizando metodologia de análise baseada em múltiplos critérios que influenciam o processo decisório (isto é, o Analytic Hierarchy Process - AHP) em relação às seções prioritárias;

- Estruturar cenários de avaliação baseados em mapas de priorização de seções de pavimento, utilizando a plataforma SIG como instrumento de trabalho, visando maximizar a eficiência econômica dos investimentos e esforços despendidos pelos órgãos públicos.

\subsection{Estrutura do trabalho}

A presente tese está estruturada em 8 capítulos. Após esta introdução, os capítulos 2, 3 e 4 apresentam as considerações teóricas do trabalho. O capítulo 2 trata da Gerência da Conservação de Pavimentos, no que diz respeito a alguns conceitos de gerência rodoviária e aplicada a pavimentos urbanos, critérios envolvidos na tomada de decisão e ainda um esboço da atual situação referente aos procedimentos utilizados nas cidades médias brasileiras.

A seguir, no capítulo 3, são tratados os modelos de definição de prioridades de manutenção e reabilitação de pavimentos, bem como os fatores que interferem nessas decisões. O capítulo 4 trata dos procedimentos e ferramentas utilizadas para apoiar a decisão em gerência de pavimentos, bem como faz uma síntese de Análise Multicritério de Decisão e dos Sistemas de Informações Geográficas.

O modelo de priorização de seções de pavimentos para cidades médias brasileiras é apresentado no capítulo 5, com a descrição da técnica e ferramenta utilizada, identificação dos critérios e pesos atribuídos a cada um deles e a estrutura hierárquica do processo de decisão. 
O estudo de caso é apresentado no capítulo 6, com aplicação da metodologia em ambiente SIG utilizando informações coletadas sobre a rede viária da cidade de São Carlos SP e desenvolvimento de cenários de avaliação.

O capítulo 7 trata da análise dos resultados, ou seja, são feitas observações importantes referentes aos cenários criados no capítulo anterior e ainda uma breve análise considerando um orçamento anual limitado.

Por fim, no capítulo 8 são apresentadas as conclusões referentes às etapas cumpridas durante o desenvolvimento do modelo proposto. Também são discutidas as vantagens da associação das técnicas da avaliação multicritério e o uso do SIG para a questão da priorização de pavimentos, além de algumas sugestões para desenvolvimentos de trabalhos futuros. 
Modelo de decisão para a priorização de vias candidatas às atividades de manutenção e reabilitação de pavimentos 


\section{GERÊNCIA DA CONSERVAÇÃO DE PAVIMENTOS}

\subsection{Conceito e Informações Gerais}

A redução progressiva da qualidade inicial do pavimento começa a ocorrer logo após a sua construção, quando sofre a ação de agentes atmosféricos e mais tarde com as solicitações do tráfego. São vários os fatores que contribuem e interferem diretamente na degradação de um pavimento:

- Fatores climáticos e relacionados ao meio ambiente que incluem a precipitação pluviométrica, a temperatura, a evapotranspiração, etc. Todos estes aspectos guardam estreita relação com a drenagem e o desgaste do pavimento;

- Fatores relacionados ao tráfego que compreendem aspectos tais como, a composição do tráfego, velocidades de operação dos veículos, número de repetições de veículos pesados;

- Fatores de projeto que incluem os materiais e os métodos de dimensionamento das camadas que compõem os pavimentos são de grande importância no desempenho e compatibilização das mesmas;

- Fatores geotécnicos de grande importância na condição dos pavimentos. O solo de fundação deve ser devidamente estudado e considerado, uma vez que as deficiências do subleito comprometerão o desempenho do pavimento.

- Fatores construtivos, tal como, o controle de qualidade é essencial para um pavimento desempenhar um bom nível de serviço durante seu tempo de vida útil. De nada adianta um bom projeto e boa seleção de materiais se o controle tecnológico deixa a desejar.

As vias de comunicação constituem a infra-estrutura fundamental para o desenvolvimento global de um país. Durante muitos anos, a maior preocupação referente à relação direta "crescimento econômico e rede de transportes" estava caracterizada pelo aumento em extensão da malha viária dos países em desenvolvimento. À medida que se passa de uma fase de construção da rede, satisfazendo as necessidades, para uma fase essencialmente de conservação da rede existente, o domínio da conservação da qualidade dos pavimentos passará a constituir a atividade mais importante, tendo em conta a relação entre o estado da rede e a qualidade do serviço oferecido ao usuário. 
Entre os anos de 1950 e 1960, foi construída a pista experimental da AASHO (American Association of State Highway Officials), a AASHO ROAD TEST, no Estado de Illinois. Planejada pelos Estados Unidos, a pista foi um elemento importante para uma grande pesquisa com pavimentos de rodovias, em que aspectos, como o efeito do tráfego e do meio ambiente sobre as características estruturais e funcionais do pavimento, puderam ser melhor estudados. A pesquisa deu o passo inicial, para fundamentar novos conceitos mais modernos sobre o projeto e dimensionamento de pavimentos e uma nova fase de pesquisas realizadas com pavimentos vem experimentando avanços tecnológicos significantes.

Um produto oriundo de todos esses avanços técnicos é o Sistema de Gerência de Pavimentos (SGP), que teve origem no final da década de 1960 e inicio da década de 1970, por grupos de pesquisadores americanos e canadenses. Naquela época, as várias atividades envolvidas na recuperação e manutenção de pavimentos passaram a ganhar mais importância e o assunto se desenvolveu rapidamente naqueles países e também na Europa.

Há hoje uma grande variedade de SGP já implantados no mundo. Nos Estados Unidos, praticamente todos os Estados têm SGP ou estão em vias de implementação. Há SGPs implantados em vários países da Europa, na Arábia Saudita, no Egito, no Chile, na Argentina, na Ásia, Oceania, etc. As metodologias variam de local para local, mas a formação de banco de dados e os métodos de obtenção de dados são praticamente os mesmos, ou seja: registros históricos da construção e coletas periódicas de dados no campo. Contudo, a estruturação do banco de dados varia de sistema para sistema (CARDOSO, 1994).

O TRRL (Transport and Road Research Laboratory of Technology), em colaboração com o Banco Mundial, desenvolveu métodos de análise econômica das normas e investimentos rodoviários capazes de fornecer os custos e benefícios ao longo da vida em serviço da rodovia. Realizaram-se estudos em vários países com características distintas e obteve-se um sistema que compara estimativas de custos e faz avaliações econômicas de diferentes opções de construção e manutenção, incluindo diferentes estratégias de intervenções ao longo do tempo. Este modelo designou-se Highway Design and Maintenance Standards Model (HDM) e é referenciado a nível mundial, com várias décadas de utilização, como um instrumento de programação e apoio às atividades de gerência rodoviária (PEREIRA \& MIRANDA, 1999). Depois deste, outros modelos, em versões mais novas do HDM (HDM-III e o HDM-4 designado por "Highway Development and Management"), foram sendo desenvolvidos, atendendo à evolução da tecnologia informatizada. Entretanto o software mais utilizado pelas agências de transportes, em todo o mundo, é o HDM-4. 
Introduzido no mercado em 2000, o HDM-4 é um sistema potente que considera o planejamento, a programação, a preparação e as operações para a análise da gerência rodoviária incluindo as opções de investimentos.

No Brasil, o Departamento Nacional de Infra-Estrutura de Transportes (DNIT), o órgão executor do Ministério dos Transportes, antes chamado de Departamento Nacional de Estradas de Rodagem (DNER), através de sua Área de Planejamento Rodoviário, desenvolveu um Sistema de Gerência de Pavimentos, com base em critérios estritamente técnicos, abrangendo uma rede rodoviária pavimentada de aproximadamente $50.000 \mathrm{~km}$. A Gerência de Pavimentos é alcançada através da utilização de um programa informatizado (SGP - DNER). O programa trabalha com as informações de um banco de dados, em que são armazenadas todas as características relevantes de cada segmento rodoviário, tais como tipo e estrutura do pavimento, tráfego, condições estruturais (deflectometria), condições de superfície (defeitos existentes) e condições de rolamento (irregularidade), bem como dados de localização e geometria. Aliado aos programas desenvolvidos pelo Banco Mundial - HDM/EBM, o SGPDNER pode traçar um Plano Gerencial, capaz de permitir ao Governo Federal optar por uma atuação que permita uma condição de uso mais favorável, mediante a elevação do conforto e segurança dos usuários.

Basicamente, o Plano consiste na adoção e desenvolvimento de intervenções planejadas, que alcancem a conservação, revitalização ou restauração das rodovias, em substituição aos métodos clássicos e convencionais que demandam maior alocação de recursos e, portanto, menor percentual de recuperação da malha. Para alcançar os objetivos traçados, o banco de dados necessita ser constantemente atualizado e consolidado, uma vez que a dinâmica de variação das condições dos pavimentos é heterogênea, função das diversas condições de deterioração ou melhoria das rodovias. Para a atualização dos dados são executados periodicamente levantamentos de campo, através de campanhas de avaliações das condições de pavimentos, em toda a rede ou em trechos específicos. Os dados levantados são então consolidados e introduzidos no sistema (DNIT, 2004a).

Um SGP, segundo Haas et al. (1994), consiste de um elenco de atividades coordenadas, relacionadas com o planejamento, projeto, construção, manutenção, avaliação e pesquisa de pavimentos, cujo objetivo principal é utilizar informações confiáveis e critérios de decisão para produzir um programa de construção, manutenção e reabilitação de pavimentos que dê o máximo retorno possível para os recursos disponíveis. Portanto, para atingir seu objetivo, um sistema de gerência de pavimentos deve ser capaz de comparar, priorizar e 
alocar os recursos de seu programa de manutenção e reabilitação entre todas as seções da rede viária.

As análises e funções de um Sistema de Gerência de Pavimentos focalizam questões relacionadas com a condição do pavimento, tráfego, necessidades de manutenção e reabilitação $(M \& R)$ e estimativa orçamentária. Estas questões representam cenários, tais como (SCHWARTS et al., 1991):

- Quais são as necessidades de M\&R e os custos associados para os próximos 1, 5 e 10 (ou mais) anos, considerando dados sobre a condição atual do pavimento, tráfego, custos de construção e nível mínimo de desempenho?

- Quais são os impactos relativos ao baixo nível de qualidade do pavimento, os custos associados sobre as atividades de $M \& R$ e a condição do pavimento?

- Quais são os impactos relativos às mudanças de tráfego sobre as atividades $M \& R$ e o desempenho do pavimento no futuro?

- Quais são os fatores de priorização de seções e as intervenções apropriadas para atender determinados níveis orçamentários e níveis de desempenho?

Mediante utilização dos procedimentos de gerência de pavimentos, os organismos rodoviários ou prefeituras municipais podem avaliar a aplicação de várias estratégias de manutenção e reabilitação, simulando seus efeitos sobre a condição dos pavimentos e os custos associados. Podem, dessa forma, escolher a melhor estratégia (“o que fazer"), com informações em nível de projeto selecionar a atividade mais indicada ("como fazer"), com informações em nível de rede indicar as seções prioritárias (“onde fazer”) e definir a melhor época para os serviços de manutenção (“quando fazer”) (BERTOLLO \& FERNANDES JR., 1997).

A gerência em nível de rede indica os trechos prioritários da malha rodoviária que devem ser objeto de investimentos em manutenção, de forma que os recursos públicos alocados para um determinado período tenham o melhor retorno econômico. Por outro lado, a gerência em nível de projeto envolve atividades detalhadas do próprio projeto e da execução de obras em um trecho específico da malha, atividades essas que deverão confirmar e detalhar as recomendações da gerência em nível de rede e que normalmente deverão subsidiar orçamentos e programas de curto prazo.

A gerência em nível de rede vem sendo apresentada subdividida em dois níveis: o nível de seleção de projetos e o nível de programação (PANTIGOSO, 1998). O primeiro refere-se aos procedimentos de priorização envolvendo um ou mais grupos de projetos. $\mathrm{O}$ nível de programação envolveria toda a rede rodoviária, considerada a totalidade dos recursos 
orçamentários disponíveis. A Figura 2.1 ilustra os três níveis de decisão de um sistema de gerência de pavimentos.

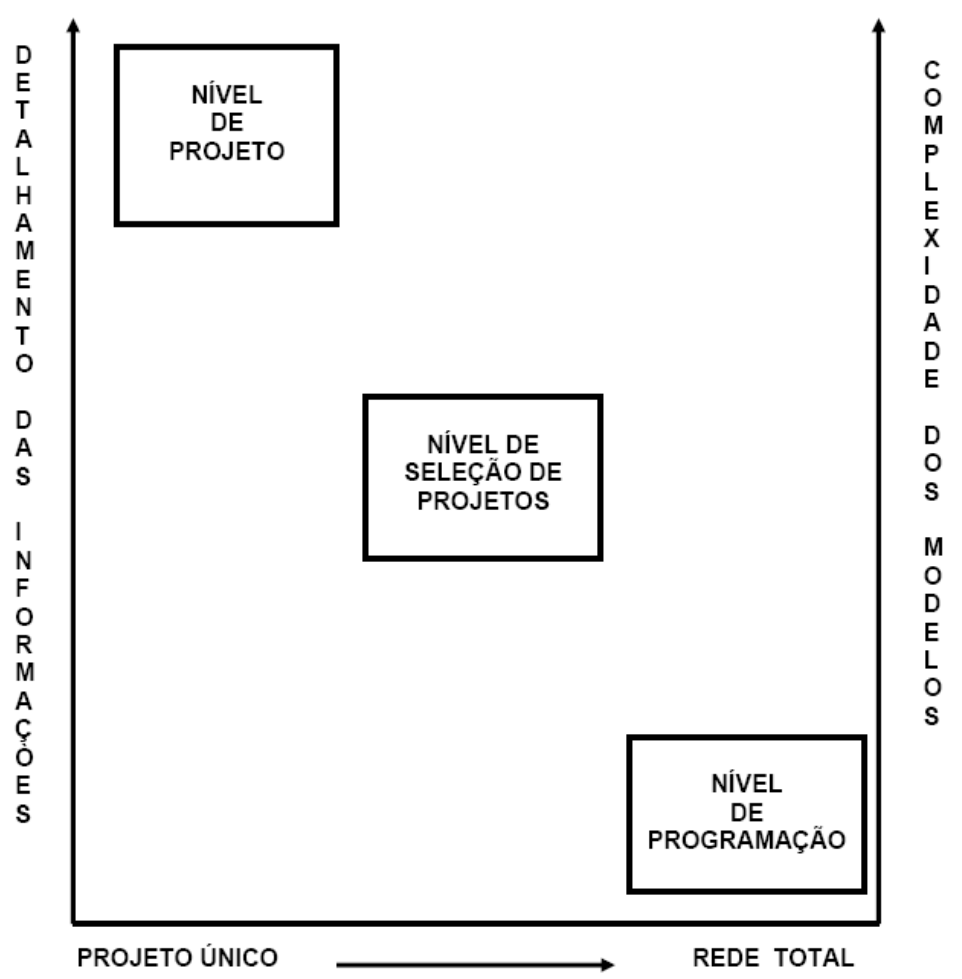

Figura 2.1: Níveis de decisão na gerência de pavimentos (VISCONTI, 2000)

Nos últimos anos, as publicações envolvendo os sistemas de gerência para manutenção e reabilitação de pavimentos vêm se multiplicando. Podem ser citados alguns trabalhos: ULLIDTZ (1983), PEREIRA (1988), PRAKASH et al. (1993), TRB (1990), KENNEDY JR. et al. (1990), MABWANA \& TURNQUIST (1996), WANG et al. (2003). Este interesse em implementar um programa sistêmico de manutenção e reabilitação de pavimentos se justifica ao se observar alguns benefícios oferecidos por um SGP:

- Desenvolvimento de inventário dos pavimentos da rede em termos de locação, tipo, classificação funcional, geometria, área pavimentada etc;

- Desenvolvimento de banco de dados com as informações organizadas e disponíveis sobre a condição do pavimento, acidentes, tráfego, construção e históricos de reabilitação e manutenção, além de qualquer outro tipo de dados que se julguem necessários;

- Avaliação da condição do pavimento com base em levantamentos estrutural elou funcional de toda a rede;

- Análise da condição futura do pavimento sob condições de tráfego e clima; 
- Indicação dos investimentos necessários para realização das atividades de recuperação e conservação da rede e para mantê-la nos níveis de qualidade desejáveis;

- Indicação das necessidades de investimentos para manter a rede em níveis especificados de desempenho em termos plurianuais (de 5, 10 ou mais anos), dependendo do nível de sofisticação incluído no SGP;

- Desenvolvimento de programas anuais e plurianuais específicos, dependendo do horizonte de planejamento;

- Estabelecimento de metodologias e procedimentos para priorização de desembolsos quando os recursos disponíveis forem menores do que o necessário para atender aos objetivos de desempenhos especificos;

- Comparação entre diferentes estratégias de manutenção, reabilitação ou reconstrução dos pavimentos da rede;

- Estabelecimento de bases de comunicação entre as várias redes de infraestrutura urbana e rural e entre grupos, tais como, legisladores, governantes locais, imprensa, usuários, concessionárias dos serviços públicos etc.

A adoção de um sistema gerencial de pavimentos por um órgão rodoviário trará benefícios, em primeiro lugar, aos usuários das rodovias e à população de uma forma geral, pois os recursos públicos serão aplicados nas obras rodoviárias com maior eficiência. Também a administração do órgão, em seus diversos níveis, será beneficiada com a utilização do sistema de gerência, através da maior possibilidade de se adotar decisões corretas, da maior coordenação entre os diversos setores do órgão e do favorecimento das atividades de treinamento e aperfeiçoamento de pessoal.

Como principais fatores externos condicionantes de um sistema gerencial de pavimentos podem ser citados os recursos orçamentários, os dados necessários ao sistema e as diretrizes políticas e administrativas. Muito mais importante do que conceituar seria conscientizar todos os níveis de decisão de um órgão rodoviário dos benefícios que a implantação de um sistema gerencial de pavimentos traz para a sociedade. Os pavimentos rodoviários representam um valioso patrimônio cuja conservação e restauração são essenciais para a sua preservação. Qualquer interrupção ou redução na intensidade ou na freqüência dos serviços necessários à manutenção desse patrimônio implicará em aumentos substanciais nos custos de operação dos veículos e na necessidade de investimentos cada vez mais vultosos para recuperação da malha rodoviária (VISCONTI, 2000).

Nesta seção tratou-se dos benefícios que os Sistemas de Gerência de Pavimentos ocasionam e os níveis administrativos que as atividades de gerência de pavimentos e os componentes dos sistemas podem estar caracterizados. A próxima seção trata dos conceitos 
agregados aos Sistemas de Gerência de Pavimentos Urbanos e as etapas para a sua implementação.

\subsection{Sistemas de Gerência de Pavimentos Urbanos (SGPU)}

De uma maneira geral, os conceitos de gerência de pavimentos são válidos tanto para rodovias como para vias urbanas. No entanto, uma das diferenças, destacada por Bertollo \& Fernandes Jr. (1997), é o grande número de redes de infra-estrutura pública que correm paralelas ou cruzando o pavimento das vias urbanas e que, para sua construção e manutenção, promovem escavação do pavimento.

A maioria das cidades brasileiras não foi planejada antes de suas construções e seus crescimentos vão acontecendo de forma desordenada. Podem-se citar algumas características e problemas encontrados numa rede viária urbana:

- O pavimento urbano sofre grande interferência causada pelos serviços de infraestrutura urbana, tais como, abertura de buracos para obras, travessias de galerias de ligação para luz, água, telefone, águas pluviais, esgotos. Estas interferências, quando não são considerados certos cuidados no processo de execução, são catastróficas para o nível de serviço apresentado pelo pavimento.

- Equipamentos de drenagem normalmente são deficientes, apresentando entupimentos devido ao lixo acumulado, insuficiência de escoamento causada pelo aumento da velocidade da água devido a grandes superficies impermeáveis e ainda, constantes problemas de vazamento causando a redução da vida dos pavimentos;

- As características do tráfego são muito diferentes daquelas verificadas em rodovias. A velocidade normalmente é mais reduzida. As solicitações do tráfego composto de automóveis, utilitários e ônibus urbanos, com pouca presença de veículos de carga pesada, influenciam no dimensionamento dos pavimentos. Nas proximidades dos sinais de trânsito, nos pontos e corredores de ônibus as paradas são inevitáveis e a deterioração dos pavimentos é marcante, não só pela maior solicitação dos pavimentos, mas pela ação deletéria dos combustíveis aos materiais asfálticos.

Fernandes Jr. et al. (1996) afirmam que a implementação de um sistema de gerência de pavimentos depende, principalmente, de três fatores: dados confiáveis, modelos realísticos para o processamento dos dados e programas amigáveis para a organização dos dados e apresentação dos resultados. Particularmente, os sistemas de gerência de pavimentos urbanos devem utilizar apenas os dados realmente necessários e permitir a adaptação dos modelos de desempenho às formas de deterioração que efetivamente condicionam as atividades de manutenção e reabilitação. As etapas para o desenvolvimento de um sistema de 
gerência de pavimentos urbanos, conforme mostrado na Figura 2.2 e segundo MAPC (1986), são:

- Inventário: coleta e organização dos dados necessários para a correta implementação e para o bom desempenho do sistema,

- Avaliação da condição do pavimento: utilização de modelos para a previsão de desempenho da condição atual e futura dos pavimentos, modelos estes baseados em avaliações periódicas dos pavimentos,

- Priorização: estabelecimentos dos níveis de prioridade, ou seja, adequação das necessidades aos recursos disponíveis,

- Programação das atividades de manutenção e reabilitação: estabelecimento dos critérios para as tomadas de decisões quanto às atividades de manutenção elou reabilitação do pavimento,

- Implementação: funcionamento efetivo do sistema, utilização da estratégia selecionada.

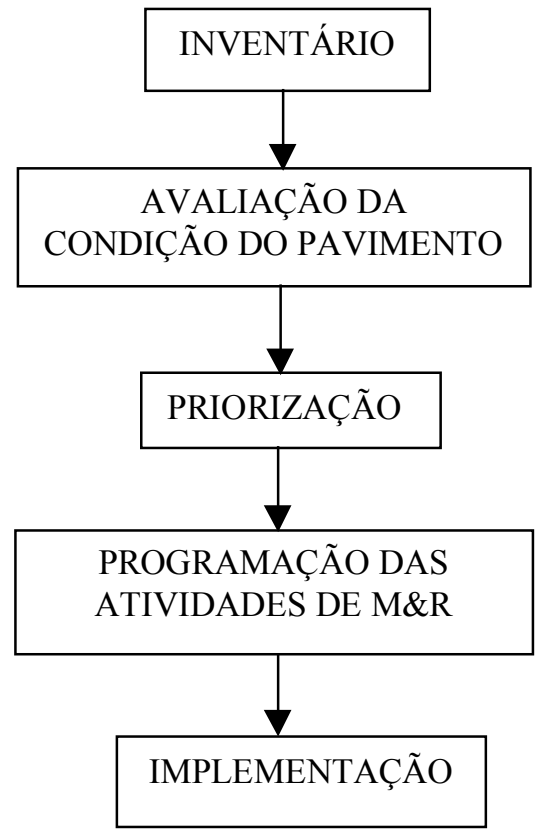

Figura 2.2- Etapas na implantação de um SGPU

O inventário de uma rede pavimentada urbana deve conter dados, como por exemplo, descrição e identificação das seções (nome da rua, tipo de pavimento, etc.), características geométricas (comprimento, largura, número de faixas, etc.), histórico de construção, manutenção e reabilitação e custos associados, características e dados de tráfego (capacidade da via, tráfego diário médio, etc.). Nesta etapa de planejamento é estabelecida uma base de dados contendo toda a informação necessária para o inventário do pavimento, incluindo também dados de acidentes, e qualquer outra característica que possa estar relacionada com o pavimento. Porém é importante proceder à coleta desse tipo de informação 
sempre vinculado a uma real utilização pelo sistema. Caso contrário corre-se o risco de se estruturar um banco de dados com excesso de informações, muitas de nenhuma utilidade, e que certamente elevarão os custos da coleta de dados desnecessariamente.

Para que estas informações sejam estruturadas numa base de dados é preciso proceder com etapas de coleta de dados que contam com a inspeção técnica das características físicas e de tráfego e avaliação do pavimento. Existem duas formas de avaliar um pavimento: avaliação subjetiva, como o próprio nome fala, o pavimento é avaliado subjetivamente, conforme a opinião do usuário; e a avaliação objetiva, realizada através de ensaios e equipamentos específicos para medir o desempenho do pavimento ou também através de medidas dos vários tipos de defeitos ou deteriorações apresentadas.

A quantificação da condição do pavimento é imprescindível para a priorização e seleção de projetos e de estratégias de manutenção e reabilitação e para a previsão orçamentária e alocação de recursos. Dadas às particularidades dos SGPU, a avaliação da condição atual das seções pode ser efetuada apenas por levantamento de defeitos no campo, ou seja, quantificar o tipo, a severidade e a extensão de cada uma das formas de deterioração normalmente encontradas na superfície do pavimento da rede a ser analisada. A avaliação estrutural, com equipamentos para medida de deflexão superficial (Viga Benkelman e FWD, por exemplo), é útil apenas para análises detalhadas em nível de projeto, pois quando usada para apoio à decisão em nível de rede acarreta grande acréscimo nos custos; a avaliação funcional, através de medida da irregularidade longitudinal (desde os simples medidores do tipo resposta até os sofisticados perfilômetros), é útil apenas nas vias de trânsito rápido (acima de $60 \mathrm{~km} / \mathrm{h}$ ); e a avaliação do atrito superficial pneu-pavimento, relacionada à segurança, é pouco utilizada no Brasil.

Após o levantamento, a avaliação da condição do pavimento e determinadas às necessidades, deve-se estabelecer prioridades (as seções) para selecionar as atividades de manutenção e reabilitação, pois geralmente os recursos são menores que as necessidades. A falta de recursos e os investimentos restritos na infra-estrutura de vias urbanas determinam a necessidade de otimizar as atividades de pavimentação. Embora os princípios da gerência de pavimentos sejam os mesmos para todos os organismos rodoviários, as administrações locais têm, normalmente, menos recursos. Os sistemas de gerência de pavimentos urbanos, sob situação de restrição orçamentária, utilizam, geralmente, a técnica de priorização para a seleção de projetos, que permite a manutenção da rede viária na melhor condição possível e ao mínimo custo. A otimização normalmente é utilizada pelas agências federais e estaduais, 
que numa situação de disponibilidade total de recursos fazem a escolha das estratégias ótimas em nível de projeto.

Logo após a definição das prioridades, diferentes estratégias de manutenção e reabilitação em nível de rede podem ser analisadas, como: não fazer nada, manutenção corretiva (conservação realizada de acordo com uma programação com base em mesma técnica para eliminar imperfeições inexistentes, com o objetivo de reparar ou sanar defeitos), manutenção preventiva periódica (conjunto de operações de conservação realizadas periodicamente com o objetivo de evitar o surgimento ou agravamento de defeitos), recapeamento e reconstrução (DNER, 1996). Feita a análise em nível de rede, passa-se à análise em nível de projeto, que consiste na definição das atividades de manutenção conforme o tipo de deterioração apresentado e, quando for o caso, no dimensionamento dos reforços e da reconstrução. Alguns sistemas de gerência de pavimentos utilizam "árvores de decisão" na escolha das estratégias de manutenção e reabilitação (FERNANDES JR., 2001). As estratégias podem ser definidas, por exemplo, a partir da condição dos pavimentos, representada pelo valor estimado através do Índice de Condição do Pavimento (ICP), da idade desde a última intervenção e do Volume de Tráfego Médio Diário (VDM). Também podem ser usadas "árvores de decisão" para seleção da atividade mais adequada, conforme o tipo de deterioração.

Existem diferenças entre as atividades de manutenção e as atividades de reabilitação de pavimentos. A manutenção tem por objetivo preservar ou manter o período de projeto do pavimento, aumentando pouco o nível de serventia, mas evitando a deterioração precoce. Desta forma, as atividades de manutenção consistem, geralmente, de remendos, selagem de trincas e capas selantes. A detecção e o reparo dos defeitos nas fases iniciais representam o trabalho mais importante desempenhado pela equipe de manutenção, ou seja, aquele que resulta na melhor utilização dos recursos disponíveis. A reabilitação, por sua vez, tem o objetivo de prolongar a vida em serviço do pavimento, elevando o nível de serventia próximo ao valor máximo e criando condições para um novo ciclo de deterioração. Dentre as atividades de reabilitação mais utilizadas estão, a fresagem (remoção do revestimento antigo, tanto para reciclagem como para acerto da superfície a ser recapeada), a reciclagem (o revestimento asfáltico é escarificado, aquecido no local, misturado, lançado e compactado), o recapeamento estrutural (espesso) e a reconstrução (FERNANDES JR. et al, 1999). 


\subsection{Critérios de Decisão na Gerência de Pavimentos}

Speicher et al. (2000) comentam que antes de desenvolver um conjunto de critérios de decisão é importante definir os problemas existentes, pois estes servem como base para gerar este conjunto. Além disso, os procedimentos usados e as pessoas envolvidas são cruciais na geração de um conjunto apropriado de critérios que alcance o objetivo inicial proposto. Procedimentos utilizados e alguns problemas comuns encontrados na maioria das prefeituras municipais de cidades brasileiras são comentados na Seção 2.4 deste trabalho.

Malczewski (1999) comenta que cada critério utilizado deve ser compreensível e mensurável. A série de atributos deve ser completa (os atributos precisam cobrir todos os aspectos do problema de decisão), operacional (de modo a serem incorporados à análise), divisível (permitindo a simplificação do processo), não redundante (para não haver mais de um critério relativo a um mesmo fator) e mínimo (o número de critérios deve ser o menor possível).

São vários os fatores e critérios que podem ser considerados para o desenvolvimento de cada etapa de um sistema de gerência de pavimentos. Existem os critérios de decisão utilizados durante o processo de avaliação dos pavimentos, os critérios utilizados para a análise da condição do pavimento, os critérios adotados para decidir sobre o tipo de intervenção, os critérios para priorização de projetos e seções, etc. Utilizar critérios conhecidos em avaliações técnicas pode aumentar a transparência do processo de análise. Quando os critérios são desconhecidos as decisões podem trazer menos benefícios do que o esperado, com maiores desperdícios do orçamento disponível e decisões sobre projetos que tenham menores prioridades.

Uma avaliação baseada em critérios técnicos e econômicos pode ser capaz de melhor quantificar e definir o grau de importância de uma determinada atividade sobre uma determinada seção de pavimento. É uma forma de adequar os serviços de $M \& R$ aos critérios de qualidade recomendados por normas técnicas e pelos sistemas de gerência de pavimentos. Haas et al. (1994) definiram critério de decisão em gerência de pavimentos como um limite determinado para algumas medidas de comportamento, resposta, desempenho, deterioração ou características de operação em relação a medições e estimativas atuais. Se a medida ou estimativa excede o limite, então a deficiência ou a necessidade existe. As razões básicas por estabelecer critérios em nível de rede são:

- Estabelecer um objetivo básico para identificar as necessidades atuais e estimar as necessidades futuras; 
- Estabelecer consistência de informações entre as características das seções e classes de rodovias ou vias urbanas;

- Ter meios para retratar efetivamente acúmulos atuais e futuros de quilometros de deficiência.

Para nível de projeto, os critérios são geralmente adotados em termos de especificações. As razões básicas para se definir critérios, são geralmente assegurar qualidade e em alguns casos, um meio para garantir desempenho. Alguns dos precedentes têm limites em termos de máximo aceitável, como por exemplo, a irregularidade ou o atrito superficial que tem um mínimo aceitável. Os limites ou critérios podem ser influenciados pelos seguintes fatores:

- Tipo e classe funcional das facilidades (rural ou urbana, freeway, arterial, coletora ou local): geralmente dominam os outros fatores;

- Tamanho da rede pavimentada e tipo de órgão responsável (público - estadual ou federal; ou privado);

- Recursos, orçamentos e política do órgão responsável.

Pereira \& Miranda (1999) comentam que o Sistema de Gestão da Conservação de Pavimentos de Portugal considera a prioridade da administração e a prioridade dos usuários como critérios no desenvolvimento da priorização de seções da rede rodoviária portuguesa. A prioridade da administração é constituída essencialmente por um critério técnico-econômico, que procura compatibilizar as ações prioritárias do ponto de vista da preservação da estrutura do pavimento, com as condições mínimas de segurança e de conforto de circulação. Por outro lado, a prioridade dos usuários considera a influência do estado do pavimento e das ações de conservação para os usuários, em particular para os custos, ou implicitamente para os seus benefícios.

Critérios técnicos geralmente consideram a condição do pavimento e a avaliação dos defeitos encontrados na superfície e estrutura de uma estrada ou via urbana. Assim, independente da consideração dos custos e benefícios relacionados aos usuários, existe um conjunto de estados dos pavimentos, os quais recomendarão a execução de atividades de conservação de prioridade máxima, principalmente no caso de atividades estruturais. Essa prioridade máxima justifica-se pela necessidade de preservar a qualidade, ainda parcialmente existente, do pavimento e reduzir as chances do mesmo necessitar de uma reconstrução completa. Entretanto, além de critérios técnicos deve ser definido outro tipo de critério, relacionado com a importância econômica da via, o qual pode ser representado, por exemplo, pela classe funcional da via e pelo volume de tráfego. Assim, critérios técnico-econômicos 
geralmente são obtidos da consideração conjunta dos três fatores: condição do pavimento, classe funcional e volume de tráfego.

Modificar algum critério de decisão pode causar o adiantamento ou o atraso das necessidades por intervenções anuais. Alterar um critério pode também afetar a lista de ações viáveis de reabilitação. Por exemplo, aumentando o mínimo aceitável de PSI (Present Serviceability Index) seria mais provável ter recapeamentos finos com maior custo efetivo do que reconstrução. Por outro lado, se o PSI mínimo aceitável for bem menor então as alternativas mais viáveis seriam recapeamentos grossos e reconstrução total ou parcial. Um outro efeito visível ao diminuir o mínimo aceitável de PSI é que aumentaria a quantidade e o custo de manutenção corretiva necessária, as interrupções no tráfego e o custo de operação dos veículos (HAAS et al, 1994).

Os critérios de decisão têm influência direta nas alternativas que são geradas pelo sistema. Estas alternativas são selecionadas de acordo com o objetivo inicialmente proposto para se chegar a uma decisão final. A maioria dos sistemas de gerência de pavimentos objetiva alocar os recursos disponíveis e aumentar a eficiência das atividades, mas de maneira geral, são muitos os objetivos que podem ser considerados e estes podem ser bastante específicos, como:

- Minimizar os custos de manutenção;

- Maximizar a produção de manutenção;

- Minimizar uso de recursos e materiais;

- Minimizar uso de empregados;

- Minimizar uso de equipamentos;

- Maximizar a condição da rede, uniformidade e consistência nos projetos;

- Minimizar flutuações de gastos na demanda anual sobre os pavimentos;

- Maximizar a satisfação do usuário.

Ainda, nas tomadas de decisão sobre atividades de gerência de pavimentos pode existir um número de objetivos ou critérios conflitantes. Por exemplo, maximizar a produção de atividades de manutenção tende a aumentar os gastos de manutenção, o que é conflitante com o objetivo de minimizar os custos de manutenção. Similarmente, maximizar as condições do pavimento e minimizar os custos de manutenção são, em geral, objetivos conflitantes. Assumindo que o objetivo ou critério é utilizar o valor de orçamento disponível, uma solução mais aceitável seria tentar manter, ao mesmo tempo, um alto nível das condições do pavimento. Isso indica claramente que a capacidade de avaliação multiobjetivo e multicritério, 
em programas de gerência de pavimentos, tem resultados satisfatórios no que diz respeito a conservar uma rede de pavimento (FWA et al, 1998).

A série de critérios para um determinado problema de decisão pode ser obtida a partir de uma análise da literatura relevante, um estudo analítico ou pesquisas de opiniões. A participação da comunidade e a opinião de técnicos na definição dos fatores, que estão associados com as estratégias de intervenção no pavimento e os seus respectivos graus de importância para o processo decisório, resultariam em desenvolvimento e representação dos resultados mais próximos à realidade. Esta participação representa o ponto de vista dos usuários de vias e principalmente a opinião dos técnicos responsáveis pelos projetos referentes à infra-estrutura viária. Kawamoto \& Furtado (1997) comentam algumas técnicas para fazer com que especialistas e a comunidade participe do processo de decisão:

- Questionários: São aplicados em uma amostra populacional que represente, do ponto de vista estatístico, a população total. Devem ser simples e objetivos;

- Discussões direcionadas: Formam-se pequenos grupos, lideradas por um moderador que se utiliza de um roteiro preestabelecido para a discussão.

- Workshops: Promovem-se reuniões para discutir medidas técnicas ou idéias e, a partir daí, passar um entendimento sobre a função, natureza e importância do processo de planejamento para a resolução dos problemas observados;

- Análise de valores: Vários grupos interessados ordenam as possíveis conseqüências das alternativas, articula-se com a comunidade em geral e através de consenso identificam os propósitos das alternativas consideradas;

- Referendum Popular: A comunidade escolhe entre as alternativas propostas através de votação. Esta votação pode ser oficial ou não-oficial.

Esta seção tratou dos critérios de decisão relacionados com as diversas análises e procedimentos da gerência de pavimentos e também das técnicas para fazer com que a comunidade e especialistas participem do processo de decisão, ou seja, as pesquisas de opiniões. A próxima seção se refere às informações coletadas a respeito dos problemas encontrados, falhas nos procedimentos e os critérios adotados para a execução dos serviços realizados no pavimento, em particular, nas cidades médias brasileiras.

\subsection{Gerência de Pavimentos em Cidades Médias Brasileiras}

Essa seção apresenta a análise estatística de uma pesquisa, em forma de questionário, sobre a situação atual da prática da gestão dos pavimentos urbanos em cidades brasileiras de médio porte. Os questionários foram destinados às prefeituras, mais especificamente aos responsáveis por obras e serviços relacionados com a conservação de 
pavimentos, entre março a junho de 2005. Os objetivos específicos da aplicação dos questionários foram:

- Identificar os sistemas e procedimentos utilizados para planejar as intervenções nos pavimentos e alocar os recursos disponíveis;

- Identificar os métodos e os critérios específicos para a seleção (priorização) de seções candidatas às atividades de $M \& R$.

O primeiro objetivo teve o intuito de contribuir para estudos futuros que visem melhorar as condições de tráfego da malha viária urbana das cidades brasileiras. Por outro lado, o segundo objetivo, o mais importante para o desenvolvimento deste trabalho, teve o intuito de servir de base na definição da lista dos critérios efetivamente relevantes para a priorização de seções de pavimentos, conforme comentado mais adiante, no Capítulo 5 deste trabalho.

No momento da elaboração do questionário, além de definir claramente os objetivos específicos também foi necessário definir as cidades que participariam da pesquisa, representando, do ponto de vista estatístico, a população total.

Segundo Costa (2003), não existe um conceito único que defina cidades médias, que possa ser usado indistintamente no meio técnico-científico. Os grupos de cidades são geralmente identificados com base em critérios demográficos, dada a sua ampla disponibilidade e simplicidade de aplicação, embora outros critérios, como relações externas, estrutura interna, nível de infra-estrutura e grau de concentração de atividades também devam ser considerados.

Portanto, foram consideradas 111 cidades, identificadas pelo Instituto de Pesquisa Econômica Aplicada (IPEA, 1999) como os principais centros urbanos que estruturam a rede municipal do país, classificados com base nos seguintes critérios: população total em 1996 acima de 100 mil habitantes; densidade demográfica em 1996 acima de 60 habitantes $/ \mathrm{km}^{2}$; porcentagem da População Economicamente Ativa (PEA) em atividades urbanas em 1991 acima de $65 \%$.

Segundo o IPEA (1999), os centros estão agrupados, de acordo com sua importância, nas seguintes categorias: metrópoles, centros regionais, centros sub-regionais de nível um e centros sub-regionais de nível dois. Este estudo concentra-se somente nas três últimas categorias, englobando 106 núcleos de centros urbanos de médio porte do país. O questionário que foi enviado as prefeituras, bem como a tabela contendo as cidades que participaram da pesquisa estão apresentadas no ANEXO A deste trabalho. 


\subsubsection{Os Resultados da Pesquisa}

Os questionários tiveram um índice de respostas suficientes para se fazer uma análise estatística, pois aproximadamente $30 \%$ das prefeituras participaram da pesquisa. De forma a facilitar a coleta das informações, o questionário foi dividido em 4 partes: dados referentes às condições locais, dados referentes à equipe técnica, dados referentes à gestão das obras de manutenção dos pavimentos e dados referentes aos procedimentos associados à priorização de seções ou ruas.

\subsubsection{Condições Locais}

A pesquisa restringiu-se às atividades de $M \& R$ de pavimentos asfálticos. Pôde-se verificar que $92 \%$ das prefeituras têm seus serviços de pavimentação municipalizados e o órgão responsável, geralmente, é um setor ou um departamento dentro de uma secretaria.

\subsubsection{Equipe Técnica}

As pessoas que integram a equipe que cuida da gestão das obras de pavimentação nas prefeituras das cidades médias brasileiras são, na maioria, funcionários de carreira (funcionários públicos) e, em 32\% dos casos, o diretor da equipe ocupa cargo de confiança (indicado por políticos). Ainda, conforme a pesquisa, $76 \%$ dos diretores têm mais de 10 anos de experiência na área, $60 \%$ das pessoas que integram a equipe possuem curso de graduação (notadamente em Engenharia Civil) e apenas 20\% são pós-graduados (8\% são da área de pavimentação ou transportes).

Alguns secretários comentam, que as prefeituras durante a execução de uma atividade de manutenção, como por exemplo, um serviço de tapa-buraco, não contam com a fiscalização sob orientação de normas técnicas, pois não possuem pessoal qualificado para tal averiguação. Dessa forma, os fiscais simplesmente observam se os serviços foram ou não realizados, sem se preocupar com a técnica utilizada e a qualidade da execução.

\subsubsection{Gestão das Obras de M\&R dos Pavimentos}

O inventário das ruas da cidade é realizado em $64 \%$ das prefeituras, estando registradas informações com documentos ou mapas contendo os nomes das ruas, características geométricas (largura e comprimento) e características geográficas (localização). Por outro lado, somente $20 \%$ das prefeituras possuem inventário e/ou banco de dados referente às características físicas e geométricas dos pavimentos. Na maioria dos casos 
ocorre pouca comunicação e integração entre os diversos setores dentro dos órgãos públicos, até mesmo entre os responsáveis pelos serviços de planejamento das atividades de manutenção e os responsáveis pelos serviços de execução. Em relação à freqüência com que são realizados os levantamentos de campo e as avaliações do pavimento, as prefeituras se manifestaram conforme a Tabela 2.1.

Tabela 2.1: Freqüência dos levantamentos de campo e avaliações do pavimento

\begin{tabular}{lc}
\hline \multicolumn{1}{c}{ Freqüência } & \% \\
\hline Todo ano & $28 \%$ \\
De dois em dois anos & $4 \%$ \\
Quando Necessário & $60 \%$ \\
Nunca fizeram & $8 \%$ \\
\hline
\end{tabular}

É alto o índice de prefeituras que fazem levantamento de campo e avaliação do pavimento somente quando há reclamações da população. Por outro lado, $60 \%$ das prefeituras possuem procedimentos específicos (ou um Sistema de Gerência de Pavimentos - SGP) para a gestão das atividades de M\&R dos pavimentos, uma porcentagem que pode ser considerada bem elevada. Entretanto, quando comparamos os objetivos específicos desses procedimentos (Tabela 2.2) percebemos que nenhuma delas possui um SGP que desempenhe todas as etapas necessárias para a alocação dos recursos disponíveis de modo sustentável a curto e longo prazo.

Deve-se destacar que $8 \%$ dos responsáveis técnicos declararam que a prestação de serviços de manutenção e reabilitação se restringe à realização e fiscalização das atividades de tapa-buraco, sem o planejamento prévio das intervenções atuais ou futuras no pavimento.

Tabela 2.2 : Procedimentos para gestão das atividades de M\&R dos pavimentos

\begin{tabular}{lc}
\hline \multicolumn{1}{c}{ Procedimentos Adotados } & \% de Prefeituras \\
\hline Banco de dados e/ou inventário dos pavimentos & $20 \%$ \\
Histórico de construção, manutenção e reabilitação dos pavimentos & $32 \%$ \\
Atualização de levantamento de campo e avaliações dos pavimentos & $12 \%$ \\
Priorização de seções ou ruas candidatas às obras de manutenção & $32 \%$ \\
Seleção de estratégias de manutenção e reabilitação de pavimentos & $28 \%$ \\
Alocação de recursos e orçamento disponível & $20 \%$ \\
Previsão de desempenho de pavimentos & $0 \%$ \\
\hline
\end{tabular}

\subsubsection{Procedimentos Associados à Priorização de Seções}

Mesmo sem o auxílio de um SGP, os responsáveis pelos serviços de manutenção geralmente estabelecem alguns critérios para realizar as atividades de M\&R de pavimentos. A 
grande maioria dos administradores $(84 \%)$ diz fazer uso de critérios para priorizar os locais onde serão realizadas as atividades.

Alguns critérios foram sugeridos: $76 \%$ acham que a hierarquia viária deve ser considerada como um critério de decisão para priorização; $72 \%$ acham importante considerar a condição do pavimento; a localização foi considerada um critério relevante por $32 \%$ dos administradores e somente $8 \%$ acha que o custo é um critério importante a ser considerado.

Além dos critérios comentados anteriormente, outros foram considerados importantes na hora de decidir o local onde os serviços são realizados. Alguns administradores comentam que a vontade política é um critério freqüentemente adotado pelas prefeituras, ou seja, serviços sugeridos durante a campanha eleitoral são relevantes para a administração. Entretanto, foram dadas algumas sugestões para a seleção de ruas ou seções para obras de M\&R de pavimentos:

- Serviços de tapa-buracos: partindo-se da idéia de que atualmente a necessidade maior é da realização de manutenção de rotina e não de prevenção, as prioridades são estabelecidas a partir da necessidade de serviços de tapaburacos;

- Localização: dar prioridade a locais que possam causar transtornos à circulação de pedestres e veículos;

- Compatibilização com outros serviços: priorizar locais onde existem intervenções das concessionárias de serviços públicos, ou seja, as atividades de todas as infra-estruturas urbanas devem ser integradas;

- Dar atenção maior aos corredores de ônibus, por se tratar de uma manutenção mais sistemática;

- Vontade política, solicitações de orçamento participativo e critérios socioeconômicos: devem ser considerados na hora de priorizar as atividades de $M \& R$ dos pavimentos.

Pouco menos da metade das prefeituras trabalha com algum método específico para selecionar ruas candidatas às obras de manutenção: análise da condição do pavimento (20\%); índices de prioridade que consideram critérios específicos (12\%); critérios pré-determinados para a hierarquização das ruas pavimentadas (12\%) e modelos de otimização de rede (4\%).

Massaro (2005) recentemente verificou que os serviços de manutenção realizados pela prefeitura de São Carlos, Estado de São Paulo, são baseados na experiência dos profissionais envolvidos, e pelos pedidos e reclamações da comunidade, muitas vezes excessivas em certas áreas da cidade. Foi verificado que não é a melhor proposta para a melhoria do rendimento das atividades de manutenção e reabilitação de pavimentos, por não 
fazer uso de uma boa avaliação técnica das vias da cidade. Isso evitaria o uso de soluções incorretas ou incoerentes, como a execução de remendos de dimensões muito grandes ou de diversos defeitos muito próximos uns aos outros.

\subsubsection{Problemas Encontrados}

Apesar de já ser de conhecimento geral e fazer parte de outras averiguações anteriores, cabem algumas considerações a respeito dos problemas e falhas nos procedimentos de gerência de pavimentos em cidades brasileiras. São constatações que infelizmente ainda fazem parte do dia a dia das administrações públicas e que não podem deixar de ser comentadas:

- Na maioria das cidades brasileiras não há procedimento específico que identifique as necessidades de $M \& R$ dos pavimentos. As intervenções baseiam-se em reclamações da população e da mídia ou, ainda, da vontade política;

- Os órgãos públicos municipais, na maioria dos casos, desconhecem a real condição e os defeitos presentes nos pavimentos. A prestação de serviços por parte das administrações restringe-se à realização e fiscalização das atividades de tapa-buraco e não há uma estratégia assumida de caráter preventivo. As intervenções geralmente acontecem quando o grau de deterioração do pavimento já está em nivel elevado, impossibilitando a análise do montante de recursos necessários para suprir as deficiências e manter toda a rede em boas condições de tráfego;

- Falta de conhecimento prévio dos defeitos, e dos pontos críticos nas vias para que seja possível a correta aplicação dos conceitos e ferramentas da Logística de Serviços, permitindo a correta alocação de recursos nos tempos e locais adequados MASSARO (2005).

- Há ausência de trabalho integrado entre as diversas áreas do serviço público municipal, que interferem no espaço da via pública, e a gerência da infraestrutura urbana de transportes é feita de maneira informal, baseada, principalmente, na experiência dos profissionais envolvidos.

A respeito de Sistema de Gerência de Pavimentos Urbanos (SGPU), deve-se destacar que uma questão relevante é a estruturação da equipe responsável pela gestão dos serviços de manutenção e reabilitação dos pavimentos. De modo geral, um SGPU possui várias etapas, desde a entrada de dados, passando por etapas de análises e priorizações, até chegar aos resultados e propostas de intervenções, como já especificado na seção 2.2 deste trabalho. Todas estas etapas devem ser de fácil acesso e entendimento para as pessoas que compõe a equipe técnica.

Além disso, o conhecimento sobre o funcionamento do sistema deve ser repassado de uma equipe para a outra, a cada novo governo, de forma que o banco de dados (inventário 
e histórico do pavimento) esteja sempre atualizado e as informações não sejam perdidas. Este é um grave problema encontrado nas prefeituras, ou seja, a cada nova administração os responsáveis técnicos precisam começar do zero, motivo pelo qual não há continuidade dos projetos, do planejamento das intervenções e da alocação dos recursos.

Nesse Capítulo foi realizada uma síntese dos conceitos de gerência de pavimentos e sobre a pesquisa realizada junto as prefeituras de cidades brasileiras de médio porte, com o objetivo maior de traduzir o ponto de vista dos especialistas para o modelo de priorização. A pesquisa serviu de base para a definição da lista de critérios efetivamente relevantes para o processo de decisão que será tratada no Capítulo 5. No próximo capítulo são tratados os modelos de definição de prioridades de manutenção e reabilitação de pavimentos, bem como os fatores que interferem nessas decisões. É o embasamento teórico, sobre métodos de priorização existentes, necessário para o desenvolvimento do modelo proposto neste trabalho. 


\section{DEFINIÇÃO DE PRIORIDADES DE MANUTENÇÃO E REABILITAÇÃO DE PAVIMENTOS}

Para manter determinados níveis de qualidade, para toda a rede viária, é preciso realizar estudos de programas de conservação, a partir do conhecimento prévio do estado dos pavimentos. No entanto, num cenário de insuficiência de recursos financeiros, as decisões devem ser tomadas, considerando as seções a serem beneficiadas perante determinado orçamento disponível. Assim, é necessário escolher quais seções são consideradas prioritárias, na melhoria da qualidade do estado dos pavimentos. É necessário classificar cada seção segundo uma determinada ordem de prioridade de intervenção, de modo a investir os recursos onde houver perspectivas de obter os maiores benefícios.

O índice de prioridades indica a prioridade de cada seção e de cada estratégia. Uma vez determinado esse índice, as atividades de manutenção e reabilitação podem ser estabelecidas para cada seção de pavimento e dentro de cada categoria de estratégia. A seguir são especificados os fatores que podem estar envolvidos no processo de decisão, as diferenças entre priorizar e otimizar as atividades e os métodos utilizados para a priorização de seções de pavimentos.

\subsection{Fatores e Parâmetros Associados à Definição de Prioridades}

A definição das prioridades de conservação deve ser realizada considerando todos os fatores técnicos e econômicos, não apenas a curto prazo, mas também analisando as conseqüências de todos os custos e benefícios a médio prazo. Isso se faz através da utilização de sistemas de gerência que permitam, através dos respectivos modelos de desempenho, simular os efeitos de diferentes estratégias de conservação. No entanto, mesmo na ausência destes meios de apoio à simulação de diferentes cenários (os modelos de desempenho), existe a possibilidade de determinar as prioridades de conservação através de um reduzido conjunto de critérios de compreensão bastante racional. Assim a definição de prioridades de manutenção deve considerar no mínimo: o estado do pavimento, a classe funcional da via e o volume de tráfego (PEREIRA \& MIRANDA, 1999). 
A grande maioria dos sistemas para gerenciamento de ações sobre o pavimento, incluindo o SGP-DNER, faz uso dos métodos propostos pelo HDM-III e deste modo, utilizam como critérios para definir prioridades aqueles contidos neste modelo, ou seja, critérios mais complexos e que consideram o fator econômico como um dos mais importantes. Entretanto, existem critérios mais simples para a definição de prioridades de manutenção, que embora não levem em consideração fatores de ordem econômica, podem ter aplicação por sua rapidez e custo reduzido.

O maior benefício, para a administração da estrada, resultante de investimentos na conservação de um pavimento está relacionado com o prolongamento da sua vida em condições aceitáveis, em face de determinados padrões de qualidade pré-definidos. Deste modo, procura-se, para um determinado período de tempo, investir o mínimo possível e obter bons resultados. Assim, em uma perspectiva mais global, considerando ao mesmo tempo os interesses da administração e dos usuários, é fundamental realizar uma análise comparativa do custo da conservação e dos respectivos benefícios para os usuários rodoviários.

$\mathrm{Na}$ realidade, a utilização de modelos de avaliação econômica com restrição orçamentária pressupõe uma estabilidade mínima no fluxo de recursos para manutenção rodoviária. Não estando satisfeita essa condição, melhor seria a adoção de critérios simplificados para definir os trechos a serem restaurados. Diversos critérios para estabelecimento das necessidades e das prioridades de restauração já foram utilizados pelo DNER. Resumidamente, em ordem crescente de complexidade, esses critérios podem ser relacionados como segue (VISCONTI, 2000):

a. Critérios subjetivos - baseados em escolha subjetiva, simples e rápida, porém sujeita a inconsistência e quase sempre tendenciosa. Utilizada pelo DNER até o final da década de 70;

b. Critérios baseados em indicadores físicos - também de aplicação simples, utiliza parâmetros como a serventia, a deflexão ou a deterioração do pavimento (por exemplo, área trincada);

c. Critérios baseados em indicadores físicos, ponderados pelo volume de tráfego relativamente simples, aproxima-se mais da solução ótima;

d. Critérios baseados em modelos de análise de investimentos - aplicação mais complexa que permite a determinação da solução ótima sob o ponto de vista econômico para cada trecho rodoviário;

e. Critérios baseados em modelos de análise de investimentos, associados a modelos de restrição orçamentária - complementa o anterior, adequando a programação ótima aos recursos disponíveis. 
A seguir são especificados alguns fatores ou critérios que, de modo geral, podem ser considerados no desenvolvimento das necessidades de intervenções em pavimentos viários ou para determinar índices de prioridades (IRRGANG \& MAZE, 1993; HAAS et al., 1994, FERNANDES JR. et al., 1999; PEREIRA \& MIRANDA, 1999).

\subsubsection{Volume de Tráfego}

O tráfego é geralmente medido através do volume de tráfego diário médio. É um fator considerado em quase todas as análises que envolvem a medição do desempenho do pavimento e a definição de estratégias e prioridades. Conforme o volume de tráfego aumenta, as necessidades de manutenção também aumentam e por este motivo, as seções de pavimento com elevado volume de tráfego geralmente recebem maiores prioridades.

\subsubsection{Classificação Funcional}

A classe funcional de uma estrada ou via urbana está quase sempre relacionada com a importância econômica da via ou hierarquia viária. As vias são classificadas de acordo com a classe funcional como, por exemplo: Via Arterial: nível mais elevado, com fluxo rápido de veículos, podendo ser um anel viário ou grandes avenidas que conduzem o tráfego de um lugar par outro mais distante; Via Coletora: nível médio de veículos, coletam o tráfego das vias locais para regiões centrais ou para vias arteriais; e Via Local: nível mais baixo, com fluxo mais lento de veículos, concentrando-se em bairros mais afastados dos grandes centros. Geralmente, quanto mais alta a classe da via que apresentar um determinado defeito, maior a prioridade de intervenção.

\subsubsection{Tipo de Rota}

Além do tráfego normal de veículos de passeio, as vias podem possuir rotas específicas, como por exemplo, de veículos especiais: ambulâncias, corpo de bombeiros, ônibus urbanos ou rotas de veículos pesados: rota de caminhões ou ônibus de transporte de passageiros e de carga. Cada tipo específico de rota pode ter uma importância relativa diferenciada.

\subsubsection{Capacidade Funcional}

Refere-se a capacidade do pavimento de satisfazer sua função principal, ou seja, fornecer uma superfície com serventia adequada em termos de qualidade de rolamento. Existe 
uma grande variedade de parâmetros para caracterizar através de índices a avaliação funcional de um pavimento. Entretanto, de uma maneira geral existe relação entre tais índices.

Entre os vários índices existentes o DNIT (2005a) menciona os seguintes: PSI Present Serviciability Index; VSA - Valor de Serventia Atual; LVC - Levantamento Visual Contínuo; IGGE - Índice de Gravidade Global Expedito (função da freqüência de ocorrência e do peso atribuído a cada tipo de deterioração); IES - Índice do Estado de Superfície; ICPF Índice de Condição dos Pavimentos Flexíveis; IRI - International Roughness Index. Destes índices os mais utilizados no Brasil são o IRI (índice de irregularidade de superfície) e o IES (avaliado em função do ICPF e do IGGE, constitui uma síntese destes dois índices). A Tabela 3.1 e a Tabela 3.2 ilustram a relação entre os índices e a condição da superfície de pavimento.

Tabela 3.1: Índice da Condição de Superfície de Pavimentos Flexíveis (DNIT, 2005a)

\begin{tabular}{ccccc}
\hline \multirow{2}{*}{ ICPF } & \multicolumn{2}{c}{ Irregularidade } & \multirow{2}{*}{ IGGE } & \multirow{2}{*}{ Conceito } \\
& QI (Cont./km) & IRI (m/km) & & \\
\hline $5-4$ & $13-25$ & $1-1,9$ & $0-20$ & Excelente \\
$4-3$ & $25-35$ & $1,9-2,7$ & $20-40$ & Bom \\
$3-2$ & $35-45$ & $2,7-3,5$ & $40-80$ & Regular \\
$2-1$ & $45-60$ & $3,5-4,6$ & $80-150$ & Ruim \\
$1-0$ & $>60$ & $>4,6$ & $>150$ & Péssimo \\
\hline QI: Quociente de Irregularidade & & \\
\hline
\end{tabular}

Tabela 3.2: Índice do Estado da Superfície do pavimento (DNIT 008/2003-PRO)

\begin{tabular}{lccc}
\hline \multicolumn{1}{c}{ Descrição } & IES & Código & Conceito \\
\hline $\mathrm{IGGE} \leq 20$ e ICPF $>3,5$ & 0 & $\mathrm{~A}$ & Ótimo \\
$\mathrm{IGGE} \leq 20$ e ICPF $\leq 3,5$ & 1 & $\mathrm{~B}$ & Bom \\
$20 \leq \mathrm{IGGE} \leq 40$ e ICPF $>3,5$ & 2 & & \\
$20 \leq \mathrm{IGGE} \leq 40$ e $\mathrm{ICPF} \leq 3,5$ & 3 & $\mathrm{C}$ & Regular \\
$40 \leq \mathrm{IGGE} \leq 60$ e ICPF $>2,5$ & 4 & & \\
$40 \leq \mathrm{IGGE} \leq 60$ e ICPF $\leq 2,5$ & 5 & $\mathrm{D}$ & Ruim \\
$60 \leq \mathrm{IGGE} \leq 90$ e ICPF $>2,5$ & 7 & & \\
$60 \leq \mathrm{IGGE} \leq 90$ e ICPF $\leq 2,5$ & 8 & $\mathrm{E}$ & Péssimo \\
$\mathrm{IGGE}>90$ & 10 & & \\
\hline
\end{tabular}

Os parâmetros técnicos, que medem a funcionalidade do pavimento, consideram a condição da superfície do pavimento e a avaliação dos defeitos na superfície de uma estrada ou via. Pavimentos com estado de deterioração avançado terão prioridade máxima de atividades de conservação, principalmente quando se tratar de defeitos estruturais. Antes que o pavimento necessite de uma reconstrução completa as atividades devem ser realizadas, 
conservando desta forma a integridade, ainda que parcialmente existente, da estrutura do pavimento. A seguir são caracterizados os parâmetros técnicos que são avaliados objetivamente (defeitos, irregularidade e atrito superficial) e avaliados subjetivamente (condição do pavimento) utilizados para determinar as necessidades de intervenções de manutenção de pavimentos. Entretanto, a avaliação do atrito superficial está diretamente relacionada a questões de segurança e é tratada na subseção 3.1.8.

\subsubsection{Defeitos Superficiais do Pavimento}

A detecção dos defeitos, ou seja, a avaliação objetiva dos pavimentos, nos estágios iniciais é fundamental para manter os níveis de qualidades exigidos. Trincas e outras fraturas no pavimento, que inicialmente quase não são percebidas pelos usuários, podem evoluir rapidamente e causar sérios problemas se não forem prontamente seladas.

Os defeitos mais considerados pelos diversos sistemas de gerência existentes são: trincas, deformação permanente, desgaste, panelas e remendos. Entretanto, em virtude da necessidade de uniformização da coleta de dados, muitos países, inclusive o Brasil, adotam o manual de levantamento de defeitos no campo do Programa SHRP (Strategic Highway Research Program), que considera 15 tipos de defeitos em pavimentos flexíveis (SHPR, 1993): trincas por fadiga, trincas em blocos, trincas nos bordos (laterais), trincas longitudinais, trincas por reflexão, trincas transversais, remendos, panelas, deformação permanente nas trilhas de rodas, corrugação, exsudação, agregados polidos, desgaste, desnível pista-acostamento e bombeamento. Uma descrição completa sobre os vários tipos de defeitos, as suas causas, tratamentos adequados bem como os modos de medição dos níveis de severidade e extensão podem ser encontrados em Fernandes Jr. et al (1999).

Os defeitos guardam uma interdependência entre si, e desde que não sejam adotadas as ações corretivas, passa a se desencadear uma superposição de efeitos com resultados desastrosos para o pavimento. Os revestimentos betuminosos tendem a trincar em algum estágio de suas vidas sob as ações combinadas do tráfego e das condições ambientais, por meio de um ou mais mecanismos. Portanto, a velocidade de deterioração de um pavimento aumenta após o aparecimento do trincamento, com impacto significativo na evolução das deformações nas trilhas de roda e da irregularidade longitudinal (DNIT, 2005a)

É de extrema importância para a seleção de estratégias e definição de prioridades a avaliação objetiva dos pavimentos. Faz parte dessa avaliação o reconhecimento do tipo de defeito, a quantificação de sua extensão (freqüência de ocorrência ou área do revestimento 
sujeita a um determinado tipo de defeito) e a identificação do nível de severidade (nível de deterioração do defeito, normalmente classificado em baixo, médio e alto). Ainda, o reconhecimento e a quantificação dos defeitos influenciam diretamente na tomada de decisão, quanto ao procedimento corretivo ou preventivo a ser adotado.

O levantamento de campo, pode ser realizado através de avaliação de dentro de veículo, trafegando a baixa velocidade $(20$ a $30 \mathrm{~km} / \mathrm{h}$ ), com cobertura de toda a rede (mas com obtenção de dados de qualidade inferior), ou mediante caminhamento, geralmente, em seções selecionadas por amostragem. Para fins de utilização em SGPUs, o levantamento de campo envolve a inspeção visual e identificação dos defeitos mais significativos e a medida e avaliação da extensão e severidade de cada defeito. O DNIT também utiliza a classificação do Manual de Identificação de defeitos do Programa SHRP (DNIT, 2004b).

Uma forma de agregar todas as informações sobre as deteriorações é determinar um índice, geralmente chamado de Índice Combinado de Defeitos, que expressa a condição do pavimento a partir de informações detalhadas da extensão e nível de severidade dos defeitos.

No Brasil o DNIT utiliza o chamado Índice de Gravidade Global (IGG), um índice combinado que permite a avaliação de deterioração de segmentos rodoviários, refletindo o estado de cada segmento isoladamente e também a comparação relativa entre os estados apresentados por segmentos distintos. O cálculo do IGG é baseado na norma DNIT 006/2003 - PRO (Avaliação objetiva da superfície de pavimentos flexíveis e semi-rígidos - DNIT, 006/2003-PRO). O IGG é obtido através da Equação 3.1.

$$
I G G=\sum I G I
$$

Onde o IGI é o Índice de Gravidade Individual que representa um valor específico de cada ocorrência (são considerados dez tipos de ocorrências, sendo oito tipos individuais de defeitos e os outros dois derivados da mensuração das flechas nas trilhas de roda). O IGI (Equação3.2) é estabelecido em função do peso ou "nível de responsabilidade" de cada evento definido através de um fator de ponderação.

$$
I G I=f_{r} \times f_{p}
$$

Onde $f_{r}$ é a freqüência relativa (número de vezes em que a ocorrência é verificada em relação ao número total de estações) obtida através da Equação 3.3 e $f_{p}$ é o fator de ponderação obtido de acordo com a Tabela 3.3. 


$$
f_{r}=\frac{100 \times f_{a}}{n}
$$

Onde:

- $f_{a}$ : freqüência absoluta;

- n: número de estações inventariadas.

Tabela 3.3 : Valor do Fator de Ponderação [DNIT 006/2003]

\begin{tabular}{clc}
\hline $\begin{array}{c}\text { Tipo } \\
\text { Ocorrência }\end{array}$ & \multicolumn{1}{c}{ Defeitos } & $\begin{array}{c}\text { Fator de } \\
\text { Ponderação }\end{array}$ \\
\hline 1 & Trincas Transversais, Trincas Longitudinais, Trincas por Reflexão (Classe 1, 2 e 3) & 0.2 \\
2 & Trincas por Fadiga e Trincas em Blocos(Classe 2) & 0.5 \\
3 & Trincas por Fadiga e Trincas em Blocos(Classe 3) & 0.8 \\
4 & Afundamento & 0.9 \\
5 & Ondulação, Corrugação e Panelas & 1.0 \\
6 & Exsudação & 0.5 \\
7 & Desgaste & 0.3 \\
8 & Remendo & 0.6 \\
\hline
\end{tabular}

Os conceitos definidos pelo DNIT para retratar o grau de degradação atingido no pavimento inventariado é apresentado também na Tabela 3.1. Embora o método apresentado pelo DNIT, para calcular um índice que expressa a condição do pavimento, seja bastante funcional, pois a avaliação é feita por amostragem e o levantamento é feito a pé e registrandose os tipos de defeitos encontrados, este método não considera a extensão dos defeitos, apenas o número de ocorrências e também não leva em conta o nível de severidade dos defeitos (com exceção das trincas).

Um outro método interessante para determinar índices combinados foi $o$ apresentado por Bandara \& Gunaratne (2001). Eles desenvolveram uma metodologia baseada no julgamento subjetivo da extensão e severidade de cada tipo de defeito associada à técnica matemática da lógica fuzzy. Primeiramente a avaliação do pavimento considerou quatro tipos mais freqüentes de defeitos e cada tipo de defeito podia estar associado a três níveis de severidade medida subjetivamente: baixa, média e alta. A extensão foi medida através da porcentagem de pavimento afetado pelos diferentes tipos de defeitos. E por fim, a cada tipo de defeito foi determinada a sua importância relativa expressada em valores lingüísticos: extremamente importante; muito importante; importante e moderadamente importante.

Números fuzzy foram adotados para representar essas avaliações que envolvem julgamentos subjetivos e incerteza. Um número fuzzy $\tilde{A}$ no espaço X é caracterizado através de uma função fuzzy $\mu_{A}(X)$ que associa a cada valor em $\mathrm{X}$ um número real dentro de um intervalo [0-1]. Exemplos de funções fuzzy são apresentados na Seção 4.2 deste trabalho. 
Entretanto, Bandara \& Gunaratne (2001) utilizaram o método da Efficient Fuzzy Weighted Average (EFWA) introduzido por Lee \& Park (1997) para determinar o índice da condição do pavimento, agregando tipo, severidade e extensão de cada defeito do pavimento aos julgamentos de especialistas, conforme a Equação3.4.

$$
F C I=\frac{\sum_{i=1}^{3} \sum_{k=1}^{n} w_{k i} A_{k i} s_{i}}{\sum_{i=1}^{3} \sum_{k=1}^{n} w_{k i} A_{k i}}
$$

Onde:

- FCI - (Weighted Fuzzy Condition Index): Índice de Condição Ponderado Fuzzy;

- $w_{k i}$ : peso subjetivo do defeito $k$ com nível de severidade $i$;

- Aki: extensão do defeito $k$ com severidade $i$;

- $S_{i}$ : valores subjetivos do nível de severidade $i$.

Esse método mostra-se eficiente por considerar não só o tipo de defeito durante as análises, mas também incluir informações subjetivas de extensão e severidade de cada tipo de defeito.

\subsubsection{2 Índice da Condição do Pavimento}

O índice da condição do pavimento também pode ser determinado através de avaliação subjetiva. Este tipo de avaliação utiliza o conceito de serventia desenvolvido durante o AASHO Road Test e definido por Carey \& Irick (1960) para determinar o estado de deterioração do pavimento.

A serventia é a capacidade de um trecho específico de pavimento de proporcionar, na opinião do usuário, rolamento suave e confortável em determinado momento, para quaisquer condições de tráfego. A serventia é expressa através de medida subjetiva das condições de superfície de um pavimento, feita por um grupo de avaliadores que percorrem o trecho sob análise, registrando suas opiniões sobre a capacidade do pavimento de atender às exigências do tráfego que sobre ele atua, no momento da avaliação, quanto à suavidade e ao conforto (DNIT, 009/2003-PRO). Um exemplo de aplicação para este tipo de avaliação subjetiva pode ser visto no capítulo 6, onde os resultados da avaliação serviram de base para o estudo de caso realizado neste trabalho. 


\subsubsection{Irregularidade Longitudinal}

A irregularidade longitudinal (IL) é o desvio de pontos da superfície do pavimento em relação a um plano de referência e medida ao longo da trajetória dos veículos ("trilhas de rodas"). A IL afeta a qualidade de rolamento, a transmissão das cargas dinâmicas ao pavimento e os custos de operação dos veículos. Portanto, é um atributo mensurável medido através do Índice de Serventia Atual e do Índice de Irregularidade Superficial, que representam o desempenho do pavimento, ou seja, a sua capacidade de servir ao tráfego com segurança e economia e, principalmente atender ao conforto dos usuários.

A medição da irregularidade longitudinal é um parâmetro quase sempre incorporado na definição de prioridades e estratégias de manutenção e reabilitação em pavimentos rodoviários, mas em pavimentos urbanos de cidades de médio porte estes índices não são muito utilizados. Isto ocorre porque a velocidade de tráfego dos veículos em pavimentos urbanos é bem inferior à velocidade em pavimentos rodoviários, fazendo com que os usuários não percebam a influência da irregularidade longitudinal durante a sua viagem (no conforto, na segurança e na economia). Portanto, a avaliação funcional, através de medida da irregularidade longitudinal (desde os simples medidores do tipo resposta até os sofisticados perfilômetros), é útil apenas nas vias de trânsito rápido (acima de $60 \mathrm{~km} / \mathrm{h}$ ).

\subsubsection{Capacidade Estrutural}

A avaliação estrutural de um pavimento pode ser resultado de uma análise dos elementos obtidos no levantamento dos defeitos de superfície ou pode ser desenvolvida, de forma mais direta, através de ensaios, destrutivos ou não destrutivos. Os ensaios não destrutivos contam com equipamentos para medida de deflexão superficial causada por um carregamento conhecido (viga Benkelman e FWD - Falling Weight Deflectometer, por exemplo) e os ensaios destrutivos mediante avaliação da capacidade de suporte e de amostras coletadas in situ.

Defeitos existentes no pavimento fornecem informações sobre o efeito do tráfego na estrutura do pavimento. Assim, certos tipos de trincas, que caracterizem fadiga, bem como o afundamento em trilhas de roda, podem indicar comprometimento estrutural.

Quando da utilização do HDM para gerenciamento de atividades sobre o pavimento, o número estrutural corrigido (SNC) apresenta-se como importante medida de resistência para a avaliação estrutural e para a utilização em modelos de previsão de 
desempenho. Ainda no que se refere à avaliação estrutural cabe ressaltar que, essas medidas são utilizadas para análises detalhadas em nível de projeto, pois quando usada para apoio à decisão em nível de rede acarretam um grande acréscimo nos custos totais de manutenção (VISCONTI, 2000).

\subsubsection{Idade}

A idade do pavimento ou dados sobre o ano da última intervenção são fatores importantes que geralmente são considerados para agregar informação nos modelos de priorização de pavimentos. Para isto, devem fazer parte do inventário da estrada em questão. Também pode ser consideradas medidas do número de anos que o desempenho do pavimento é aceitável (concito que vida útil, ou vida em serviço do pavimento).

\subsubsection{Localização}

As localizações podem ser consideradas de alta prioridade quando a seção de pavimento está localizada em local estratégico. Vias que servem áreas de produção, vias próximas a escolas e a centros de saúde, vias que atendem instalações militares, zonas industriais ou turísticas de uma cidade são exemplos relativamente comuns de questões que não estão diretamente relacionadas às condições dos pavimentos, mas que podem ser consideradas para a priorização dos pavimentos.

É importante que nas proximidades destes locais sejam mantidas boas condições de tráfego, para que não haja eventuais acidentes e atrasos durante o tempo de viagem. Além dos exemplos anteriores, é o caso também dos terminais rodoviários que possuem um elevado volume de tráfego de ônibus e de veículos de passageiros que vão e vêm e, o caso das seções próximas dos hospitais que atendem diariamente um elevado tráfego de ambulâncias e veículos de pacientes. Além disso, outras instituições públicas e de interesse da população podem ser consideradas no processo de decisão.

\subsubsection{Questões de Segurança}

As taxas de acidentes são muito utilizadas para priorização de projetos principalmente quando são consideradas as atividades de manutenção relacionadas com a segurança. Os acidentes podem estar relacionados com o usuário, com o veículo, com a drenagem, com as deficiências na geometria da via e, também podem ser causados pela falta de aderência entre pneu e pavimento. 
A perda de aderência entre pneu e superfície do pavimento pode ser provocada pela má condição do pavimento, a existência de defeitos ou de degradação da superfície de pavimento e com a existência e as más condições dos equipamentos de drenagem.

A aderência está relacionada diretamente com dois parâmetros: a resistência a derrapagem e o coeficiente de atrito. Em termos práticos, a resistência a derrapagem pode ser determinada através da avaliação de algumas características da superfície, como por exemplo: a textura, a exudação do revestimento ou a intensidade de agregados polidos. $\mathrm{O}$ atrito superficial é determinado através de equipamentos e deve ser o suficiente de modo que permita a conservação do veículo, a todo o momento, na trajetória desejada por seu condutor, e quando for necessária a frenagem, que essa seja efetuada a uma distância segura.

$\mathrm{Na}$ literatura pesquisada neste trabalho, em geral, considera-se a segurança como um critério na decisão de projetos de transportes identificando a taxa de acidentes antes e depois dos mesmos serem executados. Ou seja, num período de análise é realizada a medição da redução da taxa de acidentes e então é feito um histórico que interpreta os locais mais críticos na rede (CAFISO et al., 2002; GOTHIÉ, 1993).

A aderência é um dos fatores mais importantes quando a manutenção avaliada está relacionada com a segurança. Os pavimentos com baixo valor de aderência e/ou alto índice de acidentes devem ser identificados, permitindo ao órgão responsável realizar uma análise mais profunda, avaliar as necessidades e programar medidas corretivas. A experiência com dados de aderência no Brasil ainda é bastante limitada, porém a tendência é de que seu uso se difunda, em função da importância quanto ao aspecto segurança (DNIT, 2005a).

\subsubsection{Questões Ambientais}

Os ruídos, os impactos na qualidade do ar e os impactos na qualidade da água devido à frenagem, aceleração e congestionamento de veículos estão relacionados com a existência de deterioração do pavimento ou de obras de manutenção em determinados locais da cidade.

Um dos parâmetros ambientais que mais é percebido e considerado nas análises para programar atividades de manutenção é a relação entre a qualidade do ar e a condição do pavimento devido à emissão de gases pelos veículos. Um índice da qualidade do ar pode ser determinado comparando as taxas de concentração de poluentes e os valores permitidos por 
norma para cada tipo de substância poluente para a seção de pavimento na rede da cidade em estudo (CAFISO et al., 2002).

\subsubsection{Fatores Econômicos}

A etapa de avaliação econômica juntamente com outros critérios de decisão, dentro de um sistema de gerência de pavimentos, fornece a base para auxiliar as decisões das agências no que diz respeito à definição da melhor estratégia de conservação dos pavimentos. Quando um tratamento é previsto para um projeto com base na análise do custo do tempo de vida do pavimento, diferentes fatores podem ser usados na priorização, incluindo a razão custo-benefício e a razão custo-eficácia.

O objetivo de qualquer avaliação econômica, para definir os investimentos na manutenção de uma infra-estrutura rodoviária, consiste em procurar àqueles investimentos que minimizem o custo total de transporte, entendendo-se como custo total de transportes a soma dos custos de operação dos veículos e dos custos de manutenção da infra-estrutura (no custo de operação dos veículos, dependendo da disponibilidade de dados, podem estar incluídos os custos de acidentes). Quanto mais se investir em manutenção, menor será o custo de operação dos veículos que trafegam na malha. Haverá, no entanto, um nível de investimentos a partir do qual a redução no custo de operação não mais justificará o investimento adicional, nível este que corresponderá ao mínimo custo total de transportes (VISCONTI, 2000).

Portanto, o custo total de transportes associado à gerência de pavimentos pode ser dividido em dois grupos principais: os custos da agência e dos usuários.

\subsubsection{Custos da agência ou de administração}

Os custos da agência podem ser divididos em custos iniciais de construção, custos de manutenção e reabilitação e valor residual. Os custos iniciais de construção estão relacionados com o orçamento inicial que a agência investe para a construção de um pavimento novo, que à princípio, não precisam ser considerados na análise de estratégias de manutenção e reabilitação dos pavimentos.

Os custos de manutenção e reabilitação (M\&R) são referentes a todas as ações implementadas durante o tempo de vida útil do pavimento, com o objetivo de manter o pavimento acima de um determinado nível de qualidade ou com um determinado nível limite de degradação. É determinado, em termos monetários, em relação ao valor unitário de cada 
atividade de $M \& R$ realizada no pavimento ou, também, podem ser consideradas as estratégias de M\&R previstas, para um determinado período de análise.

O custo negativo no final do período de projeto, chamado valor residual, é determinado pela diferença entre o custo inicial do pavimento e o custo da reabilitação, de modo que apresente características idênticas às iniciais. $\mathrm{O}$ valor residual expressa o valor do pavimento quando este chega ao final do seu período de vida útil, quando ele ainda possui algum valor do ponto de vista estrutural e funcional.

\subsubsection{Custos do usuário}

Os custos do usuário são pouco considerados pelas agências e uma das razões para isso é que este custo não faz parte dos orçamentos e custos das agências. No entanto, para o cálculo do custo total é necessário que este esteja incluído, particularmente quando é o usuário quem paga o custo total de reabilitação, construção e manutenção do pavimento (HAAS et al, 1994). Os custos dos usuários compreendem:

- Custo de operação de veículos;

- Custo do tempo de viagem;

- Custo de acidentes;

- Custo do desconforto;

- Custo extra de operação do veículo e do tempo de viagem devido aos serviços de manutenção.

$\mathrm{O}$ custo de operação $(\mathrm{CO})$ de veículos depende principalmente das condições de tráfego dos veículos, envolvendo a velocidade de circulação, irregularidade da camada superficial, tipo de camada, características geométricas da estrada e estado e tipo de veículo. Estes custos envolvem consumo de combustível, consumo de lubrificante, desgaste dos pneus, etc. Para cada R \$ 1,00 investido em rodovias há uma redução de quase R\$ 3,00 no Custo Operacional dos Veículos (DNIT, 2005b). O CO apresenta uma variação muito pequena quando a camada superficial é composta de revestimento asfáltico ou de concreto, e nem sempre é fundamental a sua consideração numa análise econômica.

O custo do tempo de viagem é função principalmente da velocidade, que por sua vez é função das características geométricas da via, do tipo de veículo e do estado do pavimento. É uma componente dos custos dos usuários que pode assumir um peso muito elevado na comparação de diferentes estratégias, em particular quando se trata de estradas de tráfego intenso, pois os custos relacionados com o tempo adicional devido aos trabalhos de 
manutenção e reabilitação dos pavimentos, também são considerados na análise. Assim como os custos de acidentes, os custos de tempo de viagem são determinados através da estimativa de mudanças nos níveis de impacto durante um período de análise (tal como o número de veículos por hora ou o número de acidentes fatais) e são avaliados por valores em termos monetários de cada mudança (KULKARNI et al., 2004).

Além dos custos da agência e dos usuários também podem ser considerados os custos para a sociedade, relacionados com os danos ambientais, como poluição do ar, poluição da água e ruídos. Assim como os custos de acidentes, os de desconforto e de danos ambientais são muito difíceis de serem determinados em termos numéricos ou monetários e geralmente são omitidos nos cálculos de custos.

\subsection{Otimização de Rede e Priorização de Projetos}

Os procedimentos de análise de dados usados pelos órgãos públicos ou privados variam em sofisticação desde julgamentos estruturados de especialistas ou uma simples hierarquização subjetiva a otimização baseada em modelos de programações matemáticas complexas, passando pelo uso de índices de prioridades calculados em função de fatores que condicionam o desempenho dos pavimentos e dos custos associados (HAAS et al., 1994). Entretanto, todos os métodos de programas de prioridades incorporam basicamente quatro etapas: informação, identificação das necessidades, análises de prioridades e registros das recomendações, como mostra a Figura 3.1. Desta forma, qualquer método usado em um programa de prioridades deveria responder as questões:

- Quais projetos (ou seções) devem ser reabilitados ou mantidos (seleção de candidatos)?

- Como eles podem ser construídos ou mantidos (seleção de alternativas de novos projetos ou de alternativas do tratamento de manutenção)?

- Quando eles devem ser construídos ou mantidos (seleção de tempo, prazos)?

Dificilmente um modelo responde a todas essas questões simultaneamente (isto é, considerar e avaliar todas as possíveis combinações e trade-offs). A maioria dos organismos e administradores utiliza modelos que lidam somente com a primeira ou as duas primeiras questões. Mas se o investimento é para ser realmente otimizado, todas as possíveis combinações das três questões, devem ser avaliadas. 


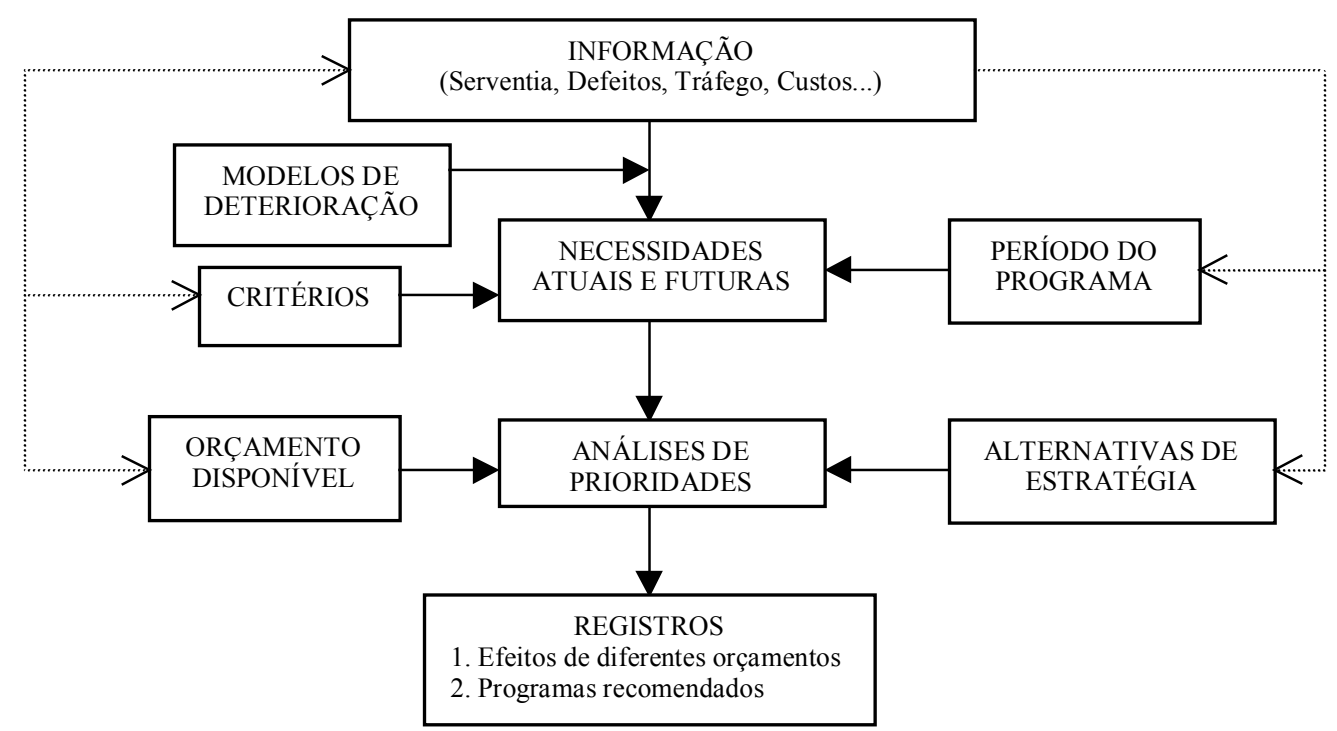

Figura 3.1: Etapas de programas de prioridades (Adaptada de Haas et al., 1994)

Os organismos criam suas próprias terminologias para estes procedimentos, como por exemplo, critérios para ranking de pavimentos, análises da condição do pavimento, modelos de avaliação de prioridades, modelos de otimização em nível de rede, modelos de priorização e identificação de estratégias de M\&R. Entretanto, as metodologias (nível de seleção de projetos) podem ser divididas em duas categorias: Modelos de priorização de projetos e Modelos de otimização de redes. Ambas podem ser utilizadas em sistemas de análises das necessidades de manutenção e reabilitação de pavimentos em nível de rede.

\subsubsection{Priorização de Projetos}

A priorização de projetos é um método de análise de dados e combina dados sobre a condição do pavimento em um score ou índice que representa a condição global do pavimento. Todas as seções de pavimento são ordenadas (ranked) e categorizadas por tipo de pavimento, volume de tráfego, classe funcional e outros fatores relacionados com a seção de pavimento. Algumas agências têm critérios de ranking mais complexos onde vários outros fatores, tais como, atrito, capacidade estrutural, deficiências geométricas e questões ambientais são considerados para o ranking das seções de pavimento. Recursos para M\&R são alocados baseados no ranking de seções de pavimento e a prioridade relacionada a essa seção (HAAS et al, 1994).

Em muitos casos, fatores de ponderação para o cálculo de Índices de Prioridade (IP) são desenvolvidos a partir de sistemas especialistas simplificados e qualificados, pois estes dependem, em grande parte, da experiência e da intuição dos profissionais. Os IPs 
podem ser utilizados para: hierarquização e seleção de trechos e de estratégias de manutenção e reabilitação. São índices combinados usados para expressar a condição da seção de pavimento em termos de uma combinação de fatores selecionados e julgamentos subjetivos de tomadores de decisão.

Os métodos de priorização são baseados em um fator ou uma combinação de fatores de priorização e podem considerar análises de intervenções para o ano atual ou para múltiplos anos. Os métodos de priorização com planejamentos anuais podem ser executados de duas formas: a primeira considera o ranking dos projetos prioritários baseado na condição atual do pavimento (defeitos existentes) e a segunda considera os projetos prioritários de acordo com a condição atual do pavimento e também da análise de custo/benefício das intervenções.

Se o desempenho do pavimento puder ser previsto com o uso de modelos de desempenho ou modelos de deterioração, o método de priorização pode ser desenvolvido considerando um plano de atividades de M\&R para múltiplos anos. O chamado "Early Multiyear Prioritization Method" (MASSEY, 2001; GAO, 2004) é frequentemente utilizado pelos engenheiros de pavimentos, devido à simplicidade e clareza do método, para justificar os gastos nos investimentos em manutenção de pavimentos.

Outro método de priorização também se destaca, o "Multi-year Prioritization Method", sendo bem mais complexo. Utiliza medidas como relação custo-eficácia, custobenefício, entre outras, para comparar diferentes alternativas de tratamentos a serem aplicadas em diferentes datas, dentro do período de análise. As análises permitem determinar os mais altos benefícios, medidos em função do melhor desempenho global, previsto para os pavimentos no período de análise (GAO, 2004).

Como exemplo de aplicação desses métodos pode-se citar o California Department of Transportation (Caltrans) e Indiana Department of Transportation (InDOT) (GAO, 2004; CHAN et al, 1994; GEORGE et al; 1994).

\subsubsection{Otimização de Rede}

Os modelos de otimização são métodos de programação matemática, utilizados em análises em nível de rede, que identificam as estratégias de $M \& R$, maximizando os benefícios no total da rede ou minimizando os custos (principalmente, quando se trata de orçamentos restritos). Valores de condição do pavimento, entre outros, são usados como parâmetros, 
variáveis de decisão que determinam qual tratamento deve ser aplicado para uma determinada seção de pavimento no ano atual ou para múltiplos anos. A maioria dos modelos de otimização considera métodos utilizados para prever o desempenho de pavimentos (condições futuras do pavimento e a alocação de recursos feita para vários anos).

A otimização não indica as prioridades por si só, mas seleciona alternativas para satisfazer uma função-objetivo específica (alguns valores são maximizados, como a eficiência ou o desempenho, ou minimizados, como os custos). As formulações usadas nestes modelos incluem diferentes variações de programação linear (Linear Programming) e programação dinâmica (Non-linear Programming e Integer Programming). A Programação Linear é uma das formulações mais utilizadas para priorização que considera múltiplos anos. Cada implementação ou ano de ação pode ser tratado como uma alternativa independente, junto com os projetos e seções da rede e, então, todas as combinações são consideradas e comparadas (HAAS et al., 1994). Mais detalhes dos métodos podem ser encontrados em WINSTON (1995) e RARDIN (2000).

\subsubsection{Comparação entre Priorização e Otimização}

A priorização e otimização de projetos não são necessariamente a mesma coisa (HAAS et al., 1994). A Tabela 3.4 apresenta um resumo das várias classes de métodos para seleção de projetos (dos locais) de manutenção e suas vantagens e desvantagens.

Tabela 3.4: Classes de métodos de programas de prioridades (HAAS et al., 1994)

\section{CLASSE DE MÉTODOS}

Ranking subjetivo simples de projetos baseado em julgamentos de especialistas
VANTAGENS E DESVANTAGENS

Ranking baseado em parâmetros, tais como, Simples e de fácil uso; resultado distante do serventia, deflecção, classe funcional da via, etc. ótimo

Ranking baseado em parâmetros com análise Razoavelmente simples; resultado próximo do econômica ótimo

Otimização por modelos de programas Menos simples; resultado próximo do ótimo sem matemáticos com base ano por ano considerar efeitos de tempo (prazos)

Otimização baseada em heurística e custoeficácia marginal (Near Optimization)

Razoavelmente simples; pode ser usado em ambiente computacional; resultado próximo do ótimo

Otimização por modelos de programas matemáticos, considerando os efeitos de tempo

Mais complexo; pode ter resultado ótimo

(máximo de benefício) 
Quando são feitas comparações entre métodos de priorização e otimização, com projetos que competem igualmente por orçamentos de $M \& R$ e que consideram o momento oportuno de intervenção, percebe-se logo a superioridade dos métodos de otimização em relação aos métodos de priorização em termos de melhorar o déficit orçamentário e a condição do pavimento sob o período de análise. A possível razão para esta constatação se deve a dificuldade dos métodos de priorização ou ranking em modelar a transição da condição da via, como é feito em modelos de otimização no qual a alocação de recursos é estabelecida para a rede inteira e geralmente para um período de 5 a 10 anos (WANG et al., 2003).

Os modelos de otimização têm a capacidade de avaliar diferentes estratégias de reabilitação e selecionar uma estratégia ótima para tratar um pavimento, incorporando o método para toda a rede. Para este fim, diferentes alternativas de tratamentos são consideradas em cada projeto ao mesmo tempo, e também aquele que ocasionar maiores benefícios. A otimização em nível de rede é desenvolvida para obter um plano "ótimo" de intervenção para toda a rede. Já nos modelos de priorização, tanto para um ano ou múltiplos anos, todos os projetos da rede são priorizados baseados em determinados parâmetros. O resultado obtido da priorização pode não ser o planejamento "ótimo" de intervenção para a rede, e esta é a principal razão de muitos sistemas de gerência desenvolverem modelos de otimização e não de priorização. Entretanto, existem várias razões para não investir em modelos de priorização. Do ponto de vista técnico, os algoritmos para soluções ótimas utilizados em vários modelos de otimização (Linear programming, nonlinear programming ou integer programming) são muito complexos. Também o modelo tradicional de Markov (Chain-based linear programming) determina somente a porcentagem de seções da rede que será tratada para cada tipo de pavimento e para cada ano do período de análise. O método não identifica projetos com tratamento específico a serem aplicados em cada tipo de pavimento. (FERREIRA et al., 2002; WANG et al., 2003; GAO, 2004).

Uma pesquisa (NCHRP Syntheses 222) dos métodos de análise das necessidades em nível de rede, empregados pelas agências dos Estados Unidos, Porto Rico e Canadá para gerência rodoviária, mostrou que a maioria das agências utiliza análises de ranking baseadas na condição do pavimento, como mostra a Tabela 3.5 (ZIMMERMAN, 1995). Estes resultados mostram que apesar de modelos de otimização ser bem mais completos, pois consideram o desempenho do pavimento, um grande número de agências prefere utilizar modelos de priorização, realizando análises mais simples e identificando tratamentos específicos para cada seção e tipo de pavimento. 
Tabela 3.5: Prática de seleção de projetos (NCHRP Syntheses 222)

\begin{tabular}{lc}
\hline Método e fatores considerados & Porcentagem de utilização \\
\hline Ranking baseado na condição do pavimento & 47 \\
Incremento de Custo-Beneficio & 19 \\
Custos do ciclo de vida & 10 \\
Custos e momento de intervenção (tempo) & 6 \\
Custo inicial & 6 \\
Modelos de Otimização de Rede & 19 \\
Outros & 2 \\
\hline
\end{tabular}

Um método simples de ranking para uma análise feita anualmente, seção por seção, não considera a condição futura do pavimento e ignora o efeito relativo da condição da rede inteira para selecionar uma seção para manutenção. É importante que seja considerada numa análise de rede, o aumento da necessidade por manutenção e a piora da condição do pavimento rodoviário, com o passar do tempo. Entretanto, no caso de vias urbanas pavimentadas as intervenções devem ser mais freqüentes e imediatas e os pavimentos têm uma vida útil mais curta do que em pavimentos rodoviários. Neste caso, o planejamento anual de atividades de manutenção preventiva pode ser uma boa solução. Desta forma, evita-se o desgaste acelerado do pavimento e os gastos desnecessários com recapeamentos precoces.

\subsection{Síntese de Modelos de Priorização}

Como especificado anteriormente, há uma diversidade grande de métodos de análises das necessidades em nível de rede que atualmente são incorporadas aos sistemas de gerência de pavimentos. As próximas seções especificam modelos utilizados pelo DNIT, pelo HDM-4 e algumas propostas de diversos órgãos responsáveis por pavimentos urbanos.

\subsubsection{Modelo Incorporado ao HDM}

O HDM (Highway Design and Maintenance Standards Model) é um instrumento para a avaliação de projetos de construção e manutenção rodoviárias. A tarefa básica do modelo consiste na comparação de alternativas de projetos e de estratégias de manutenção, a partir da avaliação conjunta dos custos de construção e de manutenção, normalmente a cargo dos órgãos públicos, e dos custos de operação dos veículos, nos quais incorrem os usuários das rodovias. Através da comparação de várias alternativas, o HDM identifica aquela que corresponda ao menor custo total para a sociedade. Os resultados e as comparações são apresentados em termos de taxa interna de retorno e valor atual dos benefícios. 
O HDM-4 utiliza um método de priorização baseado no conceito de análise de custo-benefício para o ciclo de vida do pavimento. Ou seja, utiliza um modelo de otimização que prevê o desempenho do pavimento em função do volume de tráfego, da carga transmitida pelas rodas, capacidade estrutural, padrões de manutenção e questões ambientais na rede. Os benefícios são quantificados em termos de menor custo de operação de veículos, reduzido tempo de viagem, menor número de acidentes e melhora nos efeitos ambientais.

Portanto, partindo desses conceitos, o HDM-4 se caracteriza pela aplicação de três etapas geralmente utilizadas na tomada de decisão na gerência de rodovias (CAFISO et al, 2002; GAO, 2004):

- Planejamento estratégico: estima o orçamento necessário a médio e longo prazo para o desenvolvimento e manutenção de uma rede viária, sob vários cenários orçamentários e econômicos. A análise de estratégias determina as necessidades elou prevê o desempenho do pavimento sob a ótica de orçamentos restritos para a rede inteira. A rede é primeiramente dividida em diferentes categorias (pavimento flexível, de concreto, paralelepípedos, etc). Para cada categoria são definidos o volume de tráfego, a carga e os padrões de manutenção. Então os beneficios são calculados para cada tratamento específico a ser utilizado.

- Programa de análises: estabelece as atividades por um ou múltiplos anos sob restrição orçamentária, identificando através de um planejamento tático, as seções que requerem manutenção, melhorias ou novas construções. Esta etapa prioriza projetos candidatos em cada ano dentro do período de análise com um orçamento anual restrito e considerando sempre a relação benefício/custo. Têmse por fim uma lista de projetos.

- Análise de projetos: estima a viabilidade econômica e de execução de diferentes projetos de investimentos rodoviários associados aos efeitos ambientais. Desenvolve-se a análise de projetos em que um ou mais projetos de estradas (ou vias) ou opções de investimentos são avaliados. Avaliam-se diferentes alternativas de tratamentos baseado no custo e beneficio do usuário, nas previsões de deterioração durante o ciclo de vida, os custos e efeitos das atividades de $M \& R$, etc.

Para todas estas três etapas de trabalho, o HDM-4 possui uma linha de operações baseada no conceito de análise do ciclo de vida do pavimento, envolvendo a análise de desempenho do pavimento, conseqüências e custos de serviços rodoviários, juntamente com estimativas dos custos dos usuários e conseqüências ambientais, e ainda, a comparação econômica de diferentes alternativas de projetos (KERALI et al., 2000).

\subsubsection{Modelo Utilizado pelo DNIT}

Em 1985, após a realização dos primeiros levantamentos de campo em toda a rede federal pavimentada, o DNER, através do SGP-DNER, estabeleceu as prioridades de 
investimentos em manutenção utilizando um índice chamado Índice de Suficiência (IS) com critérios baseados em indicadores físicos, ponderados pelo volume de tráfego.

O emprego do IS tornou-se atrativo por ser simples e rápido. Por outro lado, o IS não leva em consideração, ao menos diretamente, qualquer fator de ordem econômica. Desta forma, os projetos e as prioridades estabelecidas pelo IS não conduzem necessariamente ao menor custo total de transporte rodoviário.

O IS traduz quantitativamente o grau de suficiência de um subtrecho homogêneo de rodovia. Quanto maior o IS, melhor deve ser o trecho. Ao baixo valor do IS corresponderá um subtrecho deteriorado, necessitando de restauração e com tráfego prejudicado. O IS é determinado de acordo com a Equação 3.5 (DNIT, 2004a).

$$
I S=100-5,220(F Q I x F T M D x F T D P R)^{0,2788}
$$

Onde:

- FQI: Fator de Quociente de Irregularidade

- FTMD: Fator de Tráfego Médio Diário para automóveis, ônibus e caminhões

- FTDPR: Fator referente às trincas ou desgaste, a deflexão, a pluviosidade e ao relevo

Nas definições de prioridades realizadas em 1986, 1987 e 1989 pelo DNER foi utilizado o modelo HDM-III, obtendo-se a solução ótima para cada trecho sem qualquer preocupação quanto à disponibilidade de recursos. Já nas avaliações de 1994 e 1996 do SGPDNER, foi utilizado o modelo EBM (Expenditure Budgetary Model) em conjunto com o HDM-III para definir prioridades de investimentos, considerando-se um orçamento limitado. Neste sentido, seleciona-se, dentre todas as estratégias de manutenção viáveis avaliadas pelo HDM, o conjunto de soluções para a rede rodoviária que, compatível com um orçamento restrito, minimiza o custo total de transportes.

Desde 1994 o DNIT (Departamento Nacional de Infra-estrutura de Transportes) faz a priorização de seções rodoviárias através do modelo empírico desenvolvido pelo DNER, que complementa as análises de investimentos da aplicação do modelo HDM-III, recomendada pelo Banco Mundial em seus programas de financiamento. (BODI \& BALBO, 1998).

O modelo de priorização é baseado no Índice de Prioridade (IP) que por sua vez é determinado através da ponderação do Índice de Estado da Superfície (IES) e do Índice de Custo Operacional (IC), através da Equação 3.6. 


$$
I P=\frac{\left(I C^{*} w 1+I E S^{*} w 2\right)}{(w 1+w 2)}
$$

Onde w1 e w2 são pesos de ponderação que valem 2 e 3 respectivamente, dando-se uma maior importância ao estado da superfície (IES) do que ao custo operacional (IC). Ainda, o IES é determinado em função de um índice combinado de defeitos chamado Índice de Gravidade Global Expedito (IGGE) e do Valor de Serventia Atual (VSA - CAREY \& IRICK, 1960), conforme apresentado na Tabela 3.6. O IC em função do Quociente de Irregularidade (QI), obtido indiretamente através dos resultados da equação de correlação com o VSA, descrito por Visser et al. (1979) e do Volume Diário Médio (VDM), conforme Tabela 3.7. O IGGE é calculado pela Equação 3.7.

$$
I G G E=0.65 * F T+1.0 * F O A P+1.0 * F R P
$$

Onde FT, FOAP E FRP são freqüências de trincas, deformações, trincas e remendos, respectivamente, de acordo com a Tabela 3.8 .

Tabela 3.6: Índice de Estado da Superfície (DNER, 1993)

\begin{tabular}{ccccccc}
\hline CONCEITO & IGGE & VSA $<\mathbf{2 , 5}$ & $\mathbf{2 , 5}<$ VSA $<\mathbf{3}$ & $\mathbf{3}<\mathbf{V S A}<\mathbf{3 , 5}$ & $\mathbf{3 , 5}<\mathbf{V S A}<\mathbf{4}$ & $\mathbf{V S A}>\mathbf{4}$ \\
\hline $\mathbf{E}$ & $<15$ & $*$ & $*$ & 5 & 3 & 0 \\
$\mathbf{B}$ & $>15 \mathrm{e}<30$ & $*$ & 6 & 6 & 4 & 2 \\
$\mathbf{R}+$ & $>30 \mathrm{e}<60$ & 8 & 7 & 7 & 5 & 4 \\
$\mathbf{R}-$ & $>60 \mathrm{e}<80$ & 9 & 8 & 8 & 6 & $*$ \\
$\mathbf{M}$ & $>80 \mathrm{e}<120$ & 10 & 9 & 9 & $*$ & $*$ \\
$\mathbf{P}$ & $>120$ & 10 & 10 & $*$ & $*$ & $*$
\end{tabular}

(* Casos incoerentes ou inexistentes)

Tabela 3.7: Índice de Custo Operacional (DNER, 1993)

\begin{tabular}{ccccc}
\hline $\mathbf{Q I}($ contagens $/ \mathbf{k m})$ & $\mathbf{V D M}<\mathbf{8 0 0 0}$ & $\mathbf{8 0 0 0}<\mathbf{V D M}<\mathbf{1 2 0 0 0}$ & $\mathbf{1 2 0 0 0}<\mathbf{V D M}<\mathbf{2 5 0 0 0}$ & $\mathbf{V D M}>\mathbf{2 5 0 0 0}$ \\
\hline $\mathbf{Q I}<\mathbf{2 2}$ & 0 & 2 & 4 & 6 \\
$\mathbf{2 2}<\mathbf{Q} \mathbf{I}<\mathbf{4 0}$ & 1 & 3 & 5 & 7 \\
$\mathbf{4 0}<\mathbf{Q I}<\mathbf{5 5}$ & 2 & 4 & 7 & 9 \\
$\mathbf{Q I}>\mathbf{5 5}$ & 3 & 5 & 8 & 10 \\
\hline
\end{tabular}

(VDM unidirecional por pista)

Tabela 3.8: Freqüências para cálculo do IGGE (DNER, 1993)

\begin{tabular}{cc}
\hline Nível & FT, FOAP, FRP \\
\hline Baixo & 5 \\
Médio & 30 \\
Alto & 75 \\
\hline
\end{tabular}

O modelo utilizado pelo DNER enquadra vias com VDM menor ou igual a 8000 numa única categoria, pois foi desenvolvido para rodovias. Para tráfego urbano, os volumes médios de tráfego são em geral inferiores aos praticados em rodovias e, os valores de tráfego, estão em desacordo com os parâmetros de VDM da Tabela 3.7. No momento de desenvolver 
um modelo, este deve ser avaliado e calibrado para as condições locais em que se pretende empregá-lo.

\subsubsection{Modelos de Seleção de Seções de Pavimentos Urbanos}

Atualmente, há vários modelos propostos, utilizando diferentes fatores, para a definição das prioridades em gerência de pavimentos urbanos em nível de rede. Quase sempre as agências utilizam modelos de priorização que consideram as intervenções anuais, através do ranking de projetos candidatos às atividades de $M \& R$ em cada ano do período de análise. Estes métodos desenvolvem índices de prioridades utilizando formulações matemáticas, baseadas em um fator ou uma combinação de fatores de priorização. A partir de uma lista de projetos prioritários os engenheiros de pavimentos podem justificar os gastos nos investimentos em manutenção de pavimentos. Em seguida são comentadas algumas propostas para priorizar seções candidatas às atividades de manutenção e reabilitação de pavimentos.

As equações para calcular o Índice de Prioridade, baseadas principalmente na condição do pavimento são comuns em análises das necessidades de M\&R em nível de rede. Um exemplo é a expressão proposta por Smith et al. (1988) que considera como fatores a condição do pavimento, o tráfego, a classificação funcional e o tipo de rota, conforme a Equação 3.8.

$$
I P=\frac{1}{I C P} * F T^{*} C F^{*} F R
$$

Onde:

- IP: índice de prioridade;

- ICP: índice de condição do pavimento (maior prioridade quanto pior a condição do pavimento);

- FT: fator de tráfego (maior prioridade quanto maior o volume de tráfego: por exemplo, 10 para VDM 0 a 99; 20 para VDM 100 a 499; 30 para VDM 500 a 999; 40 para VDM 1000 a 1999; 50 para VDM 2000 a 4999; 100 para VDM maior que 5000);

- CF: fator de classificação funcional (maior prioridade para as ruas mais importantes, por exemplo, 1.2 para arteriais; 1.1 para coletoras; 1.0 para locais);

- FR: fator de rota de trânsito de veículos especiais (prioridade maior para rotas de ônibus, por exemplo). 
Fernando \& Hudson (1983) desenvolveram uma equação para priorização baseada na opinião de especialistas. É mais um método de ranking baseado em fatores relacionados com a condição do pavimento chamado Rational Factorial Rating Method. Um painel de engenheiros avaliou as seções, os fatores e os níveis de condição dos pavimentos e com base nos atributos selecionados, os resultados obtidos foram analisados estatisticamente para a estruturação da Equação 3.9.

$$
Y=5.4-0.0263 X_{1}-0.0132 X_{2}-0.4 \log \left(X_{3}\right)+0.749 X_{4}+1.66 X_{5}
$$

Onde:

- Y: índice de prioridade (valor 1: condição péssima - alta prioridade; valor 10: condição ótima - baixa prioridade);

- $X_{1}$ : precipitação (130 a $1000 \mathrm{~mm}$ por ano);

- $X_{2}$ : gelo e degelo (0 a 60 ciclos por ano);

- $X_{3}$ : tráfego (10 a 100.000 VDM);

- $X_{4}$ : Índice de Serventia (PSI: 4.0 a 2.0);

- $X_{5}$ : defeitos $(+1.0$ a -1.0$)$.

Outra possibilidade de priorização simplificada para seções de pavimentos urbanos é o modelo elaborado por Tavakoli et al. (1992) para gerência de malhas viárias de pequenas comunidades norte-americanas por iniciativa do governo federal dos EUA. É um modelo empírico, semelhante ao proposto por Smith et al. (1988), que prioriza seções com base numa equação, determinando um índice de prioridade em função do inverso do índice de condição do pavimento, da classe da via, do tipo de tráfego, do tipo de rota e de um fator de nível de manutenção. Dentro de um conjunto de subsistemas que compõe a estrutura de gerência de pavimentos proposto por Tavakoli et al. (1992) há o módulo de priorização e de metas que determina a ordem de prioridade para todas as seções, estima o custo total de manutenção e reabilitação, prioriza seções específicas (demandas políticas) e ainda estabelece metas a longo prazo. O índice de prioridade é então calculado pela Equação 3.10.

$$
I P=\frac{1}{I C P} *\left(F T^{*} F C^{*} F R^{*} F M\right)
$$

Onde:

- IP: índice de prioridade;

- ICP: índice de condição do pavimento (maior prioridade quanto pior a condição do pavimento); 
- FT: fator de tráfego (maior prioridade quanto maior o volume de tráfego) variando de 10 a 100;

- CF: fator de classificação funcional (maior prioridade para as ruas mais importantes), variando de 1.2 para vias arteriais, 1.1 para vias coletoras e 1.0 para vias locais;

- FR: fator de rota de trânsito de veículos especiais (prioridade maior para itinerários de ônibus ou onde existam prédios institucionais que atraem elevado fluxo de tráfego, como escolas e hospitais);

- FM: fator de manutenção igual a 1 + a taxa de manutenção/10. O FM é zero para pequeno ou nenhum custo de manutenção aumentando até 5 para custos elevados de manutenção.

Outra proposta simples foi desenvolvida por Chen et al. (1993): uma metodologia que combina duas matrizes e uma equação para determinação de Índice de Prioridade para projetos de manutenção. A metodologia está agregada a um sistema de gerência de vias urbanas URMS (Urban Roadway Management System) e os fatores considerados foram: o índice de condição do pavimento (ICP), a idade desde a última intervenção, o volume de tráfego e a classe funcional da via (Figura 3.2).

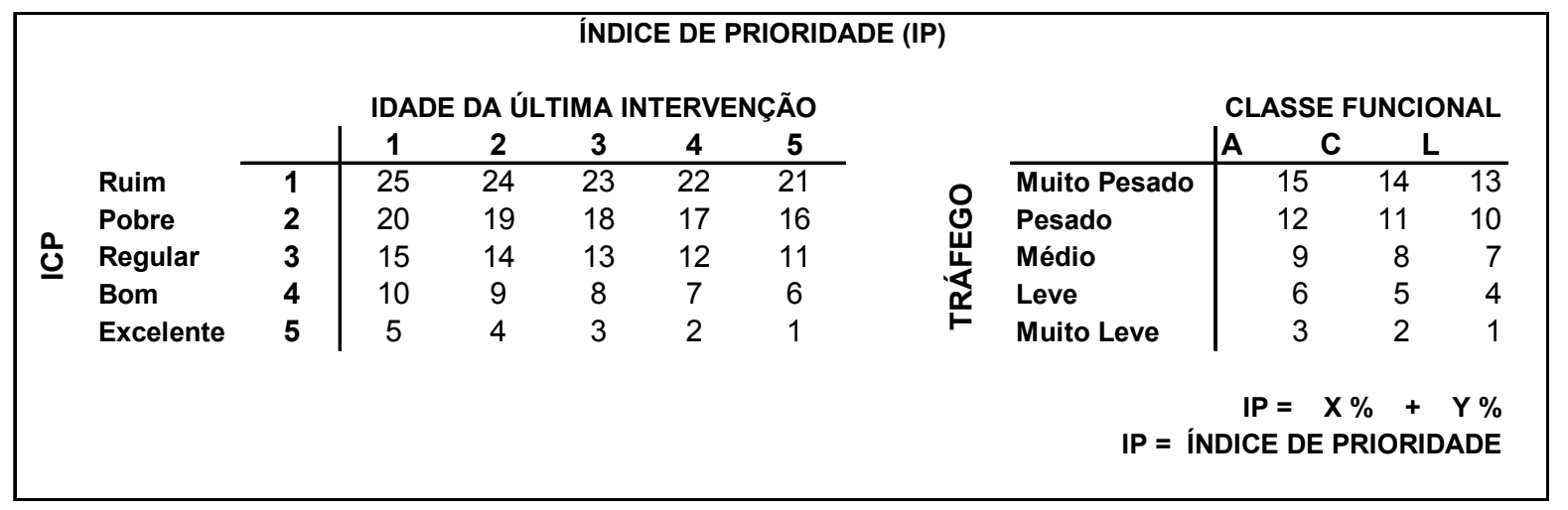

Figura 3.2: Cálculo do Índice de Prioridade segundo Chen et al. (1993)

Zhang et al. (1993) comentam que um dos problemas na priorização de pavimentos é que não existe um valor absoluto que mostre o momento da ruptura de um pavimento e o que é utilizado é um indicativo de aceitabilidade. A aceitabilidade de uma específica condição do pavimento é determinada a partir do julgamento subjetivo de especialistas e dos usuários de pavimentos. A partir desta constatação uma metodologia utilizando um índice de aceitabilidade global (Overall Acceptability Index - OAI) usando conceitos da teoria fuzzy foi desenvolvida por Zhang et al. (1993) com aplicação específica na formulação de um índice de priorização para pavimentos flexíveis. Foram considerados fatores que afetam o desempenho 
do pavimento: a irregularidade longitudinal, os defeitos superficiais, a capacidade estrutural e o fator de atrito entre pneus e superfície do pavimento.

O Departamento de Transportes dos Estados Unidos (U.S. Department of Transportation) elaborou para agências locais um Guia de Sistemas de Gerência Rodoviária para coordenar e planejar as manutenções preventivas e de rotina, a reabilitação e a reconstrução do pavimento (MISRA et al., 2003). A priorização das atividades é realizada através do índice de prioridade, que por sua vez é determinado através de uma equação matemática (Equação 3.11), em que todas as ações podem ser ordenadas numericamente. A partir deste ranking, todas as ações de M\&R são planejadas baseadas nas necessidades, no ano apropriado pelas agências locais. É importante comentar que neste caso, quanto mais baixo o valor do índice maior é a prioridade.

$$
P I=\{(0.65 x P C I)+(0.10 x T F)+0.05 x F C)+(0.10 x L F)+(0.05 x M H)+(0.05 x P R Q)\} 3.11
$$

Onde:

- $P I=$ índice de prioridade (priority index)

- $P C I=$ índice de condição do pavimento (pavement condition index)

- $T F=$ fator de tráfego

- $F C=$ fator de classificação funcional

- $L F=$ fator de localização

- $M H=$ Histórico de manutenção

- $P R Q=$ Qualidade do pavimento (pavement riding quality)

Vale comentar ainda, que todos os métodos citados anteriormente para priorização de pavimentos de ruas urbanas são constituídos de critérios simples, facilmente determinados e com grande importância para a tomada de decisão dos modelos propostos. Por outro lado, não levam em consideração fatores de ordem econômica, sendo as prioridades estabelecidas em função de características funcionais da via que não possuem necessariamente o menor custo em relação às atividades de $M \& R$. 


\section{O APOIO À DECISÃO NA GERÊNCIA DE PAVIMENTOS}

O Apoio à Decisão (do inglês Decision-Making) é uma aplicação sistemática da teoria da decisão que envolve a pesquisa, a comparação e a avaliação da informação e de alternativas de decisões. Nesse processo, vários caminhos de ações podem ser seguidos para fazer essas escolhas e solucionar um problema, e as alternativas podem representar diferentes localizações, diferentes planos, diferentes classificações, diferentes hipóteses sobre um fenômeno (RAMOS, 2000).

Os primeiros Sistemas de Apoio à Decisão (SAD) surgiram na década de 70, como um recurso para empresas envolvidas com problemas de localização de instalações, programação e distribuição da produção, planejamento de investimentos e outros problemas complexos. Visando suprir a deficiência da capacidade analítica dos sistemas de informações tradicionais, os SADs integravam em um único ambiente sistemas gerenciadores de bancos de dados, modelos analíticos e visualização gráfica. Com os avanços, nos anos 80, da microcomputação e das novas tecnologias relacionadas à computação gráfica, os modelos computacionais da Pesquisa Operacional (PO) sofreram uma reavaliação e passaram a ser agregados em sistemas computacionais, de forma invisível ao usuário não-especialista (LIMA, 2003).

Em particular, o aumento da utilização dos Sistemas de Informação Geográfica (SIG), no final da década de 80 , proporcionou amplas perspectivas para a inserção de modelos computacionais da PO nesses sistemas de informação, aumentando a capacidade analítica dos SIGs de atender satisfatoriamente parte dos problemas encontrados nos setores público e empresarial. Assim, o conceito de sistemas de apoio à decisão vem sendo ampliado, dando origem aos Sistemas de Apoio à Decisão Espacial (SADE). Um SADE é explicitamente projetado para auxiliar o processo de decisão em problemas que exijam algum tipo de análise espacial, constituindo-se em um ambiente que integra sistemas de informações geográficas, modelos analíticos, recursos gráficos para representação do problema, interface amigável ao 
usuário e recursos para geração de tabelas e relatórios apropriados ao problema que esteja sendo abordado (GALVÃO, 2000).

A tomada de decisão espacial é uma atividade do dia a dia, comum a indivíduos e grupos. As pessoas levam em conta as características espaciais quando selecionam um lugar para viver, escolhem uma estratégia de desenvolvimento urbano, alocam recursos ou gerenciam infra-estruturas (LIMA, 2003).

Muitos conceitos sobre problemas decisórios e decisão espacial definidos por vários autores, incluindo Gorry \& Morton (1971), Sprague \& Watson (1996), Densham (1991) e Malczewski (1999), tiveram como base as definições das atividades de gerência de Anthony (1965) - atividades de gerência consistem de planejamento estratégico, controle de gerenciamento e controle operacional - e a descrição de decisões programadas e não programadas de Simon (1960).

Todo processo decisório começa com o reconhecimento do problema de decisão. Os problemas de decisão programados e não programados de Simon, atualmente, são chamados de estruturados, não-estruturados e semi-estruturados. Em decisões estruturadas, os problemas são rotineiros, repetitivos, bem-estruturados, facilmente solucionados e ainda podem ser programados e resolvidos por computador. Uma vez desenvolvido o procedimento computacional adequado, um computador pode resolver o problema estruturado sem a participação de um decisor. O usuário de um sistema desse tipo pode se concentrar apenas na saída (output) do procedimento computacional, despendendo pouca ou nenhuma atenção ao processo decisório. Em decisões não-estruturadas, os problemas são novos, originais, modernos, difíceis de ser solucionados, não se repetem freqüentemente, ou as condições são bastante diferentes a cada repetição, de modo que nenhum modelo geral de resolução possa ser programado. Nesse caso, o decisor deve usar a sua experiência, empregando heurística e bom senso, sendo ele o único recurso para se chegar à decisão (MALCZEWSKI, 1999).

A maioria dos problemas de decisão espacial reais pode ser alocada em algum lugar entre esses dois casos extremos de decisões completamente estruturadas e não estruturadas. Nesse caso, as decisões são chamadas de semi-estruturadas e consistem da área na qual o conceito de SAD tem maior aplicação. Os problemas semi-estruturados podem ser resolvidos pelos decisores com o apoio de computadores, como é o caso de planejar estratégias e alocar as atividades de manutenção em gerência de pavimentos. Isso requer uma interação entre decisores e sistemas baseados em computadores. Ao computador cabe gerar uma solução automatizada para a parte estruturada do problema, enquanto a parte não 
estruturada é responsabilidade do decisor (MALCZEWSKI, 1999). Assim, Sistema de Apoio à Decisão pode ser definido como um sistema de computador que trata de um problema no qual, pelo menos, alguma etapa é semi-estruturada ou não-estruturada. Problemas mais complexos que exigem maior tempo e experiência daqueles que são responsáveis pela decisão (SHIM et al., 2002).

Segundo Sanches (1997), os componentes básicos da tomada de decisão são: informação, preferências do decisor e julgamento. As informações fornecem o conhecimento necessário para se decidir. Entretanto, de um modo geral, as pessoas não decidem apenas com base nas informações, mas, sobretudo a partir de suas experiências passadas e preferências. $O$ julgamento constitui uma qualidade essencial aos bons decisores. Será sobre o conjunto de informações disponíveis que o decisor irá exercer seus julgamentos de valor (preferências + intuições) visando a melhor escolha que caracteriza as decisões.

Pesquisas em psicologia e sistemas de informação, sobre falhas de julgamentos e intuição humana comparadas com processamentos de informação, têm mostrado que: informações processadas por combinações matemáticas são quase sempre superiores às informações processadas somente por julgamentos humanos, mas as pessoas têm a vantagem de poder detectar quando uma informação adicional ou circunstâncias atenuantes devem ser ajustadas nas máquinas (JONES \& BROWN, 2002). As vantagens de fórmulas, algoritmos ou regras são suas capacidades para desenvolver resultados mais consistentes e precisos, enquanto que a combinação do julgamento dos dados disponíveis são muitas vezes inconsistentes e imprecisos.

O processo que envolve o apoio à decisão é, na maioria das vezes, multidisciplinar, multi-objetivo e multi-critério, praticamente impossibilitando o planejador chegar sozinho a uma decisão que atenda aos interesses de todos, seja livre de preconceitos e que não privilegie algumas forças de mercado. Portanto, é necessária a formulação de uma gama de questões e opções aceitáveis para que se chegue a uma solução adequada, que muitas vezes não é única. A função de um sistema de apoio à decisão é justamente auxiliar e otimizar todo o processo, a fim de que a melhor solução seja encontrada (MENDIRATTA \& RAVIKUMAR, 1997).

A sociedade moderna exige cada vez mais o uso sistemático dos conhecimentos e experiências dos tomadores de decisão na resolução de problemas interativos. Além disso, as tomadas de decisão lidam mais efetivamente do que antes com problemas não-estruturados ou semi-estruturados. A velocidade das comunicações é outro fator importante que impõe ao 
homem moderno uma mudança de atitude sobre o seu comportamento numa posição de autoridade. A divulgação das comunicações orais e visuais está levando a uma espera bem menor das informações e respostas. O método de trabalho, a divisão de responsabilidades, o preparo de decisões, a supervisão de sua implementação - todas essas atividades estão se acelerando profundamente. Entretanto, a necessidade por maior precisão, diversidade e rapidez (imediata) de informação exige cada vez mais sistemas ágeis, de fácil acesso e que suportem o planejamento, a resolução de problemas, as operações e o gerenciamento das atividades.

Em programas relacionados às atividades de conservação de pavimentos sempre há fatores que dificultam a tomada de decisão, tais como o tempo de deterioração e a limitação de recursos (orçamento, pessoal, equipamentos e materiais). Devido a grande variedade de fatores envolvidos no processo decisório, é praticamente impossível identificar a solução ótima global e existe grande dificuldade em se aplicar técnicas de otimização convencionais para resolver o problema. Por isso, pesquisas são desenvolvidas para encontrar novos métodos e tecnologias que levem às soluções ótimas e aplicações mais práticas e rápidas, que se adaptem aos programas de gerência e aos objetivos específicos de cada sistema.

As próximas seções deste capítulo tratam os assuntos referentes ao apoio à decisão na gerência de pavimentos, nas quais são comentadas algumas técnicas e métodos que vêm sendo utilizados para este fim. Também é realizada uma síntese dos conceitos da Análise Multicritério de Decisão (MCDA) e dos Sistemas de Informação Geográfica, ou seja, a metodologia e a ferramenta utilizadas neste trabalho que, agregadas aos procedimentos de gerência de pavimentos, dão o suporte necessário para priorizar seções candidatas às atividades de M\&R de pavimentos.

\subsection{A Gerência de Pavimentos e o Apoio à Decisão}

Uma estratégia de conservação é constituída por um plano de ações que envolvem a aplicação de um conjunto de técnicas para manter o estado da rede (nível de rede) ou de um trecho de pavimento (nível de projeto), acima de um nível de qualidade pré-estabelecido. A previsão da evolução do estado do pavimento, em função da estratégia adequada, apóia-se em modelos estatísticos ou modelos probabilísticos. A escolha da estratégia ótima de intervenção realiza-se com a ajuda de algoritmos desenvolvidos para permitir a comparação das diversas estratégias para cada situação. 
Atualmente existem vários métodos e ferramentas que dão apoio à decisão em gerência de pavimentos e são utilizados tanto na seleção de alternativas e estratégias de manutenção, reabilitação e construção de rodovias quanto na priorização de projetos de transportes em geral. Os sistemas atuais de gerência de pavimentos incorporam vários procedimentos e utilizam ferramentas, como por exemplo, os sistemas de informação geográfica, que dão o suporte necessário para que o decisor faça as análises pertinentes a cada etapa de planejamento.

O processo usado para seleção de alternativas de projetos de $M \& R$ pode variar desde uma simples avaliação até um sistema especialista como, por exemplo, uma “Árvore de Decisão" mais complexa que considera várias combinações de fatores (HAAS et al., 1994). As próximas subseções comentam alguns exemplos de como essas técnicas podem ser agregadas à gerência de pavimentos. Não é o enfoque deste trabalho falar extensivamente sobre essas técnicas, mas agregar conhecimento sobre os possíveis procedimentos que dão apoio à decisão nos planejamentos de atividades relacionadas com o pavimento.

\subsection{1 Árvores de Decisão}

As “Árvores de Decisão” são utilizadas, geralmente, para a seleção de atividades de M\&R de pavimentos. Exemplos desse tipo de aplicação podem ser encontrados em Fernandes Jr. \& Pantigoso (1997) e Oda et al (1997). O que difere um modelo do outro são os fatores considerados na estruturação das árvores. Quando o número de fatores que afetam as alternativas de estratégias aumenta, as árvores de decisão tornam-se cada vez mais complexas. Assim, quando acontecem mudanças, adição ou retirada de algum fator, a árvore de decisão deve ser revisada. Esse processo acaba por se tornar muito complicado e consome tempo.

\subsubsection{Sistemas Especialistas}

Além de árvores de decisão para a seleção de alternativas, também são muito utilizadas matrizes de decisão ou mesmo os Expert Systems (ES), que são conhecidos como sistemas especialistas ou inteligentes, baseados no conhecimento. $\mathrm{O}$ enfoque é dado na pesquisa operacional e no planejamento espacial, sendo ainda ponto de partida para a geração de novos sistemas, nomeados de várias maneiras por diferentes autores como Intelligent DSS (IDSS), Expert DSS (EDSS), Expert Support Systems (ESS) e Knowledge-Based DSS (KBDSS) (ZOPOUNDIS et al. 1997). 
$\mathrm{Na}$ área da gerência de pavimentos, os ES têm sido desenvolvidos para dar um tratamento computacional aos julgamentos de especialistas e melhorar o processo de seleção, tanto em nível de rede como em nível de projeto. O desenvolvimento de um ES envolve cinco passos: identificação do problema, aquisição da informação, representação da informação, implementação e validação. Os ES possuem algumas limitações, pois para resolver problemas com muitos critérios consomem bastante tempo e necessitam ser reprogramados cada vez que um novo fator é adicionado, retirado ou modificado do sistema já em funcionamento (ABDELRAHIM \& GEORGE, 2001).

\subsubsection{Redes Neurais Artificiais}

No universo dos métodos encontrados para solucionar problemas e encontrar alternativas em gerência de pavimentos também estão as Redes Neurais Artificiais (RNA). As RNAs são uma simulação do funcionamento do sistema nervoso humano. Certos tipos de redes ensinam a si próprias, através de exposição repetida de um conjunto de dados, reconhecem características comuns entre eles e os agrupa ordenadamente. Outros tipos de rede podem ser programadas para associar um conjunto de entrada com suas respectivas saídas. As RNAs podem extrair informações essenciais das entradas contendo tanto dados relevantes como irrelevantes para o processo decisório (WASSERMAN, 1989).

As RNAs são modelos matemáticos que seguem regras e propriedades do fluxo de informações do cérebro humano. Dessa forma, apresentam-se como uma nova técnica computacional alternativa ao sistema usual, com mecanismos que permitem a entrada e saída de informações e o processo de assimilação dos conhecimentos contidos num universo de amostra, através do uso de componentes básicos como representação, o raciocínio e o aprendizado. A aplicação de RNAs para solução de problemas em engenharia civil tem sido objeto de inúmeros estudos. Na área de transportes, elas são aplicadas em estudos relacionados com planejamento e operação de transportes, tais como, geração de viagens, diagnóstico e controle de congestionamento, transporte de materiais perigosos e controle de tráfego aéreo. Na área de gerência de pavimentos, as redes neurais têm sido treinadas através de algoritmos desenvolvidos, principalmente, para permitir a comparação de alternativas na escolha da estratégia ótima de $M \& R$ de pavimentos. Exemplos dessas aplicações são encontrados em Eldin \& Senouci (1995) e Rodgher et a.l (1998). 


\subsubsection{Algoritmos Genéticos}

Os Algoritmos Genéticos (AGs) também estão presentes no grupo dos métodos de apoio à decisão aplicados na gerência de pavimentos. Fwa et al. (1998) demonstraram que a aplicação de AGs, para programar atividades de manutenção de pavimentos em nível de rede, garante uma resposta de utilização dos recursos disponíveis ótima ou próxima da ótima. Ferreira et al. (2001) mostraram a utilização da heurística de AGs agregada a um modelo de otimização (Mixed-integer Optimization Model). Semelhante a outros métodos heurísticos, os AGs, não garantem soluções ótimas globais. Entretanto, se bem projetados, eles geralmente proporcionam soluções de alta qualidade. Por esta razão, AGs estão sendo aplicados cada vez mais em modelos complexos de otimização na engenharia.

Assim, tanto as Redes Neurais Artificias como os Algoritmos Genéticos oferecem imensa capacidade de acomodar diferentes funções-objetivo e são utilizados para encontrar alternativas em problemas com um grande número de critérios, ou seja, sistemas mais complexos da gerência de pavimentos.

\subsubsection{Metodologias Multicriteriais}

As Metodologias Multicriteriais compõem uma grande área de pesquisa desenvolvida atualmente no mundo todo. Incluem aplicações que vão desde a pesquisa operacional até os sistemas especialistas em gerenciamento. No campo de transportes, as decisões se tornaram multicriterial ou multiatributo, devido à diversidade de componentes de infra-estrutura que são consideradas no planejamento de qualquer projeto ou atividade desenvolvida. Por esse motivo, a metodologia multicritério vem sendo bastante utilizada na seleção de um projeto rodoviário, quando comparado com várias outras alternativas de projetos e alocação de recursos. As análises consideram múltiplos critérios e selecionam um projeto de construção, manutenção ou melhorias de seções rodoviárias, interseções, sinalização, pontes e bueiros, além de alternativas de traçado. Geralmente, são consideradas as preferências e atitudes de risco do decisor para selecionar a alternativa mais viável em termos de eficiência e questões financeiras.

Baker \& Lambert (2000), Speicher et al. (2000), Gharaibeh \& Darter (2000) e Lisboa \& Saragiotto (2004) são alguns autores que trabalharam com a escolha de melhores alternativas de projetos em transportes utilizando a Metodologia de Análise Multicritério. 
Ainda que análises que envolvem múltiplos critérios sejam utilizadas na área de transportes, no campo da gerência de pavimentos ainda não se percebeu grande interesse pela sua utilização. Muitos sistemas especialistas e ferramentas computacionais são utilizados para seleção de alternativas de manutenção de pavimentos, mas as questões multicriteriais nem sempre são incorporadas nesses sistemas, pois elas tratam não só fatores quantitativos como também qualitativos, questões subjetivas que muitas vezes são deixadas de lado durante o processamento da informação.

Nas Metodologias Multicriteriais ocorre a influência mútua do modelo com o tomador de decisão e há a possibilidade de quantificar os aspectos objetivos e subjetivos importantes ao processo decisório. Além disso, considera as preferências dos decisores e o modo como cada um percebe o cenário decisório (ENSSLIN et al., 2000). Todas essas características diferem este método dos demais utilizados no apoio à decisão em gerência de pavimentos, comentados anteriormente. Além de haver a possibilidade de se considerar não só os fatores técnicos (objetivos) no apoio à decisão, os problemas mais complexos podem ser divididos em partes menores, analisar cada parte e integrar novamente as diversas partes produzindo soluções factíveis.

Esta seção tratou dos métodos e alguns exemplos de aplicações que são agregados à gerência de pavimentos. A próxima seção trata mais especificamente dos conceitos da Metodologia de Análise Multicritério de Apoio à Decisão, utilizada neste trabalho como método de análise de alternativas.

\subsection{Análise Multicritério de Decisão}

Os métodos multicritériais tiveram sua origem no século XVIII, com os trabalhos de Bernouilli, quando modelava as preferências individuais para escolher entre opções com riscos (SILVESTRE, 2002). A partir da Segunda Guerra Mundial, surgiu a Pesquisa Operacional (PO), que visa construir um modelo para um sistema real, com a finalidade de analisar e compreender o comportamento dessa situação. Até o final da década de 60 a PO formulava os problemas de apoio à decisão fundamentada na existência de possíveis opções, baseada em um único critério e sob o ponto de vista de um único decisor racional.

Estudos posteriores mostraram que muitos problemas de decisão não podiam ser solucionados baseados somente em um critério. Após essas observações, as pesquisas científicas começaram a tratar os problemas com decisões apoiadas em múltiplos critérios. Assim, os modelos tinham o objetivo de solucionar problemas de decisões sob diversos 
pontos de vista ou critérios, considerando várias alternativas, além da incerteza de que o ambiente se apresenta como fator relevante no contexto decisório.

Pesquisas que tratavam de análises com múltiplos critérios e múltiplos objetivos se consolidaram perante a comunidade científica com a realização da "First International Conference on Multiple Criteria Decision Making”, realizada na Universidade da Carolina do Sul, no ano de 1972. A partir desse evento, foram surgindo vários outros que tratavam de temas similares. No ano de 1992, foi publicado o primeiro Journal of Multi-Criteria Decision Analysis (JMCDA), no qual os editores reconheciam diferenças significativas entre as várias metodologias multicriteriais praticadas no mundo, diferenças que geraram muito mais incompreensão do que competição entre as duas correntes que se destacavam na época: a Americana, Multicriteria Decision Making (MCDM) e a Européia ou Francesa, Multicriteria Decision Analysis (MCDA). Após esse período, surgiu uma nova perspectiva, crescente até os dias de hoje, a de encarar essas correntes como fontes complementares de muitos ensinamentos (SILVESTRE, 2002).

A MCDM é fundamentada na existência de um conjunto de alternativas bem definidas, na qual o problema é solucionado, baseado em um único critério que representa as preferências do decisor e num modelo matemático bem conhecido na busca de uma solução ótima. No caso da MCDM, o paradigma utilizado é o racionalismo. A MCDA, por sua vez, admite que o conjunto de alternativas se modifique com o desenvolvimento do processo. $\mathrm{O}$ poder de decisão é representado por um ou mais decisores e as preferências não são bem definidas, devido à percepção, às incertezas e às contradições dos tomadores de decisão envolvidos no processo. Também se observa que não é esperada uma solução ótima somente por meio de um modelo matemático, pois os aspectos culturais, pedagógicos e situacionais também fazem parte do cenário decisório. No caso da MCDA, o paradigma utilizado é o construtivismo (ROY, 1996).

Devido a grande heterogeneidade e divergência no uso da terminologia encontrada na bibliografia existente sobre tomada de decisão nas áreas da Gerência, da Investigação e Pesquisa, foram adotadas as definições apresentadas em Malczewski (1999), Ramos (2000) e Lima (2003), de acordo com os trabalhos mais relevantes em Teoria da Decisão e adequadas ao tipo de problema tratado nesse trabalho.

No sentido de atingir um determinado objetivo, normalmente é necessário que diversos critérios tenham de ser avaliados e combinados através de procedimentos que se 
designam precisamente por Análises de Decisão Multicritério (MCDA, do inglês Multicriteria Decision Analysis) (VOOGD, 1983; CARVER, 1991; MALCZEWSKI, 1999).

Um Critério representa uma condição de avaliação, que pode ser quantificado ou avaliado de forma a ordenar as alternativas de decisão em termos do desempenho ou eficácia dessas alternativas. É, portanto, a medida de uma evidência que, entre outras, serve de base para a decisão. Os critérios podem, ainda, ser divididos em Exclusões e Fatores. Uma Exclusão é um critério que limita as alternativas em consideração na análise. Um bom exemplo de uma exclusão é a consideração de "não aptas" as áreas de reserva ecológica, quando se estuda a aptidão dos solos para a expansão urbana. Na maioria dos casos, uma exclusão traduz-se na criação de limitações ao espaço de análise, definindo as alternativas não elegíveis que deverão ser excluídas do espaço inicial de soluções possíveis. No entanto, em alguns casos, as exclusões buscam garantir que a solução final possua algumas características preestabelecidas como, por exemplo, procurar uma área de terreno livre que possua área superior a 1 hectare (RAMOS, 2000).

Alternativas ou opções de decisão estão no topo das tomadas de decisão, porque a menos que haja mais de uma alternativa ou modo de proceder, não há escolha a ser feita $\mathrm{e}$ nenhuma decisão a ser tomada. Uma alternativa define os valores das variáveis de decisão, que por sua vez são quantidades mensuráveis controladas pelo decisor (CAFISO et al., 2002). As variáveis de decisão podem ser classificadas em três categorias: Binária, Discreta e Contínua.

A mais simples decisão espacial envolve uma ação de fazer ou não fazer nada, e neste caso a decisão é definida por 0-1 ou variáveis binárias. Variáveis binárias são um caso especial de variáveis discretas. Uma variável discreta pode assumir qualquer número finito de valores, por exemplo, se a variável se refere ao número de estudantes em uma escola, os valores que representam a variável são inteiros e qualquer valor que estiver entre 1 e 4, 4 e 7 ou 7 e 10, pode representar o número de estudantes e, conseqüentemente, será uma variável discreta. Por outro lado, variáveis contínuas têm um número infinito de valores ou alternativas possíveis, dentro de um intervalo especificado. Por exemplo, o volume de tráfego de veículos em uma determinada rodovia pode ser representado dentro de um intervalo de números reais, entre um valor mínimo e um valor máximo (MALCZEWSKI,1999).

Embora em muitas decisões esteja apenas em causa um objetivo, normalmente envolvendo vários critérios, ocorrem também situações em que importa decidir face a diversos objetivos (e também diversos critérios). Este último caso configura um problema 
multi-objetivo, no qual os objetivos podem ser complementares ou conflituosos. Portanto, duas classes de MCDA podem ser identificadas: os multi-atributos (MADA, Multiattribute Decision Analyses) e os multi-objetivos (MODA, Multiobjective Decision Analyses). MADA e MODA são ainda subdivididas de acordo com o tipo de decisor, que pode ser um único indivíduo ou um grupo. Essas duas categorias são, cada uma, divididas em decisões determinísticas, probabilísticas e fuzzy.

Problemas determinísticos assumem que os dados e informações necessários são conhecidos e confiáveis e que existe uma relação determinística conhecida entre cada decisão e a correspondente conseqüência. A análise probabilística assume uma quantidade de incerteza no que tange ao estado do problema e em relação a cada decisão e sua conseqüência, tratando essa incerteza como um processo estocástico. A análise fuzzy também considera a incerteza, tratando-a sob a ótica da imprecisão inerente às informações envolvida no processo decisório (MALCZEWSKI, 1999).

O processo MCDA considera as preferências dos decisores, que são estabelecidas no momento em que se mede a importância relativa de cada critério e suporta a escolha da melhor (ou mais eficiente) alternativa. O estabelecimento de preferências pode ser a priori ou a posteriori. Os métodos de articulação a priori exigem que o tomador de decisão especifique seus julgamentos com valores, que são traduzidos na escolha particular de alternativas. É um método relevante nos casos em que as preferências do tomador de decisão devem ser justificadas e racionalizadas. Por outro lado, métodos de articulação a posteriori (ou progressiva) de preferências permitem ao tomador de decisão explorar o espaço de decisão sistematicamente, sem ter que especificar qualquer preferência anterior. É um método mais aberto à manipulação por usuários qualificados e ainda é menos defensivo quando soluções têm que ser justificadas e racionalizadas (CAFISO et al., 2002).

Um outro aspecto a considerar nos processos decisórios é o risco. Em um problema multicritério está implícita a avaliação de diferentes aspectos que contribuem (a favor ou contra) uma decisão. A forma de combinar os critérios, a consideração de todos ou apenas parte deles (os melhores, os piores, os médios, ou qualquer combinação) e a forma como uns critérios podem compensar outros, são aspectos que assumem grande importância nas decisões, particularmente em contextos de recursos escassos. Entre as atitudes mais extremas de risco na avaliação - pessimistas (conservadoras) e otimistas (arriscadas) - pode haver lugar para cenários de avaliação que sejam mais compatíveis com o problema decisório em questão (RAMOS, 2000). 


\subsubsection{Escolha do Método Apropriado}

A escolha do método de MCDA é muito importante, uma vez que tem um efeito significativo no resultado final. É, então, necessário que esse ponto seja discutido entre todos os atores. As características e propriedades desse método devem ser compatíveis com a natureza específica do problema de decisão e no propósito da avaliação. Com relação à natureza do problema, a gerência de manutenção de pavimentos deve ser considerada como um problema baseado na combinação de diferentes tipos de critérios (qualitativo e quantitativo). Algumas técnicas de MCDA trabalham bem com séries contínuas de alternativas e critérios pertencentes a um mesmo domínio (econômico, por exemplo), enquanto outras consideram apenas uma pequena série de alternativas discretas, mas são mais eficientes para lidar com critérios heterogêneos (JOERIN et al., 2001; LIMA, 2003).

Nenhum método se apresenta eficiente para todos os tipos de aplicações em processos decisórios. Além disso, como já citado, a escolha do método MCDA faz parte da fase de estruturação do problema e os decisores precisam concordar plenamente com o método escolhido. Os vários tipos de métodos diferem no modo como as preferências em relação aos vários critérios são especificadas e no modo como as alternativas são ordenadas (hierarquizadas). Os resultados também diferem de uma metodologia para a outra, por exemplo, como um ranking de alternativas, como um ranking de grupos de alternativas ou simplesmente como uma preferência (CAFISO et al, 2002).

Existem vários métodos MCDA, mas duas categorias principais podem ser consideradas: métodos que usam agregação completa, como o MAUT - Multiple Attribute Utility Function e o AHP - Analytic Hierarchy Process, e métodos que usam a agregação parcial, como o ELECTRE - Elimination and choice translating algorithm e o PROMETHEE - Preference Ranking Method for Enrichment Evaluation. Os do último tipo são chamados de métodos de subordinação, do inglês outranking (LIMA, 2003).

Joerin et al. (2001) afirmam que os métodos outranking são mais apropriados para estudos de planejamento do uso do solo, pois podem lidar simultaneamente com critérios quantitativos e qualitativos. Os scores dos critérios podem ainda ser mantidos em suas próprias unidades, o que é importante quando esses critérios são relativos a diferentes domínios (por exemplo, econômicos, sociais ou ecológicos). Além do mais, as alternativas podem ser bastante diferentes. Por exemplo, uma situação comum é uma alternativa com muitas vantagens econômicas e sérios impactos ambientais, enquanto outra apresenta as características opostas. Nesses casos, o decisor pode não ser capaz de ordená-las. Essas 
alternativas são consideradas incomparáveis, e os métodos outranking são os únicos que podem considerar essa situação. Infelizmente, esses métodos não são capazes de comparar muitas alternativas. Essa limitação tem conseqüências importantes.

Conforme Cafiso et al. (2002), o ELECTRE e o AHP parecem ser as metodologias que mais se adaptam nas aplicações e decisões na gerência de infra-estruturas viárias. Entretanto, o AHP se mostra mais satisfatório na integração com os Sistemas de Gerência de Pavimentos (SGPs), como por exemplo o HDM-4 (Highway Development and Management Tool, Versão 4), porque produz um índice baseado num ranking considerando múltiplos critérios para cada alternativa como uma medida de utilidade. E, ainda, a estrutura analítica do AHP se adapta melhor durante a implementação com as características de análise de estratégias de manutenção e reabilitação dos SGPs.

Os aspectos críticos num processo de decisão que envolve múltiplos critérios são: a avaliação de pesos para os critérios; a normalização dos critérios; e a combinação de critérios. Algumas definições a respeito desses procedimentos são descritas nas próximas sub-seções. Entretanto, para uma melhor compreensão desses aspectos, incluindo uma descrição detalhada dos métodos possíveis, ver Mendes et al (2000) e Ramos (2000).

\subsubsection{Definição de Pesos}

Um dos problemas geralmente encontrados num processo de decisão com múltiplos critérios envolvidos é a forma como se deve quantificar a importância relativa de cada um deles, somado ao fato dos mesmos possuírem graus de importância diferentes para diferentes decisores. Portanto, torna-se necessário definir qual a importância relativa de cada critério no processo decisório, o que é feito normalmente atribuindo-se um determinado peso a cada um dos critérios. A correta atribuição de pesos é importante para que sejam mantidas as preferências dos decisores (RAMOS, 2000).

Embora não se possa afirmar que exista um método consensual para a definição de pesos, encontram-se na literatura várias propostas de procedimentos para essa definição. Existem técnicas simples de atribuir pesos aos critérios, tais como, o ordenamento de critérios, a escala de pontos e a distribuição de pontos e, por outro lado, os procedimentos baseados em comparações par a par, que constitui uma forma bem mais complexa, mas também mais promissora para a obtenção de pesos para vários critérios. A seleção da técnica a utilizar depende da sua adequação à situação particular em análise, mas também dos dados e recursos disponíveis. No que se refere à avaliação de pesos, sempre que estiver em causa 
expressar as prioridades de um determinado grupo de especialistas, deverá ser utilizado o Método de Comparação Par a Par (MALCZEWSKI, 1999; RAMOS, 2000).

A metodologia de comparação par a par foi desenvolvida pelo matemático Thomas Saaty (SAATY, 1991), no final da década de 70, no contexto de uma técnica denominada de Analytic Hierarchy Process (AHP), com o objetivo de facilitar a solução de problemas complexos relacionados à tomada de decisão. Por meio dessa, pesos e prioridades são derivados a partir de um conjunto de julgamentos subjetivos realizados por avaliadores ou participantes envolvidos no processo. O modelo permite, ainda, o desenvolvimento de uma estrutura hierárquica na qual são visualizadas as relações existentes entre a meta principal ou objetivo a ser atingido e os demais elementos, critérios, sub-critérios e alternativas consideradas para a tomada de decisão (RAMOS, 2000; FORMAN \& SELLY, 2001; COSTA, 2003).

O método de Saaty pode ser usado na quantificação das características qualitativas, permitindo a ponderação de todas as características e a priorização dos direcionadores. Sua teoria reflete o que parece ser um método natural de funcionamento da mente humana. Ao defrontar-se com um grande número de elementos, controláveis ou não, que abrangem uma situação complexa, ela os agrega em grupos, segundo propriedades comuns. A questão central do método é identificar com que peso os fatores individuais do nível mais baixo de uma hierarquia influenciam seu fator máximo, ou seja, o objetivo geral (WATANABE, 2004).

A comparação par a par, entre os $n$ critérios, é realizada a partir de uma matriz quadrada $n \times n$, na qual os critérios estão dispostos na mesma ordem ao longo das linhas e das colunas. Portanto, o valor aij representa a importância do critério da linha $i$ em relação ao critério da coluna $j$, conforme a Equação 4.1.

$$
a_{i j}=\frac{1}{a_{j i}}, \text { para } \mathrm{i} \neq \mathrm{j} \quad \quad \text { e } \quad a_{i j}=1, \operatorname{para} \mathrm{i}=\mathrm{j}
$$

Essa matriz é, entretanto, uma matriz recíproca. Por exemplo, se o critério da linha $i=1$ é cinco vezes mais importante que o critério da coluna $j=3$, então $a_{13}=5$ e $a_{31}=1 / 5$. Isso implica que apenas a metade triangular superior direita da matriz necessita ser avaliada, já que a outra metade deriva desta e a diagonal principal assume valores unitários. $\mathrm{O}$ desenvolvimento das comparações par a par de critérios exige a adoção de uma escala que expresse e possibilite a normalização dos julgamentos efetuados. Neste trabalho adotou-se a 
escala proposta por Saaty (1980), composta por nove níveis numéricos, conforme a Figura 4.1 e a Tabela 4.1.

\begin{tabular}{c|c|c|c|c|c|c|c|c|}
\hline $1 / 9$ & $1 / 7$ & $1 / 5$ & $1 / 3$ & 1 & 3 & 5 & 7 & 9 \\
$\begin{array}{c}\text { Extremamente } \\
\text { menos } \\
\text { importante }\end{array}$ & $\begin{array}{c}\text { Bastante menos } \\
\text { importante }\end{array}$ & $\begin{array}{c}\text { Muito menos } \\
\text { importante }\end{array}$ & $\begin{array}{c}\text { Pouco menos } \\
\text { importante }\end{array}$ & $\begin{array}{c}\text { Igual } \\
\text { importância }\end{array}$ & $\begin{array}{c}\text { Pouco mais } \\
\text { importante }\end{array}$ & $\begin{array}{c}\text { Muito } \\
\text { importante }\end{array}$ & $\begin{array}{c}\text { Bastante mais } \\
\text { importante }\end{array}$ & $\begin{array}{c}\text { Extremamente } \\
\text { mais importante }\end{array}$ \\
\hline
\end{tabular}

Figura 4.1: Escala de Comparação de Critérios

Tabela 4.1: Escala de Comparação de Critérios Segundo Saaty (1980)

\begin{tabular}{ccl}
\hline Valor & \multicolumn{1}{c}{ Definição } & \multicolumn{1}{c}{ Des crição } \\
\hline $\mathbf{1}$ & Igual importância & $\begin{array}{l}\text { Os dois critérios contribuem de uma } \\
\text { forma idêntica para o objetivo }\end{array}$ \\
$\mathbf{5}$ & Pouco mais importante & $\begin{array}{l}\text { Um critério é um pouco mais } \\
\text { importante que o outro }\end{array}$ \\
& Muito mais importante & $\begin{array}{l}\text { Um critério é claramente mais } \\
\text { importante que o outro }\end{array}$ \\
$\mathbf{7}$ & Bastante mais importante & $\begin{array}{l}\text { Um dos critérios é predominante para } \\
\text { o objetivo }\end{array}$ \\
& Extremamente mais & Um dos critérios é absolutamente \\
importante & predominante para o objetivo \\
$\mathbf{2 , 4 , 6 , 8}$ & Valores intermediários & Também podem ser considerados \\
\hline $\begin{array}{l}\text { Valores } \\
\text { recíprocos aos } \\
\text { anteriores }\end{array}$ & $\begin{array}{l}\text { Se um critério } i \text { possui um dos valores anteriores quando } \\
\text { comparado com o critério } j, \text { então o critério j possui o valor } \\
\text { recíproco quando comparado com o critério } i \text {. }\end{array}$ \\
\hline
\end{tabular}

Em seguida, baseado nos trabalhos de Ramos (2000) e Costa (2003), são apresentadas as etapas necessárias para a determinação dos pesos de cada critério através do Processo Hierárquico Analítico. A Figura 4.2 apresenta uma matriz de comparação par a par que servirá de base para um exemplo prático.

\begin{tabular}{|l|c|c|c|c|c|c|}
\cline { 2 - 7 } \multicolumn{1}{c|}{} & Critério A & Critério B & Critério C & Critério D & Critério E & Critério F \\
\hline Critério A & 1 & $1 / 2$ & 2 & 2 & 3 & 1 \\
\hline Critério B & 2 & 1 & 4 & 4 & 6 & 2 \\
\hline Critério C & $1 / 2$ & $1 / 4$ & 1 & 1 & 2 & $1 / 2$ \\
\hline Critério D & $1 / 2$ & $1 / 4$ & 1 & 1 & 2 & $1 / 2$ \\
\hline Critério E & $1 / 3$ & $1 / 6$ & $1 / 2$ & $1 / 2$ & 1 & $1 / 3$ \\
\hline Critério F & 1 & $1 / 2$ & 2 & 2 & 3 & 1 \\
\hline
\end{tabular}

Figura 4.2: Matriz de Comparação Par a Par

A primeira etapa diz respeito à construção da Matriz de Comparação Par a Par. De acordo com a Figura 4.2, os critérios são colocados na mesma ordem nas linhas e nas colunas da matriz, que é preenchida de acordo com a escala apresentada na Figura 4.1 e na Tabela 4.1. Deste modo, define-se a matriz $\mathrm{A}=\left[a_{i j}\right]$. 
A segunda etapa refere-se ao cálculo propriamente dito dos pesos de cada critério. Depois de definida a matriz $\mathrm{A}=\left[a_{i j}\right]$ e realizada a avaliação dos pesos que expressam o julgamento de cada especialista, calcula-se o peso final de cada critério para o processo de decisão. Esta etapa conta com o cálculo do eigenvector principal e o cálculo do máximo eigenvalue. Portanto, para qualquer matriz $A$ pode-se calcular o vetor $w_{i}$ pela resolução da Equação 4.2.

$$
A w=\lambda_{\text {maxx }} w
$$

Onde:

- A: matriz de comparação par a par;

- w: vetor de pesos pretendidos;

- $\lambda_{\text {máx: }}$ máximo eigenvector da matriz A.

O eigenvector resultante do máximo eigenvalue da matriz $A$ traduz a prioridade dos fatores e preserva a preferência ordinal entre as alternativas (SAATY, 1980). Portanto, os valores do vetor $w$ podem ser obtidos pela Equação 4.3.

$$
w_{i}=\frac{\left(\prod_{j=1}^{n} a_{i j}\right)^{1 / n}}{\sum_{k=1}^{n}\left[\left(\prod_{j=1}^{n} a_{k j}\right)^{1 / n}\right]}
$$

A Equação 4.3 é traduzida pela soma dos valores de cada coluna da matriz $A$, seguida pela divisão de cada elemento da matriz pelo somatório da coluna a que pertence, obtendo-se assim uma matriz de comparação par a par normalizada; e, por fim, a divisão da soma dos scores normalizados de cada linha da matriz pelo número de critérios avaliados (para este exemplo, seis critérios). De acordo com o exemplo da Figura 4.2, obtém-se o seguinte resultado:

$$
w_{i}=\left[\begin{array}{l}
0,18675 \\
0,37349 \\
0,09810 \\
0,09810 \\
0,05681 \\
0,18675
\end{array}\right]
$$

O máximo eigenvalue $\left(\lambda_{\text {máx }}\right)$ é determinado pela Equação 4.4., sendo que o vetor w’é obtido através da Equação 4.5. Portanto, para o exemplo apresentado obtêm-se $\lambda_{\text {máx }}=6,017026$. 


$$
\begin{gathered}
\lambda_{\text {max }}=\frac{1}{n}\left(\frac{w_{1}^{\prime}}{w_{1}}+\frac{w_{2}^{\prime}}{w_{2}}+\ldots+\frac{w_{n}^{\prime}}{w_{n}}\right) \\
w^{\prime}=A \times w
\end{gathered}
$$

Onde:

- A: matriz de comparação par a par

- $w$ : vetor de pesos determinado anteriormente

Depois de ter determinado o peso de cada critério, o processo AHP permite calcular o Grau de Consistência (CR-Consistency Ratio) dos julgamentos efetuados. O Grau de Consistência é determinado através da Equação 4.6.

$$
C R=\frac{C I}{R I}
$$

Onde:

- CI: Índice de Consistência (Consistency Index);

- RI: Índice de Aleatoriedade (Random Index)

O Índice de Consistência é determinado pela Equação 4.7. Já os Índices de Aleatoriedade são valores tabelados propostos por Saaty (1980), gerados através do cálculo do valor médio de $C I$ obtido para matrizes recíprocas geradas aleatoriamente (Tabela 4.2).

$$
C I=\left(\lambda_{\text {máx }}-n\right) /(n-1)
$$

Tabela 4.2: Índice de Aleatoriedade ( $R I)$ [Adaptada de Saaty (1980)]

\begin{tabular}{cccccc}
\hline $\mathbf{n}$ & $\mathbf{R I}$ & $\mathbf{n}$ & $\mathbf{R I}$ & $\mathbf{n}$ & $\mathbf{R I}$ \\
\hline 1 & 0,00 & 6 & 1,24 & 11 & 1,51 \\
2 & 0,00 & 7 & 1,32 & 12 & 1,48 \\
3 & 0,58 & 8 & 1,41 & 13 & 1,56 \\
4 & 0,90 & 9 & 1,45 & 14 & 1,57 \\
5 & 1,12 & 10 & 1,49 & 15 & 1,59 \\
\hline \multicolumn{7}{l}{ Para valores de $\mathrm{n}=1,2, \ldots ., 15$}
\end{tabular}

Portanto, para o exemplo apresentado, obtem-se $C I=0,003405$ e $R I=1,24$. O Grau de Consistência pode então ser calculado pela Equação 4.6 e, dessa forma, tem-se $\mathrm{CR}=0,003405 / 1,24=0,00275$. 
Finalmente, uma eventual reavaliação da matriz de comparação pode ser necessária caso o valor de $C R$ seja superior a 0,1 . Este valor é freqüentemente citado na literatura como indicativo de um nível razoável de consistência para a comparação par a par. Entretanto, é necessário reavaliar os julgamentos realizados caso este valor seja ultrapassado (SAATY e VARGAS, 1991).

A obtenção de pesos para diferentes critérios utilizando $A H P$, por construir uma tarefa bastante trabalhosa, pode ser desenvolvida inclusive com o auxílio de programas específicos como, por exemplo, o Expert Choise. Através desses são estruturadas matrizes de comparação par a par e utilizadas escalas de avaliação (que podem conter palavras, gráficos ou números) de modo a traduzir os julgamentos dos profissionais e especialistas com respeito a cada par de critérios analisado. Esses programas permitem também verificar os valores de consistência das avaliações e mesmo proceder a análise de sensibilidade detalhada, a fim de avaliar os possíveis impactos dos julgamentos efetuados (COSTA, 2003).

\subsubsection{Normalização de Critérios}

Normalmente os valores de diferentes critérios não são comparáveis entre si, o que inviabiliza a sua agregação imediata. Para resolver este problema é necessário normalizar para a mesma escala de valores a avaliação dos diferentes critérios. A maior parte dos processos de normalização utiliza os valores máximo e mínimo na definição de uma escala.

A forma mais simples de normalização é a variação linear definida pela Equação 4.8 (EASTMAN et al., 1998; RAMOS, 2000).

$$
x_{i}=\left(R_{i}-R_{\min }\right) /\left(R_{\text {máx }}-R_{\min }\right) * \text { Intervalo_normalizado }
$$

Onde:

- $x_{i}$ : valor de score normalizado;

- $R_{i}$ : valor de score a normalizar;

- $R_{\text {min }}$ score mínimo;

- $R_{\text {máx: }}$ score máximo.

Um outro tipo de normalização é o chamado Z-Score, conveniente quando se está na presença de scores em número suficiente para permitir o cálculo de médias e desvios padrões com algum significado (BOSSARD, 1999; MENDES et al., 1999). O Z-Score (Equação 4.9) é o número de desvios padrões que o score daquele critério está acima ou 
abaixo da média dos scores de todas as alternativas em consideração (ZADEH, 1965; MENDES, 1999; MENDES et al., 1999; LIMA et al., 2000).

$$
\text { Zscore }=a\left(\frac{R-\mu[R]}{\sigma[R]}\right)
$$

Onde:

- Zscore: valor de score normalizado;

- $R$ : valor do score a normalizar;

- $\mu[R]$ : média dos scores das diferentes alternativas;

- $\sigma[R]$ : desvio padrão;

- a: variável que pode assumir valor +1 (quando maiores valores do score do critério contribuem positivamente para o objetivo) ou -1 (quando maiores valores do score contribuem negativamente para o objetivo).

O processo de normalização é na sua essência idêntico ao processo de fuzzification introduzido pela lógica fuzzy, segundo o qual um conjunto de valores expressos numa determinada escala é convertido em outro comparável, expresso numa escala normalizada (por exemplo 0-1). Segundo Ramos (2000), o resultado expressa um grau pertencente a um conjunto (designado por fuzzy membership ou possibilidade) que varia de 0,0 a 1,0. Fuzzification é a expressão original apresentada por Zadeh (1965), para a qual não se adotou qualquer tradução. O mesmo se passa para a palavra fuzzy. Para a normalização dos critérios, várias são as funções que podem ser utilizadas para reger a variação entre o ponto mínimo, a partir do qual os valores de score do critério começam a contribuir para a decisão, e o valor máximo, a partir do qual scores mais elevados não trazem contribuição adicional para a decisão. Algumas das formas mais utilizadas para essas funções, designadas por funções fuzzy ou, mais genericamente e do termo original em inglês, fuzzy set membership functions, são: Sigmoidal, J-Shaped, Linear e Complexa (MENDES et al, 1999). A escolha da função fuzzy adequada depende da natureza do critério, sendo que a função sigmoidal é a mais utilizada. A Figura 4.3 ilustra exemplos de curvas sigmoidal e linear na forma decrescente (o score normalizado decresce a medida que score original aumenta) e crescente (score normalizado cresce com o score original) e os respectivos pontos de controle mínimo (a) e máximo (b).

Entretanto, é importante lembrar que a seleção dos pontos de controle é um dos aspectos críticos no processo de normalização, já que de certa forma calibra a função para critérios e realidades particulares. Importa considerar o seu significado, razão pela qual se discute um exemplo simples (EASTMAN et al., 1998). Suponha-se que, no âmbito de um 
processo de seleção de traçado para a construção de uma estrada, se considerou que o declive do terreno é um critério relevante, no sentido em que é mais vantajosa uma área plana do que uma área em declive.

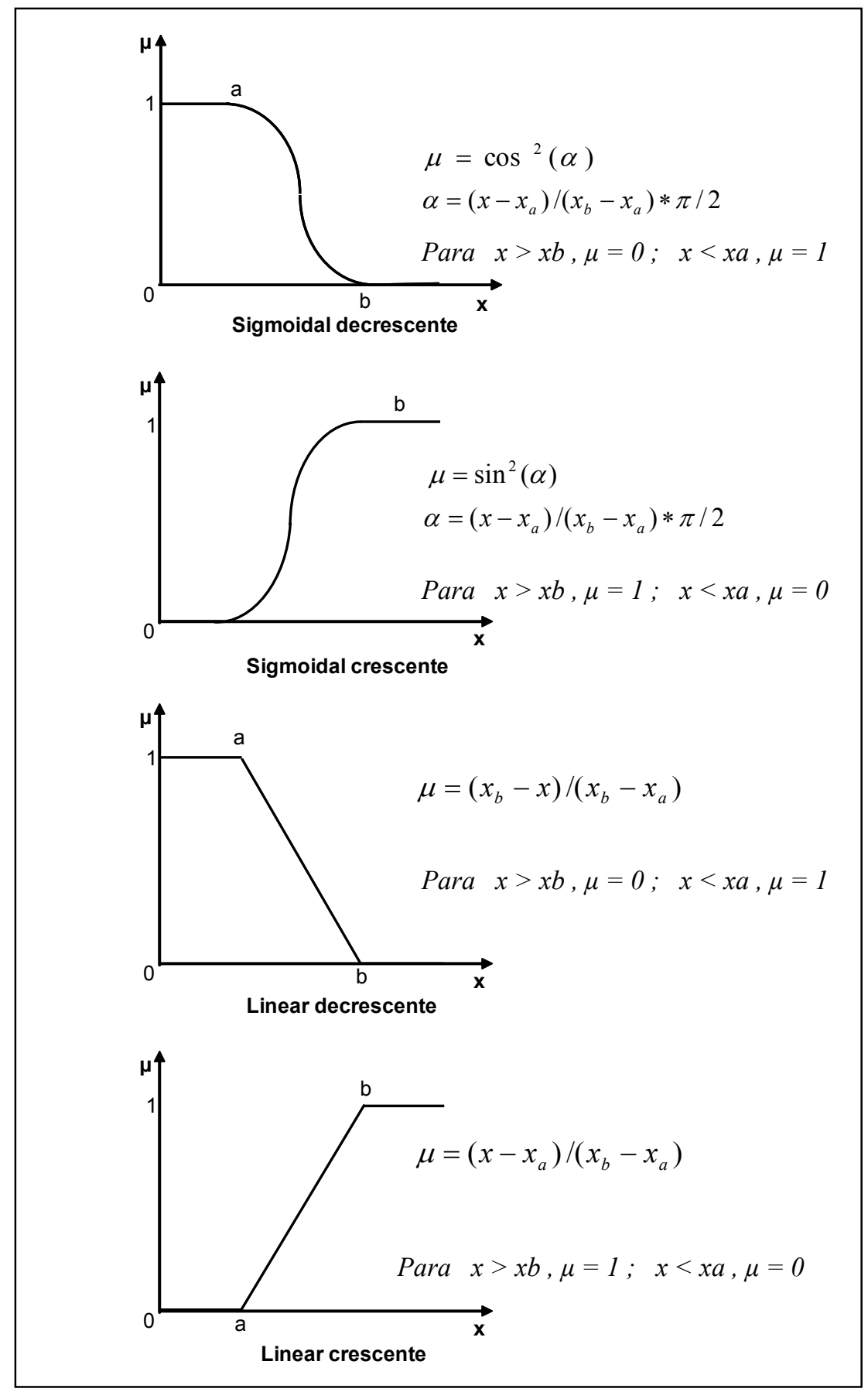

Figura 4.3: Funções Fuzzy [Adaptado de Ramos (2000)]

Plano e inclinado são conceitos que, não sendo quantificados, são pouco úteis em termos de tomada de decisão em relação ao objetivo proposto. Há então que definir qual o declive do terreno (limite) que distingue as áreas planas das áreas em declive acentuado. 
Numa perspectiva de lógica Booleana, que utiliza critérios restritivos, se fosse definido o valor de $8 \%$ para esse limite, as áreas com declive inferior a $8 \%$ seriam planas ou quase planas, logo aptas para o traçado (localização) da estrada, e as áreas com declive superior a $8 \%$ seriam inclinadas, logo não aptas. Isto significa que a área com declive 7,9\% seria boa e uma outra com $8,1 \%$ seria má, situação não muito coerente. Em contraposição, a lógica fuzzy admite um conjunto de valores do declive a que corresponde à classificação de plana ou quase plana, digamos até $3 \%$, e um conjunto de valores a que corresponde a classificação de declive, digamos acima de 12\%. Entre os valores de 3\% e 12\% (que seriam os pontos de controle mínimo e máximo), a variação seria gradual, de acordo com uma função (fuzzy) definida. Assim, o andamento da função seria (normalização para uma escala 0-1) (RAMOS, 2000):

- Declive até 3\%: score 1 (áreas aptas);

- Declive entre 3\% e 12\%: score a variar de 1 até 0 , de acordo com a função (áreas de aptidão variável);

- Decive acima de 12\%: score 0 (áreas não aptas)

No momento de definir o procedimento mais adequado para a normalização de critérios, tem-se que observar que tipo de critério se trata. Para variáveis contínuas (distância, por exemplo), o procedimento mais indicado é a aplicação de funções fuzzy, as quais deverão ser escolhidas e calibradas criteriosamente. Para variáveis discretas (com valores numéricos discretos, como por exemplo, nível de severidade do defeito), pode optar-se por calcular previamente um $z$-score para cada alternativa (seção de pavimento) e só depois aplicar a função fuzzy, o que dá alguma contextualidade ao processo, dado que os z-scores são referidos à média dos valores em análise. No caso de critérios que envolvem escalas nominais (classe funcional da via, por exemplo) deverão ser atribuídos arbitrariamente os scores normalizados, de acordo com a escala normalizada adotada (CAFISO et al., 2002).

\subsubsection{Combinação de Critérios}

Uma vez normalizados os scores dos critérios para um intervalo fixo ( 0 a 1 , ou outro qualquer), esses já podem ser agregados de acordo com a regra de decisão. Existem diversas classes de operadores para a combinação de critérios (para uma descrição extensiva ver MALCZEWSKI, 1999). Os mais utilizados nos processos de decisão espacial são a Combinação Linear Ponderada (WLC, do inglês Weighted Linear Combination ) e a Média Ponderada Ordenada (OWA, do inglês Ordered Weighted Average). 
O WLC (VOOGD, 1983) combina os fatores através de uma média ponderada, dada pela Equação 4.10. A mais importante característica desse procedimento é o fato de permitir a compensação entre critérios (Trade-off), o que significa que uma qualidade (score a respeito de um critério) muito pobre numa dada alternativa pode ser compensada por um conjunto de boas qualidades (scores mais altos a respeito de outros critérios). Aplicações do WLC podem ser encontradas em MENDES (1999); MENDES et al. (1999); RAMOS (2000); RODRIGUES (2001); LIMA et al. (2002).

$$
S=\sum_{i} w_{i} x_{i}
$$

Onde:

- $S$ : valor final do score;

- $w_{i}$ : peso do fator $i$;

- $x_{i}$ : valor normalizado do fator $i$.

O OWA (YAGER, 1988) além de utilizar os pesos de critérios usados no procedimento WLC, considera outro conjunto de pesos que não estão especificamente ligados a quaisquer fatores, mas que são aplicados por uma ordem que depende do valor dos fatores após a aplicação normal do primeiro conjunto de pesos. Os novos pesos denominam-se "pesos ordenados", do inglês Order Weights, uma vez que sua aplicação depende de uma determinada ordenação dos fatores que agregam (YAGER, 1988, EASTMAN \& JIANG, 1996; EASTMAN et al., 1998).

Depois da aplicação do primeiro conjunto de pesos aos fatores (tal como no procedimento WLC), os scores resultantes (agora ponderados) são ordenados do valor mais baixo para o mais elevado. Ao fator com o score ponderado mais baixo (o primeiro da lista ordenada) é aplicado o primeiro order weight, ao fator com o segundo valor mais baixo é aplicado o segundo order weight, e assim sucessivamente. Trata-se, portanto, de ponderar os fatores de acordo com sua ordem, do mínimo para o máximo.

Fazendo variar os order weights, o procedimento OWA permite implementar uma gama vastíssima (na verdade infinita) de operadores de agregação. Em um processo de decisão que envolva três fatores, um conjunto order weight $\left[\begin{array}{lll}1 & 0 & 0\end{array}\right]$ aplicaria todo o peso ao fator com o menor score, produzindo assim uma solução sem risco (dita pessimista ou conservadora), equivalente ao operador lógico AND; um conjunto order weight $\left[\begin{array}{lll}0 & 0 & 1\end{array}\right]$, pelo contrário, aplicaria todo o peso ao fator de mais alto score, produzindo assim uma solução de elevado risco (dita otimista), equivalente ao operador lógico OR; um conjunto order weight 
[0,33 0,33 0,33], por sua vez, aplicaria igual peso a todos os fatores, produzindo assim uma solução de risco neutro (intermédia), equivalente ao operador WLC (EASTMAN et al., 1998).

Nos dois primeiros casos, apenas os scores extremos são considerados (o mínimo no primeiro e o máximo no segundo), o que significa que os fatores não podem ser compensados uns pelos outros (ausência de Trade-off). Contudo, no terceiro caso, como foi atribuído um conjunto de "pesos ordenados" perfeitamente equilibrado, os fatores podem compensar-se mutuamente (Trade-off total), no sentido em que maus scores em alguns fatores podem ser compensados por bons scores em outros. Portanto, este terceiro caso é um equivalente do WLC ou, ainda mais corretamente, o procedimento WLC é um caso particular do procedimento mais geral OWA (RAMOS, 2000).

Tomando como exemplo uma rede de estradas que precisa de serviços de conservação, definem-se os trechos com maior necessidade de intervenção como aqueles que terão os scores mais elevados. Se para este caso tivermos quatro critérios envolvidos no processo de decisão, um conjunto order weight $\left[\begin{array}{llll}1 & 0 & 0 & 0\end{array}\right]$ aplicaria todo o peso ao fator com o menor score, produzindo, uma solução com risco mínimo. Isto implica considerar como estratégia de decisão os trechos com intervenções mais prioritárias. Por outro lado, para um conjunto order weight $\left[\begin{array}{llll}0 & 0 & 0 & 1\end{array}\right]$ todo o peso é dado ao fator de mais alto score, produzindo assim uma solução de risco máximo, na qual se considera todas as intervenções necessárias, sendo elas prioritárias ou não.

Considerando-se, por exemplo, os quatro fatores (A, B, C e D) com os scores e os pesos da Tabela 4.3 e reordenando-os do menor para o maior, logo após a aplicação dos respectivos pesos (Avaliação 1) teremos a seguinte ordem: A, C, D e B. Aplicando-se os conjuntos [ $\left[\begin{array}{llll}1 & 0 & 0 & 0\end{array}\right],\left[\begin{array}{llll}0 & 0 & 0 & 1\end{array}\right]$ e $[0,25$ 0,25 0,25 0,25] de order weights teremos os resultados apresentados na Tabela 4.4.

Tabela 4.3: Fatores do exemplo de agregação OWA

\begin{tabular}{cccc}
\hline Fator & Score & Peso & Avaliação 1 \\
\hline A & 100 & 0,2 & 20 \\
B & 250 & 0,3 & 75 \\
C & 300 & 0,1 & 30 \\
D & 150 & 0,4 & 60 \\
\hline
\end{tabular}

Qualquer combinação de order weights é possível, mas observando-se sempre a unidade do somatório. A Figura 4.4 representa um espectro triangular estratégico de decisão, definido pela atitude de risco e pelo nível de Trade-off. 
Tabela 4.4: Resultados do exemplo de agregação OWA

\begin{tabular}{ccccc}
\hline Fator & Avaliação 1 & $\begin{array}{c}\text { Order } \\
\text { Weight }\end{array}$ & Avaliação 2 & $\begin{array}{c}\text { Score final } \\
\text { (Soma Ponderada) }\end{array}$ \\
\hline A & 20 & 1 & 20 & 20 \\
C & 30 & 0 & 0 & (Avaliação \\
D & 60 & 0 & 0 & pessimista) \\
B & 75 & 0 & 0 & \\
A & 20 & 0 & 0 & 75 \\
C & 30 & 0 & 0 & (Avaliação \\
D & 60 & 0 & 0 & otimista) \\
B & 75 & 1 & 75 & 46,2 \\
A & 20 & 0,25 & 5,0 & (WLC) \\
C & 30 & 0,25 & 7,5 & \\
D & 60 & 0,25 & 15,0 & \\
B & 75 & 0,25 & 18,7 & \\
\hline
\end{tabular}

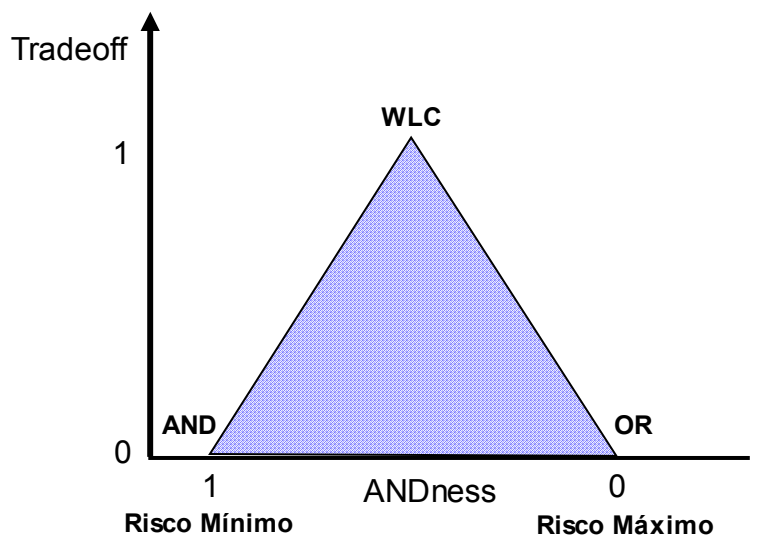

Figura 4.4: Espaço estratégico de decisão - OWA [Adaptado de Ramos (2000)]

O deslocamento relativo dos order weights no sentido do mínimo ou do máximo controla o nível de risco, designado por ANDness. Por sua vez, a homogeneidade da distribuição dos order weights através das posições controla o nível global de Trade-off. O nível de risco (ANDness) e a compensação entre scores (Trade-off) são medidos, respectivamente, através das Equações 4.11 e 4.12, onde $n$ é o número total de fatores, $i$ é a ordem de cada fator e $O_{i}$ é o peso (order weight) do fator de ordem $i$. Mais detalhes e exemplos sobre análises de risco podem ser encontrados em EASTMANN et al. (1998) e RAMOS (2000).

$$
\text { ANDness }=\frac{1}{n-1} \sum_{i}\left((n-i) O_{i}\right)
$$




$$
\text { Tradeoff }=1-\sqrt{\frac{n \sum_{i}\left(O_{i}-1 / n\right)^{2}}{n-1}}
$$

Finalmente, o objetivo da utilização de MCDA é auxiliar a busca por soluções aos problemas decisórios com múltiplas alternativas de escolha, que possam ser avaliadas em termos de características de desempenho, denominadas critérios de decisão. Considerável atenção na última década foi devotada à integração de MCDA com os Sistemas de Informação Geográfica (SIG), pois muitos dos modelos elaborados nos SIGs trabalham com avaliação e escolha de alternativas baseadas em critérios de aptidão. A literatura internacional recente é repleta de trabalhos combinando SIG e MCDA (JANKOWSKI et al., 2001; COSTA et al., 2004; RODRIGUES et al., 2004; ZAMBON, 2004). O próximo capítulo trata dos conceitos e a capacidade dos SIGs como ferramenta de apoio à decisão, em aplicações na gerência de pavimentos.

\subsection{Sistemas de Informações Geográficas}

Ao longo da última década tem havido um vasto e crescente interesse em Sistemas de Informações Geográficas (SIG) no mundo acadêmico, nas grandes empresas e em empresas de software e, mais recentemente, entre os profissionais liberais. $\mathrm{O}$ aumento da capacidade de processamento e a redução dos custos dos microcomputadores, aliados ao aumento da disponibilidade de bases de dados cartográficas digitais, têm contribuído para a crescente utilização de SIG (LIMA, 2003).

Os SIGs estão inseridos no contexto de geoprocessamento como uma ferramenta para processar dados gráficos e não gráficos, com ênfase às análises espaciais e modelagens de superfícies. O termo geoprocessamento envolve um conceito bastante abrangente e representa qualquer tipo de processamento de dados georeferenciados (CÂMARA et al., 2001).

A empresa norte-americana Environmental Systems Research Institute Inc. - ESRI (1996) define Sistemas de Informações Geográficas como sendo uma coleção de hardware, software, dados geográficos e pessoais, com o propósito de capturar, armazenar, atualizar, manipular, analisar e visualizar eficientemente todas as formas de informação geograficamente referenciadas.

Os SIGs permitem um maior controle e gerência em prefeituras e outros órgãos de planejamento e propiciam um sistema de consulta com maior velocidade de coleta e manuseio 
de informações, melhorando a qualidade do serviço. Departamentos essenciais da administração municipal (planejamento, cadastro tributário, transportes, obras, saúde, educação, entre outros) podem e devem ser integrados a um SIG, pois fornece ao decisor ferramentas para atualizar e controlar as informações, auxiliando com antecedência as decisões que irão permitir o controle no futuro (ROSADO, 2000).

\subsubsection{SIG e a Gerência de Pavimentos}

O volume crescente de informações relativas às redes viárias tem exigido sistemas cada vez mais eficientes de processamento dos dados, particularmente daqueles que se distribuem espacialmente (WISCONSIN DOT, 1990).

A rede viária desenvolve-se numa determinada região geográfica, caracterizada por elementos com características diferenciadas segundo a sua localização. Desse modo, é conveniente poder representar as características da rede sobre um suporte gráfico, representando a localização real da rede no espaço.

As características do SIG mais relevantes para a gerência de pavimentos são as que tratam do acesso e interpretação dos dados. A apresentação geográfica de um SIG é uma interface que possibilita selecionar seções de pavimentos para análises da informação. Mais importante, a apresentação das condições e desempenho do pavimento em mapas coloridos possibilita a interpretação e síntese dos dados distribuídos no tempo e espaço. Isto é um fator importante, não só para engenheiros responsáveis pela manutenção do pavimento, mas também para os responsáveis pela gerência de políticas e prioridades e ainda a geração de documentos (SCHWARTZ et al., 1991).

Fernandes Jr. \& Pantigoso (1997) comentam que os SIGs são uma ferramenta capaz de auxiliar e agilizar os procedimentos de planejamento, gerência e de apoio à decisão e fornecem a plataforma para o desenvolvimento de todos os processos envolvidos num sistema de gerência de pavimentos.

Durante os últimos 5 a 10 anos, vários estudos têm sido desenvolvidos com o uso de SIG e já produzem resultados satisfatórios para a gerência de rodovias, aeroportos e infraestrutura urbana de muitos países, não só na representação de dados mas também no processamento e análise dos mesmos. Por exemplo, Ferreira et al (2001) desenvolveram na Universidade de Coimbra (Portugal) um SGP baseado num SIG, consistindo de três módulos: Banco de Dados da rede viária, Avaliação da Condição e Apoio à Decisão. Os recursos 
oferecidos pelos SIGs proporcionaram melhor gestão das atividades existentes na gerência de pavimentos, no que se refere a reduzir os erros e integrar vários aspectos dos usos de dados, criando uma base sólida para tratar com o inesperado. A percepção da informação é facilmente visualizada através de mapas, favorecendo a tomada de decisão final. O Illinois Department of Transportation - IDOT (HALL et al., 2000) e o Texas Department of Transportation-TxDOT (ZHANG et al., 2001) são mais alguns exemplos de aplicação de SIG em gerência de pavimentos.

Uma pesquisa realizada entre engenheiros de pavimentos, baseada em suas tarefas diárias e atividades, identificou alguns benefícios da integração SIG e SGP (ZHANG et al., 2001):

- Interface amigável e flexível para os usuários;

- Análise estatística de vários dados de SGP;

- Integração, extração e operação de banco de dados com vários métodos;

- Capacidade para questões complexas;

- Um sistema simples de localização com múltiplos métodos de referenciamento;

- Apresentação gráfica de dados de SGP;

- Poder de uso de um Sistema Global de Posicionamento (GPS);

- Capacidade de segmentação dinâmica;

- Uso efetivo de informação multimídia, tais como, vídeo, som, imagens etc.

- Facilita a análise dos dados;

- Integração com outros sistemas de gerência;

- Acesso através de Intranet e Internet;

- Habilidade para integrar-se com vários bancos de dados;

- Facilidade de entendimento e uso;

- Apresentação da informação para os tomadores de decisão num formato mais compreensivel.

Segundo Zhang et al. (2001), existem dois estágios de interação na implementação de um SIG em SGP. O primeiro refere-se ao planejamento e projeto de onde os recursos e limitações do sistema de gerência existente são examinadas e o potencial das atividades que podem ser solucionadas pelo SIG são identificadas e selecionadas. O segundo estágio referese à gerência e operação das atividades do SIG segundo o plano de implementação. Portanto, embora muitas características do SIG não sejam utilizadas, a apresentação espacial dos dados 
e suas capacidades de análises são valiosas para o processo de tomada de decisão em gerência e engenharia.

A capacidade dos SIGs para gerar uma série de alternativas de decisão está baseada principalmente nas relações espaciais de conectividade, contigüidade, proximidade e sobreposição (as operações fundamentais dos SIG). Contudo, quando a seleção de alternativas envolver conflitos de preferências em relação aos critérios de avaliação, as funções de sobreposição do SIG não provêem suporte analítico suficiente, devido às capacidades limitadas de incorporação das preferências dos decisores. Devido a essa deficiência, há a necessidade de se integrar técnicas de decisão às funções do SIG, através da incorporação direta de modelos analíticos ou criando-se uma interface amigável com sistema de análise de decisões já desenvolvido. Isto resultaria numa acentuada melhoria na capacidade do SIG de realizar funções analíticas avançadas, especialmente modelos de simulação e otimização (LIMA, 2003).

A capacidade de incorporar as preferências do decisor no processo decisório é outro fator crítico para o uso do SIG. Em geral, os SIG não provêem mecanismos para representação de escolhas e prioridades num contexto de avaliação de critérios e objetivos conflitantes. Um modo de se fazer isso é incorporar técnicas de Análise de Decisão Multicritério (MCDA) no processo decisório. Enquanto os SIG podem ajudar como ferramenta no tratamento das descontinuidades dos dados, provendo mais e melhores informações, as técnicas de análises de decisão podem ajudar administrando as divergências entre as partes de interesse conflitante (MALCZEWSKI, 1999; LIMA, 2003).

Tipicamente, os problemas de priorização envolvem selecionar e ordenar um grande número de alternativas. O SIG, associado aos métodos de decisão multicritério, pode beneficiar a solução de problemas reais que envolvam o planejamento de atividades considerando vários critérios de decisão.

\subsubsection{SIG-ArcView}

Os SIGs são sistemas que correlacionam a totalidade da informação, obtida da cartografia técnica e temática, e desenvolvem, a partir da sua elaboração racional e combinação mais sofisticada, profundos conhecimentos, para o estudo e gestão territorial. Além disso, vieram alterar radicalmente os conceitos cartográficos ao resolverem a condicionante básica da cartografia tradicional e impressa: a forma estática de elaboração e a apresentação dos dados, oriundos da mudança de escala dos mapas. 
Usuários de Sistemas de Informação Geográfica (SIG) possuem diferentes necessidades quanto à qualidade, quantidade e ao tipo de informação armazenada. Essas necessidades criam certas restrições ou limitações, na representação da informação espacial e na apresentação dos dados (SANTO et al., 2006).

As ferramentas de análise espacial dos SIGs melhoraram substancialmente seu desempenho nos últimos anos. Alguns SIGs já possuem funções analíticas avançadas para apoiar a análise espacial, incluindo análise de decisão (autocorrelação espacial, interação espacial, modelos de localização de atividades, simulação e otimização). Cabe ressaltar, no entanto, que as funções analíticas avançadas fazem parte de softwares específicos. Por exemplo, o TransCAD, um sistema projetado especificamente para planejamento de transportes, inclui uma série de funções utilizadas no projeto de complexos sistemas de transporte. Várias funções disponíveis em SIG especializados, tal como o TransCAD, não estão disponíveis em SIGs mais genéricos (MALCZEWSKI, 1999; ROSE, 2001).

O Sistema de Informação Geográfica utilizado para o modelo de priorização de seções de pavimento desenvolvido neste trabalho é o ArcView GIS 3.2. O ArcView trabalha com dois modelos espaciais para a representação da realidade: modelo vetorial e modelo matricial (raster). No modelo vetorial, as entidades (temas ou camadas) são representadas por pontos, linhas ou áreas, com os significados inerentes a cada caso estudado. Uma cidade pode ser representada por um ponto quando se pretende determinar a distância entre elas, por exemplo, ou pode ser representada por uma área quando se pretende determinar aspectos como tráfego urbano, densidade populacional etc. $\mathrm{O}$ modelo vetorial permite representar às várias entidades (temas) de maneira muito aproximada da realidade, principalmente em relação aos atributos que são designados a cada entidade. Porém, muitas vezes, ocorre a necessidade de simplificação para permitir a representação e as premissas adotadas em decorrência deste fato.

Em modelos do tipo matricial, a realidade é representada por uma malha que pode ser colocada sobre o mundo real, como por exemplo, na forma de fotografias aéreas ou de satélites. Esta malha é formada por células regulares, às quais são designados atributos. Nesta situação, uma entidade pontual é representada por uma célula, uma entidade linear por uma sucessão de células e uma entidade do tipo polígono por um agrupamento de células contíguas. A regularidade das células facilita a utilização de ferramentas de análises. Entretanto, é preciso criar várias malhas, cada uma contendo atributos relativos a apenas uma característica do mundo real, para representar diversas características de uma mesma área. 
O modelo utilizado para o desenvolvimento deste trabalho foi o vetorial. Quase todas as análises foram realizadas em "temas ou camadas" de linhas, contendo a rede viária urbana, com exceção de alguns temas de pontos utilizados para localizar equipamentos públicos, infra-estruturas de transportes e áreas industriais e de lazer.

Cada tema armazena um banco de dados, com campos vinculados, e registros vinculados aos campos. Cada tema possui por "defaut" um campo de tipo de camada (linha, ponto ou polígono) e outro com um número identificador (ID) que diferencia um registro do outro. Por exemplo, conforme a Figura 4.5, o tema Volume de Tráfego possui 7500 registros (seções de vias representadas por linhas) e 4 campos, sendo eles: shape, ID, Nome da via e tipo de tráfego. O mapa contido na "View", janela de visualização de mapas e temas, refere-se ao tema volume de tráfego e está desenhado de acordo com o campo tipo de tráfego (leve L, médio $\mathrm{M}$ ou pesado $\mathrm{P})$.

A sobreposição, de vários temas de linhas, pontos e polígonos, possibilita a realização de análises de rede, tal como a realizada no trabalho para localizar as seções de preferências pessoais, próximas aos equipamentos públicos e próximas às infra-estruturas de transportes. A Figura 4.6 é um exemplo de sobreposição de temas para fins de análises de rede, considerando temas de pontos (postos de saúde e hospitais) e de linhas (localização: rede e snet 4 e 5: criados pela rotina para localizar as seções próximas aos postos de saúde e aos hospitais, respectivamente).

O ArcView não possui ferramentas específicas de avaliação multicritério, o que torna necessário o acréscimo de colunas ou campos ao banco de dados georeferenciado. Os campos acrescidos guardam os atributos, que são normalizados, ponderados e depois agrupados durante os procedimentos WLC e/ou OWA, desenvolvidos com simplicidade diretamente em ambiente SIG.

Nesse capítulo realizou-se uma síntese da metodologia de Análise Multicritério e dos Sistemas de Informações Geográficas como instrumentos que podem dar apoio à decisão na gerência de pavimentos. No próximo capítulo é apresentado o modelo de priorização de seções de pavimentos para cidades médias brasileiras, com a descrição mais específica da técnica utilizada, identificação dos critérios e pesos atribuídos a cada um deles, assim como a estrutura hierárquica do processo de decisão. 


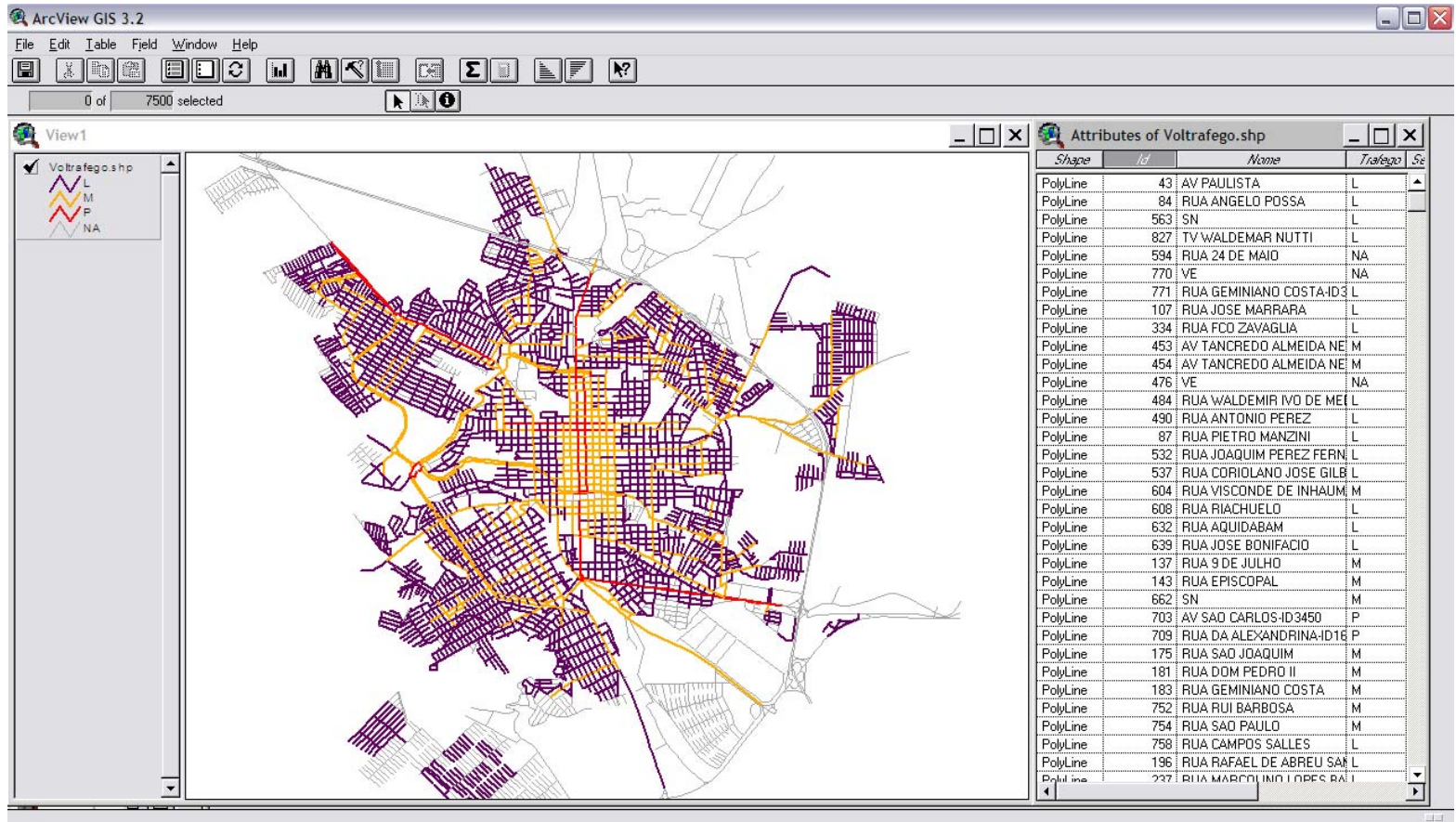

Figura 4.5: Exemplo de banco de dados em SIG - ArcView

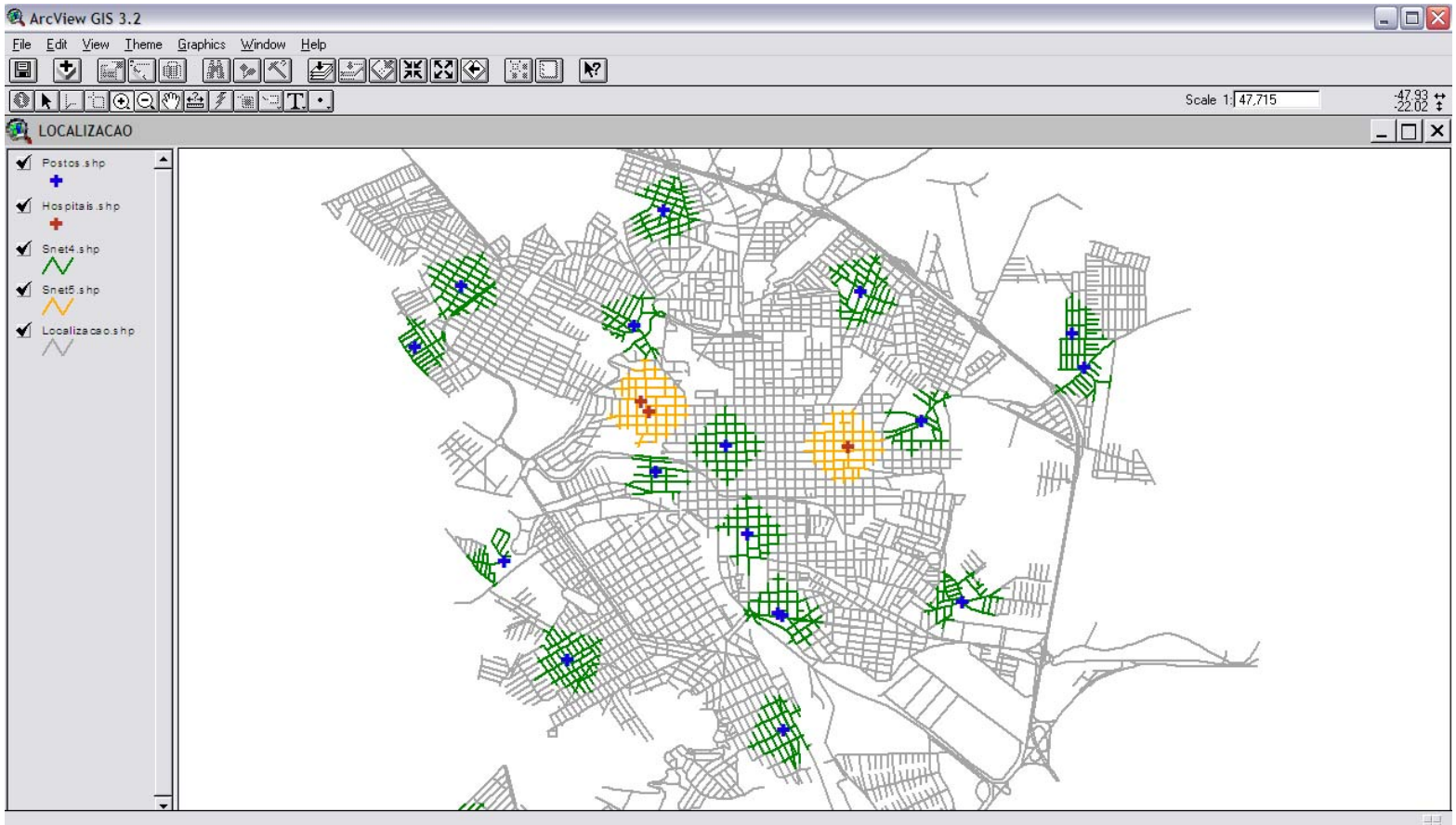

Figura 4.6: Exemplo de sobreposição de temas de linhas e pontos no ArcView 
Modelo de decisão para a priorização de vias candidatas às atividades de manutenção e reabilitação de pavimentos 


\section{O MODELO DE PRIORIZAÇÃO DE SEÇÕES DE PAVIMENTOS PARA CIDADES MÉDIAS BRASILEIRAS}

Este trabalho tem o objetivo de desenvolver diretrizes de apoio à decisão que considerem critérios objetivos e subjetivos na seleção de seções candidatas às atividades de M\&R de pavimentos. Por outro lado, estrutura-se um modelo que agrega a Gerência de Pavimentos, principalmente no que diz respeito aos modelos existentes de priorização de pavimentos, à Metodologia de Análise Multicritério, como ferramenta de avaliação de alternativas, e um Sistema de Informação Geográfica, como ambiente de análise e processamento espacial da informação.

O capítulo 5 objetiva estruturar o modelo de decisão, baseado em todos os conceitos tratados nos capítulos anteriores, em que foram definidas as particularidades da gerência de pavimentos, foram vistos os procedimentos adotados atualmente pelas prefeituras de cidades médias e as propostas existentes para a priorização de vias pavimentadas. Além disso, os critérios que assumem grande importância para o planejamento das atividades realizadas sobre o pavimento, foram tratados um a um, bem como as tecnologias disponíveis para o apoio à decisão na gerência de pavimentos. Portanto, nas próximas seções serão estabelecidos o método e a ferramenta utilizados para o desenvolvimento do modelo de priorização proposto neste trabalho e todos os processos envolvidos na elaboração da estrutura hierárquica de decisão.

\subsection{Definição de Técnica e da Implementação em Ambiente SIG}

A seleção de seções de pavimentos é essencialmente um processo de decisão através do qual se pretende comparar as várias seções alternativas (com características específicas) que compõem uma rede viária ou, de forma mais geral, identificar as seções mais prioritárias a receber atividades de manutenção e reabilitação de pavimentos.

A priorização de seções de pavimentos pode ser desenvolvida de várias maneiras, em função do propósito que se pretende atingir e as respectivas variáveis associadas. Podemos considerar três objetivos distintos na determinação de índices de prioridades: 
- Político, cujos motivos de dar maior prioridade a uma determinada via ou seção estão associados aos programas traçados durante campanhas eleitorais e a vontade política;

- Socioeconômico, no qual são traçados projetos que consideram locais estratégicos, nos quais o custo é o menor possível dentro do orçamento disponível, buscando diminuir o custo dos projetos e aumentar o benefício dos usuários (social e econômico);

- Técnico, no qual a meta é manter a rede em boas condições de tráfego e aumentar a vida do pavimento em serviço.

Frente a esses propósitos, o estudo desenvolvido abrange os dois últimos objetivos, ou seja, na forma de avaliar, para determinada rede de pavimento, os índices de prioridade consideram os fatores que avaliam a importância da via, tanto pela sua localização como a sua classificação, e também a condição do pavimento e os custos associados às estratégias de M\&R. Para a priorização das seções de pavimento admite-se que:

- As prioridades são avaliadas por objetivos, neste caso socioeconômicos e técnicos;

- O índice de prioridade é um valor que incorpora os atributos relacionados a cada seção de pavimento e resulta da combinação desses atributos, para cada critério;

- Os grupos de fatores (critérios), assim como os fatores e os atributos (subgrupos de critérios), possuem importâncias diferenciadas (pesos);

- $O$ índice de prioridade de cada seção da rede resulta da média ponderada dos scores dos grupos, que por sua vez resulta da média ponderada dos scores dos fatores, que da mesma forma resulta da média ponderada dos scores normalizados dos atributos.

Os valores numéricos, nomeadamente de scores, nesse trabalho, são quantidades que inicialmente representam os atributos em escalas variadas e, que passaram por um processo de normalização para obter valores comparáveis entre si, dentro de uma mesma escala (nesse trabalho, de 0 a 1). Portanto, os scores são valores normalizados de cada fator ou grupo de fatores.

A forma adotada para a quantificação da importância dos vários fatores e grupos de fatores, ou seja, a sua importância na avaliação das prioridades de $M \& R$ de pavimentos, a hierarquização e a forma de agregação dos fatores são estabelecidas no modelo desenvolvido, que recorre a técnicas de Avaliação Multicritério (MCDA- Multicriteria Decision Analysis ). No modelo admite-se que os grupos de fatores baseados nos objetivos/propósitos funcionam como critérios na avaliação de prioridades de $M \& R$ de pavimentos, ou seja, que possuem 
importâncias distintas que serão traduzidas em contribuições diferenciadas no valor final do índice de prioridade.

O processo considera múltiplos critérios organizados em vários níveis, em grupos e subgrupos de critérios. Nesse tipo de estrutura, na qual o problema é dividido em grupos de critérios e subdividido em outros, de níveis inferiores, o nível mais alto deverá ser a meta do problema, o objetivo final do processo de decisão. Os níveis inferiores devem ser estruturados de modo que se possa descer de níveis mais abrangentes para níveis mais específicos, terminando em um nível de atributos, isto é, critérios quantificáveis ou de fácil avaliação (RAMOS, 2000).

Não existem regras para a forma de estruturar as hierarquias nem para definir o número de níveis a criar, o que permite ao decisor inserir ou eliminar elementos e níveis da forma que julgue necessário para clarificar as suas prioridades ou para evidenciar algumas partes do processo de decisão (SAATY, 1980).

A quantificação do índice de prioridade $(I P)$ de cada seção $(i)$ da rede resulta da agregação dos scores dos grupos $\left(\right.$ Score $\left._{g}\right)$, isto é, a média ponderada dos scores de cada grupo (g) de fatores, que por sua vez são dados pela agregação dos scores dos fatores $\left(\right.$ Score $\left._{f}\right)$, e que ainda, por sua vez, são dados pela agregação dos scores normalizados dos indicadores $\left(\right.$ Score $\left._{i}\right)$. A expressão que agrega todos os scores normalizados correspondente a uma Combinação Linear Ponderada (WLC - Weighted Linear Combination - Voogd, 1983), permitindo aos critérios compensar entre eles as suas qualidades. No caso da determinação de índices de prioridades, esse tipo de agregação admite que a seção menos prioritária em relação a um critério mais utilizado tradicionalmente nos modelos atuais existentes (como por exemplo, Índice da Condição do Pavimento) pode ser compensada por seções mais prioritárias em relação a múltiplos critérios de utilização menos freqüentes. No entanto, os vários critérios (fatores) em análise podem ser complementares ou equivalentes, e frente a essa situação, faz-se a agregação em grupos de critérios similares. Assim, o IP passa a ser avaliado por grupos de critérios (ou grupos de fatores), conforme a Equação 5.1, onde Score $_{g}$ e $w_{g}$ são respectivamente o score normalizado e ponderado e o peso atribuído a cada grupo $(g)$ de critérios.

$$
I P=\frac{\sum_{g} \text { Score }_{g} \times \omega_{g}}{\sum_{g} \omega_{g}}
$$


Para que os valores dos diferentes critérios possam ser agregados é necessário a sua normalização. Os critérios contínuos são normalizados recorrendo-se às funções Fuzzy, segundo as quais um conjunto de valores expresso numa dada escala é convertido num outro, comparável e expresso numa escala normalizada (por exemplo 0-1). Por outro lado, alguns critérios com valores lingüísticos subjetivos são normalizados atribuindo-se valores de scores de forma arbitrária, dentro da mesma escala dos critérios contínuos. A forma arbitrária de atribuir valores de scores dentro de uma determinada escala normalizada não afeta a confiabilidade do modelo, sendo que é sempre possível adaptá-lo a cada aplicação, atribuindo valores e variáveis diferentes para serem estudados caso a caso. Do mesmo modo, também é possível incorporar qualquer outra forma de função fuzzy ao processo.

O modelo para avaliação multicritério de seções prioritárias apresentado neste trabalho foi implementado num Sistema de Informação Geográfica, em formato vetorial, através de uma estrutura sistêmica que envolve a agregação dos critérios, através da normalização para uma escala comum e da combinação de pesos para obter médias ponderadas. Sendo o modelo de fácil integração em ambiente SIG, após a digitalização dos dados espaciais e a organização dos dados alfanuméricos em tabelas, foi possível recorrer às análises de redes e de mapas para obter os índices de prioridades em questão. A Figura 5.1 representa a estrutura utilizada para a avaliação multicritério de seções prioritárias em ambiente SIG.

No modelo de avaliação dos índices de prioridades, os critérios (fatores) envolvidos são expressos em termos de características da via ou da seção de pavimento. Essas características podem assumir valores numéricos (objetivos) ou lingüísticos (subjetivos), dependendo do tipo de critério que está sendo considerado.

Portanto, fazendo-se uso de mapas que contenham a rede e os atributos vinculados a cada seção de pavimento da rede, o primeiro passo consiste em identificar as formas de medidas referentes a cada fator e, a seguir, proceder com a normalização dessas medidas, obtendo-se os scores dos fatores. Através da aplicação dos pesos de cada fator aos scores obtidos, resultam os respectivos scores normalizados e ponderados. Em seguida, os scores normalizados são agrupados, obtendo-se, então, os índices de prioridade para cada grupo de fatores. Finalmente, através de um novo agrupamento, determina-se o índice de prioridade global. A Figura 5.2 representa a modelagem utilizada na generalização dos índices de prioridades para todas as seções da rede. 


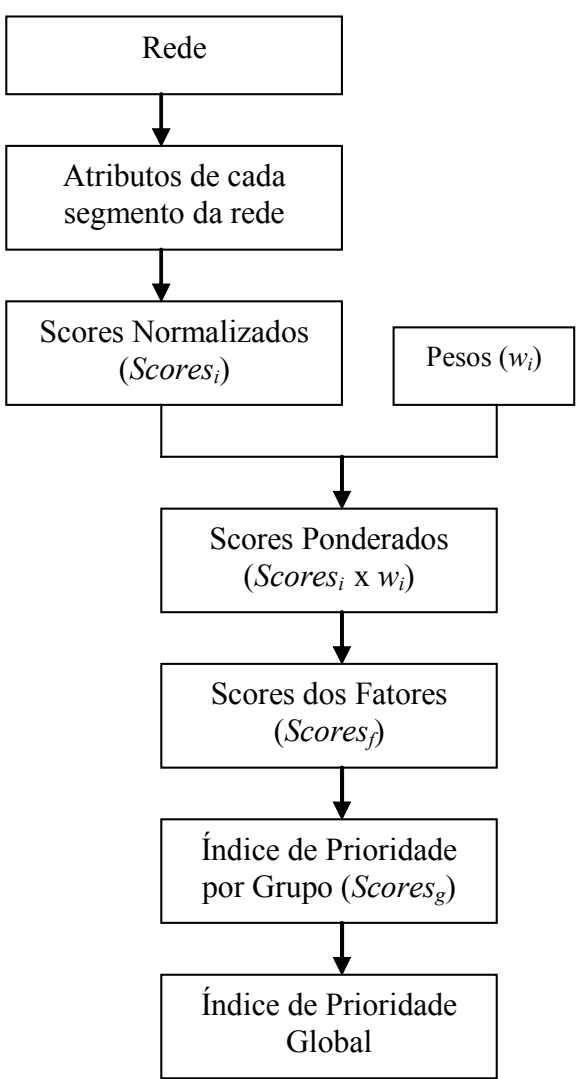

Figura 5.1: Modelo de avaliação multicritério de prioridades de M\&R em ambiente SIG

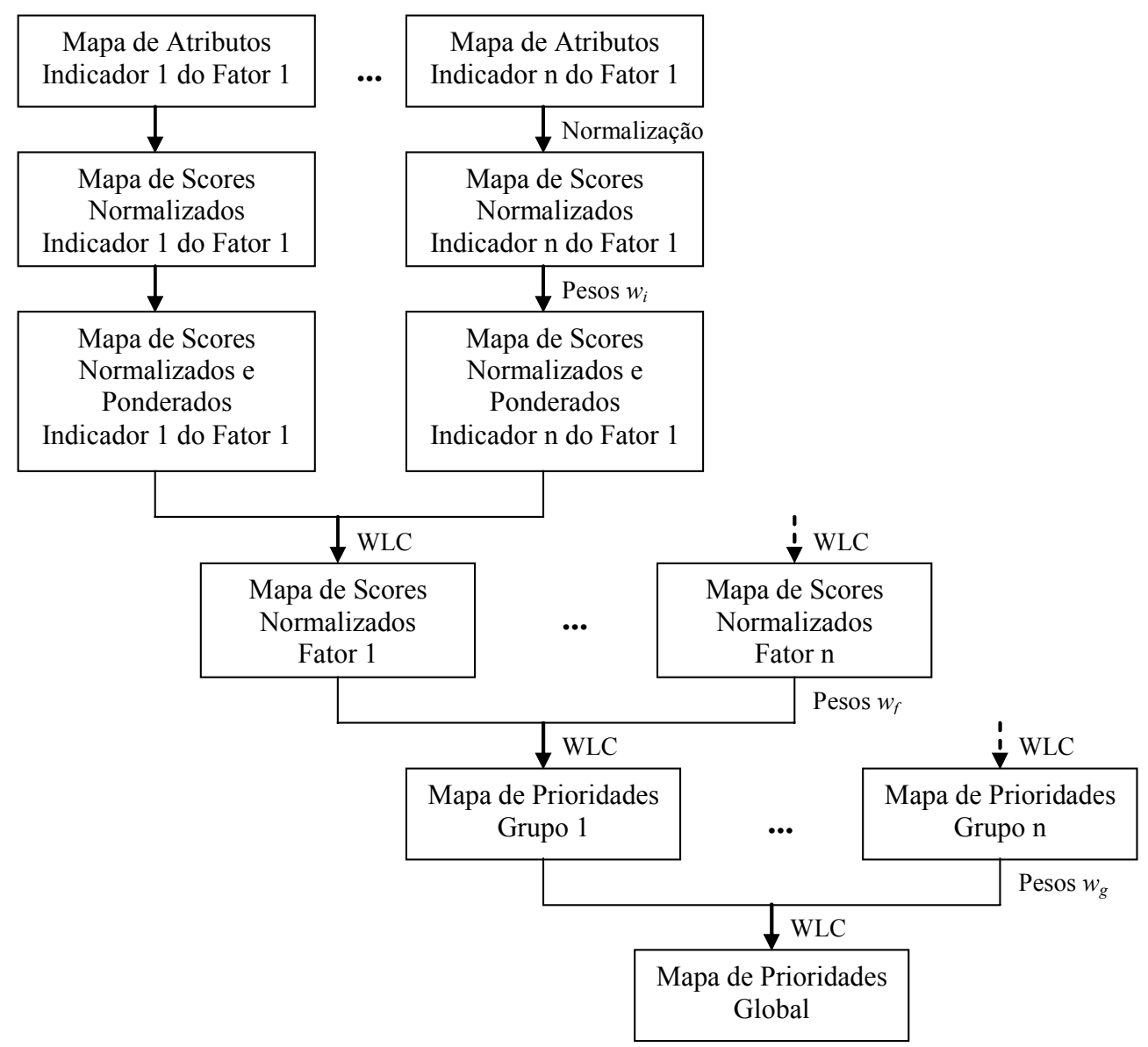

Figura 5.2: Modelagem utilizada para a obtenção do mapa final de prioridades 
A seguir é apresentada a especificação do modelo de priorização de seções candidatas às atividades de $M \& R$ de pavimentos, desenvolvido para as cidades médias brasileiras. Essa parte do trabalho contou com as seguintes etapas: i. Identificação dos critérios e grupos de critérios relevantes para a tomada de decisão; ii. Definição dos pesos associados aos critérios e grupos de critérios; iii. Identificação e calibração das funções fuzzy através dos pontos críticos para aplicar aos critérios.

\subsection{Identificação dos Critérios de Decisão}

A identificação dos critérios e grupos de critérios relevantes para a priorização de seções desenvolveu-se em duas etapas:

- Revisão bibliográfica: com base na literatura consultada sobre critérios de decisão em gerência de pavimentos (apresentada nos Capítulos 2 e 3) e de acordo com o tipo de problema, estruturou-se uma lista preliminar de critérios de decisão, que serviu de base para a etapa seguinte (elaboração do questionário destinado aos responsáveis por serviços de $M \& R$ de pavimento em prefeituras de cidades médias)

- Opinião de engenheiros responsáveis e especialistas: com o intuito de traduzir o ponto de vista dos especialistas para o modelo de priorização, foi realizada uma pesquisa, na forma de questionário. A pesquisa serviu de base para a definição da lista de critérios efetivamente relevantes para o processo de decisão. Aproveitando-se da elaboração e envio dos questionários, a pesquisa foi além da necessidade de definir os critérios, tendo um enfoque mais amplo, possibilitando uma análise estatística em relação aos procedimentos de conservação de pavimentos utilizados atualmente no Brasil, conforme foi especificada no Capítulo2, Seção 2.4.

Durante a revisão bibliográfica percebeu-se a diversidade de critérios que são considerados pelos órgãos responsáveis para a manutenção de pavimentos em relação à seleção de projetos de manutenção. Entretanto, não há um consenso com relação à relevância ou o grau de importância dos critérios e parâmetros considerados nos processos de decisão. Cada país, estado e órgão responsável (estadual ou municipal) determina os parâmetros que farão parte da formulação matemática ou método adotado para priorizar as seções de pavimentos. Essa escolha é realizada de acordo com a realidade de cada local e, quase sempre, orientada pelos métodos utilizados pelo HDM, programa de gerência de pavimentos desenvolvido pelo Banco Mundial e considerado como exemplo no mundo inteiro. Portanto, com base na revisão bibliográfica, foi produzida uma lista extensa de critérios de priorização, que serviu de base para a elaboração de um questionário.

Considerando essas observações, realizou-se uma pesquisa junto às prefeituras de cidades médias brasileiras, de março a junho de 2005. Os questionários foram enviados pelo 
correio. A opção por aplicação de questionários indiretos (sem iteração, via postal) foi em razão da abrangência da amostra, de grande dimensão. Para este estudo era inviável a opção de reunir especialistas em um painel, numa base de diálogo direto.

De posse das respostas e opiniões obtidas de profissionais responsáveis por obras e serviços relacionados com os pavimentos urbanos, definiu-se uma lista mais reduzida de critérios efetivamente relevantes e, igualmente, os agrupamentos pertinentes aos mesmos (ANEXO B).

Deve-se enfatizar que os critérios considerados devem ser passíveis de avaliação, tanto do ponto de vista da disponibilidade de dados quanto do ponto de vista do esforço de aquisição dos mesmos. Na próxima seção deste capítulo são descritos os procedimentos de avaliação dos conjuntos de critérios para a priorização de seções de pavimentos, os quais permitiram a obtenção de pesos para os mesmos.

\subsection{Definição dos Pesos e das Funções Fuzzy Associadas aos Critérios}

Para a definição dos pesos, adotou-se o método de comparação par a par, através do Processo Analítico Hierárquico. Foram desenvolvidas matrizes de comparação par a par, utilizando a escala de nove níveis de Saaty.

As avaliações ocorreram em duas etapas de trabalho. A primeira etapa foi realizada por meio de planilhas eletrônicas desenvolvidas por COSTA (2003) e adaptadas para esta pesquisa. As planilhas foram enviadas a especialistas e profissionais convidados a participar do painel de avaliação. O painel de avaliadores contou com profissionais da área de transportes, entre professores doutores, mestres e alunos de pós-graduação, totalizando 20 avaliadores, dentre os quais, a metade participou da avaliação preenchendo as planilhas.

As planilhas continham não só as matrizes de comparação, como também todas as instruções e informações necessárias para o preenchimento das mesmas. Aos profissionais consultados foi solicitado que efetuassem uma comparação, par a par, de critérios ou grupo de critérios de decisão, definindo a importância relativa dos mesmos, para a priorização de seções candidatas às atividades de manutenção e reabilitação de pavimentos. Também foi possível a averiguação do Grau de Consistência dos julgamentos. Uma vez realizadas todas as comparações par a par, foram determinados os pesos finais, através da média aritmética dos pesos calculados a partir das avaliações individuais. 
A segunda etapa das avaliações foi relacionada aos critérios contínuos (localizações - distâncias) e, da mesma forma que a anterior, também foi realizada por meio de planilhas eletrônicas. Nesta etapa os especialistas tinham a opção de escolher uma entre duas opções de funções fuzzy de normalização (linear e sigmoidal), bem como de identificar os pontos de controle necessários para a calibração das curvas fuzzy, isto é, quantificar a área de abrangência num intervalo de 0 a 1000 metros (distância em metros) correspondente aos limites mínimo e máximo de relevância do critério. A estrutura hierárquica pré-definida, as matrizes de comparação par a par, bem como a planilha de definição das funções avaliadas pelo painel de especialistas, são apresentadas no ANEXO C deste documento.

A seguir são apresentados os pesos dos critérios (fatores) e as funções fuzzy para os critérios contínuos adotadas com base nas avaliações dos especialistas. Os fatores foram reunidos em 4 grandes grupos, no nível mais elevado da estrutura de avaliação hierárquica: Hierarquia Viária, Questões Técnicas e Operacionais, Localização de Seções de Pavimentos e Custos.

\subsubsection{Fatores Associados à Hierarquia Viária}

Os fatores associados à hierarquia viária foram divididos em três categorias: Classe Funcional, Tipo de Rota e Volume de Tráfego. Tais fatores são, quase sempre, caracterizados por valores lingüísticos, ou subjetivos, que expressam uma classificação em relação à importância da estrada em termos de quantidade e tipo de veículos que trafegam na via.

A Classe Funcional expressa os níveis hierárquicos das estradas, como, por exemplo: Via Arterial: nível mais elevado, com fluxo rápido de veículos, podendo ser um anel viário ou grandes avenidas que conduzem o tráfego de um lugar para outro mais distante; Via Coletora: nível médio de veículos que coletam o tráfego das vias locais para regiões centrais ou para vias arteriais; Via Local: nível mais baixo, com fluxo mais lento de veículos, concentrando-se em bairros mais afastados dos grandes centros.

A forma de considerar a classe funcional no modelo de priorização é mediante a atribuição de scores aos diferentes níveis de classificação funcional das vias, dentro da escala normalizada adotada. Numa situação típica para cidades médias brasileiras, a cada classe funcional, como no exemplo anterior, é atribuído um valor, conferindo maior prioridade de M\&R às vias arteriais (por exemplo, 90\% do score máximo), passando por valores 
intermediários para vias coletoras $(75 \%$ do score máximo, por exemplo) e naturalmente, conferindo menor prioridade de M\&R para as vias locais ( $30 \%$ do score máximo).

Do mesmo modo, o fator Tipo de Rota também é expresso em valores lingüísticos, como por exemplo, rotas de ônibus ou simplesmente rota de automóveis de passeio (rotas normais). A cada classe da via, quanto ao tipo de rota, importa atribuir um valor, sempre dentro da escala adotada, que pode variar de 100\% do score máximo (para rotas de ônibus, por exemplo), passando por valores intermediários até chegar às rotas normais (como $30 \%$ do score máximo, por exemplo).

Por outro lado, o fator Volume de Tráfego pode ser expresso tanto em valores numéricos (por exemplo, volume diário médio - VDM) como em valores lingüísticos (por exemplo, Tráfego Leve, Tráfego Médio, Tráfego Pesado). Se for expresso em valores numéricos (contínuos), esses valores podem ser normalizados a partir de funções fuzzy. Entretanto, se os valores forem lingüísticos, como no exemplo anterior, interessa atribuir scores, dentro da escala adotada, a cada classe de volume de tráfego. Dessa forma, pode-se adotar, por exemplo, $90 \%$ do score máximo para vias com Tráfego Pesado, considerando menores valores para vias com Tráfego Médio (60\% do score máximo, por exemplo) e para as vias de Tráfego Leve (por exemplo, 30\% do score máximo). Portanto, dá-se maior prioridade de $M \& R$ às vias com maior volume de tráfego.

Na Tabela 5.1 são apresentados os resultados da avaliação dos especialistas em relação ao grupo de fatores que representam a hierarquia viária. Observa-se que o Volume de Tráfego é o fator de maior relevância, assumindo aproximadamente o dobro do peso em relação aos outros fatores.

Tabela 5.1:Pesos dos fatores associados à hierarquia viária

\begin{tabular}{lc}
\hline \multicolumn{1}{c}{ Fatores } & Pesos \\
\hline Classe Funcional & 0.286 \\
Tipo de Rota & 0.214 \\
Volume de Tráfego & 0.500 \\
\hline
\end{tabular}

\subsubsection{Fatores Associados às Questões Técnicas e Operacionais}

Os fatores associados às questões técnicas e operacionais estão divididos em três categorias: Questões Ambientais, Segurança e Necessidade Técnica por Intervenção. Este conjunto de fatores avalia medidas que estão relacionadas diretamente com a condição do pavimento. As questões ambientais são medidas através de índices de poluição do ar e ruído devido ao tráfego de veículos para determinada condição do pavimento. A segurança envolve 
o risco de acidentes devido à falta de aderência entre pneu e a superfície do pavimento, relacionada com a degradação da superfície do pavimento e com a condição de drenagem. Já o fator Necessidade Técnica por Intervenção avalia medidas que identificam diretamente o estado do pavimento e a necessidade de manutenção, incluindo os seguintes atributos:

- Índice Combinado de Defeitos: agrega as informações sobre severidade e extensão referentes a cada tipo de deterioração do pavimento, coletadas objetivamente em campo;

- Índice de Condição do Pavimento: relacionado com julgamentos subjetivos, de avaliadores em campo, do estado do pavimento;

- Idade: diz respeito à idade desde a última intervenção registrada em inventário.

A Tabela 5.2 ilustra o resultado da avaliação dos especialistas em relação aos atributos de Necessidade Técnica por Intervenção. Para compor o Índice Combinado de Defeitos adotou-se o método proposto por LEE e PARK (1997) e utilizado por BANDARA e GUNARATNE (2001) para priorização de pavimentos (Equação 3.4, item 3.1.4.1). É um método que agrega a importância relativa de cada tipo de defeito aos valores normalizados de severidade e extensão.

Tabela 5.2: Pesos e funções fuzzy dos atributos de necessidade técnica por intervenção

\begin{tabular}{|c|c|c|c|c|}
\hline Fatores & Pesos & $\begin{array}{c}\text { Função } \\
\text { Fuzzy }\end{array}$ & $\begin{array}{c}\text { Ponto } \\
\text { a }\end{array}$ & $\begin{array}{c}\text { Ponto } \\
\text { b }\end{array}$ \\
\hline Índice Combinado de Defeitos & 0.470 & & - & - \\
\hline Índice da Condição do Pavimento & 0.328 & Sigmoidal & $*$ & $*$ \\
\hline Idade do Pavimento & 0.201 & Sigmoidal & $*$ & $*$ \\
\hline \multicolumn{5}{|c|}{$\begin{array}{l}\text { * Valor que depende da variável utilizada no processo de fuzzification. } \\
\text { Geralmente utiliza-se o } z \text {-score, com os pontos de controle da curva fuzzy iguais a } \pm n \text {, sendo } n \text { o número de } \\
\text { desvios padrão acima ou abaixo da média. }\end{array}$} \\
\hline
\end{tabular}

Cada tipo de defeito está associado à sua extensão, dada em uma escala de 0 a $100 \%$ e a três níveis de severidade, medida subjetivamente: baixa, média e alta. A severidade é caracterizada por valores lingüísticos que são considerados no modelo de priorização, atribuindo-se scores aos diferentes níveis de severidade, dentro da escala normalizada adotada. Os scores conferem maior prioridade de $M \& R$ às seções que apresentam defeitos com severidade alta (por exemplo, $100 \%$ do score máximo), passando por valores intermediários para severidade média (60\% do score máximo, por exemplo) e, naturalmente, conferindo menor prioridade de M\&R para as seções que apresentam defeitos com severidade baixa (por exemplo, 20\% do score máximo). 
Para a determinação do índice combinado de defeitos foi necessário que os especialistas também avaliassem a importância relativa de cada tipo de defeito na priorização de seções candidatas às atividades de $M \& R$ de pavimentos, conforme o Manual de Identificação de Defeitos dos Pavimentos do Strategic Highway Research Program (SHRP, 1993). Os resultados estão especificados na Tabela 5.3.

Os resultados da avaliação par a par dos diferentes tipos de defeitos foi dentro do esperado, sendo que maior importância foi dada ao defeito Panelas, tendo aproximadamente o dobro do peso dos defeitos Deformação Permanente e Trincas por Fadiga, os quais, por sua vez, têm aproximadamente o dobro do peso dos defeitos restantes. Dentro do grupo restante, o defeito que levou a maior importância foi o Desgaste.

Tabela 5.3: Pesos dos tipos de defeitos

\begin{tabular}{lc}
\hline \multicolumn{1}{c}{ Defeitos } & Pesos \\
\hline Trincas por Fadiga & 0.134 \\
Trincas em Blocos & 0.036 \\
Defeito nos Bordos & 0.031 \\
Trincas Longitudinais & 0.040 \\
Trincas por Reflexão & 0.053 \\
Trincas Transversais & 0.044 \\
Remendos & 0.049 \\
Panelas & 0.211 \\
Deformação Permanente & 0.146 \\
Corrugação & 0.049 \\
Exudação & 0.027 \\
Agregados Polidos & 0.023 \\
Desgaste & 0.059 \\
Desnível (entre pista e acostamento) & 0.048 \\
Bombeamento & 0.050 \\
\hline
\end{tabular}

A grande importância dada ao defeito panela se justifica pelo fato do avaliador considerar mais prioritárias as seções candidatas às atividades de manutenção corretiva, que é o caso da atividade de tapa buraco. As panelas devem ser imediatamente reparadas, pois comprometem a segurança, o conforto e aumentam os custos dos usuários. Além disso, se não tratadas com certa urgência, permitem a entrada de água, enfraquecendo a estrutura e acelerando a deterioração.

Os defeitos Trincas por Fadiga e Deformação Permanente se devem a problemas estruturais, que se agravam com o tráfego repetido de veículos e se não tratados podem comprometer as camadas inferiores do pavimento. 
O Desgaste é um Defeito que pode ser reparado com atividades de manutenção (capa selante, tratamento superficial ou lama asfáltica) e que, se tratado nos estágios iniciais, não necessita de maiores gastos com atividades de reabilitação, motivos pelos quais tem uma importância diferenciada para os avaliadores em relação ao restante dos defeitos.

A Tabela 5.4 mostra os resultados da avaliação da importância relativa dos fatores associados às Questões Técnicas e Operacionais realizada pelos especialistas, sempre através da matriz de comparação par a par. Pode-se notar que, pela opinião dos avaliadores, o fator Segurança foi considerado o mais relevante, mesmo em relação ao fator Necessidade Técnica por Intervenção, que é um dos critérios mais considerados nos modelos de priorização existentes, pois envolve medidas da condição do pavimento. Isto se deve ao fato da Segurança, para este modelo, ser caracterizada pela variação dos índices de acidentes registrados num determinado período de análise, devido à perda de aderência entre pneu e superfície do pavimento, provocada pela existência de defeitos ou devido às más condições da drenagem. $\mathrm{O}$ avaliador considera que manter a integridade do usuário, reduzindo os índices de acidentes, é o mais importante. Por outro lado, as Questões Ambientais, que são caracterizadas pelos índices de poluição do ar e índices de ruídos devido ao tráfego de veículos, foi considerado o menos importante para o processo de priorização de seções candidatas às atividades de M\&R dos pavimentos.

Tabela 5.4: Pesos e funções fuzzy dos fatores associados às questões técnicas e operacionais

\begin{tabular}{lcccc}
\hline \multicolumn{1}{c}{ Fatores } & Pesos & Função & Ponto & Ponto \\
& & Fuzzy & a & b \\
\hline Necessidade Técnica por Intervenção & 0.343 & - & - & - \\
Questões Ambientais & 0.127 & Sigmoidal & $*$ & $*$ \\
Segurança & 0.529 & Sigmoidal & $*$ & $*$ \\
\hline
\end{tabular}

- Fator determinado pelos scores normalizados dos atributos.

* Valor que depende da variável utilizada no processo de fuzzification.

Geralmente utiliza-se o $z$-score, com os pontos de controle da curva fuzzy iguais a $\pm n$, sendo $n$ o número de desvios padrão acima ou abaixo da média.

\subsubsection{Fatores Associados à Localização das Seções de Pavimento.}

O conjunto de fatores associados à localização das seções considera questões que não estão diretamente relacionadas às condições dos pavimentos, mas que participam do processo de decisão. Este conjunto de fatores valoriza as seções próximas a locais estratégicos e que por vezes apresentam-se em condições ruins de tráfego, prejudicando o acesso a essas localidades. Portanto, este conjunto de fatores participa do modelo de priorização e está 
dividido em três categorias: Proximidade a Infra-estruturas de Transportes; Proximidade a Equipamentos e Prédios Institucionais; Preferências Pessoais e Administrativas. Todos estes fatores são caracterizados por medidas de distâncias das seções até os atributos em questão.

Conforme a Tabela 5.5, o fator proximidade a infra-estrutura de transportes inclui a avaliação de seções próximas a terminal rodoviário, terminal ferroviário, portos e aeroportos e próximas a rodovias. É importante lembrar que os pontos de controle das funções fuzzy, dos critérios que envolvem distâncias, foram definidos pelo painel de avaliadores, que decidiram pela distância máxima de relevância do critério (Tabela 5.5, limite mínimo: "ponto a" e limite máximo: "ponto b"), para uma área de abrangência pré-definida, conforme comentado no início desta seção. Para o "ponto a" foram adotados valores nulos, ou seja, a curva sigmoidal parte do eixo $y$, com valor de " $\mathrm{x}_{\mathrm{a}}$ " igual a zero. Os valores estabelecidos para os limites máximos (ponto b) foram relativamente pequenos, considerando que os avaliadores tinham um intervalo de valores 0 a $1000 \mathrm{~m}$ para serem adotados. À medida que se afasta do local considerado (terminal rodoviário, escolas, hospitais, etc), a condição do pavimento da via já não interfere mais no uso desses equipamentos e, pode sim, atrapalhar quando o pavimento estiver deteriorado em seções muito próximas, como por exemplo, em frente a uma escola, causando congestionamento e prejudicando o acesso ao local em questão.

Tabela 5.5: Pesos e funções fuzzy dos atributos associados à proximidade a Infra-estrutura de Transportes

\begin{tabular}{lcccc}
\hline \multicolumn{1}{c}{ Fatores } & Pesos & $\begin{array}{c}\text { Função } \\
\text { Fuzzy }\end{array}$ & $\begin{array}{c}\text { Ponto } \\
\text { a(m) }\end{array}$ & $\begin{array}{c}\text { Ponto } \\
\text { b(m) }\end{array}$ \\
\hline Proximidade a terminal rodoviário & 0.346 & Sigmoidal & - & 300 \\
Proximidade a terminal ferroviário & 0.149 & Sigmoidal & - & 329 \\
Proximidade a portos e aeroportos & 0.205 & Sigmoidal & - & 329 \\
Proximidade a rodovias & 0.300 & Sigmoidal & - & 414 \\
\hline
\end{tabular}

A Tabela 5.6 contém os pesos dados aos atributos associados à proximidade a Equipamentos e Prédios Institucionais. Tais atributos incluem a avaliação de seções próximas a escolas (considerando as instituições de educação infantil, ensino básico, ensino fundamental e ensino médio, públicas e privadas), universidades (públicas e privadas), hospitais, postos de saúde, centros administrativos (prefeitura municipal, secretarias, câmara municipal, fórum, etc.), corpo de bombeiros e instalações militares (policia civil e militar). As seções próximas a hospitais têm maior prioridade de manutenção, segundo a opinião dos avaliadores. Como justificativa têm-se que as vias próximas aos hospitais atendem um 
elevado tráfego de ambulâncias e veículos de pacientes e necessitam ser mantidas em boas condições.

Tabela 5.6: Pesos e funções fuzzy dos atributos associados à proximidade a equipamentos e prédios institucionais

\begin{tabular}{lcccc}
\hline \multicolumn{1}{c}{ Fatores } & Pesos & $\begin{array}{c}\text { Função } \\
\text { Fuzzy }\end{array}$ & $\begin{array}{c}\text { Ponto } \\
\text { a(m) }\end{array}$ & $\begin{array}{c}\text { Ponto } \\
\text { b(m) }\end{array}$ \\
\hline Proximidade a escolas & 0.101 & Sigmoidal & - & 386 \\
Proximidade a universidades & 0.113 & Sigmoidal & - & 314 \\
Proximidade a hospitais & 0.237 & Sigmoidal & - & 486 \\
Proximidade a postos de saúde & 0.183 & Sigmoidal & - & 429 \\
Proximidade a centros administrativos & 0.082 & Sigmoidal & - & 300 \\
Proximidade a corpo de bombeiros & 0.185 & Sigmoidal & - & 414 \\
Proximidade a instalações militares & 0.099 & Sigmoidal & - & 271 \\
\hline
\end{tabular}

O Fator Preferências Pessoais e Administrativas também é composto por atributos de proximidades. A Tabela 5.7 contém o resultado da avaliação da importância relativa dos atributos, incluindo a avaliação de seções próximas a centros comerciais, bairros com particular qualidade de vida (as seções são priorizadas de acordo com a qualidade de vida do bairro a que ela pertence), áreas de lazer, esporte e cultura (ginásios de esportes, clubes e praças de recreação, bibliotecas e teatros), áreas industriais e áreas turísticas.

Tabela 5.7: Pesos e funções fuzzy dos atributos associados à preferências pessoais e administrativas

\begin{tabular}{lcccc}
\hline \multicolumn{1}{c}{ Fatores } & Pesos & $\begin{array}{c}\text { Função } \\
\text { Fuzzy }\end{array}$ & $\begin{array}{c}\text { Ponto } \\
\text { a(m) }\end{array}$ & $\begin{array}{c}\text { Ponto } \\
\text { b (m) }\end{array}$ \\
\hline Proximidade a centros comerciais & 0.334 & Sigmoidal & - & 414 \\
Proximidade a áreas de lazer e esporte & 0.110 & Sigmoidal & - & 386 \\
Proximidade a áreas industriais & 0.234 & Sigmoidal & - & 257 \\
Proximidade a áreas turísticas & 0.181 & Sigmoidal & - & 329 \\
Proximidade a bairros com particular & 0.141 & Sigmoidal & $*$ & $*$ \\
qualidade de vida & & & & \\
* Valor que depende da variável utilizada no processo de fuzzification. \\
$\begin{array}{l}\text { Geralmente utiliza-se o } z \text {-score, com os pontos de controle da curva fuzzy iguais a } \pm n \text {, sendo } n \text { o número de } \\
\text { desvios padrão acima ou abaixo da média. }\end{array}$
\end{tabular}

A Tabela 5.8 contém o resultado da avaliação de importância relativa dos fatores associados à Localização de Seções de Pavimento, realizada pelos especialistas, através da matriz de comparação par a par. A proximidade a infra-estrutura de transportes foi o fator considerado mais relevante na opinião dos avaliadores para o processo de decisão. 
Tabela 5.8: Pesos dos fatores associados à localização de seções de pavimento

\begin{tabular}{ll}
\hline \multicolumn{1}{c}{ Fatores } & Pesos \\
\hline Proximidade a infra-estrutura de transportes & 0.425 \\
Proximidade a equipamentos e prédios institucionais. & 0.304 \\
Preferências pessoais e administrativas & 0.271 \\
\hline
\end{tabular}

\subsubsection{Fatores Associados aos Custos}

Os fatores associados aos custos estão divididos em Custos dos Usuários e Custos da Administração, todos caracterizados por valores monetários. Entretanto, o custo dos usuários inclui três atributos: custo de operação de veículos, custo do tempo de viagem e o custo de acidentes. O custo da administração é dado pelos custos de manutenção e reabilitação dos pavimentos. Conforme a Tabela 5.9, os resultados da avaliação da importância relativa de cada indicador que compõe o custo dos usuários mostra que o custo de acidentes foi considerado o mais relevante na opinião dos avaliadores.

Tabela 5.9: Pesos e funções fuzzy dos atributos associados aos custos de usuários

\begin{tabular}{lcccc}
\hline \multicolumn{1}{c}{ Fatores } & Pesos & Função & Ponto & Ponto \\
& & Fuzzy & a & b \\
\hline Custos de operação de veículos & 0.246 & Sigmoidal & $*$ & $*$ \\
Custos do tempo de viagem & 0.183 & Sigmoidal & $*$ & $*$ \\
Custos de acidentes & 0.571 & Sigmoidal & $*$ & $*$ \\
\hline * Valor que depende da variável utilizada no processo de fuzzification. \\
$\begin{array}{l}\text { Geralmente utiliza-se o } z \text {-score, com os pontos de controle da curva fuzzy iguais a } \pm n \text {, sendo } n \text { o número de } \\
\text { desvios padrão acima ou abaixo da média. }\end{array}$
\end{tabular}

Os resultados da avaliação da importância relativa dos Fatores Associados aos Custos são apresentados na Tabela 5.10. Nesse caso, os avaliadores consideraram quase o mesmo grau de importância em relação aos custos de usuários e aos custos de administração para a priorização de seções de pavimentos.

Tabela 5.10: Pesos e funções fuzzy dos fatores associados aos custos

\begin{tabular}{lcccc}
\hline \multicolumn{1}{c}{ Fatores } & Pesos & Função Fuzzy & Ponto a & Ponto b \\
\hline Custos de usuários & 0.508 & - & - & - \\
Custos de administração & 0.492 & Sigmoidal & $*$ & $*$ \\
\hline - Fator determinado pelos scores normalizados dos atributos. & & & \\
$*$ Valor que depende da variável utilizada no processo de fuzzification. \\
$\begin{array}{l}\text { Geralmente utiliza-se o } z \text {-score, com os pontos de controle da curva fuzzy iguais a } \pm n \text {, sendo } n \text { o número de } \\
\text { desvios padrão acima ou abaixo da média. }\end{array}$
\end{tabular}


Finalmente, a Tabela 5.11 contém os pesos atribuídos aos Grupos de Fatores de priorização de seções de pavimentos. De acordo com a opinião dos avaliadores, a maior relevância para o processo de decisão é dada ao grupo dos fatores associados às Questões Técnicas e Operacionais, valorizando, portanto, os modelos existentes de priorização para o gerenciamento da conservação de pavimentos. O grupo dos fatores associados aos custos e à hierarquia viária também tem pesos importantes no processo de decisão, ficando o grupo dos fatores associados à localização com a menor importância relativa atribuída pelos avaliadores.

Tabela 5.11: Pesos dos grupos de fatores de priorização de seções de pavimentos

\begin{tabular}{lc}
\hline \multicolumn{1}{c}{ Fatores } & Pesos \\
\hline Fatores associados à Hierarquia Viária & 0.223 \\
Fatores associados às Questões Técnicas e Operacionais & 0.378 \\
Fatores associados à Localização das Seções de Pavimento & 0.128 \\
Fatores associados aos Custos & 0.271 \\
\hline
\end{tabular}

\subsection{Estrutura do Processo de Decisão}

O modelo, que permite desenvolver índices de prioridades para cada seção de via de cidades médias brasileiras, é dado a partir de uma estrutura hierárquica de decisão. Nesse processo, os critérios são agrupados partindo do nível mais baixo até se chegar ao nível mais elevado da estrutura, ou seja, ao objetivo/propósito do modelo de decisão. Para agregar os fatores do segundo e primeiro nível, além da combinação linear fazem-se, também, análises de risco com diferentes cenários de avaliação, recorrendo-se a novo procedimento WLC (Weighted Linear Combination) ou ao procedimento OWA (Ordered Weighted Average), abordados no Capítulo 4 e Seção 4.2, sendo que neste último procedimento os pesos são adotados arbitrariamente.

A Tabela 5.12 faz uma síntese do modelo proposto, com os agrupamentos de fatores desenvolvidos para compor todos os níveis da estrutura hierárquica de decisão multicritério, com os pesos dos grupos de fatores, fatores e atributos de acordo com a opinião dos especialistas consultados (conforme abordado na Seção 5.3). A Figura 5.3 representa a estrutura hierárquica que compõe o modelo de priorização de seções de pavimentos. Ainda, assim como as funções fuzzy de normalização, as importâncias relativas dos critérios envolvidos no processo podem ser atribuídas de acordo com a opinião dos decisores envolvidos no processo. O próximo capítulo é composto por um estudo de caso que permite dar continuidade e validade ao modelo. 


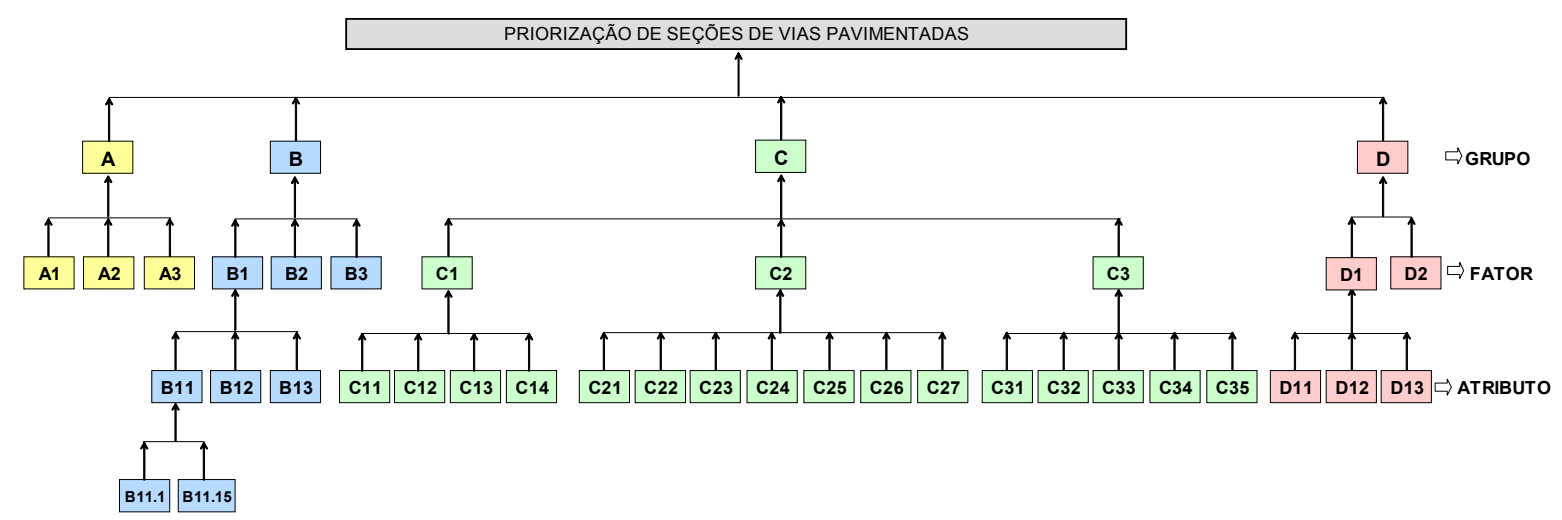

Figura 5.3: Estrutura hierárquica do modelo de priorização de seções de vias pavimentadas

Tabela 5.12: Modelo de priorização - Fatores e grupos de fatores

\begin{tabular}{|c|c|c|}
\hline Código & Fatores e Grupos de Fatores & Pesos \\
\hline A & Fatores associados à hierarquia viária & 0,223 \\
\hline$A 1$ & Classe funcional & 0,286 \\
\hline$A 2$ & Tipo de rota & 0,214 \\
\hline$A 3$ & Volume de tráfego & 0,500 \\
\hline $\bar{B}$ & Fatores associados às questões técnicas e operacionais & 0,378 \\
\hline B1 & Necessidade técnica por intervenção & 0,343 \\
\hline B1.1 & Índice combinado de defeitos & 0,470 \\
\hline B1.1.1 & Trincas por Fadiga & 0,134 \\
\hline B1.1.2 & Trincas em Blocos & 0,036 \\
\hline B1.1.3 & Defeito nos Bordos & 0,031 \\
\hline B1.1.4 & Trincas Longitudinais & 0,040 \\
\hline B1.1.5 & Trincas por Reflexão & 0,053 \\
\hline B1.1.6 & Trincas Transversais & 0,044 \\
\hline B1.1.7 & Remendos & 0,049 \\
\hline B1.1.8 & Panelas & 0,211 \\
\hline B1.1.9 & Deformação Permanente & 0,146 \\
\hline B1.1.10 & Corrugação & 0,049 \\
\hline B1.1.11 & Exudação & 0,027 \\
\hline B1.1.12 & Agregados Polidos & 0,023 \\
\hline B1.1.13 & Desgaste & 0,059 \\
\hline B1.1.14 & Desnível & 0,048 \\
\hline B1.1.15 & Bombeamento & 0,050 \\
\hline B1.2 & Índice da condição do pavimento & 0,328 \\
\hline B1.3 & Idade do pavimento & 0,202 \\
\hline$B 2$ & Questões Ambientais & 0,128 \\
\hline$B 3$ & Questões de Segurança & 0,529 \\
\hline$\overline{\mathrm{C}}$ & Fatores associados à localização das seções de pavimento & 0,128 \\
\hline$C 1$ & Proximidade a infra-estruturas de Transportes & 0,425 \\
\hline $\mathrm{C} 1.1$ & Proximidade a terminal rodoviário & 0,346 \\
\hline $\mathrm{C} 1.2$ & Proximidade a terminal ferroviário & 0,149 \\
\hline $\mathrm{C} 1.3$ & Proximidade a portos e aeroportos & 0,205 \\
\hline $\mathrm{C} 1.4$ & Proximidade a rodovias & 0,300 \\
\hline$C 2$ & Proximidade a equipamentos ou prédios institucionais & 0,304 \\
\hline $\mathrm{C} 2.1$ & Proximidade a escolas primárias e secundárias & 0,100 \\
\hline $\mathrm{C} 2.2$ & Proximidade a universidades & 0,113 \\
\hline $\mathrm{C} 2.3$ & Proximidade a postos de saúde & 0,183 \\
\hline $\mathrm{C} 2.4$ & Proximidade a hospitais & 0,237 \\
\hline $\mathrm{C} 2.5$ & Proximidade a centros administrativos & 0,082 \\
\hline $\mathrm{C} 2.6$ & Proximidade a corporação de bombeiros & 0,185 \\
\hline $\mathrm{C} 2.7$ & Proximidade a instalações militares & 0,099 \\
\hline$C 3$ & Preferências pessoais ou administrativas & 0,271 \\
\hline C3.1 & Proximidade a centros comerciais & 0,334 \\
\hline $\mathrm{C} 3.2$ & Proximidade a bairros com particular qualidade de vida & 0,141 \\
\hline $\mathrm{C} 3.3$ & Proximidade a áreas de lazer e esportes & 0,110 \\
\hline C3.4 & Proximidade a áreas turísticas & 0,234 \\
\hline $\mathrm{C} 3.5$ & Proximidade a áreas industriais & 0,181 \\
\hline $\begin{array}{l}\mathbf{D} \\
\end{array}$ & Fatores associados aos custos & $\mathbf{0 , 2 7 1}$ \\
\hline D1 & Custos dos Usuários & 0,508 \\
\hline D1.1 & Custo de operação de veículos & 0,246 \\
\hline D1.2 & Custo do tempo de viagem & 0,183 \\
\hline D1.3 & Custo de acidentes & 0,571 \\
\hline$D 2$ & Custos da Administração & 0,492 \\
\hline
\end{tabular}



manutenção e reabilitação de pavimentos 


\section{APLICAÇÃO DO MODELO DE PRIORIZAÇÃO: ESTUdO DE CASO PARA A CIDADE DE SÃO CARLOS}

O município de São Carlos está situado na região central do estado de São Paulo, Brasil, a $230 \mathrm{~km}$ da capital do estado. Possui uma área total de $1.132 \mathrm{~km}^{2}$, dos quais apenas $55 \mathrm{~km}^{2}$ correspondem à área urbana. A cidade de São Carlos pode ser considerada uma típica cidade média brasileira, com aproximadamente 200.000 habitantes, com forte atração agroindustrial e grande caráter tecnológico, com duas universidades públicas situadas na cidade. A cidade apresenta em torno de $4.000 .000 \mathrm{~m}^{2}$ de vias urbanas, organizadas ortogonalmente. A Figura 6.1 ilustra a localização da cidade de São Carlos no estado de São Paulo e as vias urbanas da cidade.

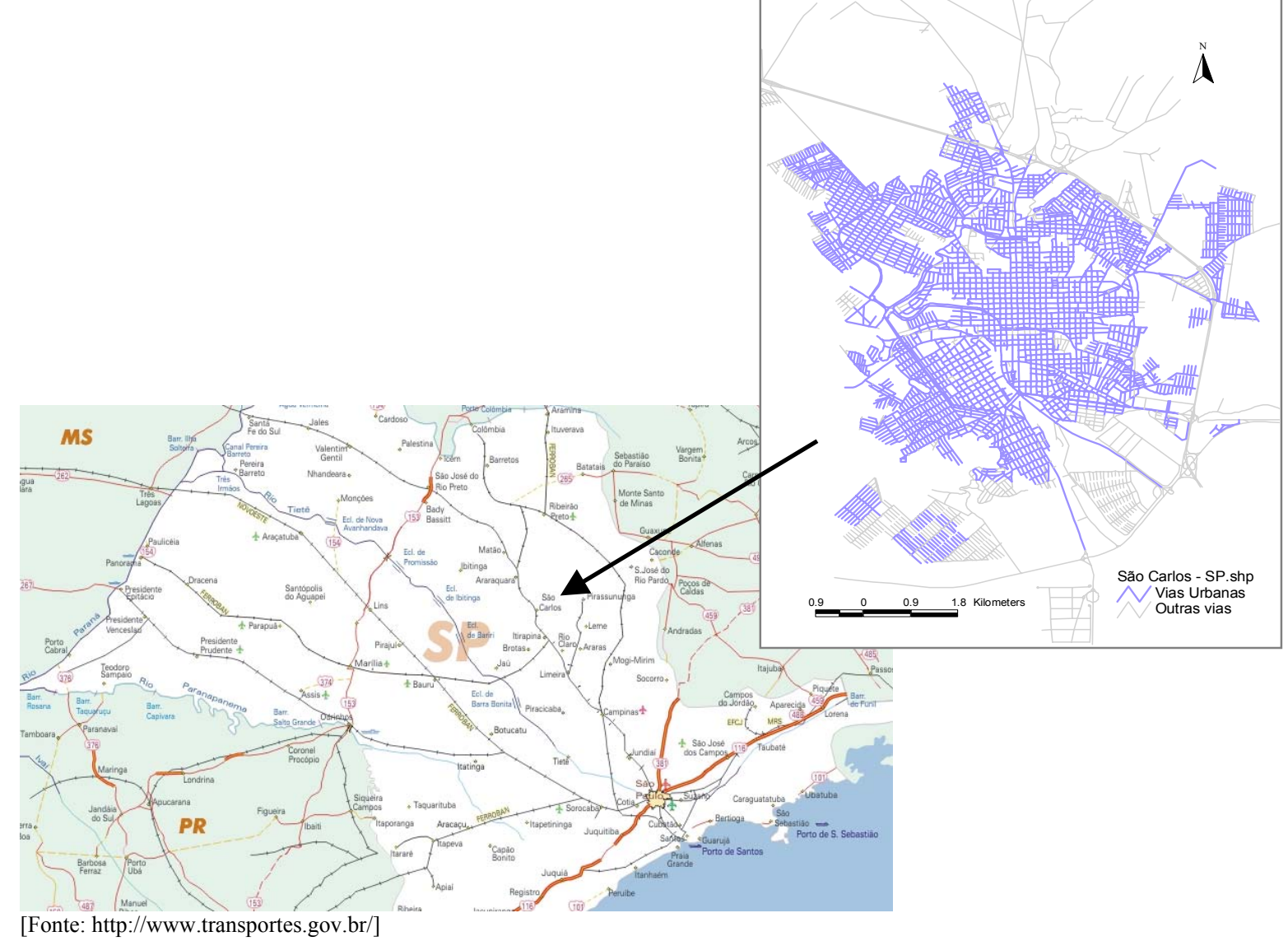

Figura 6.1: Localização da cidade de São Carlos- SP 
Realizou-se um estudo de caso, desenvolvido na cidade de São Carlos, mediante o desenvolvimento deste trabalho e, que tem por objetivo uma aplicação do modelo de priorização das seções de pavimentos das vias urbanas, facilitando o planejamento das atividades de manutenção e reabilitação a curto prazo.

A plataforma de trabalho adotada é o SIG (Sistema de Informação Geográfica) ArcView, utilizando o formato vetorial do programa computacional, dentro do qual agrega-se a metodologia de avaliação multicritério e são desenvolvidas todas as etapas de combinação de critérios e análises dos diversos cenários de decisão do modelo proposto.

\subsection{Coleta Preliminar de dados e informações}

Coletar os dados significa armazenar toda a informação existente em relação às vias urbanas, que são de responsabilidade da Prefeitura Municipal de São Carlos e, que se fizeram necessárias para o desenvolvimento do trabalho. O segundo passo consistiu em organizar e vincular toda a informação coletada aos mapas georeferenciados de modo consistente, dentro da plataforma SIG. Entre as informações coletadas para este trabalho estão:

- Resultados de um levantamento de campo, contendo informações de inventário das vias urbanas e avaliação do pavimento;

- Base georeferenciada (linhas) do SAAE (Serviço Autônomo de Água e Esgoto de São Carlos) contendo os eixos das vias urbanas;

- Base cartográfica e base georeferenciada (pontos) contendo a localização de equipamentos públicos, infra-estruturas de transportes e outras instalações especificas;

- Base georeferenciada (linhas) com a divisão espacial da cidade em setores censitários do IBGE, contendo informações sobre a qualidade de vida em cada setor.

\subsubsection{Levantamento de campo sobre as vias urbanas da cidade de São Carlos}

Esta subseção apresenta uma síntese dos procedimentos adotados e os resultados do levantamento de campo realizado junto às vias urbanas da cidade de São Carlos, durante o ano de 2003. O levantamento de campo contou com o desenvolvimento de inventário sobre características físicas e geométricas de ruas e com a avaliação do pavimento de toda a rede da cidade. Este levantamento fez parte de um projeto de implementação de um sistema de gerência de pavimentos urbanos sob a orientação do Professor Associado José Leomar Fernandes Júnior, também orientador deste trabalho e que teve o apoio da Prefeitura 
Municipal de São Carlos. Ainda, contou-se com a participação de uma equipe de avaliadores, composta por alunos de mestrado e de doutorado do Departamento de Transportes da EESCUSP (Escola de Engenharia de São Carlos - Universidade de São Paulo).

As informações de inventário e da avaliação do pavimento foram utilizadas para a aplicação do método de priorização de pavimentos proposto neste trabalho. O levantamento em campo foi o mais preciso possível, considerando a condição dos pavimentos e os serviços e equipamentos a eles relacionados, no que se refere às seções de vias urbanas que são de responsabilidade da prefeitura de São Carlos.

Uma base de dados digitalizada do mapa da cidade foi fornecida pela Prefeitura Municipal. Foram selecionados os campos de interesse para o Sistema de Gerência de Pavimentos (ruas, quadras, setores fiscais, divisão de loteamentos, limites da cidade), os quais serviram de base para os levantamentos de campo. Os dados coletados em campo foram transferidos e organizados de modo georeferenciado em um SIG-T (Sistema de Informações Geográficas para Transportes).

Os dados de inventário foram coletados conforme a Figura 6.2, na qual cada planilha representava uma seção da rede, que é identificada pelo seu ID (número identificador do SIG), consistindo das seguintes informações: nome do logradouro, logradouro de início e de fim de cada seção, números do setor e da quadra no cadastro imobiliário do município, classe funcional, tipo de pavimento, tipo de estrutura do pavimento, largura e extensão da seção, ano da construção do pavimento, tipo e ano da última atividade de manutenção e reabilitação (M\&R), capacidade de suporte do subleito e ainda informações sobre o tráfego (número de faixas de tráfego, sentido do tráfego, volume de tráfego, volume de caminhões, taxa de crescimento do tráfego e tipo de rotas especiais).

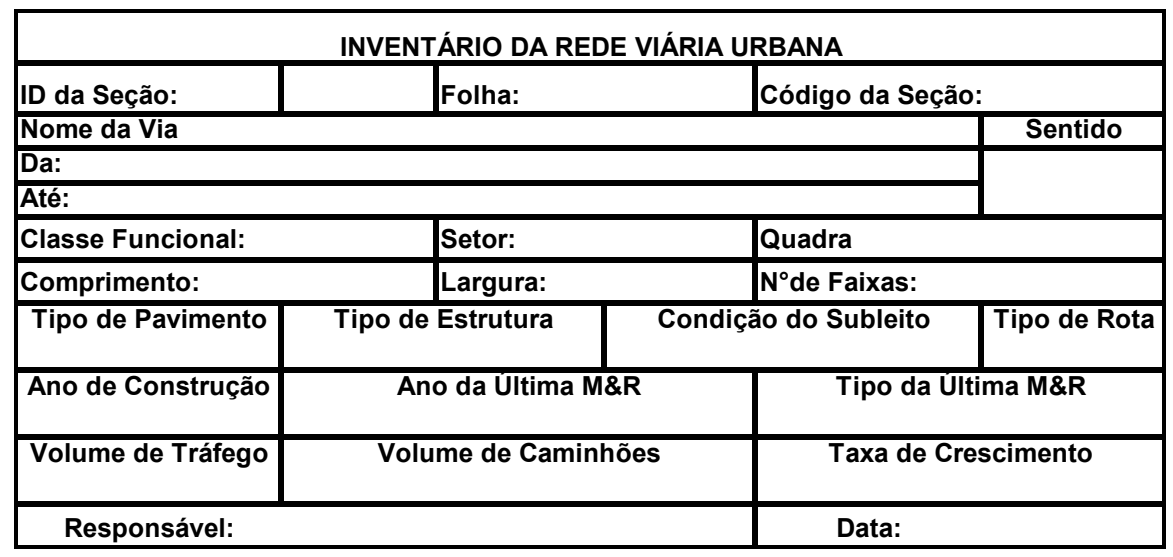

Figura 6.2: Planilha para coleta de dados de inventário. 
A prefeitura do município de São Carlos não tinha a divisão das vias em classes funcionais. Portanto, as classes funcionais foram adotadas pelos avaliadores com base no conhecimento prévio das principais vias e na observação, no campo, do volume de tráfego, da porcentagem do tráfego de caminhões e da presença de rotas de ônibus, tendo sido classificadas em vias locais, vias coletoras e vias arteriais. Os comprimentos das seções foram obtidos do mapa digitalizado da cidade, mas as larguras foram medidas pelos avaliadores. A condição do subleito foi definida pela ocorrência ou não de defeitos associados à baixa capacidade de suporte do solo de fundação. Foram observados os pavimentos flexíveis (revestimento asfáltico), rígidos (revestimento de concreto de cimento Portland), de paralelepípedo (granito ou gnaisse) e blocos intertravados (concreto de cimento Portland). Entretanto, o modelo de priorização proposto neste trabalho considera somente as seções com pavimentos flexíveis.

Algumas informações do inventário foram obtidas dos arquivos da Secretaria de Obras, Transportes e Serviços Públicos da Prefeitura Municipal de São Carlos: tipo de estrutura, ano de construção, ano da última intervenção de $M \& R$, rotas de ônibus, volume de tráfego e taxa de crescimento do tráfego. Deve-se destacar que, para muitas seções, não estavam disponíveis o "ano de construção" e o "ano da última atividade de M\&R" do pavimento. E, para a grande maioria das seções, o volume de tráfego só pode ser considerado de forma qualitativa (leve, médio e pesado).

As informações do inventário comentadas anteriormente foram quase que totalmente utilizadas na aplicação do modelo de priorização, com exceção de alguns dados (ano da última intervenção, por exemplo) que, por serem difíceis de avaliar e não estarem disponíveis nos históricos da prefeitura, não foram considerados. Entretanto, as informações sobre a condição e o estado de degradação do pavimento foram aplicadas integralmente no processo de priorização de pavimentos.

A avaliação da condição do pavimento foi primeiramente realizada de forma subjetiva, utilizando o conceito de serventia desenvolvido durante o AASHO Road Test (CAREY E IRICK, 1960). Mediante inspeção visual, foi anotado em planilha o valor do Índice de Condição dos Pavimentos (ICP) em uma escala de 0 a 100. A equipe de avaliadores também analisou a aceitabilidade de cada seção e a estratégia de M\&R prevista para o próximo ano, assim como as práticas usualmente adotadas pela prefeitura municipal de São Carlos e pelas concessionárias de serviços públicos da cidade, principalmente as intervenções do SAAE (Serviço Autônomo de Água e Esgoto de São Carlos), na condição dos pavimentos. 
O ICP registrado em campo foi mais uma informação de grande relevância utilizada no modelo abordado neste trabalho.

Em uma segunda etapa do levantamento de campo sobre as vias urbanas da cidade de São Carlos foi realizado o estudo sobre os defeitos dos pavimentos. Este estudo teve como base o Manual de Identificação de Defeitos dos Pavimentos do Programa SHRP (SHRP, 1993). Contou com a observação dos tipos de defeitos de acordo com o grau de severidade (grau de deterioração), normalmente classificado em três níveis (alto, médio e baixo) e da extensão de cada defeito (porcentagem de superfície de rolamento sujeita a um determinado tipo de defeito).

A Figura 6.3 ilustra a planilha utilizada para as anotações de campo dos defeitos existentes (severidade e extensão), realizadas mediante caminhamento ou de dentro de veículo a baixa velocidade. Essas informações sobre defeitos foram utilizadas neste trabalho para quantificar a condição do pavimento através de um índice combinado de defeitos, conforme abordado no Capítulo 5 (subseção 5.3.2).

\begin{tabular}{|c|c|c|c|c|c|}
\hline \multicolumn{6}{|c|}{ QUANTIFICAÇÃO DOS DEFEITOS } \\
\hline TIPO & \multicolumn{3}{|c|}{ SEVERIDADE } & \multicolumn{2}{|c|}{ PONTOS DEDUTÍVEIS } \\
\hline DE DEFEITO & Baixa & Média & Alta & Intervalo & Avaliação \\
\hline $\begin{array}{l}1 \text { - Trincas por } \\
\text { Fadiga }\left(\mathrm{m}^{2}\right)\end{array}$ & & & & 0 a 15 & \\
\hline $\begin{array}{l}2 \text { - Trincas em } \\
\text { Blocos }\left(m^{2}\right)\end{array}$ & & & & 0 a 5 & \\
\hline $\begin{array}{l}3 \text { - Defeitos nos } \\
\text { Bordos }(m)\end{array}$ & & & & 0 a 5 & \\
\hline $\begin{array}{l}4 \text { - Trincas } \\
\text { Longitudinais }(\mathrm{m})\end{array}$ & & & & 0 a 5 & \\
\hline $\begin{array}{l}5 \text { - Trincas por } \\
\text { Reflexão }\left(\mathrm{m}^{2}\right)\end{array}$ & & & & 0 a 5 & \\
\hline $\begin{array}{l}\text { - Trincas } \\
\text { Transversais (m) } \\
\end{array}$ & & & & $N / C$ & \\
\hline 7 - Remendos $\left(m^{2}\right)$ & & & & 0 a 15 & \\
\hline 8 - Panelas $\left(\mathrm{m}^{2}\right)$ & & & & 0 a 10 & \\
\hline $\begin{array}{l}9 \text { - Deformação } \\
\text { Permanente }(\mathrm{m})\end{array}$ & & & & 0 a 15 & \\
\hline $\begin{array}{l}10 \text { - Corrugação } \\
\left(\mathrm{m}^{2}\right)\end{array}$ & & & & 0 a 5 & \\
\hline 11 - Exsudação $\left(\mathrm{m}^{2}\right)$ & & & & 0 a 5 & \\
\hline $\begin{array}{l}12 \text { - Agregados } \\
\text { Polidos }\left(\mathrm{m}^{2}\right) \\
\end{array}$ & & & & $\mathrm{N} / \mathrm{C}$ & \\
\hline 13 - Desgaste $\left(\mathrm{m}^{2}\right)$ & & & & 0 a 15 & \\
\hline $\begin{array}{l}14 \text { - Desnível Pista- } \\
\text { Acostamento (m) }\end{array}$ & & & & $\mathrm{N} / \mathrm{C}$ & \\
\hline $\begin{array}{l}15 \text { - Bombeamento } \\
\left(\mathrm{m}^{2}\right)\end{array}$ & & & & $\mathrm{N} / \mathrm{C}$ & \\
\hline \multicolumn{5}{|l|}{ OBSERVAÇÃO: } & $\Sigma=$ \\
\hline FOTO: & & & & & ICP = \\
\hline
\end{tabular}

Figura 6.3: Planilha para avaliação de defeitos no pavimento. 
Foram consideradas nas avaliações 7500 seções, perfazendo mais de $500 \mathrm{~km}$, o que corresponde ao total da malha viária urbana do município de São Carlos. Destas, 5828 seções são de pavimentos flexíveis e participaram da avaliação do pavimento. As seções avaliadas passaram por todo o processo de verificação de consistência posteriormente ao levantamento de campo, digitação para entrada de dados em planilha eletrônica e transferência dos dados para o SIG-T. Mais informações sobre os estudos e levantamentos de campo realizados nas vias urbanas da cidade de São Carlos podem ser encontradas em LIMA et al. (2004), FERNANDES JR. et al. (2004) e ZANCHETTA et al. (2004).

\subsubsection{Localização de equipamentos públicos, infra-estruturas de transportes e outras instalações especificas.}

A outra etapa do trabalho contou com a localização das seções próximas às infraestruturas de transportes, aos equipamentos públicos e prédios institucionais e às áreas com preferências administrativas ou pessoais de priorização.

Essas localizações foram realizadas, de acordo com a base cartográfica disponibilizada pela prefeitura municipal e uma base georeferenciada (Mendes et al., 2000), que continham as localizações necessárias, sendo as informações transferidas para o mapa dos eixos da via, no SIG - ArcView, conforme ilustrado no ANEXO D.

As seções próximas às estruturas de transportes, aos equipamentos públicos e às áreas com preferências administrativas ou pessoais foram identificadas através de rotinas existentes no SIG - ArcView (Network Analyst - Find Service Area), até a distância máxima de relevância atribuída pelos avaliadores (conforme abordado no Capítulo 5, seção 5.3), para cada instalação de prédio ou instituição.

No caso dos bairros com particular qualidade de vida, foi utilizada uma base georeferenciada com a divisão espacial da cidade em setores censitários do IBGE (Instituto Brasileiro de Geografia e Estatística), contendo informações sobre a qualidade de vida em cada setor. Desta forma, as seções são priorizadas de acordo com a qualidade de vida do bairro a que ela pertence. Para mais informações sobre as bases contendo informações de qualidade de vida e localização de equipamentos, consultar Mendes et al. (2000).' 


\subsection{Identificação dos fatores considerados no estudo de caso}

O objetivo da aplicação do modelo é realizar um estudo considerando as características peculiares da rede viária da cidade e traduzir, desse modo, as prioridades de manutenção e reabilitação dos pavimentos.

Poucos foram os critérios que não puderam ser considerados na aplicação do modelo com o estudo de caso realizado para a cidade de São Carlos. A Tabela 6.1 apresenta os fatores considerados no estudo de caso e os respectivos pesos e desvio padrão. Os pesos foram remodelados com base nos graus de importância atribuídos pelos avaliadores para os fatores em questão, sempre levando em conta o grau de consistência da avaliação. Portanto, não fizeram parte do estudo de caso os seguintes fatores:

- $3^{o}$ Nivel:

$>$ Fator do Grupo B: Idade desde a última intervenção

> Fator do Grupo C: Proximidade a Portos e Aeroportos

- $2^{o}$ Nivel:

Fator do Grupo B: Questões Ambientais

$>$ Fator do Grupo B: Questões de Segurança

$>$ Fator do Grupo D: Custos dos Usuários

Em relação aos fatores associados à localização, especialmente a proximidade a infra-estruturas de transportes, foram desconsideradas as seções próximas a portos e aeroportos, por não haver ocorrência em vias da rede urbana da cidade de São Carlos.

O fator segurança não pôde ser considerado por falta de informação e dados históricos sobre as taxas de acidentes nas vias da cidade. Da mesma forma, as questões ambientais não foram consideradas no estudo de caso devido à falta de dados confiáveis sobre os índices de poluição do ar e de ruído relacionados ao tráfego de veículos. As informações encontradas sobre acidentes, poluição do ar e ruídos são de pesquisas realizadas em regiões ou ruas específicas e, portanto, não sendo informações coletadas para toda a rede viária da cidade, não é viável sua aplicação.

Considerando as características peculiares dos pavimentos urbanos, os Sistemas de Gerência de Pavimentos Urbanos nem sempre utilizam os custos desenvolvidos sob condições de operação de veículos, entretanto eles completam as informações para análises mais complexas. Por outro lado, depara-se com a dificuldade de se determinar as componentes do custo dos usuários (operação de veículos, custo do tempo de viagem e custo de acidentes), o 
que se deve, principalmente, à indisponibilidade de dados confiáveis para as análises. Portanto, os custos dos usuários não foram considerados no estudo de caso.

Tabela 6.1: Fatores, pesos e desvio padrão considerados no estudo de caso

\begin{tabular}{|c|c|c|c|c|}
\hline & Código & Fatores & $\begin{array}{l}\text { Pesos } \\
\text { (média) }\end{array}$ & $\begin{array}{l}\text { Desvio } \\
\text { Padrão }\end{array}$ \\
\hline \multirow{4}{*}{$\underset{\bar{z}}{\bar{d}}$} & A & Fatores Associados à Hierarquia Viária & 0,223 & 0,123 \\
\hline & B & Fatores Associados às Questões Técnicas e Operacionais & 0,378 & 0,158 \\
\hline & $\mathrm{C}$ & Fatores Associados à Localização & 0,128 & 0,121 \\
\hline & $\mathrm{D}$ & Fatores Associados aos Custos & 0,271 & 0,184 \\
\hline \multirow{8}{*}{$\frac{2}{d z}$} & A1 & Classe Funcional & 0,286 & 0,245 \\
\hline & $\mathrm{A} 2$ & Tipo de Rota & 0,214 & 0,122 \\
\hline & $\mathrm{A} 3$ & Volume deTráfego & 0,500 & 0,263 \\
\hline & B1 & Índice Combinado de Defeitos & 0,592 & 0,219 \\
\hline & B2 & Índice da Condição do Pavimento & 0,408 & 0,219 \\
\hline & $\mathrm{C} 1$ & Proximidade a Infra-Estruturas de Transportes & 0,425 & 0,162 \\
\hline & $\mathrm{C} 2$ & Proximidade a equipamentos ou prédios institucionais & 0,304 & 0,106 \\
\hline & $\mathrm{C} 3$ & Preferências pessoais ou administrativas & 0,271 & 0,218 \\
\hline \multirow{30}{*}{$\frac{m}{0}$} & B1.1 & Trincas por Fadiga & 0,134 & 0,081 \\
\hline & B1.2 & Trincas em Blocos & 0,036 & 0,020 \\
\hline & B1.3 & Defeito nos Bordos & 0,031 & 0,019 \\
\hline & B1.4 & Trincas Longitudinais & 0,040 & 0,020 \\
\hline & B1.5 & Trincas por Reflexão & 0,053 & 0,039 \\
\hline & B1.6 & Trincas Transversais & 0,044 & 0,033 \\
\hline & B1.7 & Remendos & 0,049 & 0,037 \\
\hline & B1.8 & Panelas & 0,211 & 0,064 \\
\hline & B1.9 & Deformação Permanente & 0,146 & 0,051 \\
\hline & B1.10 & Corrugação & 0,049 & 0,037 \\
\hline & B1.11 & Exudação & 0,027 & 0,019 \\
\hline & B1.12 & Agregados Polidos & 0,023 & 0,008 \\
\hline & B1.13 & Desgaste & 0,059 & 0,048 \\
\hline & B1.14 & Desnível & 0,048 & 0,042 \\
\hline & B1.15 & Bombeamento & 0,050 & 0,045 \\
\hline & $\mathrm{C} 1.1$ & Proximidade a terminais rodoviários & 0,437 & 0,190 \\
\hline & $\mathrm{C} 1.2$ & Proximidade a terminais ferroviários & 0,195 & 0,156 \\
\hline & $\mathrm{C} 1.3$ & Proximidade a rodovias & 0,368 & 0,149 \\
\hline & $\mathrm{C} 2.1$ & Proximidade a escolas primárias e secundárias & 0,100 & 0,061 \\
\hline & $\mathrm{C} 2.2$ & Proximidade a universidades & 0,113 & 0,061 \\
\hline & $\mathrm{C} 2.3$ & Proximidade a postos de saúde & 0,183 & 0,062 \\
\hline & $\mathrm{C} 2.4$ & Proximidade a hospitais & 0,237 & 0,086 \\
\hline & $\mathrm{C} 2.5$ & Proximidade a centros administrativos & 0,082 & 0,070 \\
\hline & $\mathrm{C} 2.6$ & Proximidade a corporações de bombeiros & 0,185 & 0,075 \\
\hline & $\mathrm{C} 2.7$ & Proximidade a instalações militares & 0,100 & 0,070 \\
\hline & $\mathrm{C} 3.1$ & Proximidade a centros comerciais & 0,334 & 0,163 \\
\hline & $\mathrm{C} 3.2$ & Proximidade a bairros com particular qualidade de vida & 0,141 & 0,117 \\
\hline & $\mathrm{C} 3.4$ & Proximidade a áreas de lazer e esportes & 0,110 & 0,044 \\
\hline & $\mathrm{C} 3.5$ & Proximidade a áreas turísticas & 0,234 & 0,129 \\
\hline & $\mathrm{C} 3.6$ & Proximidade a áreas industriais & 0,181 & 0,100 \\
\hline
\end{tabular}

Como fator associado ao custo total considerou-se, no estudo de caso, somente uma componente dos custos de administração, ou seja, os custos das estratégias de M\&R para as 
áreas atingidas por um ou mais defeitos (KULKARNI et al., 2004). A cada estratégia de manutenção está associado um custo unitário por $\mathrm{m}^{2}$, que por sua vez está associado às especificações dos serviços e dos materiais a serem empregados. A Tabela 6.2 indica os custos unitários das estratégias de M\&R adotadas neste estudo.

Tabela 6.2: Custos unitários adotados para estratégias de M\&R de pavimentos

\begin{tabular}{lc}
\hline Estratégia de Manutenção e Reabilitação & $\begin{array}{c}\text { Custo unitário } \\
\left(\mathbf{R} \$ \mathbf{m}^{\mathbf{2}}\right)\end{array}$ \\
\hline Não Fazer Nada (NF) & 0,00 \\
Manutenção Corretiva (MC) & 2,00 \\
Manutenção Preventiva (MP) & 10,00 \\
Reforço (RF) & 25,00 \\
Reconstrução (RC) & 50,00 \\
\hline
\end{tabular}

\subsection{Aplicação da Metodologia em SIG-ArcView}

Seguindo as etapas de um processo de avaliação multicritério, primeiramente com a definição da importância relativa dos critérios através de pesos e depois com a normalização dos critérios através de funções fuzzy, a próxima etapa é a combinação dos critérios.

De acordo com o código apresentado na Tabela 6.1, pode-se observar como foi reorganizada a estruturada hierárquica apresentada na Figura 6.4. Todos os procedimentos de análise multicritério em ambiente SIG, foram desenvolvidos com base na Tabela 6.1 e Figura 6.4, portanto merecem um acompanhamento constante por parte do leitor.

No intuito de gerar um conjunto de cenários de avaliação de prioridades de $M \& R$ de pavimentos, as combinações WLC (Weighted Linear Combination) e OWA (Ordered Weighted Average) de fatores são realizadas de acordo com cada nível e agrupamento da estrutura. O procedimento OWA deve ser utilizado em agrupamentos em que os critérios justificam este tipo de análise, combinando um conjunto de critérios no qual pelo menos um possua uma interpretação um pouco distinta dos restantes, ou quando se pretende simular situações de risco no processo decisório (abordado no Capítulo 4 - subseção 4.2.4).

As análises foram realizadas sob um mapa georeferenciado em formato vetorial da rede viária da cidade. Inicialmente, realizou-se a normalização dos valores dos fatores com o auxílio de planilhas eletrônicas. A seguir são apresentados alguns exemplos do modo como se procedeu a normalização dos vários tipos de valores dos fatores envolvidos e também os resultados da combinação destes fatores depois de serem normalizados e ponderados. 


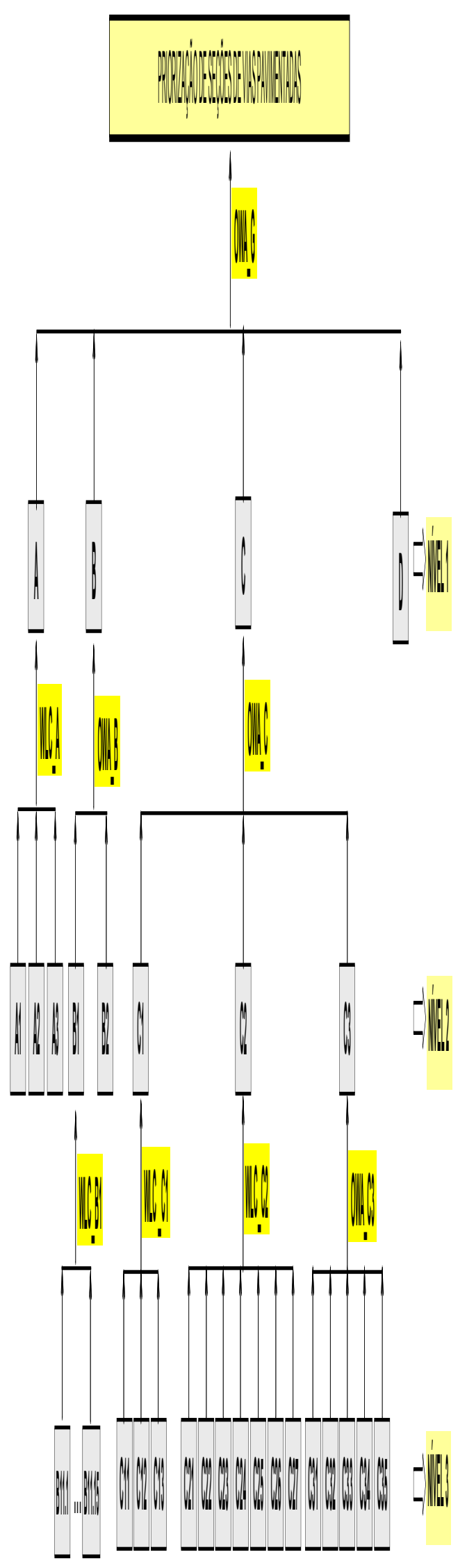

Figura 6.4: Estrutura hierárquica reorganizada para o estudo de caso 


\subsubsection{Desenvolvimento de mapas com scores normalizados}

6.3.1.1 Mapas envolvendo valores lingüísticos

Os mapas com valores lingüísticos ou classes de um determinado fator possuem, para cada seção, uma classificação que corresponde a atributos qualitativos. Como são mapas no formato vetorial, ou seja, com pontos, linhas e polígonos, cada seção (linha) da rede viária possui atributos qualitativos que por vezes assumem o mesmo valor para uma via inteira. Portanto, no processo de normalização, são atribuídos valores numéricos que caracterizam as classes de um determinado fator. A Figura 6.5 apresenta um exemplo de mapa com valores lingüísticos (o mapa do fator A1 - classe funcional da via, sem e com normalização).

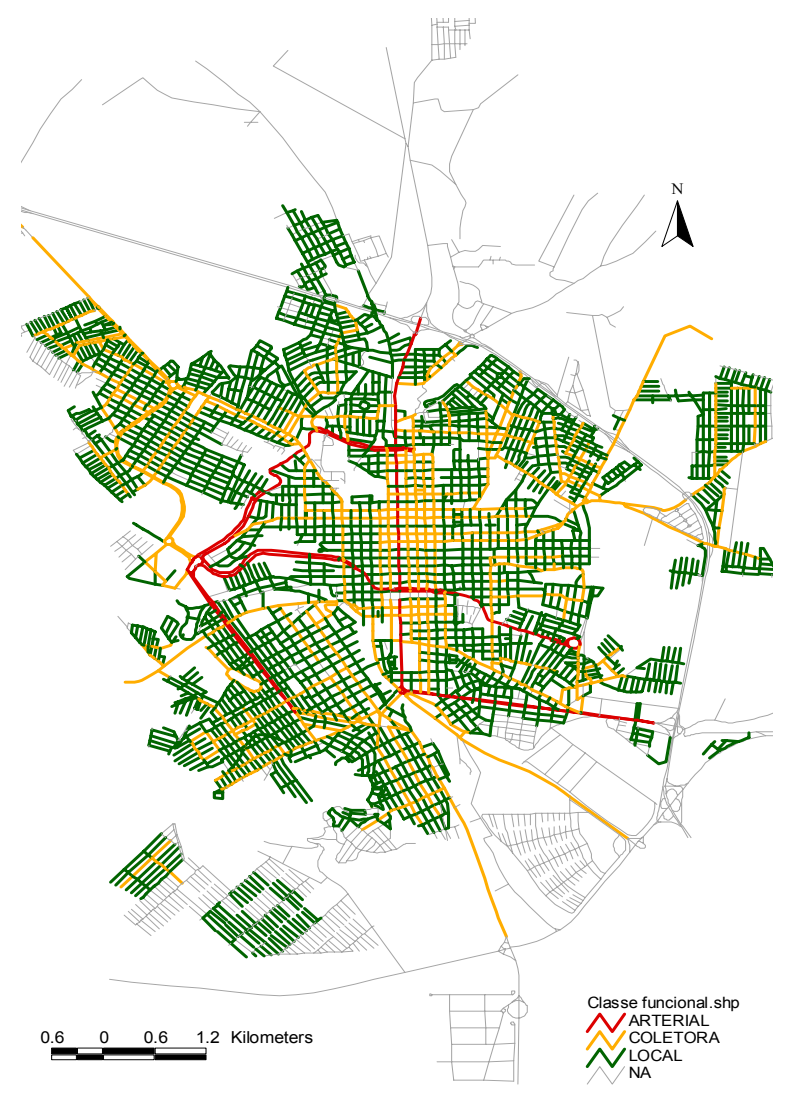

(a) valores sem normalização

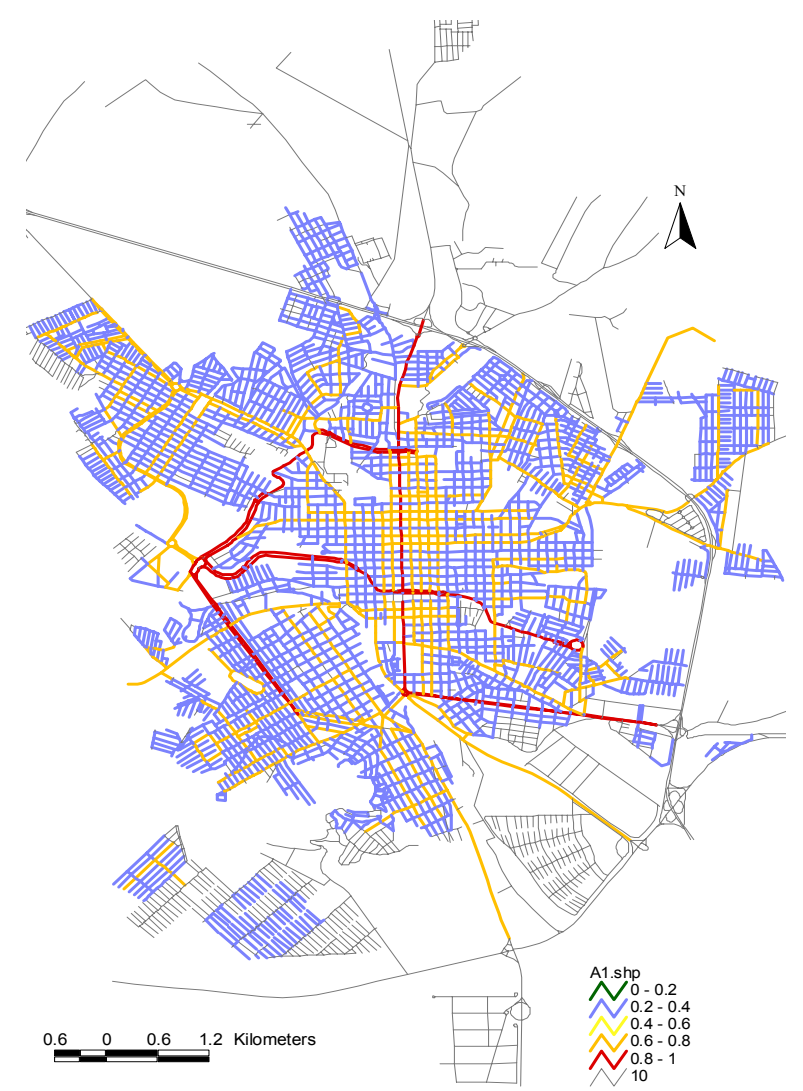

(b) valores normalizados

Figura 6.5: Fator A1 - mapas não normalizado e normalizado

Os mapas dos fatores A2 e A3 também foram desenvolvidos a partir de valores lingüísticos, produzindo mapas com scores normalizados dentro da escala considerada, conforme os valores adotados para cada situação em particular.

Os scores do fator Índice Combinado de Defeitos (fator B1) foram determinados a partir de informações sobre a severidade e extensão de cada tipo de defeito. Entretanto, a 
severidade de cada defeito apresentado é um valor lingüístico e também passou pelo processo de normalização, conforme comentado na subseção 5.3.2.

\subsubsection{Mapas envolvendo valores numéricos}

Neste caso, os atributos são caracterizados por valores numéricos que passam por normalização através da aplicação de funções fuzzy como, por exemplo, o fator B2 - Índice de Condição do Pavimento, conforme representado na Figura 6.6. Portanto, cada seção (linha) da rede viária possui atributos quantitativos que expressam os valores do fator em questão.

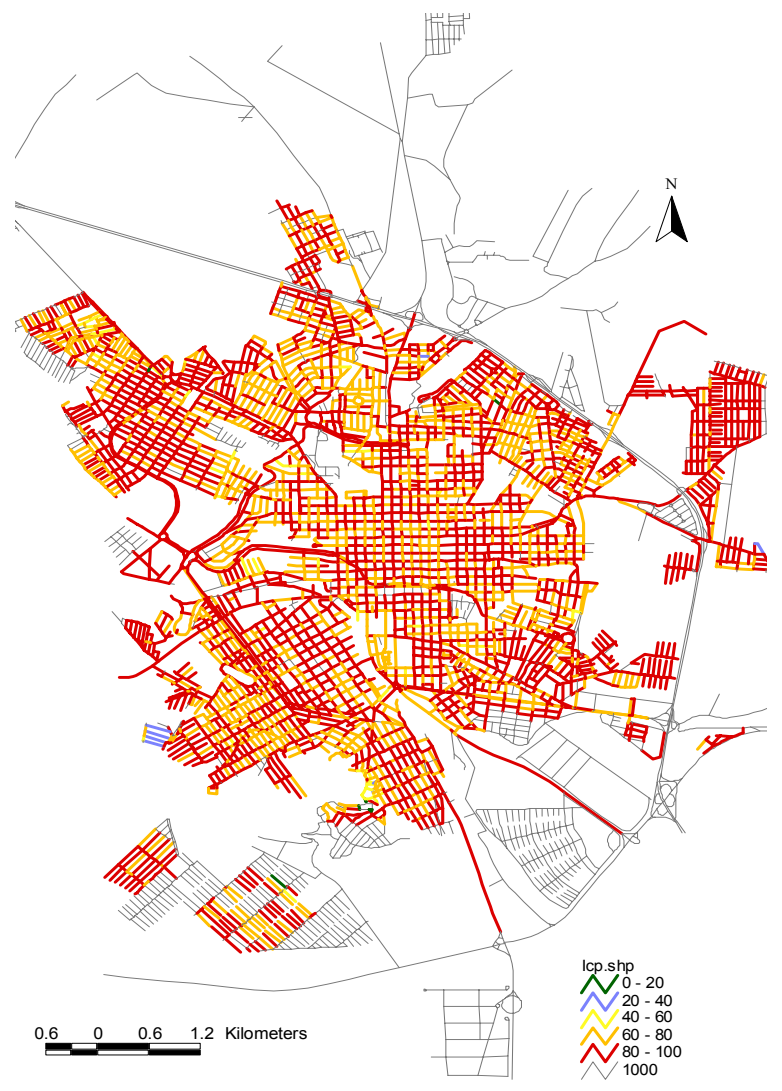

(a) valores sem normalização

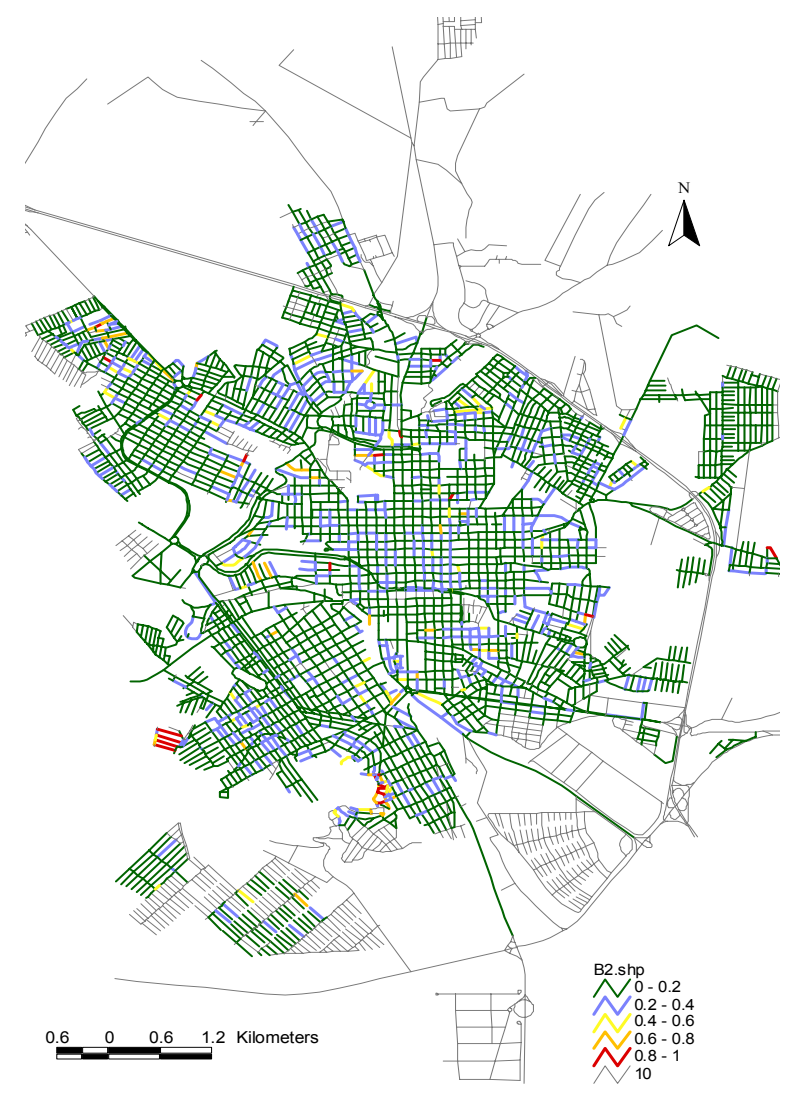

(b) valores normalizados

Figura 6.6: Fator B2 - mapas não normalizado e normalizado

O fator C32 - Proximidade a bairros com particular qualidade de vida, também possui valores numéricos. A cada seção foram atribuídos valores de índices de qualidade de vida do bairro a que ele pertence. Estes valores foram normalizados através de uma função fuzzy sigmoidal crescente.

Todos os mapas que passaram pelo processo de normalização (A1, A2, A3, B2, C32 e D), assim como as funções fuzzy ou valores adotados para tal são apresentados no ANEXO E. 


\subsubsection{Mapas envolvendo distâncias}

Os mapas baseados em distâncias referem-se à proximidade a um conjunto de pontos, um conjunto de linhas ou um conjunto de áreas. As análises envolvendo distâncias levaram em consideração os fatores de localização e foram desenvolvidas utilizando o Network Analyst - Find Service Área, ferramenta de análise contida no SIG - ArcView. Essas análises consideraram as seções de pavimentos localizadas próximas aos equipamentos e infra-estruturas urbanas até a distância máxima (Dmáx) de relevância considerada pelos avaliadores, conforme a Tabela 5.5, a Tabela 5.6 e a Tabela 5.7. Entretanto, para os atributos das seções de pavimentos localizadas próximas dos bairros com particular qualidade de vida, foram consideradas as seções contidas nos bairros e os scores das mesmas, conforme comentado na subseção 6.1.2. Funções fuzzy sigmoidal decrescentes foram aplicadas para a normalização dos valores de cada fator, considerando, respectivamente, 0 e Dmáx os pontos de controle mínimo e máximo de cada função. Os mapas que serviram para localização dos equipamentos estão ilustrados no ANEXO D.

Os valores de scores normalizados dos fatores do nível 3 foram transferidos para a base de dados desenvolvida no SIG, possibilitando que os fatores fossem posteriormente agrupados. Esses agrupamentos foram realizados através dos procedimentos de agregação Weighted Linear Combination (WLC) e Ordered Weighted Average (OWA). Portanto, a seguir é apresentada uma síntese dos processos de combinação e os mapas dos diversos cenários de avaliação resultantes de cada nível de agrupamento.

\subsection{Cenários de Avaliação}

Foram realizados vários cenários de avaliação das seções de pavimentos, combinando os diversos critérios em cada nível de agrupamento e utilizando para este fim os dois métodos abordados na subseção 4.2.4, ou seja, WLC e OWA. O resultado da aplicação destes procedimentos é a produção de vários mapas contendo a rede viária da cidade de São Carlos, cada um representando um cenário que caracteriza a prioridade de intervenção para cada seção da rede. A Tabela 6.3 mostra como foram desenvolvidos os procedimentos de combinação de critérios, considerando cada nível de agrupamento.

Cabe lembrar que todas as análises foram realizadas com base na Tabela $6.1 \mathrm{e}$ Figura 6.4, que contêm os fatores, os pesos, a estrutura hierárquica e a indicação dos agrupamentos em todos os níveis. A Tabela 6.3 mostra os procedimentos adotados bem como a nomenclatura dada para cada agrupamento por nível de decisão. 
No Nível 3 foram realizadas combinações WLC, considerando, com exceção dos critérios que formam os mapas $\mathrm{C} 3$, todos os mapas contendo scores normalizados dos critérios que representam o $3^{\circ}$ nível da estrutura hierárquica $(\mathrm{B} 1.1$ a B1.15; $\mathrm{C} 11$ a C13; $\mathrm{C} 21 \mathrm{a}$ C27). Para estas combinações foram utilizados os pesos de todos os critérios envolvidos em cada agrupamento (conforme Tabela 6.1). Ainda neste nível, foi desenvolvida uma combinação OWA com os mapas contendo os scores normalizados que representam o agrupamento C3 (representa o fator Preferências Pessoais e Administrativas, dos fatores associados à localização). Para este procedimento são simulados seis cenários de avaliação, correspondendo a diferentes níveis de risco e trade-off (pontos de decisão).

Tabela 6.3: Procedimentos adotados para a combinação de critérios

\begin{tabular}{|c|c|c|c|}
\hline NÍVEL & COMBINAÇÕES & APLICAÇÃO & AGRUPAMENTOS \\
\hline 1 & OWA & $\begin{array}{l}\text { Combinação dos mapas do Nível 1, } \\
\text { para todos os grupos de critérios, } \\
\text { gerando } 6 \text { cenários finais de } \\
\text { avaliação: Pi_1, Pii_1, Piii_1 e } \\
\text { Pi_2, Pii_2 e Piii_2 }\end{array}$ & OWA_G \\
\hline & WLC & $\begin{array}{l}\text { Combinação de mapas do nível } 2, \\
\text { para gerar o mapa do grupo A } \\
\text { utilizando os pesos dos respectivos } \\
\text { critérios }\end{array}$ & WLC_A \\
\hline 2 & OWA & $\begin{array}{l}\text { Combinação dos mapas do Nível 2, } \\
\text { gerando } 3 \text { cenários para o grupo B - } \\
\text { Bi, Bii e Biii e } 6 \text { cenários para o } \\
\text { grupo C: Ci.1, Cii.1, Ciii.1 e } \\
\text { Ci.2, Cii.2 e Ciii. } 2\end{array}$ & $\begin{array}{l}\text { OWA_B } \\
\text { OWA_C }\end{array}$ \\
\hline \multirow[t]{2}{*}{3} & WLC & $\begin{array}{l}\text { Combinação de mapas do nível } 3 \\
\text { para gerar os mapas B1, C1, e C2, } \\
\text { utilizando os pesos dos respectivos } \\
\text { critérios }\end{array}$ & $\begin{array}{l}\text { WLC_B1 } \\
\text { WLC_C1 } \\
\text { WLC_C2 }\end{array}$ \\
\hline & OWA & $\begin{array}{l}\text { Combinação dos mapas do Nível 3, } \\
\text { gerando } 6 \text { cenários de avaliação - } \\
\text { C3i, C3ii, C3iii, C3iv, C3v, C3vi }\end{array}$ & OWA_C3 \\
\hline
\end{tabular}

Assim como no nível 3 da estrutura, no Nível 2 também foram realizadas combinações do tipo WLC e OWA. Neste caso, para o grupo A foi realizado somente o procedimento WLC e o procedimento OWA foi desenvolvido para os agrupamentos B e C (fatores associados a questões técnicas e fatores associados à localização), combinando mapas do Nível 2, resultantes da agregação do Nível 3. Foram simulados três cenários de avaliação para o grupo B (risco mínimo, risco neutro e risco máximo) e para o grupo C usaram-se duas combinações de cenários e três cenários de avaliação, obtendo-se no total seis cenários de avaliação. 
Finalmente, no Nível 1 da estrutura hierárquica, foi realizada através do procedimento OWA, a combinação de mapas de todos os grupos (A, B, C, D), utilizando para este procedimento cenários variados de risco, com duas combinações de cenários do Nível 2 e três cenários de avaliação. No total obtiveram-se seis cenários finais de priorização de seções de pavimentos.

\subsubsection{Processo de Combinação WLC - Nivel 3}

Após a normalização, o primeiro passo foi criar um mapa para cada fator do nível 3 da estrutura hierárquica. O segundo passo foi proceder ao WLC dos fatores do nível 3, utilizando para isto, os pesos atribuídos pelo grupo de avaliadores, conforme a Tabela 6.1. Das combinações nomeadamente WLC_B1, WLC_C1 e WLC_C2, conforme ilustrado na Figura 6.4 resultaram respectivamente os mapas B1, C1, C2 com os scores dos fatores do nível 2 normalizados. Entretanto, os mapas dos fatores A1, A2, A3 e B2, também do nível 2, foram criados simplesmente a partir da normalização dos scores destes fatores. $\mathrm{O}$ agrupamento WLC_B1, do qual resultou o mapa B1, foi desenvolvido com o auxílio de uma planilha Excel contendo informações sobre severidade e extensão de todos os defeitos em consideração para todas as seções analisadas da rede e, utilizando para este fim a Equação 3.4 comentada no item 3.1.4.1. Os outros dois agrupamentos WLC deste nível (WLC_C1 e WLC_C2) foram realizados utilizando ferramentas disponíveis do SIG.

Os mapas dos fatores A1, A2 e A3 compõem o grupo A (Hierarquia Viária), os mapas dos fatores B1 e B2 compõem o grupo B (Questões Técnicas e Operacionais) e os mapas dos fatores $\mathrm{C} 1, \mathrm{C} 2$ compõem o grupo C (Localização). O grupo D possui somente o nível mais elevado da hierarquia, o nível 1 e é comentado na subseção 6.4.5. A Figura 6.7 até a Figura 6.13 ilustram todos os mapas desenvolvidos para compor os fatores do nível 2 da estrutura hierárquica, ou seja, resultantes ou não do processo de combinação WLC do nível 3. 


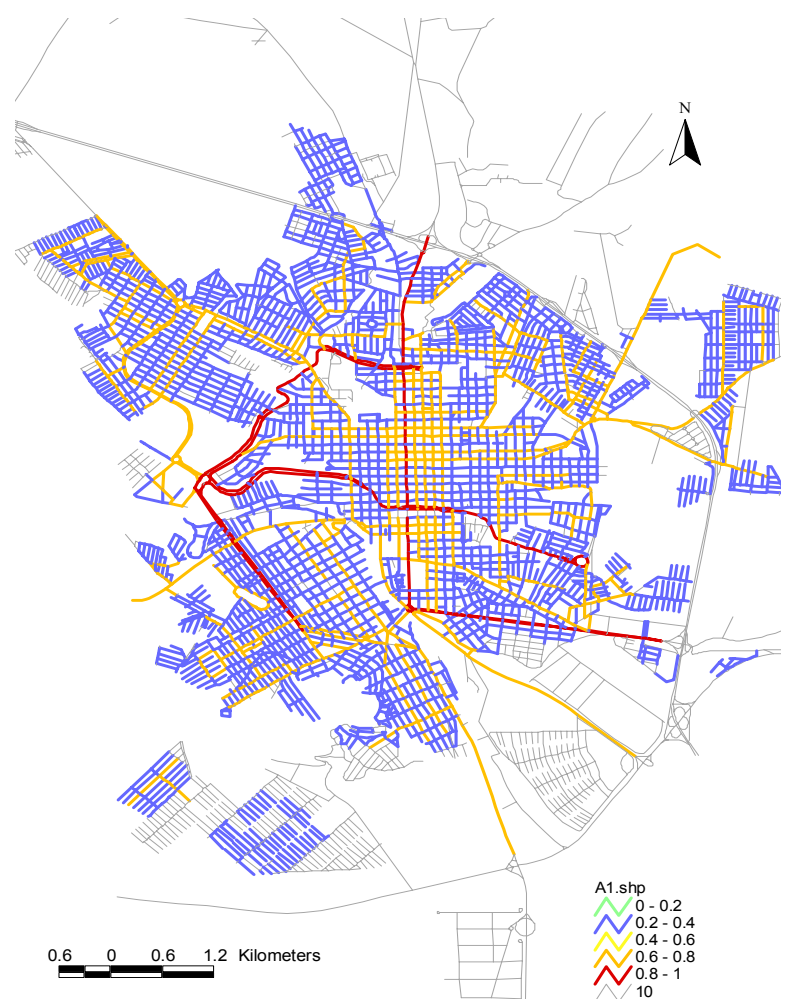

Figura 6.7: Mapa com scores normalizados do fator A1

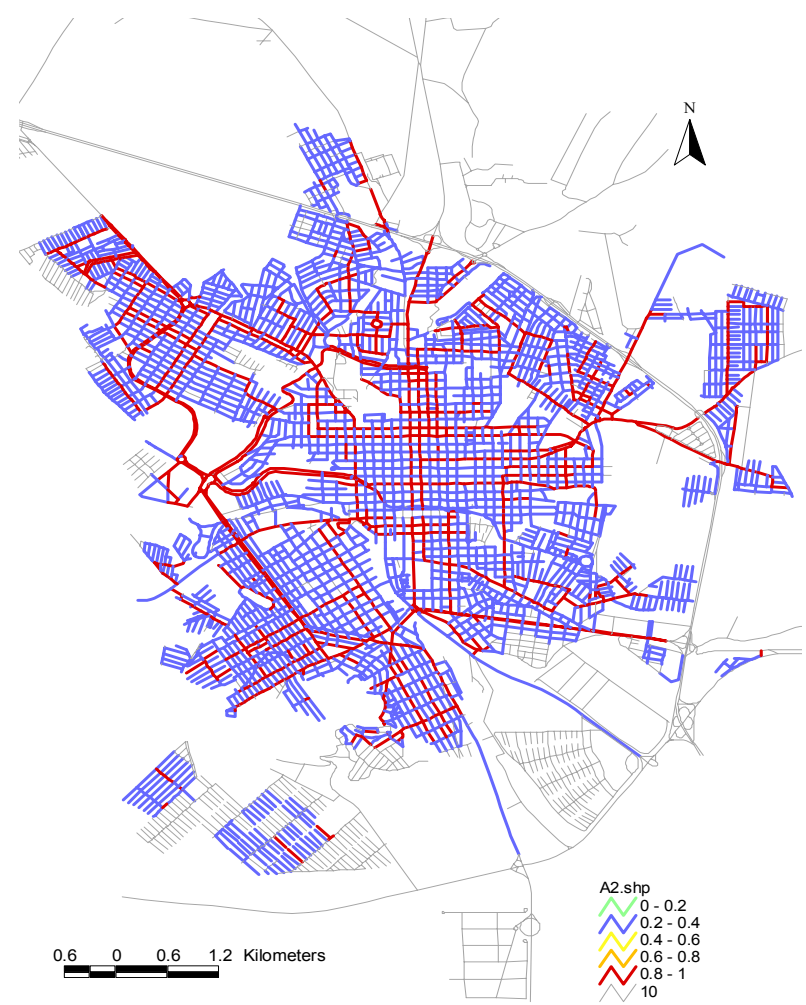

Figura 6.8: Mapa com scores normalizados do fator A2

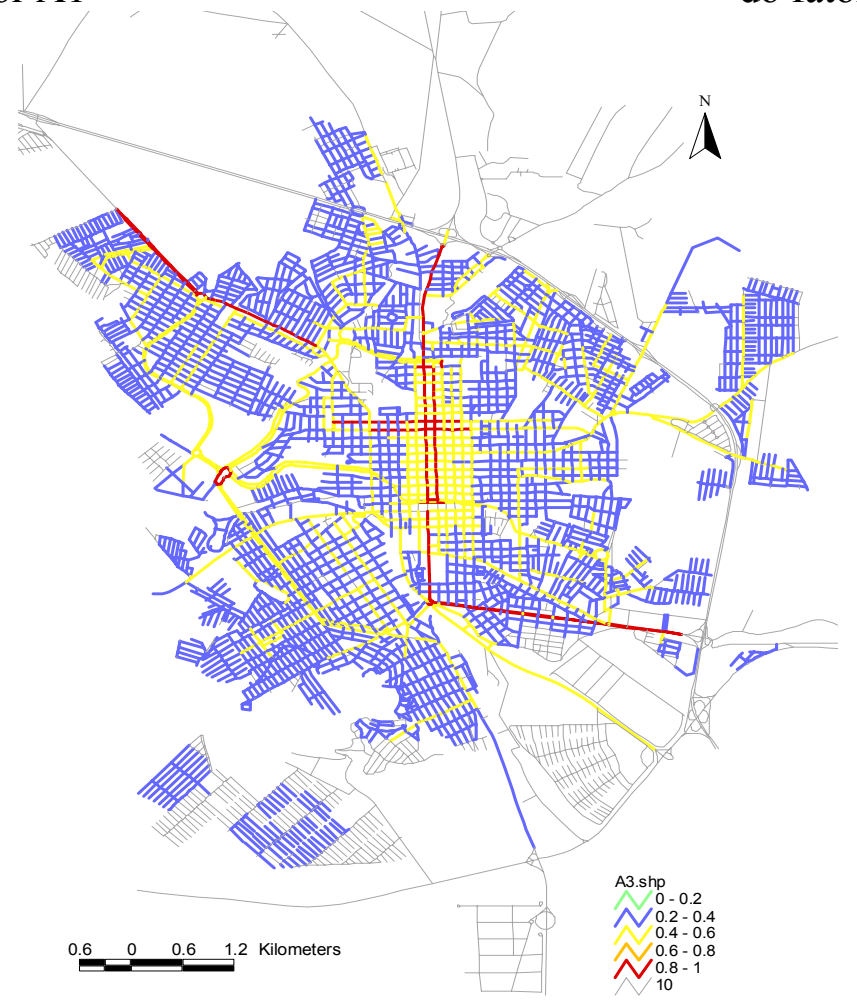

Figura 6.9: Mapa com scores normalizados do fator A3 


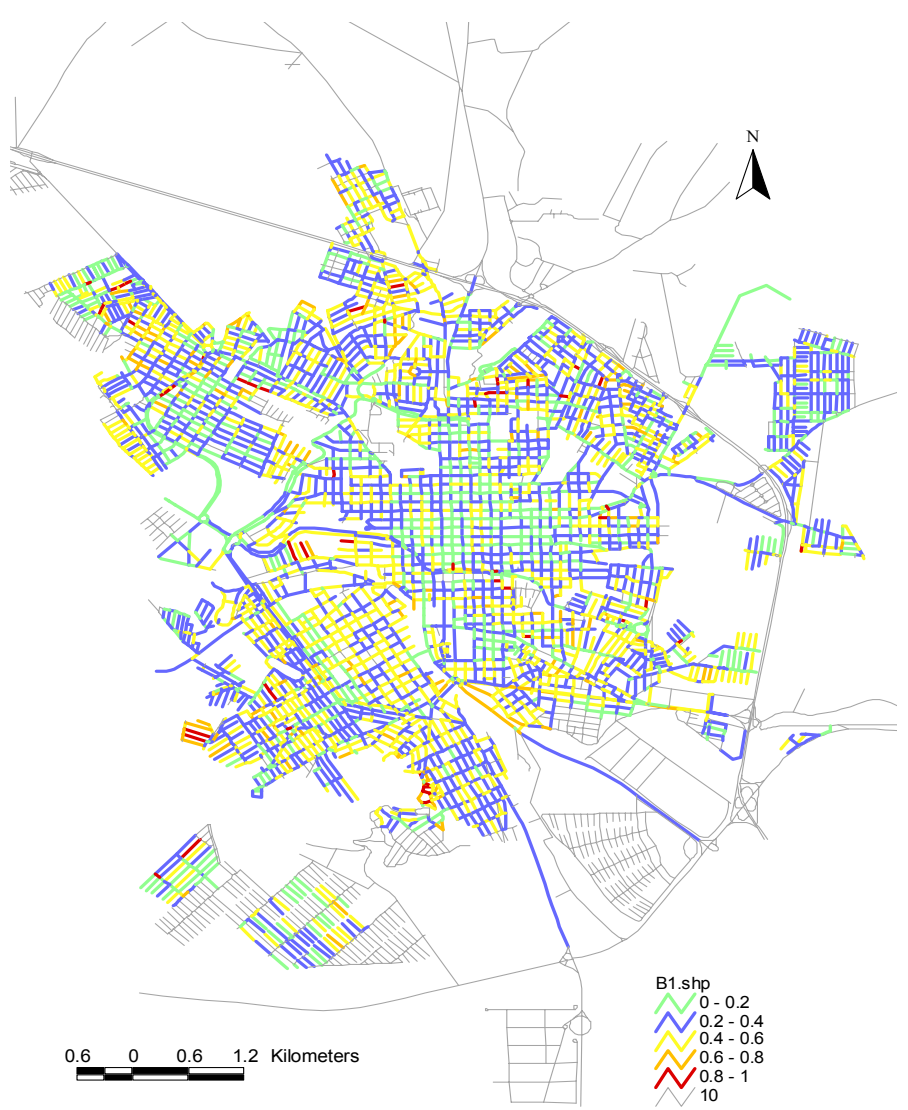

Figura 6.10: Mapa B1 resultante de WLC_B1

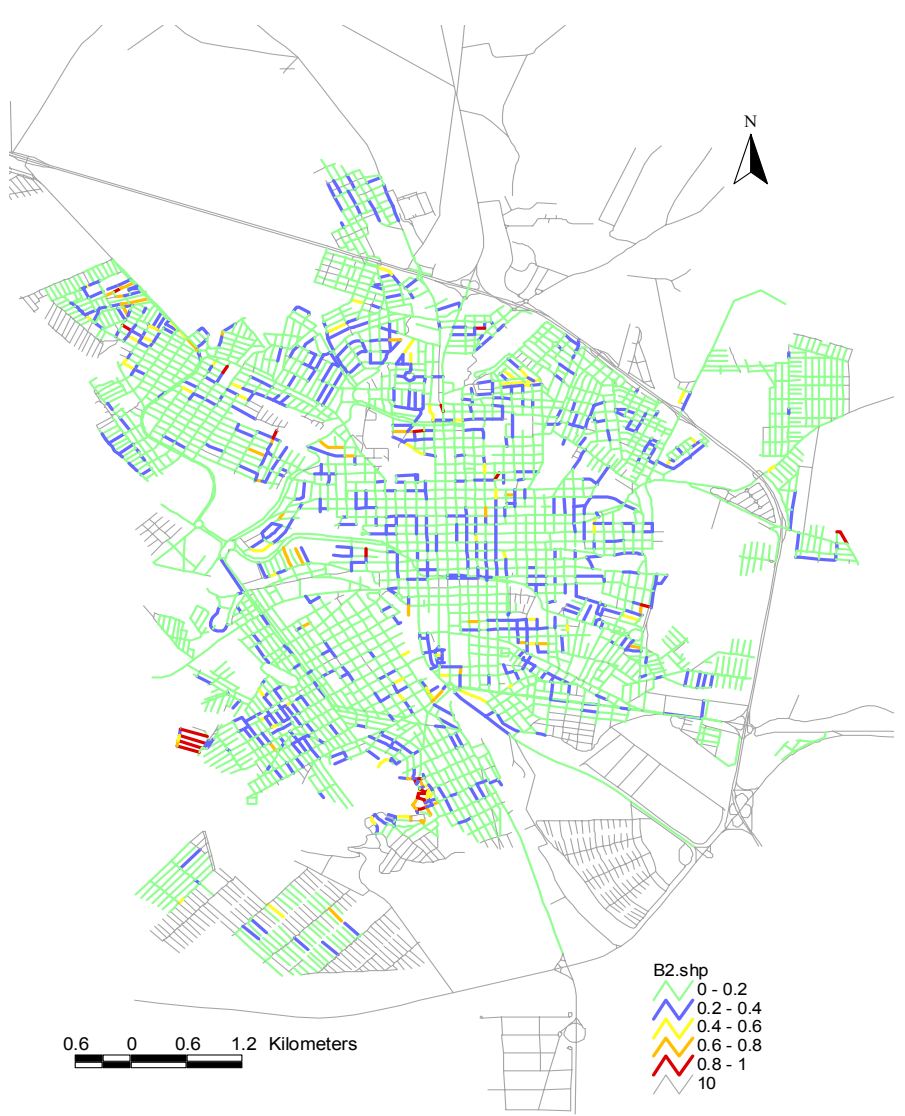

Figura 6.11: Mapa B2 com scores normalizados 


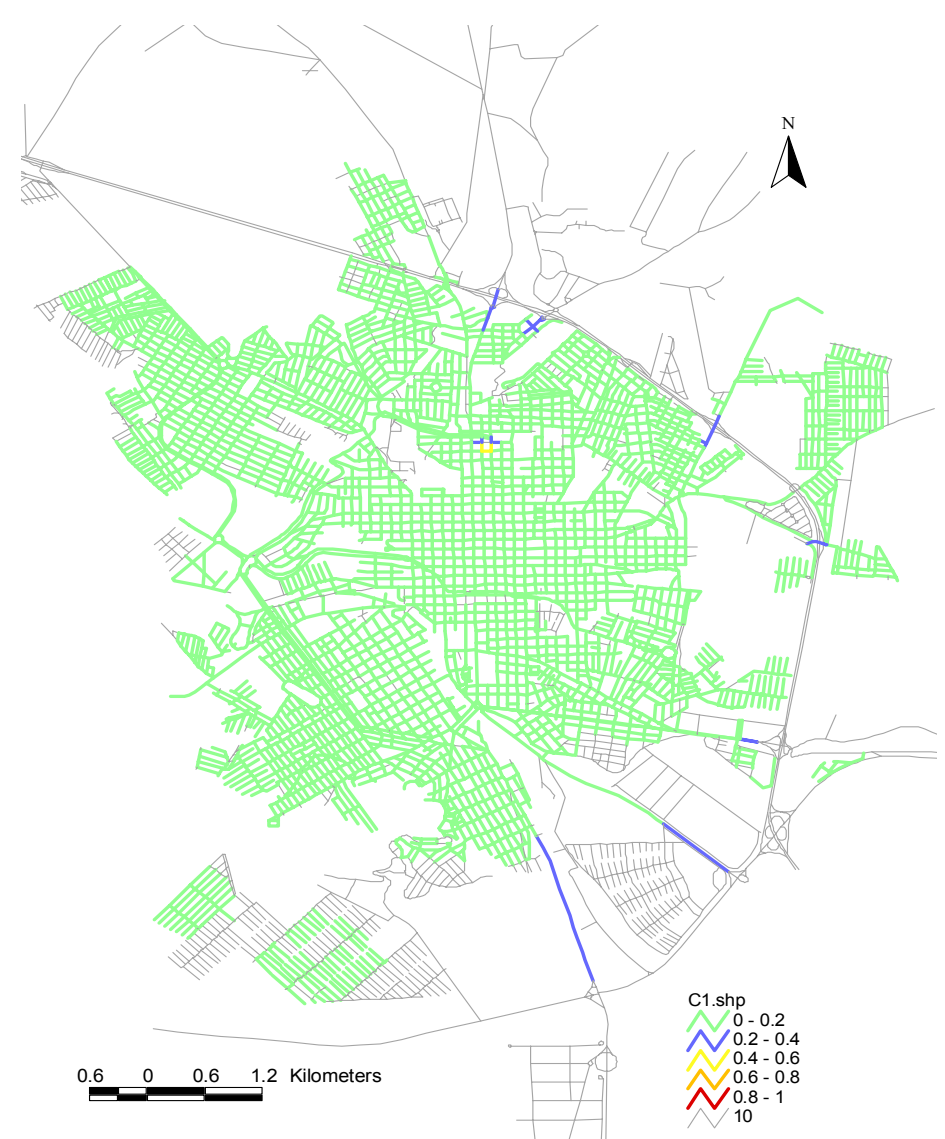

Figura 6.12: Mapas C1 resultantes de WLC_C1

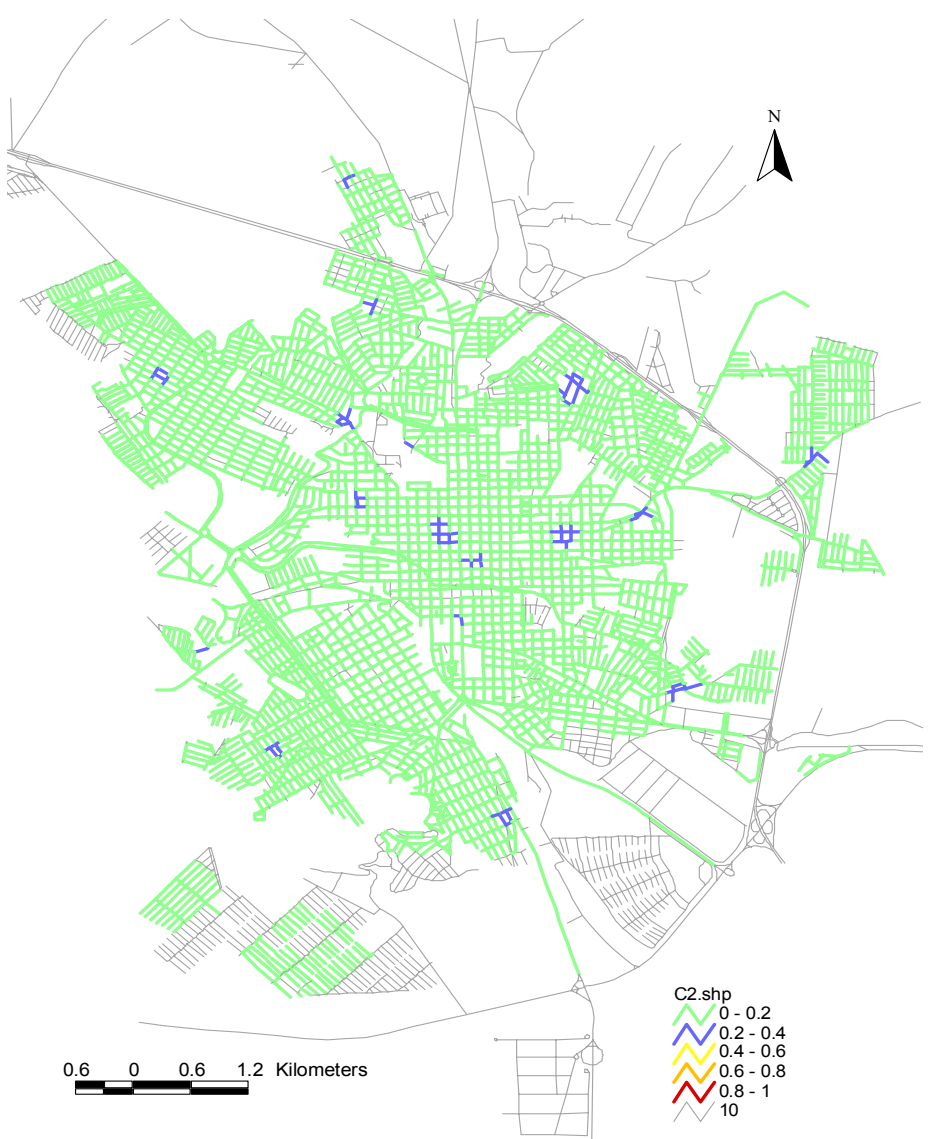

Figura 6.13: Mapas C2 resultantes de WLC_C2 


\subsubsection{Processo de Combinação OWA - Nível 3}

A combinação correspondente ao nível 3 dá origem ao mapa $\mathrm{C} 3$, no qual foram simulados, através do procedimento OWA - nomeadamente OWA_C3, seis cenários de avaliação (i, ii, iii, iv, v, vi), correspondendo a diferentes atitudes de risco e trade-off, representados pela Figura 6.14.

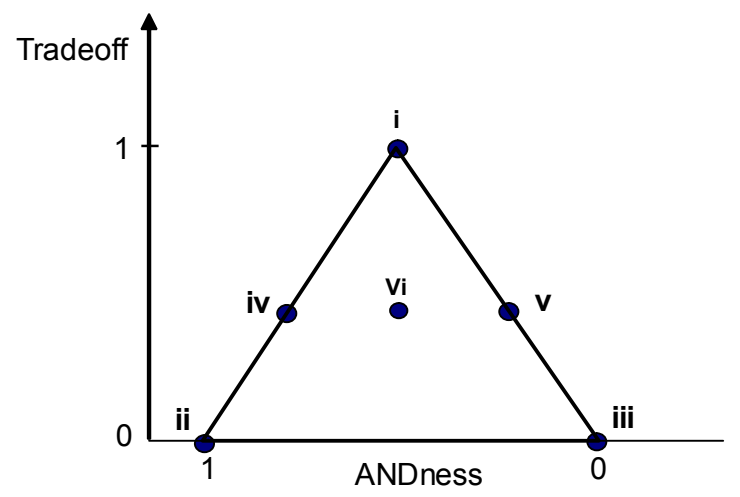

Onde:
$i$ : risco neutro - trade-off total
ii: risco mínimo- sem trade-off
iii: risco máximo - sem trade-off
$i v$ : baixo risco - trade-off parcial
$v$ : alto risco - trade-off parcial
$v i$ : risco neutro - trade-off parcial

Figura 6.14: Pontos de decisão - OWA_C3

Vale lembrar que a análise de risco máximo produz uma solução otimista na qual se aplica todo o peso aos fatores com maior score, o que significa que os critérios não podem ser compensados uns pelos outros. Por outro lado, a análise de risco mínimo produz uma solução pessimista, na qual se aplica todo o peso aos fatores com menor score (os outros fatores possuem com certeza, scores mais elevados), não podendo os critérios ser compensados uns pelos outros. Já a análise de risco neutra, contribui com a aplicação de um conjunto de pesos de mesmo valor, perfeitamente equilibrado, produzindo uma das condições: compensação parcial ou total entre as qualidades das alternativas, ou seja, baixos scores em alguns critérios são compensados por scores elevados de outros critérios. Desta forma, o valor 1 de Trade-off indica a compensação total entre os fatores, já o valor 0 indica que os fatores não podem ser compensados uns pelos outros.

Os seis cenários de avaliação simulados através do procedimento OWA, contaram com os novos conjuntos de pesos (Order Weights), que foram aplicados em ordem crescente dos scores ponderados correspondentes aos fatores C31, C32, C33, C34 e C35, conforme apresentado na Tabela 6.4. Da simulação resultaram os mapas C3i, C3ii, C3iii, C3iv, C3v e C3vi representando o fator Preferências Pessoais e Administrativas (C3), dos fatores associados à localização. 
Tabela 6.4: Cenários de avaliação empregados para gerar os mapas do fator C3

\begin{tabular}{lccc}
\hline Cenários & Order Weights & ANDNess & Trade-off \\
\hline C3i & $(0,20 ; 0,20 ; 0,20 ; 0,20 ; 0,20)$ & 0,50 & 1,00 \\
C3ii & $(1,00 ; 0,00 ; 0,00 ; 0,00 ; 0,00)$ & 1,00 & 0,00 \\
C3iii & $(0,00 ; 0,00 ; 0,00 ; 0,00 ; 1,00)$ & 0,00 & 0,00 \\
C3iv & $(0,50 ; 0,20 ; 0,15 ; 0,10 ; 0,05)$ & 0,75 & 0,60 \\
C3v & $(0,05 ; 0,10 ; 0,15 ; 0,20 ; 0,50)$ & 0,25 & 0,60 \\
C3vi & $(0,30 ; 0,15 ; 0,10 ; 0,15 ; 0,30)$ & 0,50 & 0,79 \\
\hline
\end{tabular}

O SIG-ArcView não conta com módulo específico que permite realizar a combinação OWA dos mapas vetoriais apresentados. Porém, dentro do tema que contém as informações sobre o fator C3 (Pp - Preferências pessoais) foram criadas várias colunas que serviram para desenvolver a seqüência de passos necessários para o procedimento OWA, conforme apresentado na Figura 6.15.

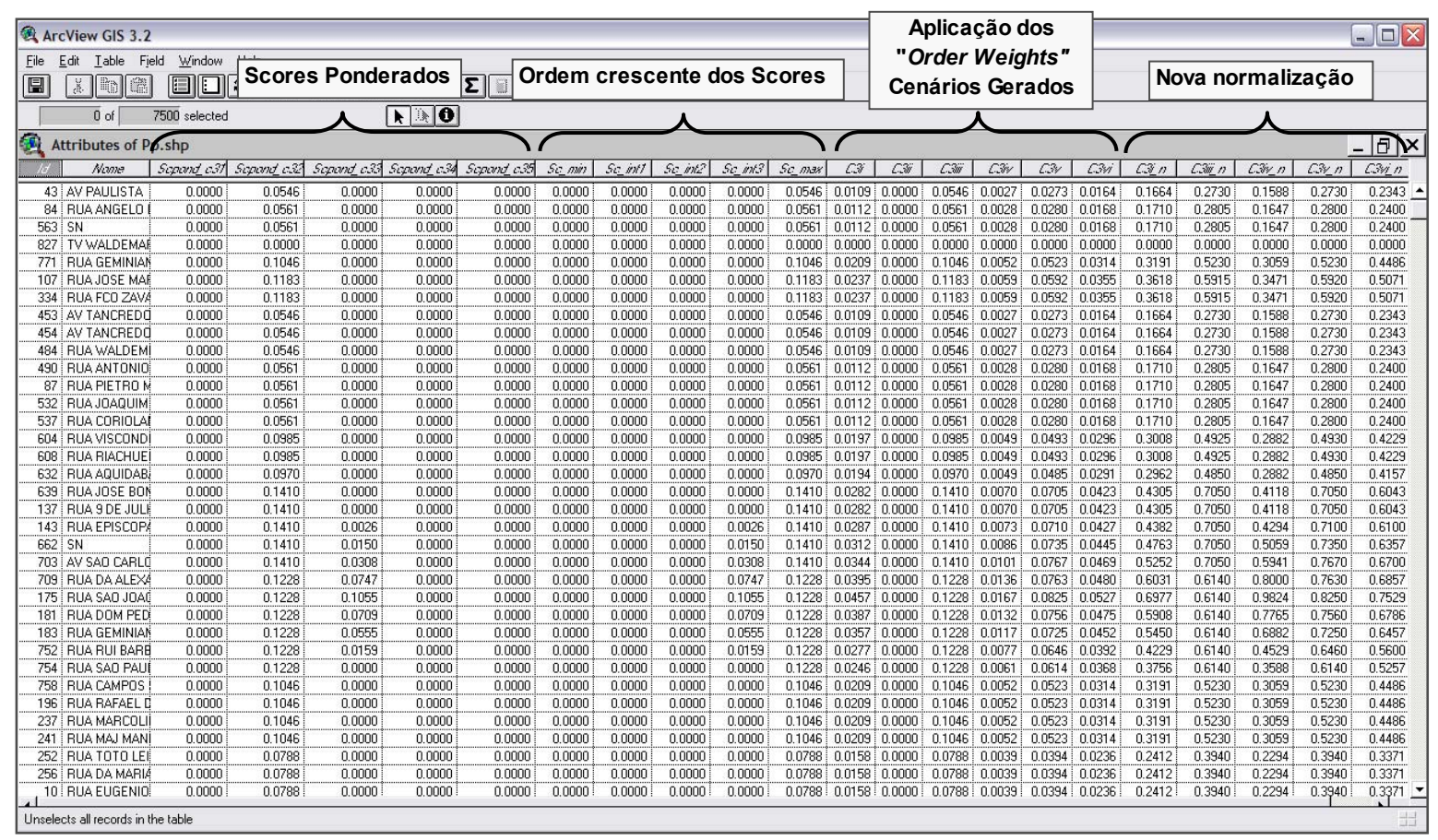

Figura 6.15: Combinação OWA_C3 em SIG-ARCView

Após todos os cálculos, é possível realizar uma análise conjunta e comparativa de todos os cenários criados, sobrepondo-se todos os mapas na View (janela do ArcView), chamada neste caso de OWA_C3, conforme o exemplo da Figura 6.16.

No procedimento OWA os scores são multiplicados por dois conjuntos de pesos (os dos critérios e os dos “Order Weights”), tornando os valores finais muito pequenos ou, por vezes, iguais a zero. Portanto, para que os mapas fossem mais bem representados e pudessem ser comparáveis entre si, os cenários $\mathrm{C} 3 \mathrm{i}$ a $\mathrm{C} 3 \mathrm{vi}$, passaram por uma nova 
normalização. Desta forma, a letra " $n$ " foi acrescentada em todos os mapas que foram normalizados pela segunda vez para uma escala de 0 a 1 . As estatísticas dos valores gerados em cada mapa do nível 2 são apresentadas na Tabela 6.5. Os mapas resultantes dos seis cenários são apresentados na Figura 6.17 a Figura 6.22.

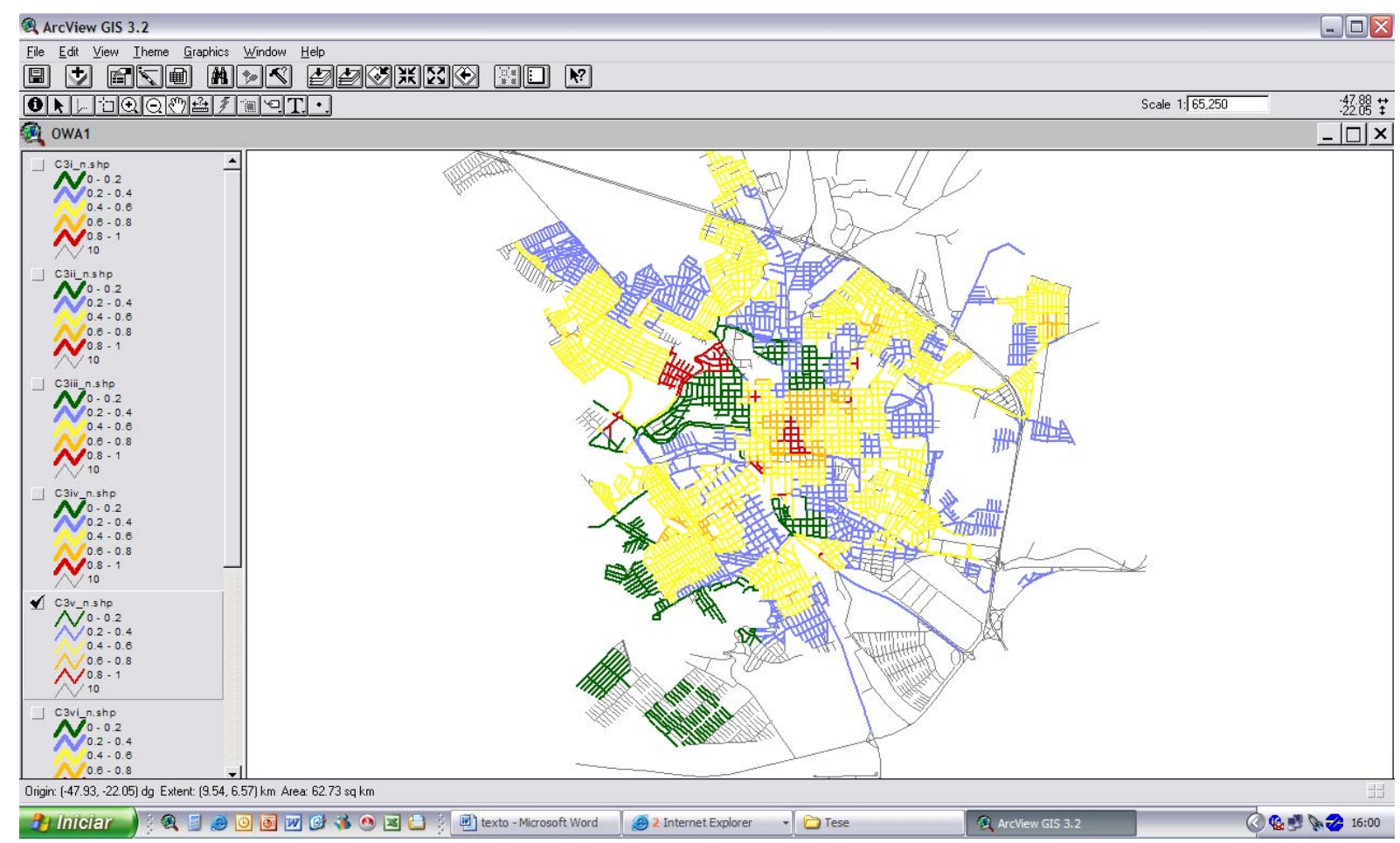

Figura 6.16. Cenários do procedimento OWA_C3 no ARCView

Tabela 6.5: Estatísticas dos mapas do nível 2

\begin{tabular}{cccccc}
\hline Mapa & $\begin{array}{c}\text { Score } \\
\text { Mínimo }\end{array}$ & $\begin{array}{c}\text { Score } \\
\text { Máximo }\end{array}$ & Média & $\begin{array}{c}\text { Desvio } \\
\text { Padrão }\end{array}$ & $\begin{array}{c}\text { \% de valores } \\
\text { zero }\end{array}$ \\
\hline A1 & 0,30 & 0,90 & 0,436 & 0,216 & 0 \\
A2 & 0,30 & 1,00 & 0,492 & 0,313 & 0 \\
A3 & 0,30 & 0,90 & 0,382 & 0,161 & 0 \\
B1 & 0,00 & 1,00 & 0,350 & 0,148 & 2 \\
B2 & 0,00 & 1,00 & 0,076 & 0,129 & 36 \\
& & & & & \\
C1 & 0,00 & 0,43 & 0,003 & 0,026 & 97 \\
C2 & 0,00 & 0,33 & 0,032 & 0,050 & 42 \\
C3i_n & 0,00 & 1,00 & 0,252 & 0,125 & 7 \\
C3ii_n & 0,00 & 0,00 & 0,000 & 0,000 & 100 \\
C3iii_n & 0,00 & 1,00 & 0,392 & 0,171 & 7 \\
C3iv_nn & 0,00 & 1,00 & 0,259 & 0,153 & 7 \\
C3v_n & 0,00 & 1,00 & 0,402 & 0,180 & 7 \\
C3vi_nn & 0,00 & 1,00 & 0,346 & 0,158 & 7 \\
\hline
\end{tabular}




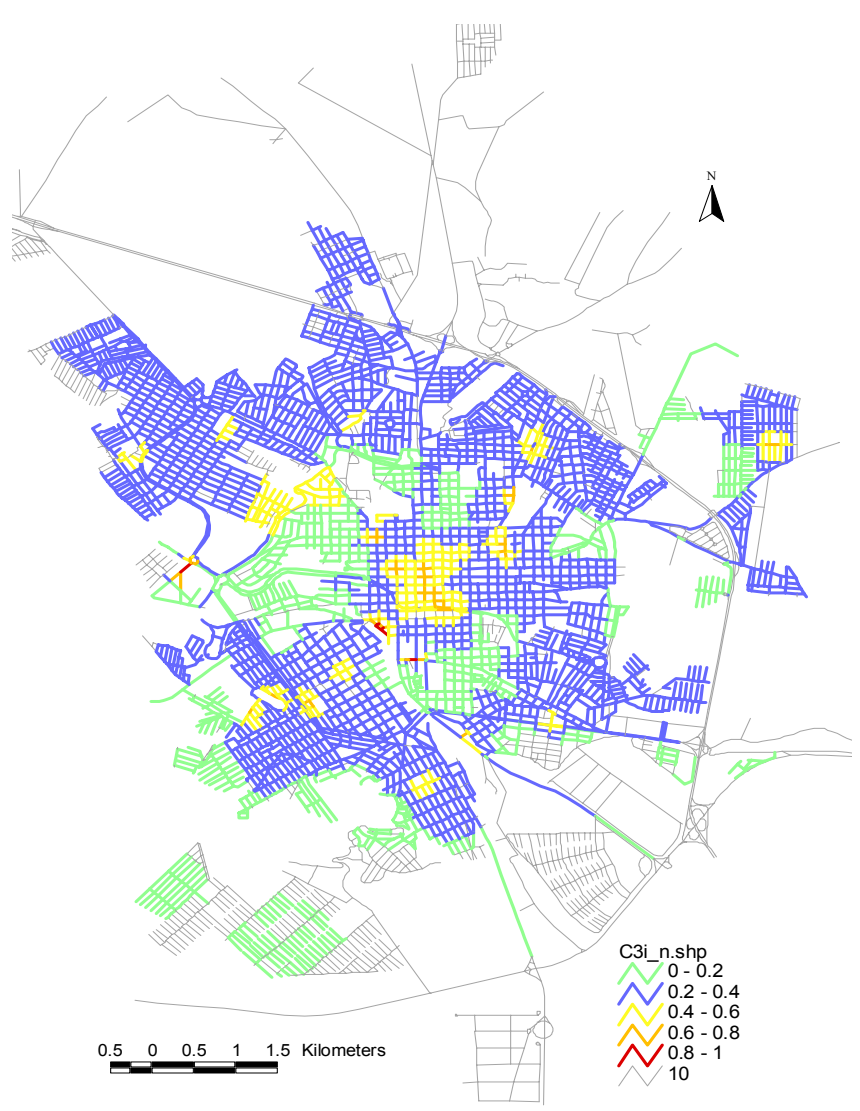

Figura 6.17: Mapa do cenário C3i_n

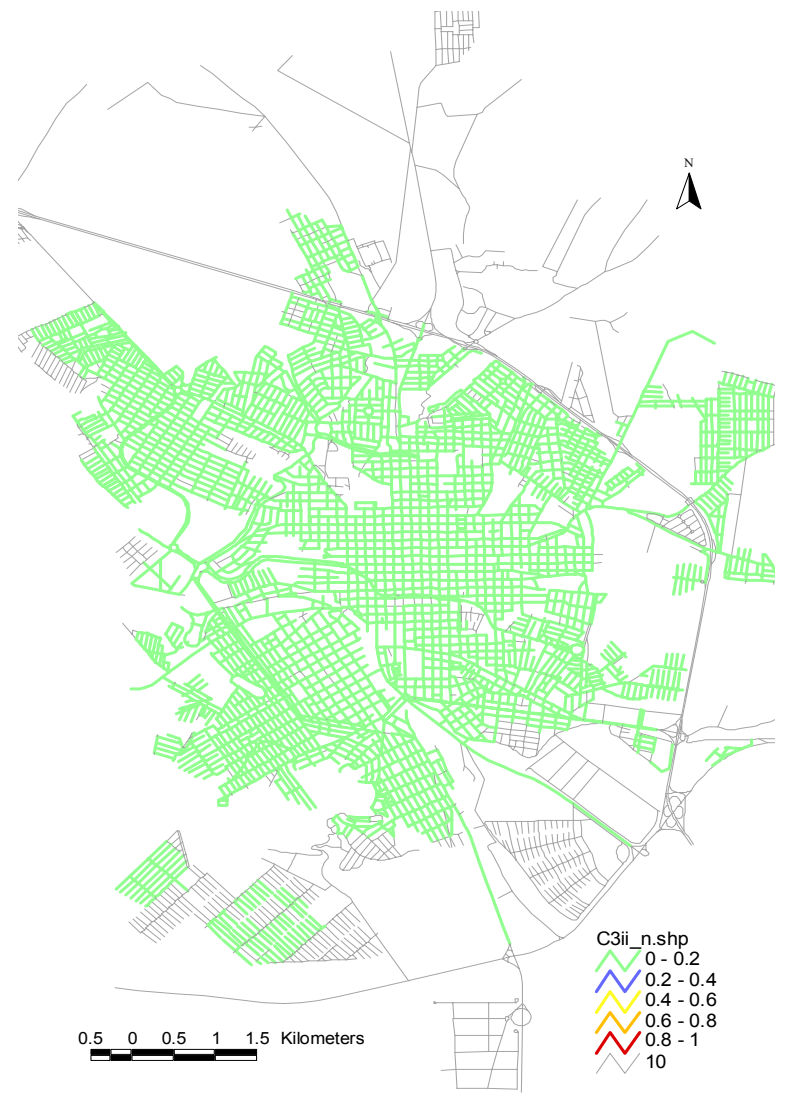

Figura 6.18: Mapa do cenário C3ii_n

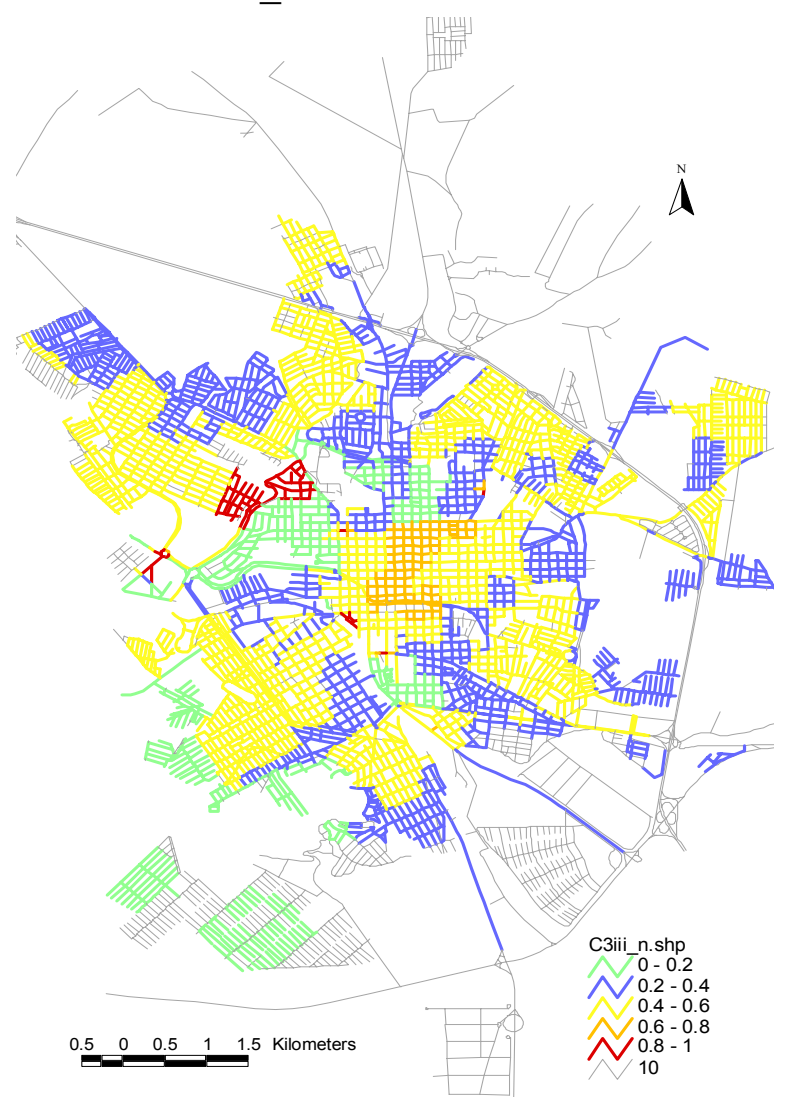

Figura 6.19: Mapa do cenário C3iii_n 


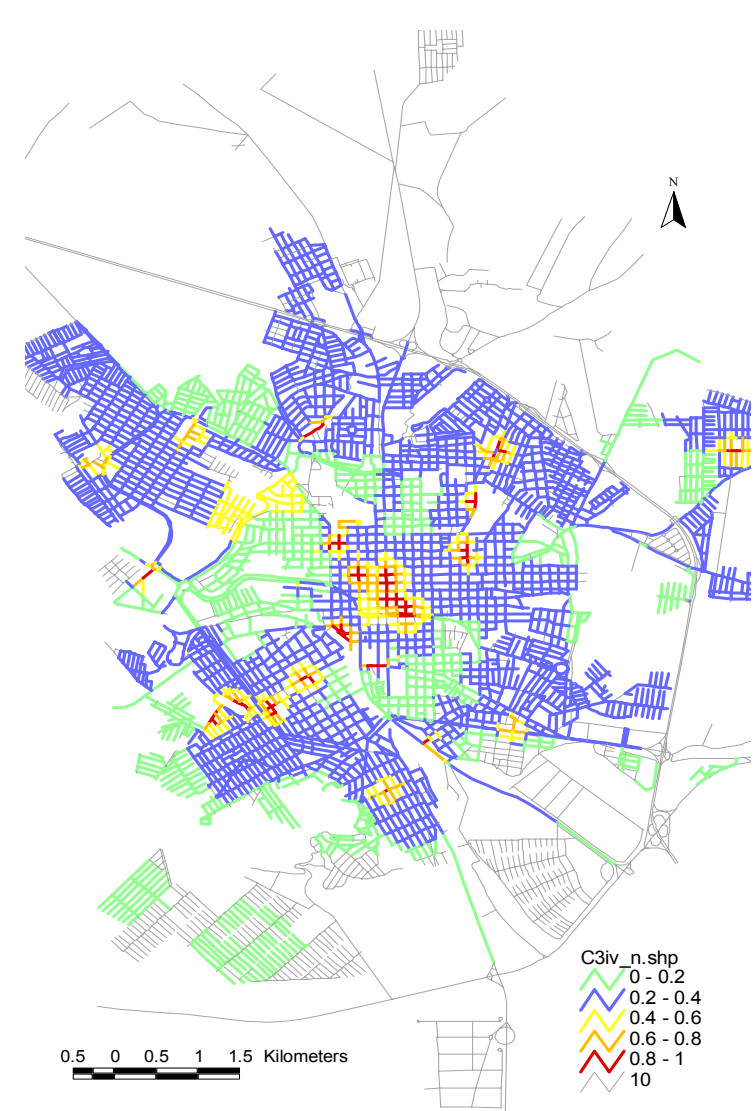

Figura 6.20: Mapa do cenário C3iv_n

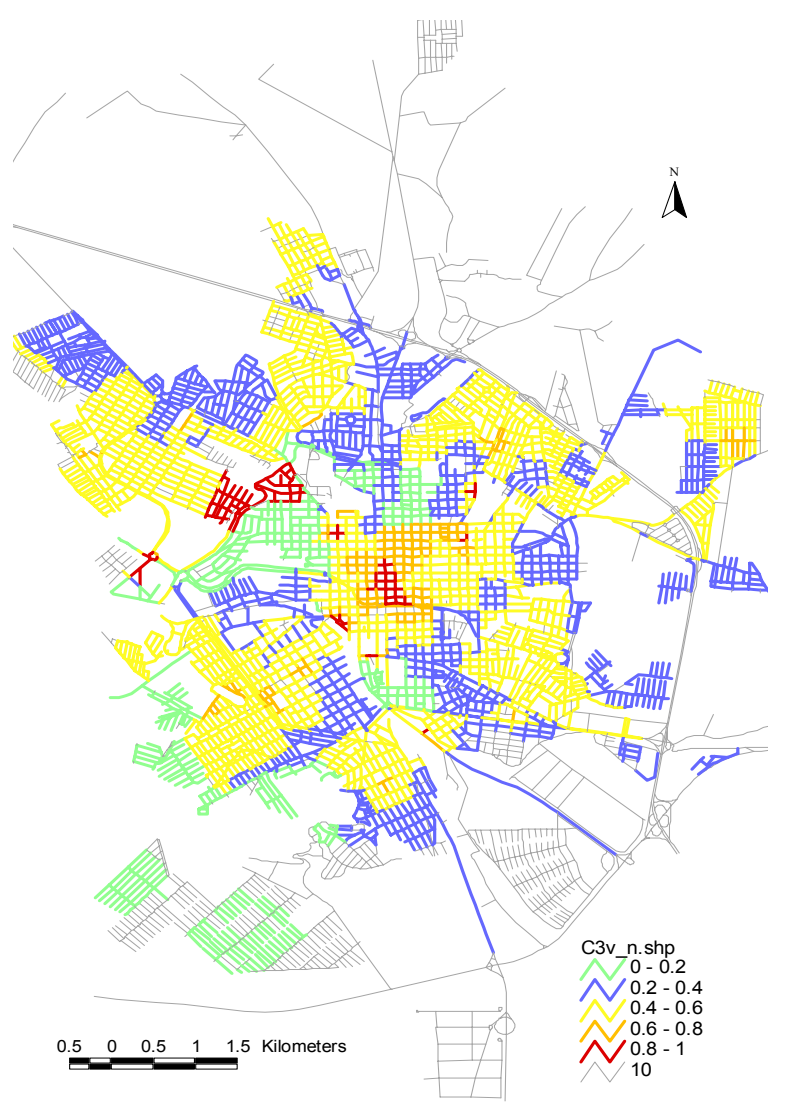

Figura 6.21: Mapa do cenário C3v_n

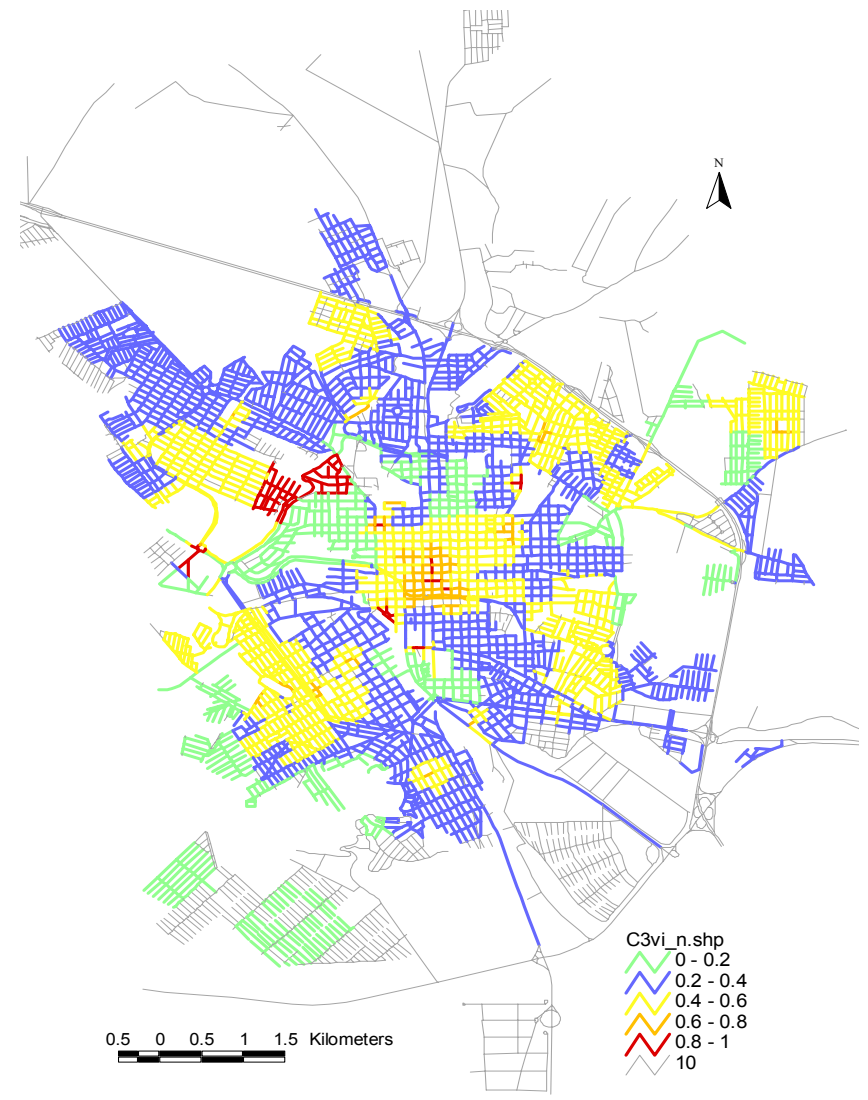

Figura 6.22: Mapa do cenário C3vi_n 
6.4.3 Processo de Combinação WLC - Nível 2

Após realizar os procedimentos WLC e OWA dos fatores do nível 3, procederamse os agrupamentos do nível 2, utilizando os pesos atribuídos pelo grupo de avaliadores, conforme a Tabela 6.1 .

Em relação ao processo de combinação WLC, foi realizada a combinação nomeadamente WLC_A (conforme Tabela 6.3 e Figura 6.4), agrupando os fatores A1, A2 e A3 do nível 2, da qual deu origem ao mapa A, representando o grupo A - Fatores Associados à Hierarquia Viária no nível 1. (Figura 6.23).

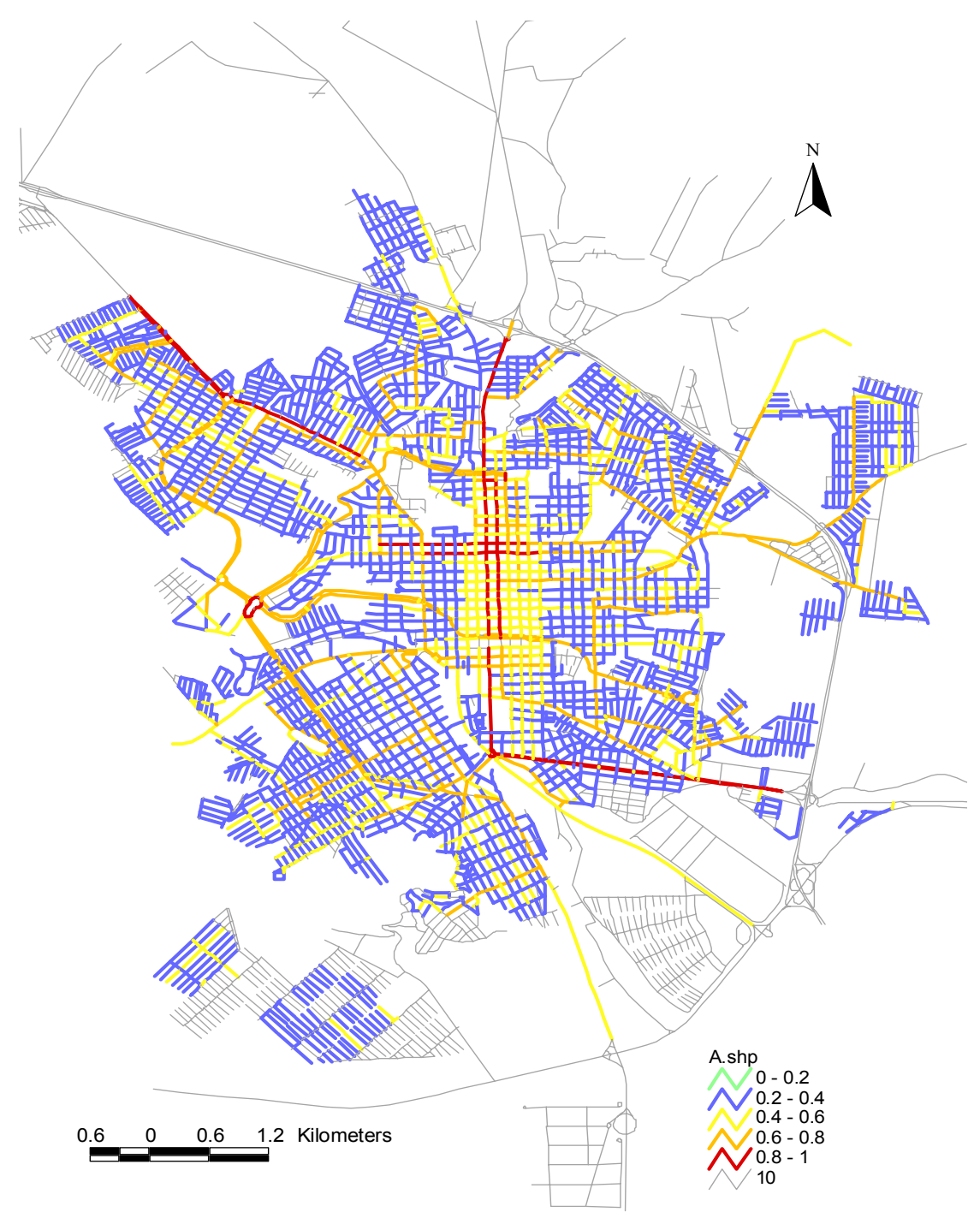

Figura 6.23: Mapa A resultante de WLC_A

6.4.4 Processo de Combinação OWA - Nivel 2

As combinações correspondentes ao nível 2, dão origem aos mapas $\mathrm{B}$ e $\mathrm{C}$, através dos procedimentos OWA_B e OWA_C respectivamente. Para ambos os procedimentos foram 
simulados três cenários de avaliação (i, ii e iii), correspondendo às atitudes de risco neutro, risco mínimo e máximo.

As simulações do procedimento OWA_B agregaram os scores ponderados dos fatores B1 e B2 contando com novos conjuntos de pesos (Order Weights), conforme apresentado na Tabela 6.6. Esse procedimento deu origem aos cenários Bi, Bii e Biii, representando o grupo de Fatores Associados a Questões Técnicas e Operacionais (grupo B conforme Figura 6.4).

Tabela 6.6: Cenários de avaliação empregados para gerar o mapas do fator B

\begin{tabular}{llccl}
\hline Cenários & Order Weights & ANDNess & Trade-off & Atitudes de Risco \\
\hline Bi & $(0,50 ; 0,50)$ & 0,50 & 1,00 & Risco neutro - Trade-off total \\
Bii & $(1,00 ; 0,00)$ & 1,00 & 0,00 & Risco mínimo - Sem Trade-off \\
Biii & $(0,00 ; 1,00)$ & 0,00 & 0,00 & Risco máximo - Sem Trade-off \\
\hline
\end{tabular}

A Figura 6.24 mostra, para efeito de exemplo, a tabela de atributos do grupo B desenvolvida no ARCView para fazer a combinação OWA_B. Várias colunas são criadas com o intuito de realizar todos os passos necessários para a combinação dos critérios.

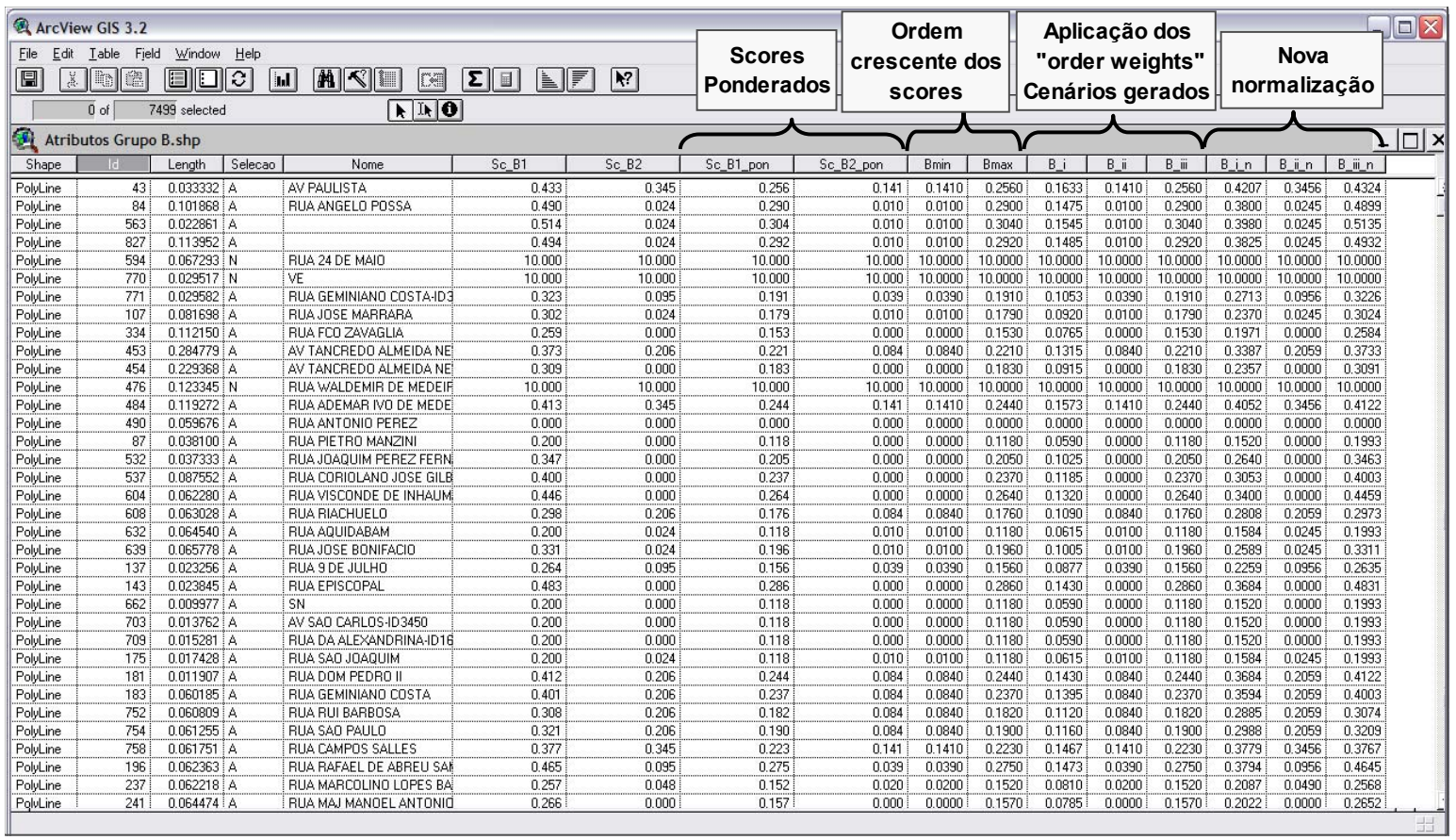

Figura 6.24: Combinação OWA_B em SIG-ARCView

Os cenários Bi, Bii e Biii, passaram por uma nova normalização (colocando os valores na escala de 0 a 1) de modo que a letra " $n$ " foi acrescentada identificando este procedimento. Os mapas dos três cenários são apresentados na Figura 6.25. 


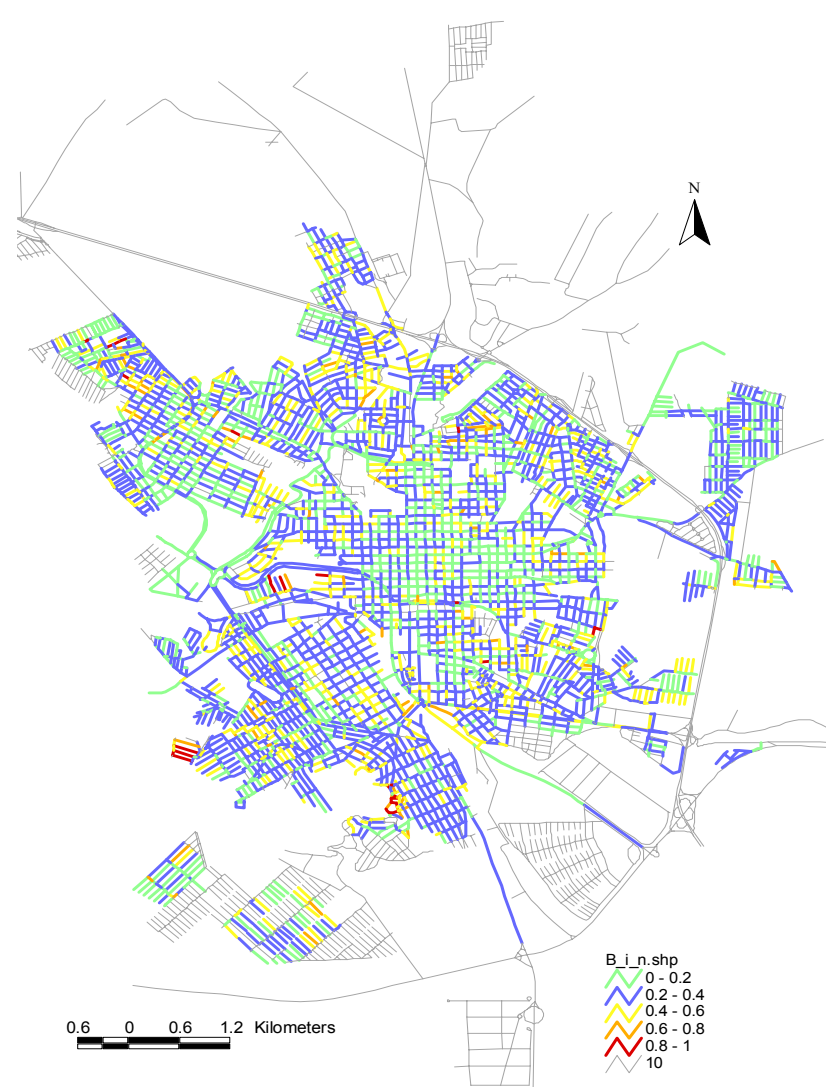

(a) Cenário Bi_n

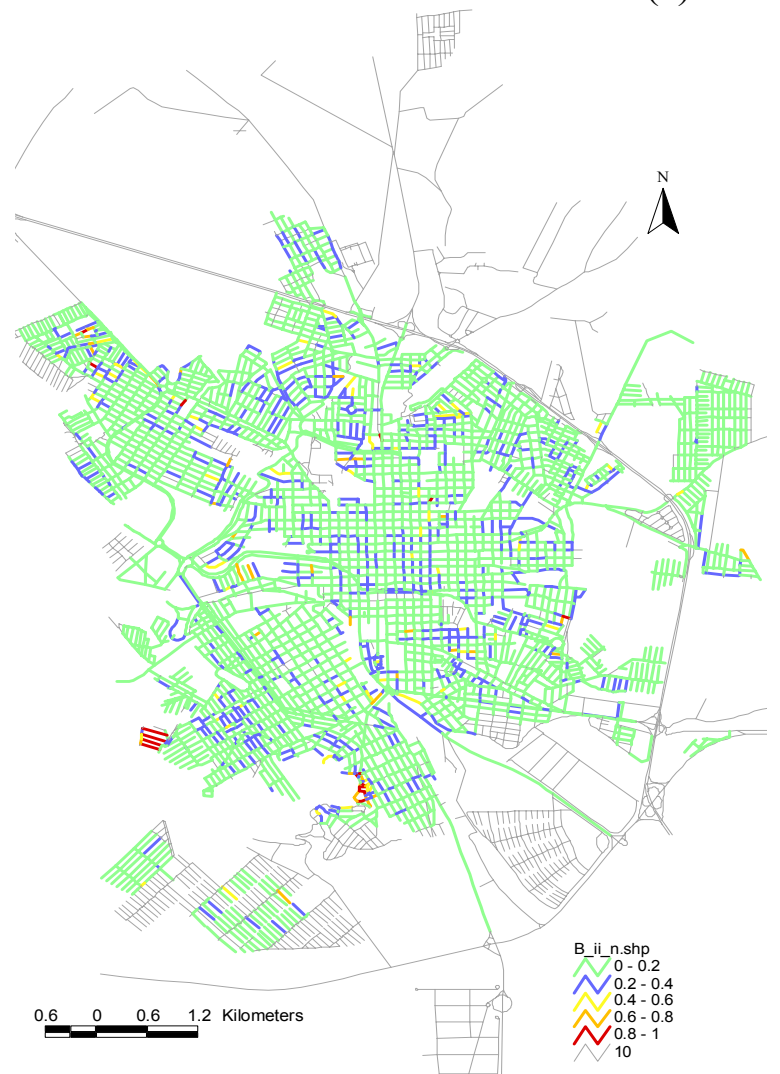

(b) Cenário Bii_n

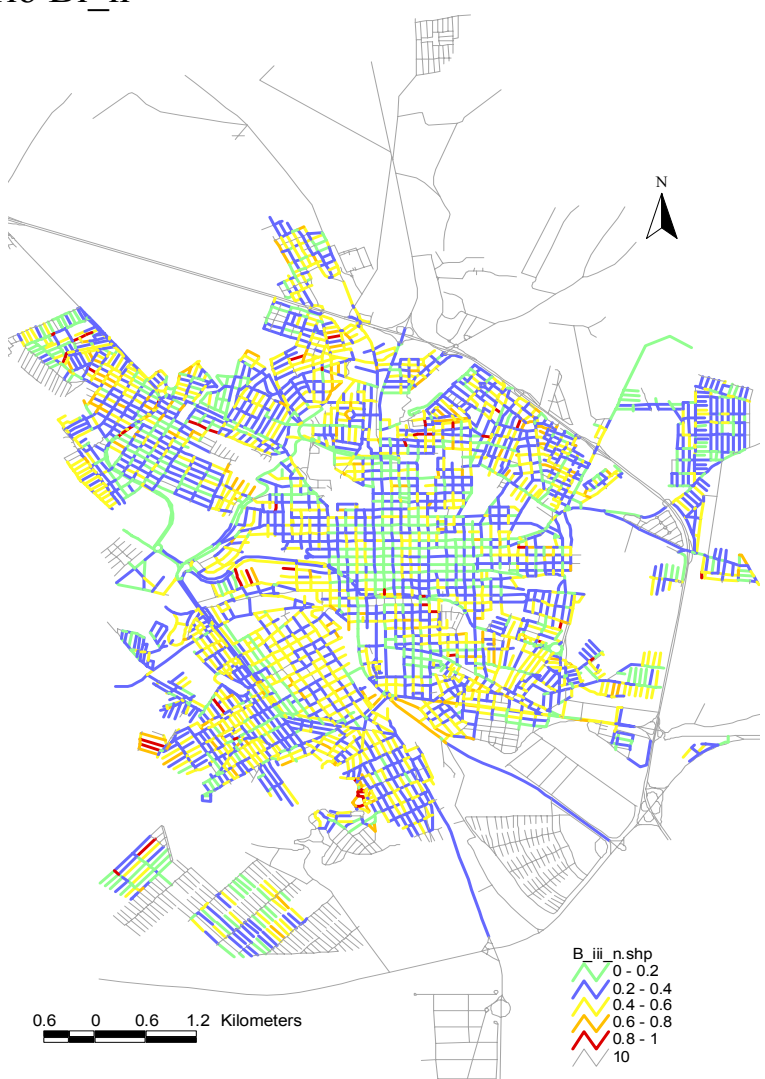

(c) Cenário Biii_n

Figura 6.25: Mapas resultantes do procedimento OWA_B 
As simulações do procedimento OWA_C foram realizadas em duas partes, agregando os scores normalizados dos mapas C1_n e C2_n (2a normalização) com mapas resultantes do procedimento OWA_C3, do nível3 (C3i_n e C3v_n). Os cenários escolhidos para estas combinações e os novos conjuntos de pesos aplicados são apresentados na Tabela 6.7. Os cenários resultantes, Ci.1, Cii.1, Ciii.1 da primeira etapa e Ci.2, Cii:2 e Ciii.2 da segunda etapa de combinação, representam o grupo de Fatores Associados à Localização (grupo C).

Tabela 6.7: Cenários de avaliação empregados para gerar os mapas do fator C

\begin{tabular}{cllll}
\hline Procedimento & Cenário & Order Weights & \multicolumn{2}{c}{ Cenários combinados } \\
\hline & Ci.1 & $(0,33 ; 0,33 ; 0,33)$ & C1_n & WLC \\
& Cii.1 & $(1,00 ; 0,00 ; 0,00)$ & C2_n & WLC \\
OWA_C & Ciii.1 & $(0,00 ; 0,00 ; 1,00)$ & C3i_n & WLC \\
\cline { 2 - 5 } & Ci.2 & $(0,33 ; 0,33 ; 0,33)$ & C1_n & WLC \\
& Cii.2 & $(1,00 ; 0,00 ; 0,00)$ & C2_nn & WLC \\
& Ciii.2 & $(0,00 ; 0,00 ; 1,00)$ & C3늠 & Alto risco-trade-off parcial \\
\hline
\end{tabular}

A primeira etapa do procedimento OWA_C combina os mapas $\mathrm{C} 1$ e $\mathrm{C} 2$, gerados através de WLC e, o cenário C3i_n, resultante de OWA referente ao nível 3, sendo todos de risco neutro. Neste caso, optou-se por realizar a compensação total entre os scores mais baixos e mais elevados e gerar mapas neutros para o processo de decisão.

A segunda etapa combina dois cenários neutros ( $\mathrm{C} 1$ e $\mathrm{C} 2$, de trade-off total) e um cenário de alto risco, com trade-off parcial, o cenário C3v_n. Considera-se uma atitude neutra em relação às opções por seções próximas a infra-estrutura de transportes e a equipamentos públicos e prédios institucionais e, uma atitude mais otimista em relação às preferências pessoais e administrativas. Nesse caso, optou-se por valorizar pelo menos um aspecto (proximidade a áreas de lazer, esporte, centros comerciais ou em relação à qualidade de vida dos bairros) que esteja colaborando para a priorização da via, ou seja, que tenha valor elevado, podendo os outros aspectos ter valores baixos e até muito baixos. Os mapas gerados para os seis cenários são mostrados na Figura 6.26 e na Figura 6.27.

Além dos grupos A, B e C, o grupo D também faz parte do nível 1, porém não contém outros níveis mais baixos da estrutura hierárquica, sendo desenvolvido diretamente através de scores normalizados referentes aos custos de M\&R de pavimentos (Figura 6.28). As estatísticas dos valores gerados em cada mapa do nível 1 são apresentadas na Tabela 6.8. 


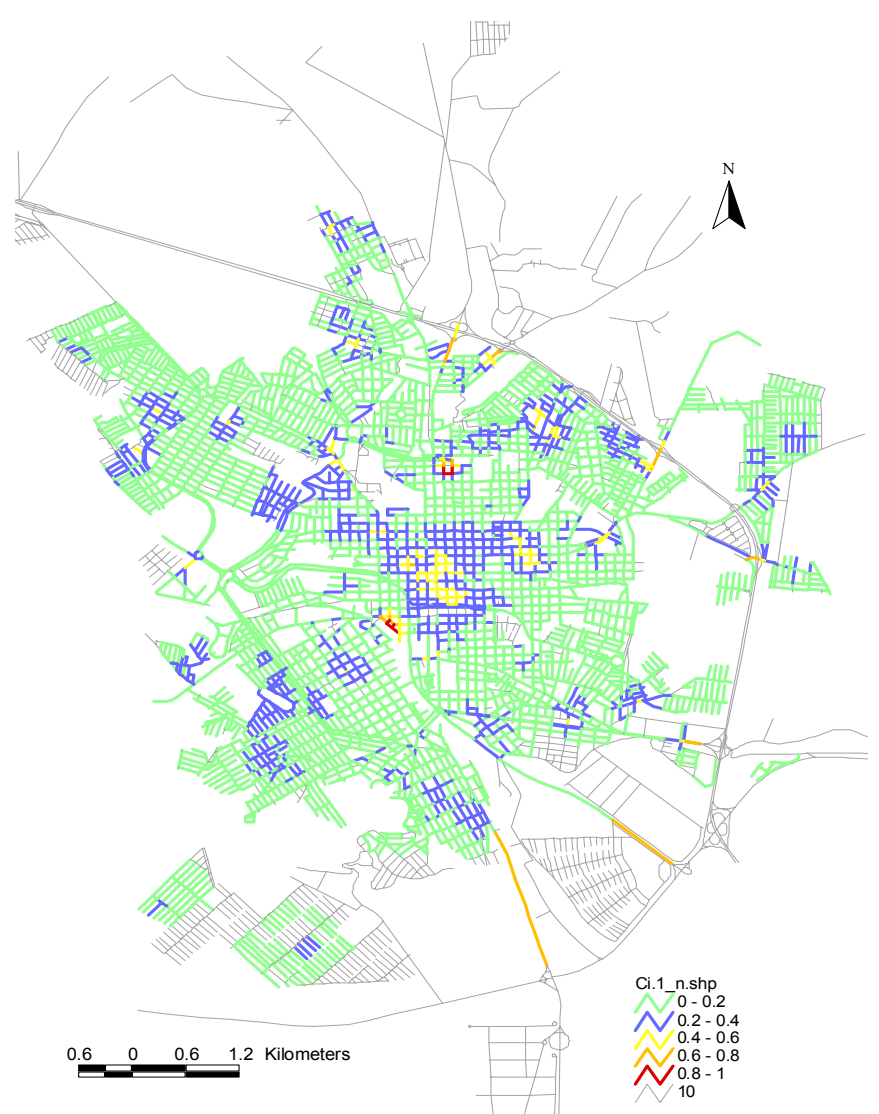

(a) Cenário Ci.1_n

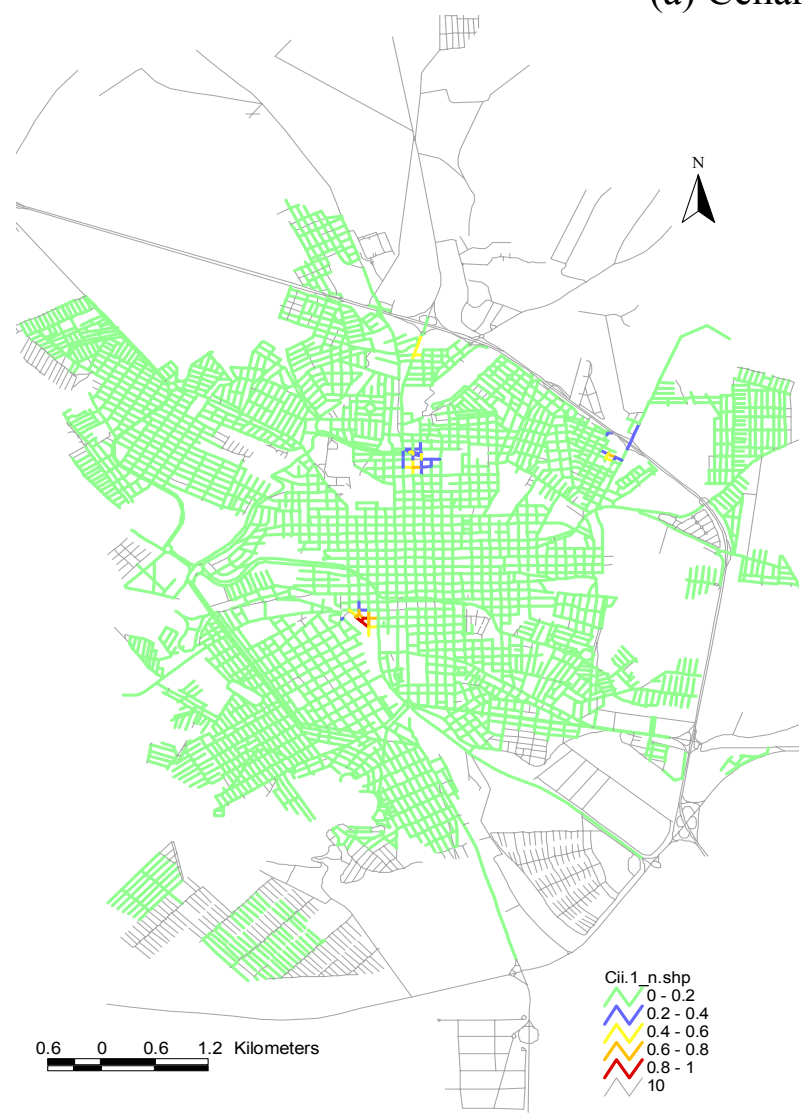

(b) Cenário Cii.1_n

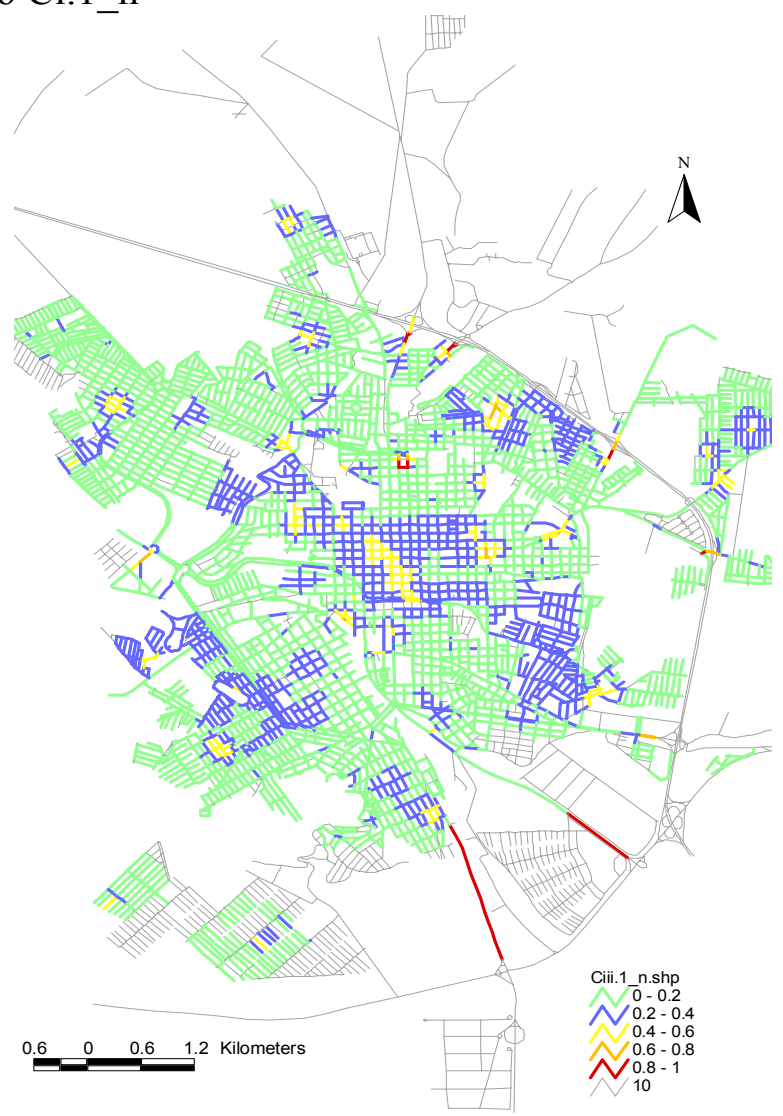

(c) Cenário Ciii.1_n

Figura 6.26: Mapas resultantes da primeira etapa do procedimento OWA_C 


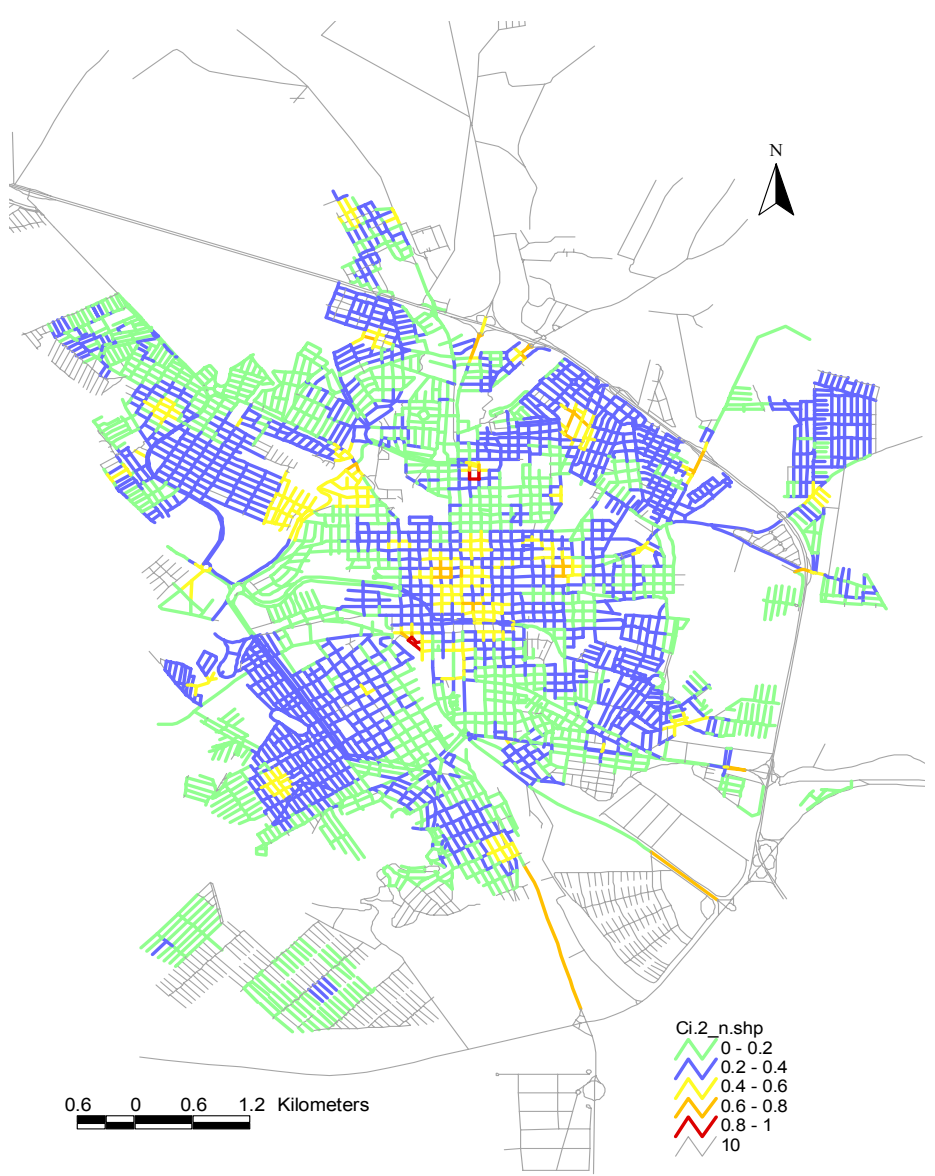

(a) Cenário Ci.2_n

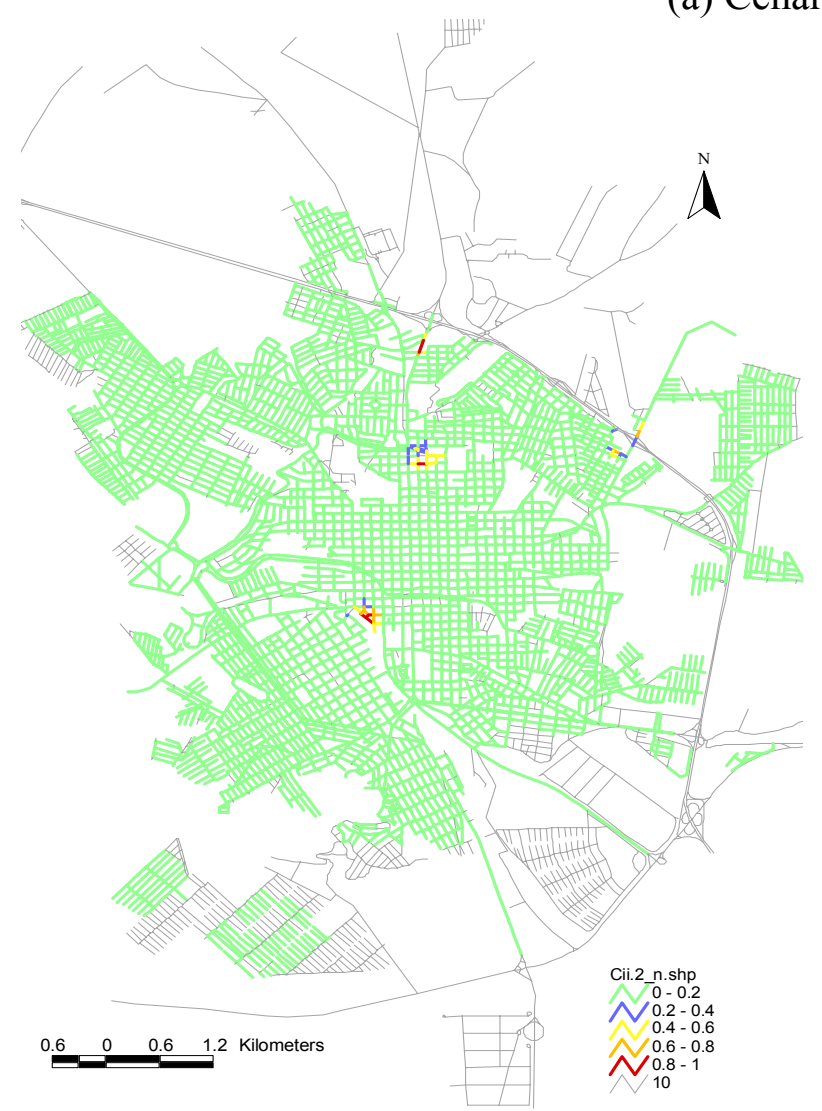

(b) Cenário Cii.2_n

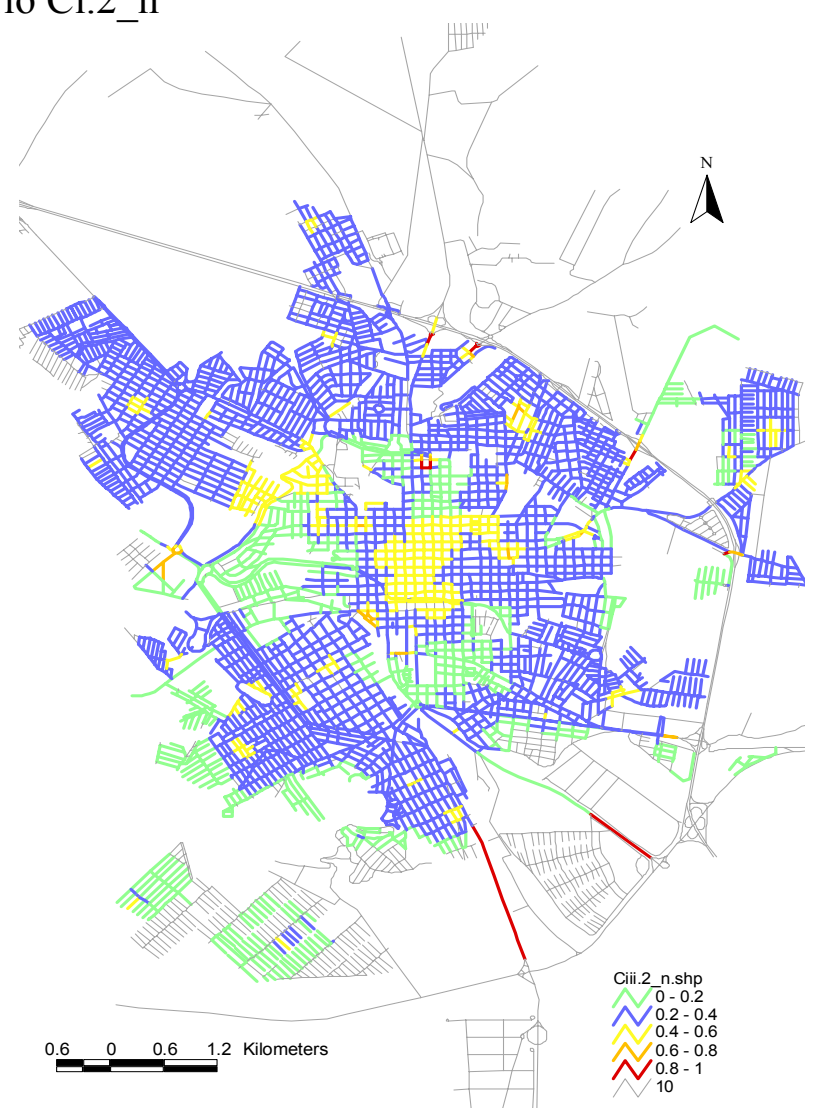

(c) Cenário Ciii.2_n

Figura 6.27: Mapas resultantes da segunda etapa do procedimento OWA_C 


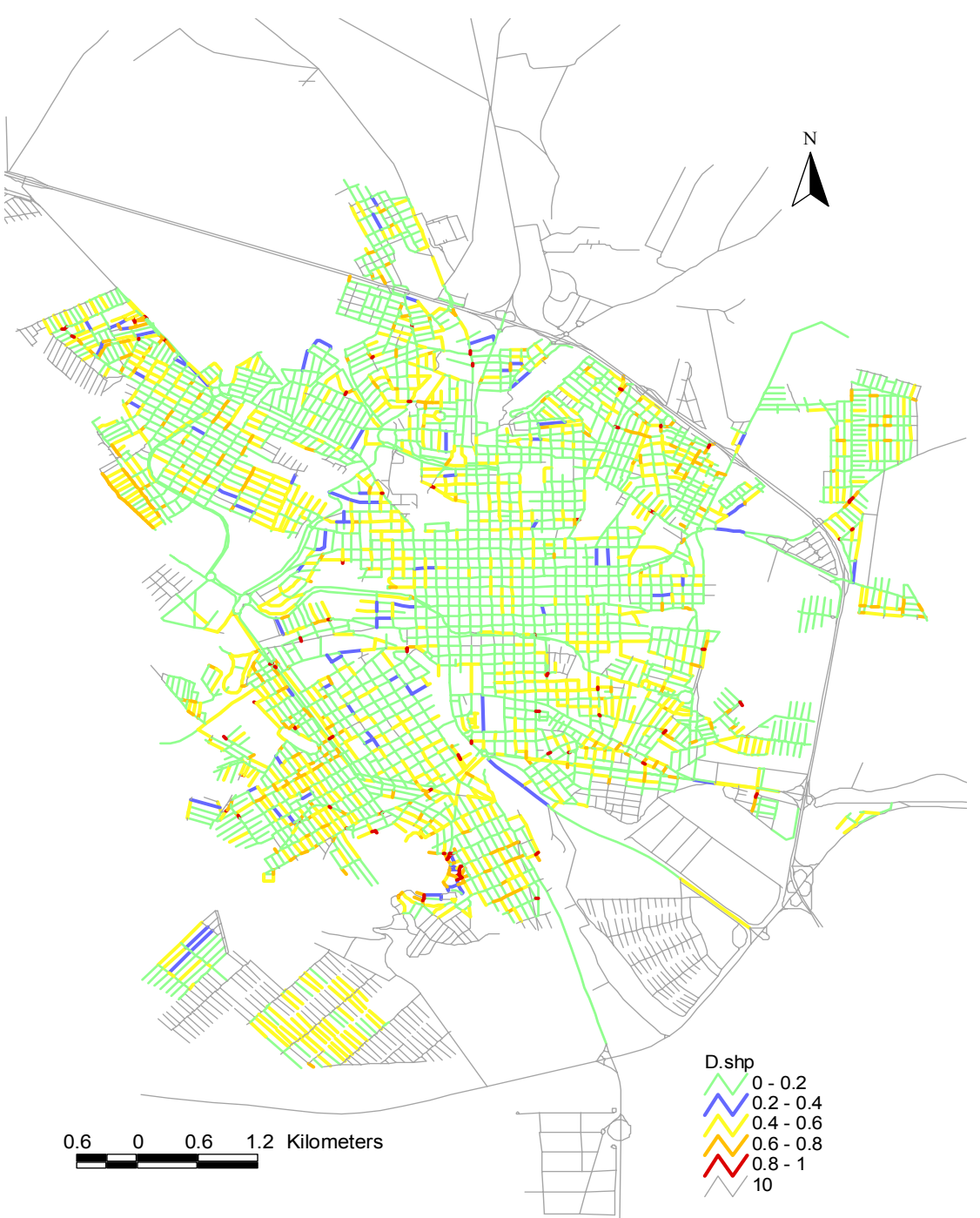

Figura 6.28: Mapa com scores normalizados do grupo D

Tabela 6.8: Estatísticas dos mapas do nível 1

\begin{tabular}{lcccl}
\hline \multicolumn{1}{c}{ Mapa } & Média & Desvio Padrão & \% de valores zero & Tipo de Avaliação \\
\hline A & 0,621 & 0,188 & 0 & Risco Neutro \\
Bi $\mathrm{n}$ & 0,291 & 0,132 & 1 & Risco Neutro \\
Bii $\mathrm{n}$ & 0,074 & 0,124 & 37 & Risco Mínimo \\
Biii $\mathrm{n}$ & 0,355 & 0,146 & 1 & Risco Máximo \\
Ci.1_n & 0,164 & 0,099 & 4,6 & Risco Neutro \\
Cii.__n & 0,006 & 0,052 & 98 & Risco Mínimo \\
Ciii.__n & 0,188 & 0,102 & 5 & Risco Máximo \\
Ci.2_n & 0,222 & 0,116 & 4,5 & Risco Neutro \\
Cii.__n & 0,006 & 0,055 & 98 & Risco Mínimo \\
Ciii.__n & 0,273 & 0,117 & 4,5 & Risco Máximo \\
D & 0,147 & 0,063 & 73 & $*$ \\
\hline
\end{tabular}

Os mapas possuem scores normalizados, com valores mínimo e máximo iguais a 0 e 1 , respectivamente.

* Scores normalizados de Custo de M\&R. 


\subsubsection{Processo de Combinação OWA - Nível 1}

A combinação de critérios do nível 1 considera os mapas dos grandes grupos gerados no nível 2, ou seja, grupo A através de WLC e grupos B e C, ambos através de OWA, com três e seis cenários de avaliação, respectivamente, e o grupo D gerado através de scores normalizados de custos M\&R de pavimentos.

As combinações dos fatores associados à hierarquia viária (grupo A), fatores associados às questões técnicas e operacionais (grupo B), fatores associados à localização (grupo C) e fatores associados aos custos (grupo D) originam os mapas finais, ou seja, os mapas de ranking das seções de pavimentos, de acordo com a ordem crescente dos scores e de prioridades. Através do procedimento OWA são desenvolvidos seis cenários de avaliação, considerando análises de risco neutro (com compensação total entre os critérios), risco mínimo e risco máximo (ambos sem compensação entre os critérios).

O procedimento, nomeadamente de OWA_G (ver Figura 6.4), é dividido em duas etapas. A primeira etapa combina o mapa A, os cenários Bi_n e Ci.1_n e o mapa D, sendo todos de risco neutro. A segunda etapa combina dois cenários neutros $\mathrm{A}$ e $\mathrm{D}$, um cenário de risco mínimo Bii_n e um cenário de risco máximo Ciii.1_n. Os seis cenários de avaliação são simulados através do procedimento OWA, contando com novos conjuntos de pesos (Order Weights), que foram aplicados em ordem crescente dos scores ponderados correspondentes aos grupos de fatores A, B, C e D, resultando os mapas Pi.1, Pii.1 e Piii.1 da primeira etapa e Pi.2, Pii.2 e Piii.2 da segunda etapa. A Tabela 6.9 mostra os seis cenários desenvolvidos para gerar os mapas finais de priorização de pavimentos.

Na primeira etapa, foi realizada, em todos os níveis, uma análise de decisão neutra, ou seja, atitude neutra com scores mais altos compensando os scores mais baixos. Entretanto, a segunda etapa combina um cenário A neutro, resultante de procedimento WLC do nível 2, um cenário $\mathrm{B}$ pessimista (risco mínimo, sem compensação entre critérios), um cenário $\mathrm{C}$ otimista (risco máximo, sem compensação entre critérios) e um cenário $\mathrm{D}$, gerado através de scores normalizados. Optou-se por uma atitude conservadora, adversa ao risco em relação às questões técnicas e operacionais (cenário $\mathrm{B}$, menores scores são valorizados), no qual é garantido que todas as seções de vias, com scores altos, sejam identificadas. Ainda, optou-se por uma atitude neutra em relação à hierarquia viária (cenário A) e aos custos de $M \& R$ (cenário D) e uma decisão otimista, em que se valorizam os scores mais elevados quanto à localização das seções de pavimentos (cenário C). Esta decisão favorece a identificação das vias com problemas técnicos e operacionais mais graves, ou seja, defeitos e condição do 
pavimento que prejudicam o tráfego na via. A hierarquia viária e os custos da estratégia de M\&R são considerados de forma neutra e, ainda, valoriza pelo menos um aspecto de localização que esteja colaborando para a priorização da via.

Tabela 6.9: Cenários de avaliação empregados para gerar os mapas finais de priorização

\begin{tabular}{|c|c|c|c|}
\hline Procedimento & Cenário & Order Weights & Cenários combinados \\
\hline \multirow{6}{*}{ OWA_G } & Pi.1 & $(0,25 ; 0,25 ; 0,25 ; 0.25)$ & \multirow{3}{*}{$\begin{array}{l}\text { A: } \quad \text { WLC } \\
\text { Bi_n: WLC } \\
\text { Ci.1_n: WLC } \\
\text { D: } \quad \text { Scores normalizados }\end{array}$} \\
\hline & Pii.1 & $(1,00 ; 0,00 ; 0,00 ; 0,00)$ & \\
\hline & Piii.1 & $(0,00 ; 0,00 ; 0,00 ; 1,00)$ & \\
\hline & Pi.2 & $(0,25 ; 0,25 ; 0,25 ; 0.25)$ & \multirow{2}{*}{$\begin{array}{l}\text { A: WLC } \\
\text { Bii_n: Risco mínimo } \\
\text { Ciii.1_n: Risco máximo }\end{array}$} \\
\hline & Pii. 2 & $(1,00 ; 0,00 ; 0,00 ; 0,00)$ & \\
\hline & Piii. 2 & $(0,00 ; 0,00 ; 0.00 ; 1,00)$ & D: $\quad$ Scores normalizados \\
\hline
\end{tabular}

A Figura 6.29 ilustra a primeira etapa da combinação OWA_G desenvolvida no ArcView. Os mapas gerados para os seis cenários finais de avaliação são mostrados da Figura 6.30 até a Figura 6.35. As estatísticas dos valores gerados em cada mapa final de priorização são apresentadas na Tabela 6.10 .

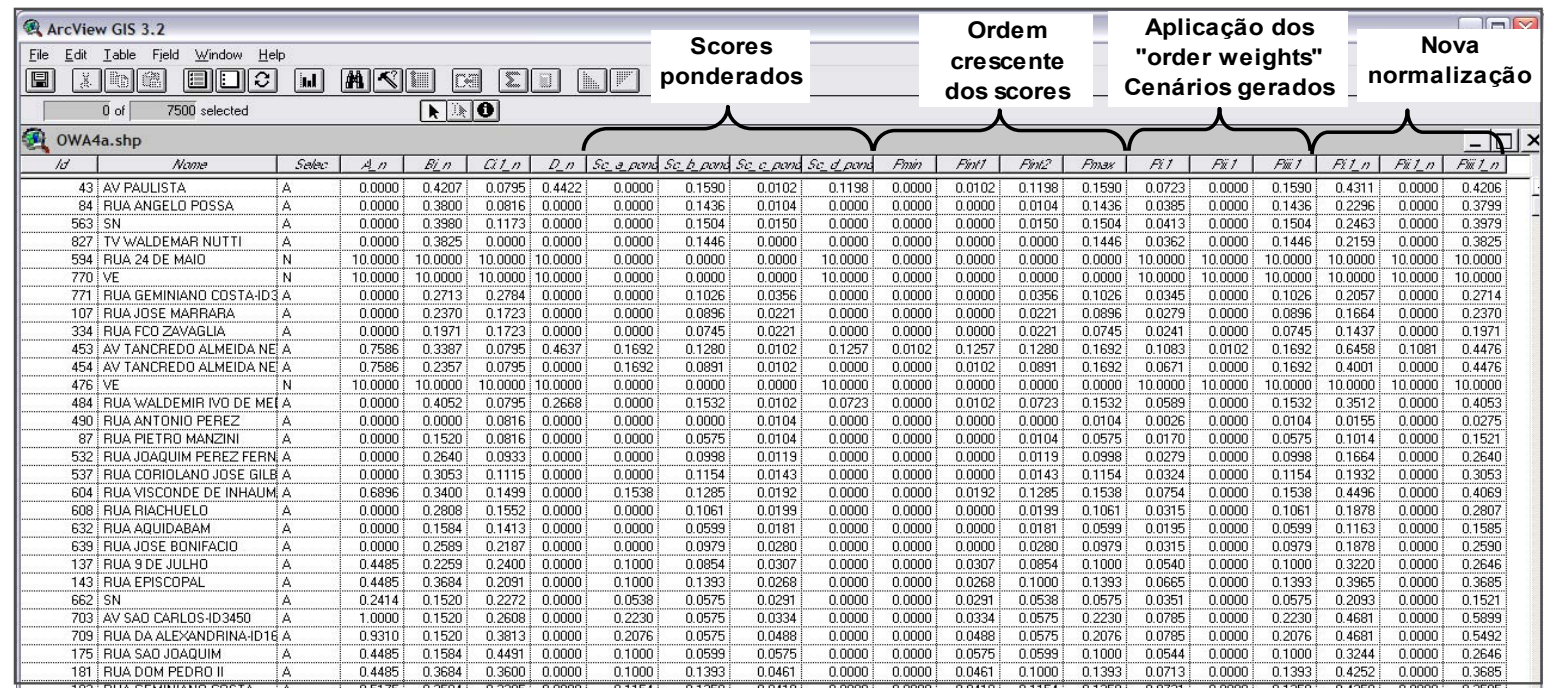

Figura 6.29: Primeira etapa da combinação OWA_G em SIG-ARCView

Tabela 6.10: Estatísticas dos mapas finais de priorização

\begin{tabular}{lcccl}
\hline \multicolumn{1}{c}{ Mapa } & Média & Desvio Padrão & \% de valores zero & \multicolumn{1}{c}{ Tipo de Avaliação } \\
\hline Pi.1_n & 0,322 & 0,168 & 0 & Risco Neutro \\
Pii.1_n & 0,018 & 0,073 & 92 & Risco Mínimo \\
Piii.1_n & 0,349 & 0,137 & 0 & Risco Máximo \\
Pi.2_n & 0,221 & 0,181 & 1 & Risco Neutro \\
Pii.__n & 0,020 & 0,086 & 93 & Risco Mínimo \\
Piii.2_n & 0,247 & 0,182 & 1 & Risco Máximo \\
\hline
\end{tabular}

Todos os mapas possuem scores normalizados, com valores mínimo e máximo iguais a 0 e 1 , respectivamente. 


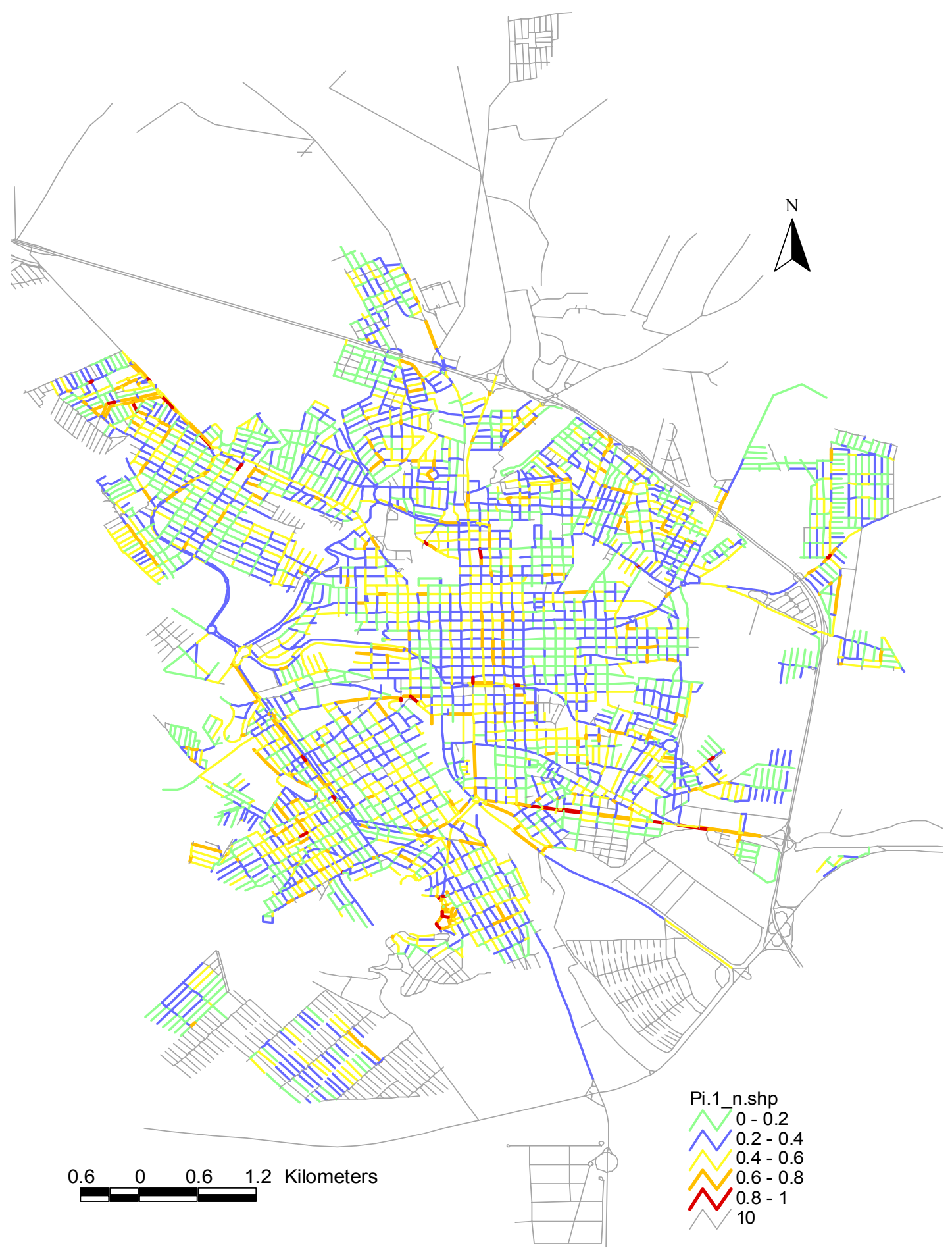

Figura 6.30: Mapa do cenário final Pi.1_n

O mapa Pi.1 (Figura 6.30), combina os quatro grandes grupos A, B, C e D, todos com risco neutro, resultando num cenário neutro de decisão. Aplicando-se um conjunto de order weight $[0,25 ; 0,25 ; 0,25 ; 0,25]$, em que todos os pesos têm o mesmo valor, as seções são priorizadas de acordo com a média da soma dos scores de cada critério em questão. Assim, os scores mais elevados compensam os scores mais baixos. 


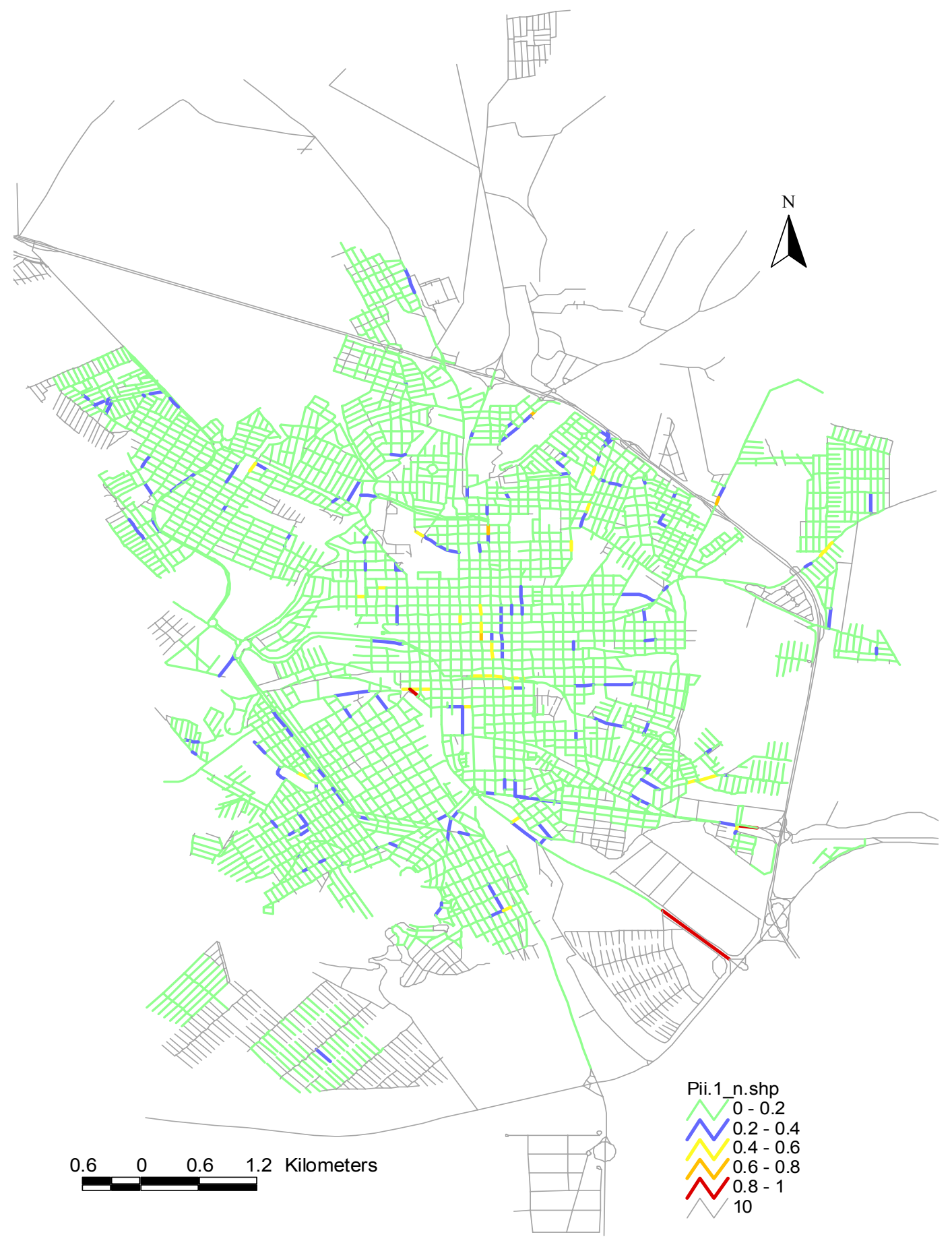

Figura 6.31: Mapa do cenário final Pii.1_n

O mapa Pii.1 (Figura 6.31), combina os quatro grandes grupos A, B, C e D, todos com risco neutro, resultando num cenário neutro de decisão. Aplicando-se um conjunto de order weight $[1,00 ; 0,00 ; 0,00 ; 0,00]$ somente os menores scores participam da análise. A prioridade (score elevado) de uma seção é definida pelo score de um determinado critério, em que todos os outros critérios têm scores mais elevados ou iguais ao que foi utilizado. Por outro lado, basta que um dos critérios possua um valor igual à zero para que a seção seja considerada sem prioridade. Por isso, é uma situação de risco mínimo. 


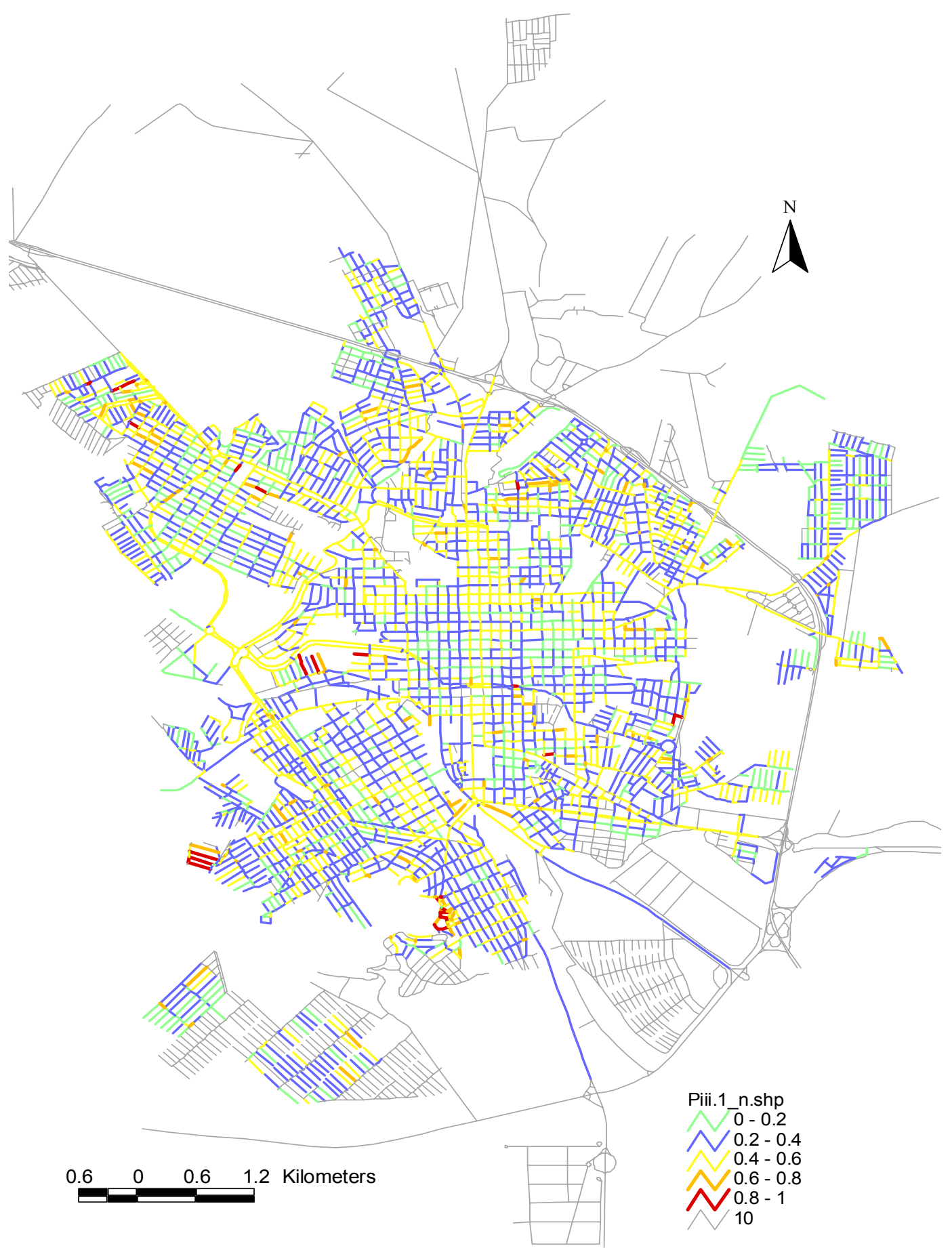

Figura 6.32: Mapa do cenário final Piii.1_n

O mapa Piii.1 (Figura 6.32), combina os quatro grandes grupos A, B, C e D, todos com risco neutro, resultando num cenário neutro de decisão. Aplicando-se um conjunto de order weight $[0,00 ; 0,00 ; 0,00 ; 1,00]$ somente os maiores scores participam da análise. A prioridade (índice elevado) de uma seção é definida pelo score de um determinado critério, em que não necessariamente os outros critérios têm scores elevados, podendo possuir valores muito mais baixos daquele utilizado na análise e, portanto, é considerada uma situação de risco máximo. 


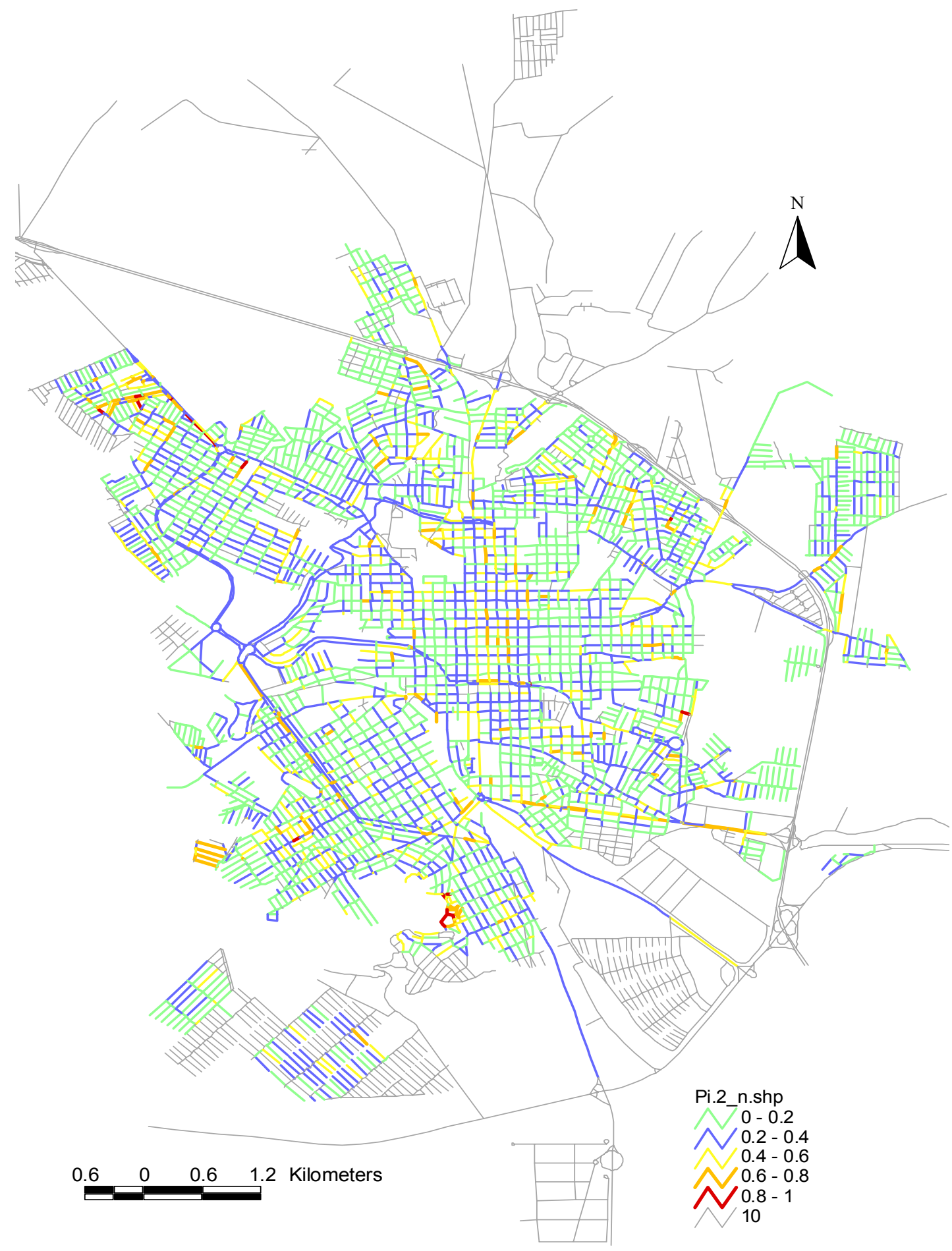

Figura 6.33: Mapa do cenário final Pi.2_n

O mapa Pi.2 (Figura 6.33), combina os quatro grandes grupos A, B, C e D, sendo os grupos $\mathrm{A}$ e $\mathrm{D}$ de risco neutro, $\mathrm{B}$ de risco mínimo e $\mathrm{C}$ de risco máximo. Aplicando-se um conjunto de order weight $[0,25 ; 0,25 ; 0,25 ; 0,25]$, resultando num cenário de risco neutro, da mesma forma que realizado com o mapa Pi.1, da Figura 6.30 . 


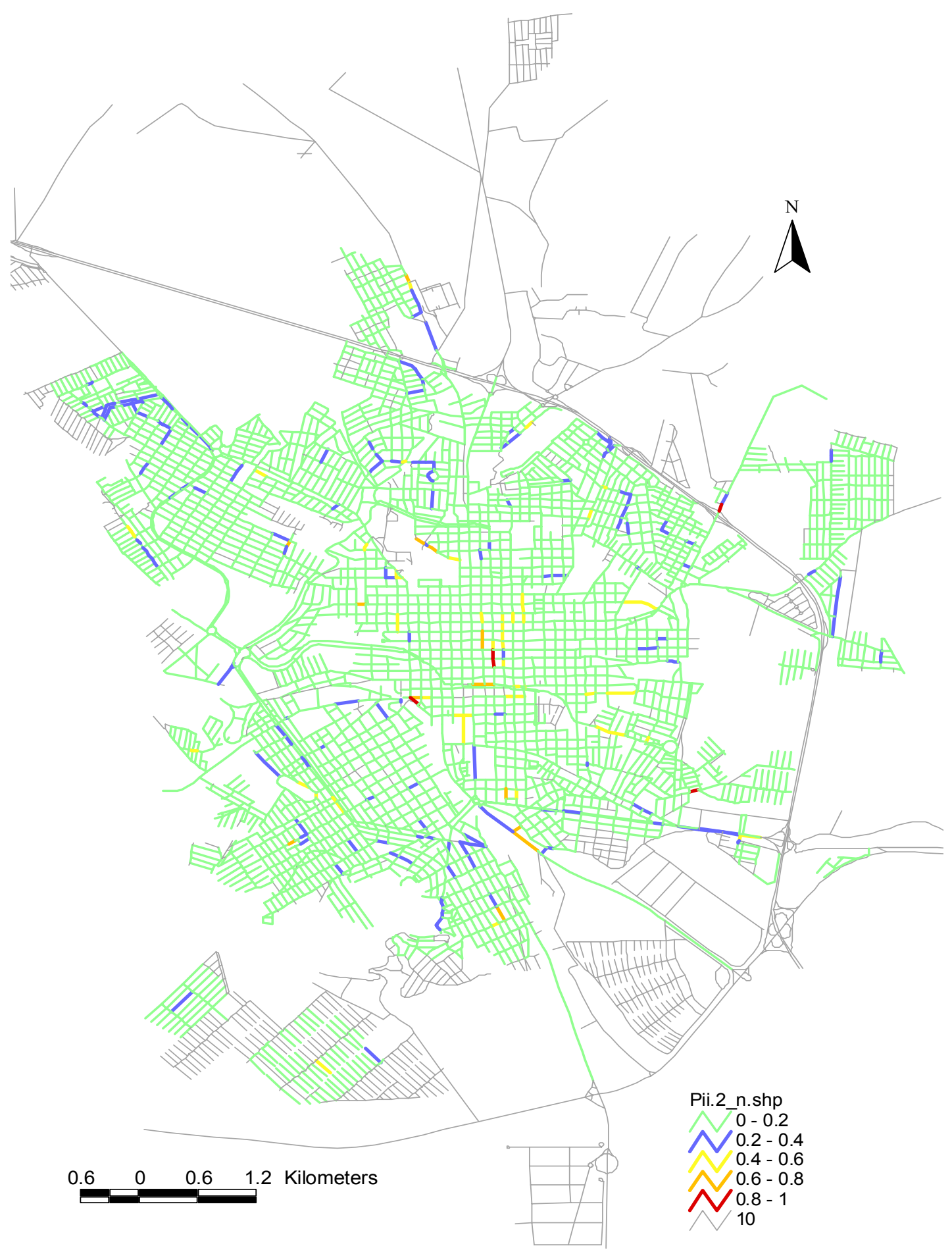

Figura 6.34: Mapa do cenário final Pii.2_n

O mapa Pii.2 (Figura 6.34), combina os quatro grandes grupos A, B, C e D, sendo os grupos $\mathrm{A}$ e $\mathrm{D}$ de risco neutro, $\mathrm{B}$ de risco mínimo e $\mathrm{C}$ de risco máximo. Aplicando-se um conjunto de order weight $[1,00 ; 0,00 ; 0,00 ; 0,00]$, resultando num cenário de risco mínimo, da mesma forma que realizado com o mapa Pii.1, da Figura 6.31. 


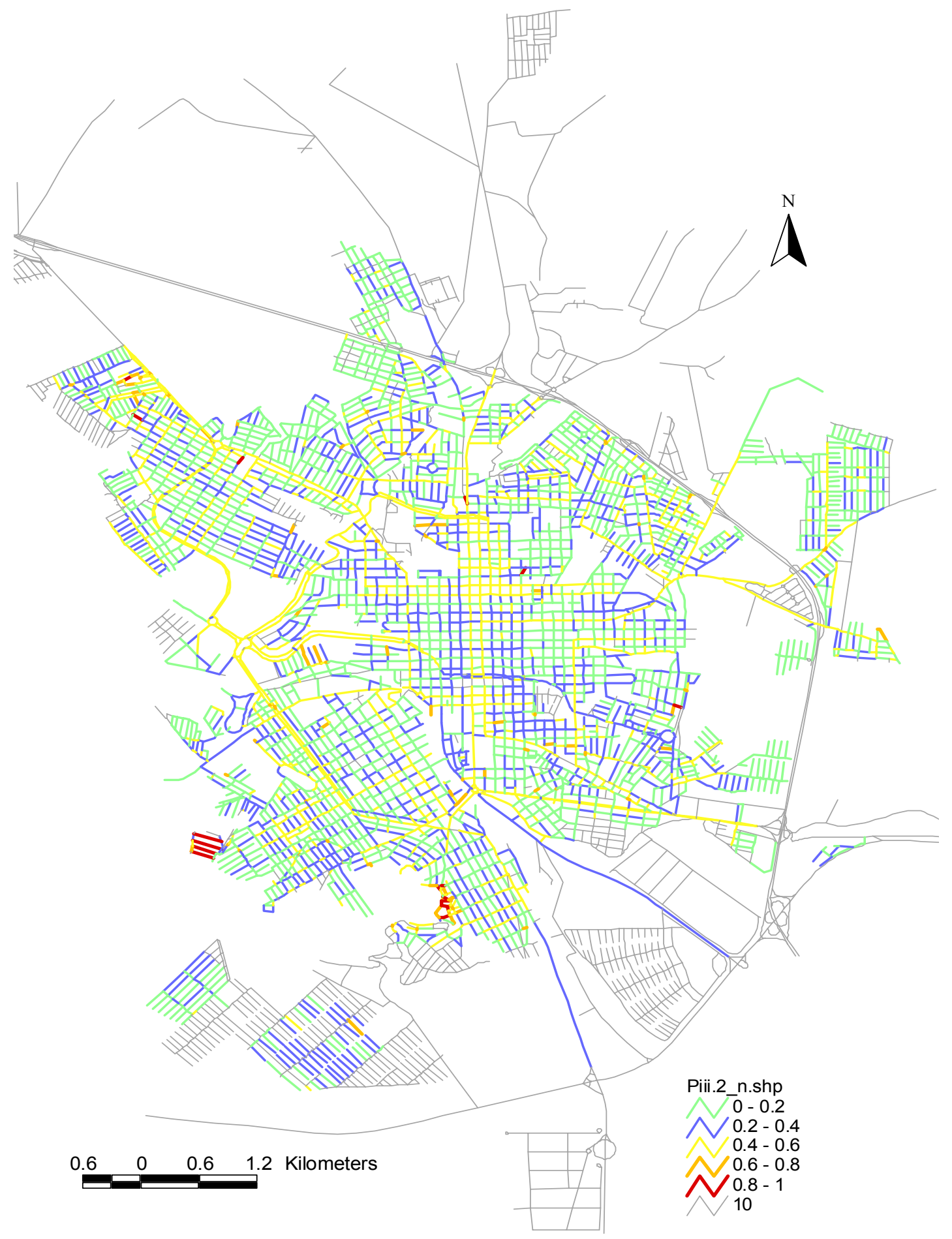

Figura 6.35: Mapa do cenário final Piii.2_n

O mapa Piii.2 (Figura 6.35), combina os quatro grandes grupos A, B, C e D, sendo os grupos $\mathrm{A}$ e $\mathrm{D}$ de risco neutro, $\mathrm{B}$ de risco mínimo e $\mathrm{C}$ de risco máximo. Aplicando-se um conjunto de order weight $[0,00 ; 0,00 ; 0,00 ; 1,00]$, resultando num cenário de risco máximo, da mesma forma que realizado com o mapa Piii.1, da Figura 6.32. 


\section{ANÁLISE DOS RESULTADOS}

A análise dos resultados para a priorização de seções de pavimentos foi realizada de acordo com o nível de agregação de cada conjunto de critérios (ver Estrutura hierárquica ilustrada na Figura 6.4). Considerando que a combinação dos critérios é feita do nível 3 passando pelos níveis 2 e 1 até o objetivo final (gerar cenários finais de avaliação), as primeiras análises são referidas a combinação de critérios do nível 3. Os comentários têm como base as Figuras dos mapas gerados e alguns quantitativos em relação às seções observadas e aos respectivos scores obtidos.

\subsection{Mapas do Nível 2}

A combinação de critérios do nível 3 resultou os mapas $\mathrm{B} 1, \mathrm{C} 1, \mathrm{C} 2$ e $\mathrm{C} 3$, que formam o nível 2. Devem também ser considerados os mapas A1, A2, A3 e B2, que embora não tenham sido gerados através de processos de agregação também fazem parte desse nível (Figura 6.8 a Figura 6.12). O critério C3, em especial, foi gerado a partir de procedimento OWA, que deu origem aos cenários C3i a C3vi (Figura 6.17 a Figura 6.22).

\subsubsection{Mapas do grupo A}

O mapa A1 (Figura 6.7) refere-se aos scores de Classificação Funcional de vias, sendo destacadas as vias com maior classificação, ou seja, vias arteriais. Pode-se citar, por exemplo, a Avenida São Carlos, a principal avenida do centro da cidade, ligando as regiões norte e sul, e as Avenidas Francisco Pereira Lopes e Henrique Gregori, que funcionam quase como um anel viário na região entre a zona oeste e central. Ainda observa-se alta prioridade na Avenida Alfredo Maffei, por ser uma via arterial que faz a ligação entre as regiões leste e oeste, passando ainda pela região central. Já as vias locais são menos prioritárias e, dessa forma, possuem o menor score. Conforme a Tabela 6.5, os scores iniciam em 0,30 e vão até um valor de 0,90 (sendo o intervalo possível de 0 a 1), com uma média de 0,44, onde a maioria das seções é de vias locais. O desvio padrão de 0,216 pode ser considerado um valor 
baixo. A Figura 7.1 mostra algumas ruas e avenidas importantes da cidade de São Carlos SP. A localização dos bairros da cidade pode ser verificada no ANEXO F.

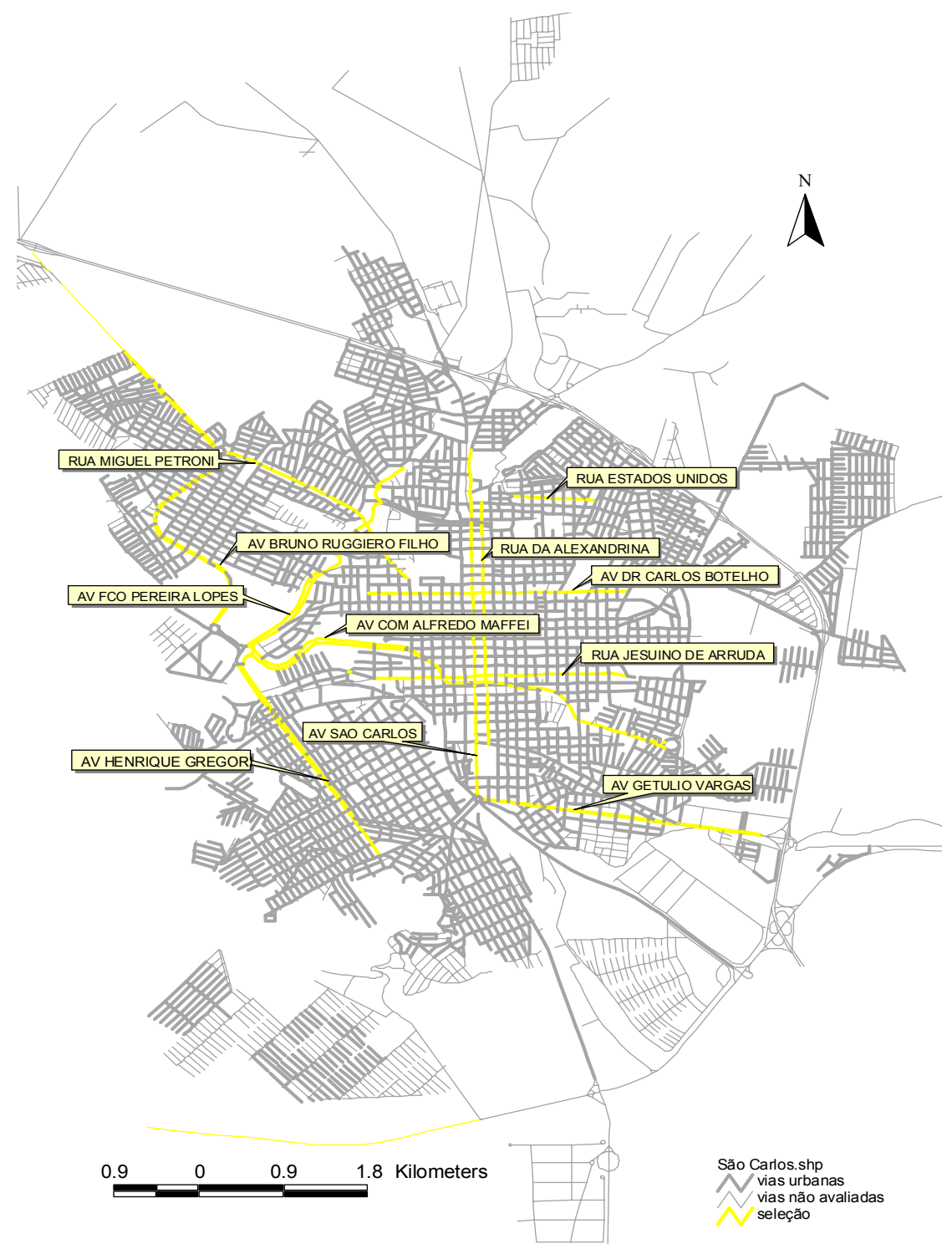

Figura 7.1: Mapa de algumas das principais vias urbanas de São Carlos - SP

O mapa A2 (Figura 6.8), relacionado com o tipo de rota, considera rotas de tráfego normal de veículos de passeio e rotas específicas de ônibus urbanos. Observam-se os maiores scores em função das rotas de ônibus, que estão espalhadas por toda a cidade e levemente concentradas nas ruas com maior classe funcional. Este fato deve-se à existência de uma relação entre o tipo de tráfego e a capacidade de tráfego que as ruas suportam, não sendo necessariamente sempre dessa forma, pois as rotas de ônibus são traçadas de acordo com a necessidade da população. Conforme a Tabela 6.5, os scores iniciam em 0,30 até um valor de 1,0, com uma média de 0,49 e desvio padrão de 0,313 . 
O mapa A3 (Figura 6.9), referente aos scores de Volume de Tráfego, mostra duas vias de saída da cidade, Rua Miguel Petroni e Avenida Getúlio Vargas, com grande prioridade. Essas vias são de pista dupla e possuem elevado volume de tráfego. Ainda destacam-se a Avenida São Carlos e a Rua Alexandrina, vias centrais paralelas que captam todo o fluxo de veículos que trafegam no binário norte-sul e, finalmente, a Rua Carlos Botelho, responsável pelo tráfego de veículos e ônibus a pontos com grande fluxo de pessoas, tais como a Santa Casa e a Universidade de São Paulo. Os scores iniciam em 0,30 e vão até um valor de 0,9, com uma média de 0,38 e desvio padrão de 0,161 (Tabela 6.5).

Cabe comentar que a relação entre os três mapas A1, A2 e A3 são bem próximas, pois se tratam de fatores de hierarquia viária, onde um fator pode estar intimamente correlacionado com o outro. Por exemplo, a Avenida São Carlos, por ser uma das principais avenidas da cidade, possui altos scores para os três fatores (Classe Funcional, Tipo de Rota e Volume de Tráfego).

\subsubsection{Mapas do Grupo B}

O mapa B1 (Figura 6.10), resultado da combinação WLC_B1, apresenta os scores que representam o Índice Combinado de Defeitos (avaliação objetiva do pavimento). Pode-se observar que as seções com maior prioridade de manutenção estão localizadas em bairros residenciais. Por exemplo, uma pequena seção na Rua Estados Unidos, na Vila Costa do Sol, apresentou cor vermelha $($ score $=0,898)$ em virtude da presença de remendo de baixa severidade e desgaste de alta severidade em $85 \%$ do trecho, que elevou o valor final do score calculado. Outro exemplo é a Avenida Bruno Ruggiero Filho, no Bairro Santa Felícia, que apresentou algumas seções com score máximo $($ score $=1,0)$ devido à presença de defeitos nos bordos e remendos de baixa severidade e desgaste de alta severidade em $70 \%$ do trecho. A grande parte da região central está em boas condições de tráfego, representado pelos baixos valores dos scores, ou seja, sem muitos problemas com defeitos nos pavimentos.

No geral, os scores estão bem distribuídos por toda a rede e poucas são as seções com valores entre 0,8 e 1,0. Alguns pontos isolados possuem defeitos mais severos que elevam os valores dos scores. A grande maioria da rede possui scores variando entre 0,2 e 0,6, ou seja, de baixa a média prioridade, em que muitas vias apresentam algum tipo de defeito, mas são defeitos com baixo grau de severidade e pequena extensão. Por exemplo, a Rua Jesuíno de Arruda, na Vila Néri, apresenta seção de pavimento com cor amarelo, com remendos, panelas e desgaste de severidade baixa em 10\% da seção. No mapa B1 apenas 2\% 
de scores são iguais à zero, ou seja, com prioridade nula. Os scores variam de 0 a 1,0, com uma média de 0,35 e desvio padrão de 0,148 (Tabela 6.5).

O mapa B2 (Figura 6.11) apresenta os scores que representam o Índice de Condição do Pavimento (avaliação subjetiva do pavimento). Os scores são baixos, mostrando que durante a avaliação realizada sobre a condição da rede, os avaliadores observaram que a grande maioria das seções está em boas condições de tráfego. Verifica-se, por exemplo, que algumas seções isoladas, como nos bairros Vila Conceição e Jardim Medeiros (ANEXO F), possuem scores elevados entre 0,8 e 1,0. Conforme a Tabela 6.5, os scores variam de 0 a 1,0, onde $36 \%$ deles possuem valor igual a zero, com uma média de 0,076 e desvio padrão de 0,129. Cabe comentar que são consideradas, além da condição do pavimento para o tráfego, a existência e estado dos dispositivos de drenagem. A elevada incidência de valores iguais à zero, reflete o fato de que a maioria das seções se encontra em bom estado em relação à qualidade do pavimento, não prejudicando o tráfego local.

\subsubsection{Mapas do grupo C}

O mapa C1 (Figura 6.12), resultado da combinação WLC_C1 dos mapas C1.1 a C1.3, representa os scores relativos à Proximidade às infra-estruturas de transportes. Observam-se valores de scores mais elevados em vias próximas à rodoviária, sendo essas de grande importância para o tráfego local. Ainda, destacam-se com grande prioridade seções de vias de saída da cidade, próximas aos principais viadutos que ligam às rodovias que a contornam. Tem-se uma alta parcela de valores nulos (97\%), o que se deve ao fato das infraestruturas de transportes estarem em locais muito específicos, tornando o restante da rede com prioridades nulas de intervenção. Os scores variam de 0 a 0,44, com média de 0,003 e desvio padrão de 0,026 (Tabela 6.5).

O mapa C2 (Figura 6.13), resultado da combinação WLC_C2 dos mapas C2.1 a C2.7, referente aos scores de Proximidade a equipamentos ou prédios institucionais, mostra a concentração de valores elevados principalmente em vias próximas a postos de saúde e hospitais, dada a importância relativa desses dois critérios em relação aos outros. Assim como as escolas, os postos estão espalhados por vários bairros da cidade aumentando os scores das vias próximas a essas instituições. É visível uma concentração maior de instituições na região central da cidade, tornando esta região mais uma vez com elevado índice de prioridade. No mapa $\mathrm{C} 2$, conforme a Tabela 6.5 , os scores variam de 0 a 0,33 , sendo que $42 \%$ das seções possuem scores igual a zero, com média de 0,032 e desvio padrão de 0,050 . 
O resultado da combinação OWA_C3 dos mapas C3.1 a C3.5, do nível 3, são os cenários C3i_n a C3vi_n do nível 2 (representando o grupo C3 - Figura 6.17 a Figura 6.22). Os cenários de risco neutro (C3i_n e C3vi_n) permitem que os scores baixos sejam compensados por scores altos e resultam em valores intermediários na escala adotada. Os cenários de risco mínimo e baixo risco (C3ii_n e C3iv_n) ou máximo e alto risco (C3iii_n e C3v_n) limitam, inferior ou superiormente, a tomada de decisão. Observa-se que os mapas C3ii_n e C3iv_n apresentam, respectivamente, total tonalidade verde (scores nulos) e predominância de verde e azul (os mais baixos scores) enquanto que nos mapas C3iii_n e C3v_n predominam cores amarelo, passando pelo laranja até o vermelho (scores elevados).

O cenário C3ii_n (Figura 6.18) apresenta no seu total um valor nulo (100\% de scores igual à zero). Ocorre que pelo menos um critério combinado continha valor igual a zero. O cenário C3ii_n é de risco mínimo, sem trade-off, e por isso considerou apenas os scores mais baixos sem permitir qualquer compensação, neste caso scores iguais à zero. Para este ponto de decisão basta que apenas um fator (entre os critérios considerados) contenha valor insatisfatório (prioridade nula) para que toda a solução seja considerada sem prioridade, o que indica uma atitude conservadora de total ausência de risco.

\subsection{Mapas do Nível 1}

A combinação dos critérios do nível 2 resultou nos mapas A, B e C. Além destes, o mapa $\mathrm{D}$ resultante de scores normalizados de custos de $\mathrm{M} \& \mathrm{R}$, também é considerado. O mapa A foi gerado através da combinação WLC. Os mapas B e C foram gerados a partir de procedimentos OWA, que deram origem aos cenários Bi, Bii e Biii (Figura 6.25) e Ci.1, Cii.1, Ciii.1, Ci.2, Cii.2 e Ciii.2 (Figura 6.26 e Figura 6.27), respectivamente.

\subsubsection{Mapa do grupo A}

O mapa A (Figura 6.23), resultante da combinação WLC_A, refere-se aos scores dos fatores associados à hierarquia viária. Observam-se, entre outras, que três grandes e importantes vias da cidade foram priorizadas, com score entre 0,8 e 1,0: Avenida São Carlos, Avenida Getúlio Vargas e Rua Miguel Petroni. Outras vias, como a Avenida Francisco Pereira Lopes, Avenida Henrique Gregori e Avenida Comendador Alfredo Maffei tiverem um score elevado entre 0,6 e 0,8 (sendo o intervalo possível de 0 a 1), evidenciando a importância relativa da hierarquia das vias e de outras que podem ser vistas no mapa. Conforme a Tabela 
6.8, o mapa não possui seções com scores zero (sem prioridade), com média de valores de 0,621 e desvio padrão de 0,188 .

\subsubsection{Mapas do grupo B}

A combinação dos mapas B1 e B2 do nível 2, através do procedimento OWA, deu origem aos cenários Bi_n, Bii_n e Biii_n do nível 1 (Figura 6.25 a, b e c, respectivamente), representando o grupo $\mathbf{B}$ referente às questões técnicas e operacionais. $\mathrm{O}$ cenário de risco neutro Bi (com trade-off total) apresentou valores bem variados dentro da escala considerada, pois os scores baixos são compensados por scores altos, o que resulta em valores intermediários, com média de 0,291 e desvio padrão 0,132. Para efeito de exemplo, a Rua Cezar Ricome apresenta uma seção que no mapa B1 possui cor amarelo (score $=0,571$ ), no mapa B2 possui cor vermelha $($ score $=0,90)$ e no cenário Bi_n apresentou cor laranja (score = 0,654), indicando a neutralidade da avaliação que considera dois conjuntos de pesos, o primeiro dos critérios e o segundo dos Order Weights com igual valor para todos os scores.

O cenário de risco mínimo Bii_n, por buscar os menores scores, possui uma grande porcentagem de cores verdes, sendo que $37 \%$ das seções possuem valores iguais à zero, média de 0,074 e desvio padrão 0,124. O cenário de risco máximo Biii_n, ao contrário do mínimo, apresenta valores mais elevados, com valores médios de 0,35 e desvio padrão de 0,099 (Tabela 6.8). Nos cenários de risco neutro e máximo apenas $1 \%$ dos scores são nulos.

Se compararmos o cenário de risco mínimo Bii_n com o cenário de risco máximo Biii_n (ambos sem trade-off), no primeiro somente em $2 \%$ das seções há valores maiores que 0,4 , enquanto no segundo aumentou para $35 \%$, sendo a distribuição dessas seções muito mais ampla no cenário Biii_n.

É importante comentar que a maioria dos modelos de priorização baseia-se em mapas da condição do pavimento, considerando principalmente os defeitos apresentados durante a avaliação em campo. No caso deste trabalho, os mapas foram desenvolvidos considerando, além da condição do pavimento, outros critérios que também são importantes para o desenvolvimento do modelo apresentado.

\subsubsection{Mapas do grupo $C$}

Seis cenários foram gerados em duas etapas, para representar o grupo $\mathbf{C}$, referente à localização das seções de pavimento. A primeira etapa combinou os mapas C1_n, C2_n e 
C3i_n (risco neutro - trade-off total) do nível 2, através do procedimento OWA, dando origem aos cenários Ci.1, Cii.1 e Ciii.1 do nível 1 (Figura 6.26 a, b e c, respectivamente). A segunda etapa combinou os mapas $\mathrm{C} 1 \_\mathrm{n}, \mathrm{C} 2 \_\mathrm{n}$ (risco neutro) e C3v_n (alto risco - trade-off parcial) do nível 2, através do procedimento OWA, dando origem aos cenários Ci.2, Cii.2 e Ciii.2 do nível 1 (Figura 6.27 a, b e c, respectivamente). Os cenários Ci.1 e Ci.2 são resultados de análises de risco neutro, Cii.1 e Cii.2 de risco mínimo e Ciii.1 e Ciii.2 de risco máximo.

Os comentários em relação ao risco do grupo B valem também para o grupo C, sendo que os cenários de risco mínimo ou máximo limitam, inferior ou superiormente, a tomada de decisão, enquanto que no cenário de risco neutro os scores são compensados, resultando em valores intermediários. Observa-se, nos mapas Ci.1 e Ci.2 (risco neutro), a predominância de tonalidades verde e azul, com algumas seções em amarelo na região central e em locais próximos a postos de saúde (valores baixos, com apenas 4,5\% de valores nulos). Também é perceptível, em ambos os mapas, a presença de maior prioridade (cor laranja) em seções próximas a rodovias. Os mapas Cii.1 e Cii.2 (risco mínimo) são quase totalmente verdes com aproximadamente $98 \%$ das seções com scores iguais a zero (Tabela 6.8), salientando algumas seções próximas à rodoviária e rodovias. Os mapas Ciii.1 e Ciii.2 (risco máximo) diferem um pouco em relação ao resultado final, percebendo-se um aumento da cor azul em relação ao verde e das cores laranja e vermelho (scores mais elevados).

É importante comentar que a escolha do cenário a ser combinado reflete diretamente no resultado. O mapa Ciii.1 foi gerado pela combinação de três mapas de risco neutro, com valores de scores intermediários, enquanto que o mapa Ciii.2 foi gerado pela combinação de dois mapas de risco neutro com um mapa de risco máximo. Comparando Ciii.1 com Ciii.2, observa-se que o primeiro (Figura $6.26 \mathrm{c}$ ) possui mais seções verdes do que o segundo (Figura 6.27 c) onde a maior porcentagem é de seções azuis. Portanto, houve um aumento dos valores quando se utilizou, na combinação dos critérios, um cenário de risco máximo em que os maiores scores são considerados. Dessa forma, o índice de 5\% de valores iguais a zero no cenário Ciii. 1 caiu para $4,5 \%$ no cenário Ciii.2 (Tabela 6.8).

\subsubsection{Mapa do grupo D}

O mapa D (Figura 6.28), resultado de scores normalizados de custos de M\&R, apresenta $73 \%$ de seções com valores nulos, onde as atividades previstas são de não fazer nada, levando, portanto, o custo à zero. $25 \%$ das seções possuem scores maior que 0,4 , 
indicando a prioridade de intervenção. O mapa D possui valores dentro da escala normalizada de 0 a 1, com média de 0,147 e desvio padrão de 0,063 (Tabela 6.8).

\subsection{Mapas finais de priorização}

A combinação dos critérios do nível 1, que agrega os mapas dos quatro grandes grupos de critérios (grupo A - Hierarquia viária, grupo B - Questões Técnicas e Operacionais, grupo C - Localização e grupo D - Custos) foi realizada em duas etapas e teve como resultado seis cenários finais de priorização.

A primeira etapa combinou os mapas A, Bi_n, Ci.1_n e D (risco neutro - trade-off total) do nível 1, através do procedimento OWA, dando origem aos cenários Pi.1, Pii.1 e Piii.1 (Figura 6.30, Figura 6.31 e Figura 6.32, respectivamente). A segunda etapa combinou os mapas A e D (risco neutro), Bii_n (risco mínimo - sem trade-off) e Ciii.1_n (risco máximo sem trade-off) do nível 1, através do procedimento OWA, dando origem aos cenários Pi.2, Pii.2 e Piii.2 (Figura 6.33, Figura 6.34 e Figura 6.35, respectivamente). Os cenários Pi.1 e Pi.2 são resultados de análises de risco neutro, Pii.1 e Pii.2 de risco mínimo e Piii.1 e Piii.2 de risco máximo, conforme especificado na Tabela 6.9.

De modo geral observa-se, de acordo com a Tabela 6.10, que os mapas gerados na primeira etapa, em que foram considerados somente cenários de risco neutro, possuem valores mais elevados em relação aos mapas gerados na segunda etapa. Comparando os cenários de risco neutro Pi.1_n e Pi.2_n, o primeiro não possui valores iguais a zero enquanto que o segundo já tem $1 \%$ de valores nulos. A combinação de um cenário de risco mínimo com outros na segunda etapa, nos quais valores nulos são considerados, diminui o valor médio dos scores, que passou de 0,322 na primeira etapa para 0,221 na segunda etapa.

Em relação à escolha de seções de pavimentos, os cenários Pii.1_n e Pii.2_n, de risco mínimo, oferecem poucas seções a serem priorizadas, sendo que aproximadamente 93\% das seções apresentam scores nulos em ambos os mapas. Os mapas de risco máximo, Piii.1_n e Piii.2_n, já mostram uma grande quantidade de seções amarelas (36\% no Piii.1_n e 35\% no Piii.2_n) e laranja (3\% no Piii.1_n e 2\% no Piii.2_n) e uma pequena parcela de seções vermelhas, que não existiam nos mapas anteriores, destacando-se algumas seções no Jardim Medeiros e na Vila Monte Carlo (ANEXO E). A seleção das seções, neste caso, torna-se mais abrangente, pois são maiores as opções de priorização.

Nesse tipo de análise, em que são selecionadas seções de vias (mapas de linhas no sistema vetorial do SIG), considera-se como principal fator na tomada de decisão as 
condições de risco que se assumem na hora de escolher um cenário em relação ao outro. A distribuição espacial das seções interfere na forma como os serviços serão realizados futuramente, ou seja, no planejamento da seqüência que será adotada para a efetivação da manutenção propriamente dita. Entretanto, o enfoque deste trabalho é mostrar, perante um conjunto pré-definido de critérios, quais as seções que são as prioritárias para a realização das atividades. Portanto, a distribuição dos scores no espaço físico (regiões leste, oeste, norte ou sul da cidade, por exemplo) não interfere na decisão quanto à escolha do cenário de avaliação.

\subsection{Análise de viabilidade econômica}

O modelo proposto para priorizar seções de pavimentos pode ser explorado considerando a real situação de orçamentos limitados, em se tratando de redes urbanas pavimentadas com revestimento asfáltico. Sabe-se que essa situação é um fator limitante na hora de decidir sobre as atividades de manutenção e os locais onde os serviços serão realizados.

Apesar de um dos critérios considerados no modelo tratar de custos, no caso específico deste trabalho, esse critério considera de forma específica os custos das atividades previstas em cada seção e prioriza as seções com menores custos. Estudos anteriores, realizados pela autora e publicados em Lima et al. (2004), verificaram que o valor necessário para intervenções na malha viária urbana da cidade de São Carlos era muito maior do que o orçamento anual destinado a obras viárias. Constatou-se que não havia condições práticas de resolver o problema de imediato. Entretanto, depois de realizado um estudo mais amplo de prioridades, é possível elaborar uma lista de seções prioritárias, atendendo, desta forma, o orçamento limitado para a realização da manutenção.

Se considerarmos que foram priorizados aproximadamente $355 \mathrm{~km}$ de vias urbanas, podemos programar, dentro desse universo, quantas seções, no período de um ano, poderão ser mantidas, considerando o orçamento disponível para o período. Para tal análise e efeito de exemplo, considera-se o cenário Pi.2_n, de risco neutro, no qual os critérios são compensados uns pelos outros.

A Tabela 7.1 indica o orçamento necessário para realizar as atividades de manutenção dos pavimentos em cada intervalo de índice de prioridades IP (valores entre 1,0 e $0,8$, descendo até o menor intervalo, de 0,2 a 0,0$)$. Observa-se que o custo total para realizar a manutenção da rede é de aproximadamente R \$ 8.000.000,00, que corresponde ao dobro do orçamento anual disponível para atividades de manutenção viária. Entretanto, mesmo com um 
orçamento restrito $(\mathrm{R} \$ 4.000 .000,00)$ é possível realizar as atividades de $M \& \mathrm{R}$ em quase todas as seções que possuem IP acima de 0,4.

Tabela 7.1: Orçamento para o cenário Pi.2_n

\begin{tabular}{|c|c|c|c|c|}
\hline $\begin{array}{c}\text { Indice de Prioridade } \\
\text { Cenário Pi.2_n }\end{array}$ & Estratégia & $\begin{array}{c}\text { Extensão } \\
(\mathbf{K m})\end{array}$ & $\begin{array}{c}\text { Custo Unitário* } \\
\text { (R\$/Km) }\end{array}$ & $\begin{array}{c}\text { Custo Total } \\
\text { (RS) }\end{array}$ \\
\hline \multirow{6}{*}{1,0 a 0,8} & NF & 0,00 & 0,00 & 0,00 \\
\hline & $\mathrm{MC}$ & 0,45 & $40.000,00$ & 18132,00 \\
\hline & MP & 0,04 & $110.000,00$ & 5335,00 \\
\hline & $\mathrm{RF}$ & 0,39 & $220.000,00$ & 86504,00 \\
\hline & $\mathrm{RC}$ & 0,03 & $290.000,00$ & 7540,00 \\
\hline & & & & $117.511,00$ \\
\hline \multirow{6}{*}{0,8 a 0,6} & NF & 0,0992 & 0,00 & 0,00 \\
\hline & $\mathrm{MC}$ & 6,25 & $40.000,00$ & 249948,00 \\
\hline & MP & 2,61 & $110.000,00$ & 287342,00 \\
\hline & $\mathrm{RF}$ & 1,00 & $220.000,00$ & 219692,00 \\
\hline & $\mathrm{RC}$ & 1,84 & $290.000,00$ & 533861,00 \\
\hline & & & & $1.290 .843,00$ \\
\hline \multirow{6}{*}{0,6 a 0,4} & NF & 6,13 & 0,00 & 0,00 \\
\hline & $\mathrm{MC}$ & 20,77 & $40.000,00$ & 830876,00 \\
\hline & MP & 11,56 & $110.000,00$ & 1271479,00 \\
\hline & $\mathrm{RF}$ & 2,81 & $220.000,00$ & 618354,00 \\
\hline & $\mathrm{RC}$ & 0,59 & $290.000,00$ & 172724,00 \\
\hline & & & & 2.893.433,00 \\
\hline \multirow{6}{*}{0,4 a 0,2} & $\mathrm{NF}$ & 64,61 & 0,00 & 0,00 \\
\hline & $\mathrm{MC}$ & 43,99 & $40.000,00$ & 1759528,00 \\
\hline & MP & 11,41 & $110.000,00$ & 1255199,00 \\
\hline & $\mathrm{RF}$ & 2,20 & $220.000,00$ & 484792,00 \\
\hline & $\mathrm{RC}$ & 0,30 & $290.000,00$ & 88798,00 \\
\hline & & & & 3.588.317,00 \\
\hline \multirow{6}{*}{0,2 a 0,0} & $\mathrm{NF}$ & 177,08 & 0,00 & 0,00 \\
\hline & $\mathrm{MC}$ & 0,00 & $40.000,00$ & 0,00 \\
\hline & MP & 0,32 & $110.000,00$ & 35618,00 \\
\hline & $\mathrm{RF}$ & 0,00 & $220.000,00$ & 0,00 \\
\hline & $\mathrm{RC}$ & 0,00 & $290.000,00$ & 0,00 \\
\hline & & & & $35.618,00$ \\
\hline Total & & 354,51 & & $7.925 .722,00$ \\
\hline
\end{tabular}

Realizar atividades de conservação em todas as seções de pavimentos, para o cenário de avaliação considerado (Pi.2_n), que possuem IP acima de 0,4 , equivale a um custo de $\mathrm{R} \$ 4.301 .787,00$. Para aproximar esse custo do orçamento anual disponível, pode-se, por exemplo, descontar a metade da quilometragem de seções com previsão de reforço (RF) e IP entre 0,6 e 0,4 (1,41 km), atingindo, dessa forma, um custo de $\mathrm{R} \$ 3.993 .303,00$. As seções programadas para receber as intervenções de conservação podem ser visualizadas, com o auxílio do SIG, na Figura 7.2. É importante observar que $100 \%$ das seções com IP maior ou igual a 0,5 fazem parte da estratégia de $M \& R$ dos pavimentos. 


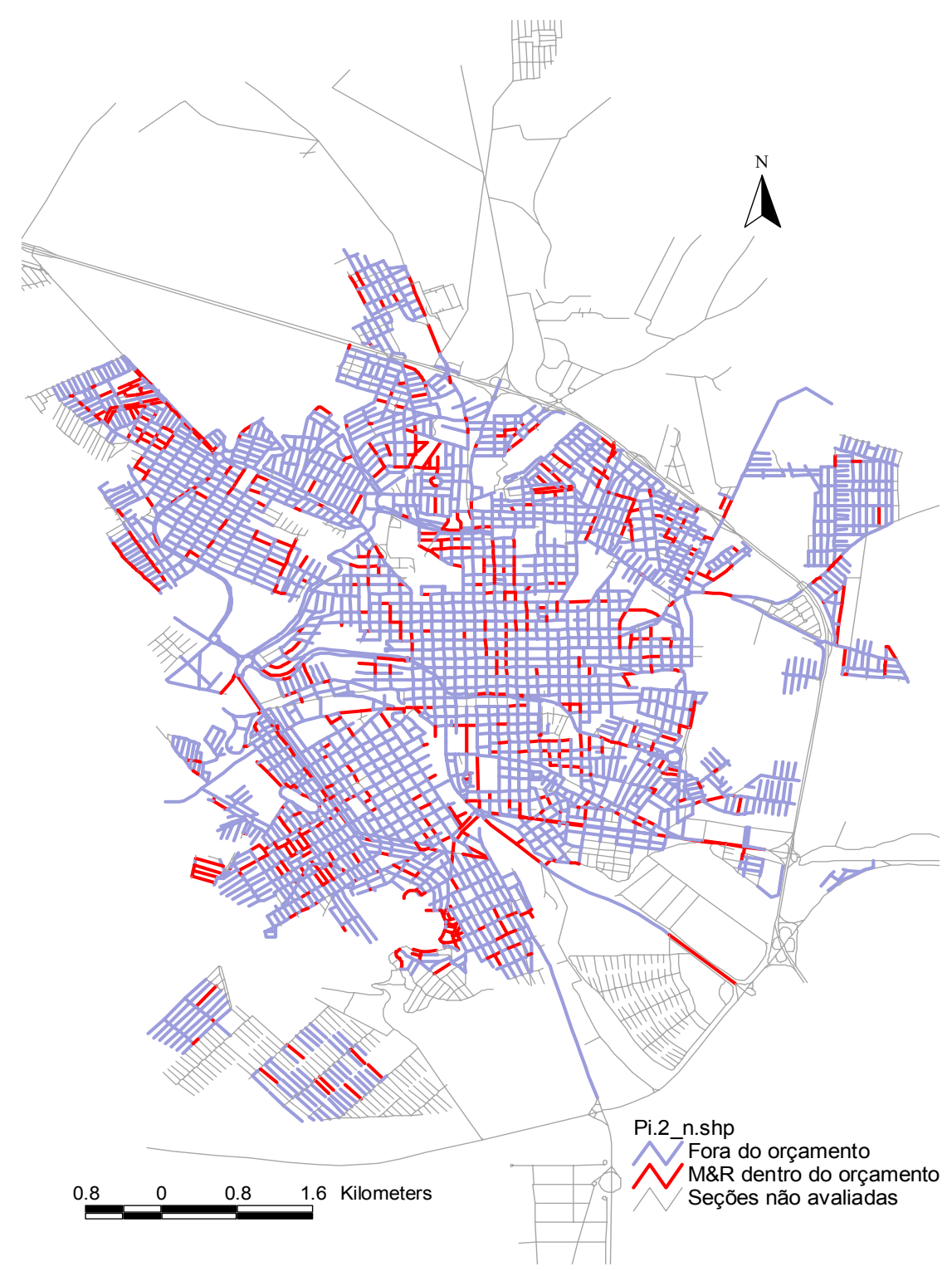

Figura 7.2: Seções de vias urbanas com orçamento limitado

Constata-se ainda, através da Tabela 7.1, que a maioria das seções com IP menor que 0,4 , possuem como estratégia não fazer nada (NF) e uma outra parcela necessita de manutenção corretiva (MC) e preventiva (MP), devendo entrar no planejamento do próximo ano, a fim de evitar que o pavimento atinja um nível avançado de deterioração, mediante intervenções de caráter preventivo. 

manutenção e reabilitação de pavimentos 


\section{CONCLUSÕES E CONSIDERAÇÕES}

O objetivo geral deste trabalho foi utilizar a Metodologia de Análise Multicritério e os Sistemas de Informação Geográfica para apoiar as decisões envolvidas na conservação de pavimentos viários e, mais especificamente, propor um modelo para a priorização de vias. $\mathrm{O}$ modelo desenvolvido fornece análises globais para uma determinada rede de vias urbanas, selecionando as melhores seções, em termos de prioridades, para a realização de atividades de manutenção e reabilitação (M\&R) dos pavimentos.

Optou-se por trabalhar com cidades de médio porte, onde os modelos de priorização de projetos se fazem necessários, tanto pela carência de sistemas especialistas como pela necessidade de alocar os recursos disponíveis. Algumas grandes cidades utilizam um programa de computador desenvolvido pelo Banco Mundial (HDM - Highway Design and Maintenance Standards Model) para gerenciamento de vias, enquanto que cidades muito pequenas possuem atividades de conservação simples, pois muitas ruas não são pavimentadas.

O modelo utiliza o Processo Hierárquico Analítico (AHP - Analytic Hierarchy Process), seguindo uma hierarquia de análise por agrupamento de critérios e níveis de agrupamento. A estrutura de análise é implementada num SIG, no modelo vetorial, em que cada seção de pavimento é sujeita a um processo de avaliação através da geração de um índice de prioridade. Tem como uma das características fundamentais permitir a aplicação para qualquer rede urbana, desde que seja adequado às particularidades de cidades com outras dimensões, fazendo, para isso, as devidas substituições e atualizações dos bancos de dados utilizados.

Durante a fase de desenvolvimento de critérios, que foi baseada em revisão bibliográfica e em um questionário enviado às prefeituras, buscou-se conhecer os métodos e critérios utilizados para priorização de projetos em gerência de pavimentos. No estudo dos conceitos e métodos percebeu-se, como primeira conclusão deste trabalho, que as formulações matemáticas, que determinam um índice de prioridade, são simples e consideram, geralmente, critérios relacionados com a condição do pavimento e volume de tráfego. A condição é 
caracterizada através de avaliação visual, por observação dos defeitos ou até, em se tratando de rodovias, através de equipamentos específicos. Além disso, não há um consenso com relação à relevância ou o grau de importância dos critérios considerados nos processos de decisão. Dessa forma, cada órgão define como será tomada a decisão em relação à seleção das atividades sobre o pavimento.

Procurou-se pesquisar informações atuais, dos procedimentos de conservação de pavimentos utilizados nas cidades médias brasileiras, através da aplicação de questionário, enviados às prefeituras. $\mathrm{O}$ questionário foi de grande valia, evidenciando as necessidades atuais das prefeituras, tais como, a falta de tecnologia adequada, de pessoal especializado e até mesmo de planejamento prévio para realizar os serviços de manutenção e reabilitação dos pavimentos. Observou-se, também, que as atividades de manutenção, geralmente, são realizadas com base em critérios simples, como por exemplo, reclamações da comunidade, ruas com maior volume de tráfego e com defeitos mais graves, que por não terem sido tratada de forma preventiva, devem ser reabilitadas.

Um dos objetivos era propor um modelo que ampliasse as expectativas em relação aos critérios utilizados na tomada de decisão, quanto à priorização de vias candidatas às atividades de M\&R dos pavimentos. Nesse sentido, o modelo proposto neste trabalho mostrou ser uma metodologia eficiente, que trouxe bons resultados, por considerar um grande número de critérios relevantes no que diz respeito ao estudo de prioridades em vias urbanas. Considerar, por exemplo, a localização das seções de pavimento ou as infra-estruturas e equipamentos localizados nas vias analisadas, fez com que o modelo ficasse ainda mais atrativo, no sentido de valorizar tudo aquilo que possa interferir, mesmo que intuitivamente, na hora de decidir sobre a realização de um serviço. Os decisores levam em conta critérios como, por exemplo, um bairro mais central da cidade, uma via arterial de grande fluxo de tráfego, a ocorrência de hospitais ou até mesmo a existência de um shopping center em um local mais afastado para priorizar ou não determinadas vias.

O modelo mostrou-se flexível devido à possibilidade de modificar a estrutura hierárquica que foi desenvolvida, no instante que se pretende retirar ou adicionar algum critério de decisão. A importância atribuída a cada um dos critérios também pode ser reconsiderada, pois dependendo da cidade em que o modelo será aplicado, novas opiniões podem surgir.

Os critérios adotados para o modelo de priorização são aqueles considerados de grande relevância no processo de decisão e de fácil adaptação a cada caso específico, sendo, 
também, passíveis de avaliação, tanto do ponto de vista da disponibilidade de dados quanto do ponto de vista do esforço de aquisição dos mesmos. Os critérios foram classificados em 4 grandes grupos: Hierarquia Viária, Questões Técnicas e Operacionais, Localização e Custos. Do primeiro grupo constam: Classificação Funcional, Tipo de Rota e Volume de Tráfego, os quais valorizam as vias de acordo com a sua funcionalidade econômica e social. Os critérios de Questões Técnicas e Operacionais incluem Necessidade Técnica por Intervenção (índice de condição do pavimento, índice combinado de defeitos e idade do pavimento, todos relacionados com o estado do pavimento), Questões Ambientais e Questões de Segurança. O grupo Localização inclui a Proximidade a Infra-estruturas de Transportes, Proximidade a Equipamentos ou Prédios Institucionais e Preferências Pessoais ou Administrativas. Nesse caso, as seções de pavimentos são valorizadas de acordo com a sua localização geográfica. Por último, o grupo Custos considera os Custos dos Usuários e da Administração.

Assim como a definição de critérios, a fase de avaliação do grau de importância de cada um deles e de seus agrupamentos é um ponto crucial para um processo estruturado em uma hierarquia de decisão. As avaliações do grau de importância dos critérios foram realizadas por especialistas e profissionais da área de transportes. Adotou-se o método de comparação par a par, através do Processo Hierárquico Analítico (AHP), confirmando-se a capacidade do processo na aplicação em critérios de priorização de pavimentos, uma vez que efetuou com eficiência a atribuição de pesos, com a averiguação do Grau de Consistência dos julgamentos.

Entre os quatro grandes grupos considerados, o maior peso $(0,378)$ foi atribuído ao grupo B: Fatores Associados a Questões Técnicas e Operacionais, confirmando a importância que já é dada a esse critério nos métodos existentes de priorização de projetos de manutenção, uma vez que a condição atual do pavimento interfere decisivamente em qualquer planejamento de conservação. Em segundo (com peso 0,271) ficou o grupo D: Fatores Associados aos Custos e logo atrás (com peso 0,223) o grupo A: Fatores Associados à Hierarquia Viária. O custo é um critério envolvido diretamente em qualquer atividade de manutenção. Não existe realização de serviços sem uma previsão orçamentária, assim, podese justificar a importância dada a esse critério, pelos especialistas. Não muito atrás, a hierarquia viária também tem peso importante no processo de decisão, explicado pela grande aceitação que possui em propostas de métodos de priorização já existentes. O grupo C: Fatores Associados à Localização ficou com a menor importância relativa (com peso 0,128) atribuída pelos especialistas, confirmando que é o critério menos utilizado e, é importante 
ressaltar, que apesar de ter o menor peso, a sua participação foi considerada relevante no processo de decisão.

O levantamento preliminar da condição do pavimento, realizado com o apoio da Prefeitura Municipal de São Carlos, beneficiou a montagem do banco de dados contendo informações sobre todas as seções pavimentadas da cidade. A coleta dessas informações em campo foi de grande importância para a aplicação do modelo proposto e, sem dúvida, para estudos posteriores, pois a prefeitura, até então, não possuía uma base georeferenciada e atualizada da condição das ruas da cidade. A partir dessa base georeferenciada, novos dados de inventário, da condição do pavimento ou qualquer questão relacionada com a infraestrutura das vias, podem ser adicionados, desde que se mantenha atualizada. Para isso, é importante que se tenha uma equipe de trabalho consistente, responsável pela constante atualização das informações de entrada no sistema. Manter uma equipe de trabalho é necessário para que se mantenha o banco de dados atualizado e, também, possibilitar o planejamento de novas intervenções de conservação, auxiliar pesquisas futuras. Disso depende o sucesso da aplicação do modelo proposto, com o desenvolvimento das várias etapas de trabalho envolvidas em um processo hierárquico de decisão.

O banco de dados foi remodelado para aplicação do modelo de priorização. Outras bases geográficas foram coletadas para completar as informações e possibilitar o desenvolvimento do trabalho. Observou-se que a disponibilidade de dados é sempre um ponto crucial para pesquisas dessa natureza. Apesar de que grande parte da informação necessária para o projeto foi obtida, alguns critérios não puderam participar da aplicação do modelo devido à falta de dados confiáveis.

Dessa forma, alguns critérios não foram considerados no estudo de caso realizado. São eles: Idade desde a última intervenção, Proximidade a Portos e Aeroportos, Questões Ambientais, Questões de Segurança e Custos dos Usuários. Essa é uma característica também muito importante observada durante a concepção do modelo desenvolvido, ou seja, o fato de terem sido desprezados alguns critérios não tão representativos, não impede que outros critérios sejam futuramente incorporados ao modelo, mediante a disponibilidade de seus dados. Mais uma vez o modelo se mostra flexível.

De posse das informações necessárias e com os dados organizados no SIG para o desenvolvimento do modelo, a combinação de critérios e grupos de critérios por nível hierárquico deu origem aos diversos cenários de avaliação. A etapa de geração de alternativas de priorização é concluída, restando tomar a decisão pela melhor opção. O modelo mostrou-se 
interessante pelo fato de estruturar de forma transparente o processo de decisão. Uma das características importantes é a geração de cenários de avaliação baseados em atitudes de risco, possibilitando a visualização das estratégias de decisão em formato geográfico, passível de averiguação por parte dos decisores. O desenvolvimento de mapas gerados a partir de um conjunto relevante de critérios em ambiente SIG é uma forte ferramenta de apoio à decisão, em que foram desenvolvidos mapas mostrando com clareza, para o estudo de caso desenvolvido em São Carlos - SP, a situação real para priorizar as vias da cidade.

No mais baixo nível de análise, a agregação de critérios permite a averiguação ampla das características da rede, que pode ser útil em outros contextos de estudos. A criação dos mapas de condição do pavimento e de proximidade a infra-estruturas são exemplos da eficiência da análise espacial e da análise multicritério, que sintetizaram informações em mapas de prioridades. Fazendo uma análise rápida dos mapas do grupo B: Questões técnicas e operacionais, podem-se definir as prioridades em relação a esse critério específico, importante em qualquer modelo de priorização. Uma conclusão importante é o mapa que traduz as prioridades considerando os defeitos do pavimento (o mapa B1). Somente 4,5\% das seções têm índice de prioridade maior que 0,6 (na escala de 0 a 1), indicando que a rede urbana de São Carlos está, de modo geral, em boas condições de tráfego. Além dessa informação, outras podem ser visualizadas diretamente no mapa, tais como, ruas específicas que possuem maior prioridade de manutenção. É uma abordagem interessante do modelo, em que qualquer etapa ou nível da estrutura hierárquica pode ser analisada isoladamente.

No nível intermediário de análise, os mapas foram gerados por Combinação Linear Ponderada (WLC - Weighted Linear Combination ), Média Ponderada Ordenada (OWA Ordered Weighted Average) e, ainda, simplesmente por scores normalizados, dependendo do critério em questão. Vários mapas ou cenários foram produzidos, definindo as estratégias de decisão. Alguns dos cenários resultantes da agregação de critérios do nível intermediário foram adotados e combinados, para gerar os seis cenários finais de avaliação.

A adoção de um cenário em relação ao outro, para efetuar uma combinação entre critérios, é um ponto crítico de decisão. Neste trabalho as decisões foram tomadas pela própria autora, no sentido de exemplificar todas as etapas de análises contidas no modelo proposto. Os primeiros cenários finais (Pi_1, Pii_1 e Piii_1) foram gerados a partir de uma combinação de cenários de risco neutro. Com relação aos outros mapas finais de priorização, um cenário de risco máximo (Ciii_1) foi adotado, de modo a ilustrar uma situação extrema, na qual basta um critério (de localização, nesse caso) possuir um valor elevado para que a seção 
seja considerada prioritária. Por outro lado, um cenário de risco mínimo (Bii) também foi adotado, para ser combinado com o de risco máximo e os cenários neutros A e D. Nesse caso, trata-se de uma atitude conservadora, fazendo com que as seções mais críticas, em relação à condição do pavimento, fossem consideradas. Dessa combinação foram gerados os cenários finais Pi.2, Pii.2 e Piii.2. Os cenários Pii.1 e Pii.2, de risco mínimo, oferecem poucas seções a serem priorizadas, a maioria apresentando scores nulos em ambos os mapas. Uma boa opção talvez fosse realizar os serviços para as seções sugeridas no mapa Pi.2 (risco neutro), tratando-se de um cenário com menos seções na lista de prioridades do que o mapa Pi.1(risco neutro). Os mapas de risco máximo, Piii.1 e Piii.2, possuem uma quantidade maior de seções com altos scores, tornando a seleção mais abrangente, com mais opções de priorização. Portanto, conclui-se dessa fase de geração de alternativas, que em relação à priorização de vias pavimentadas, a opinião do decisor (do especialista ou técnico responsável pelo planejamento dos serviços) é o fator que tem maior relevância quando são elaborados os diversos cenários de avaliação e faz-se a opção por um deles. A decisão final por qualquer um dos cenários gerados deve considerar as necessidades de cada órgão administrativo e a disponibilidade de recursos para a execução dos serviços selecionados.

$\mathrm{Na}$ análise realizada, explorando a viabilidade econômica das seções prioritárias determinadas para um dos cenários desenvolvidos (Pi.2), o custo para a realização das atividades de $M \& R$, na extensão de via selecionada com índice de prioridade maior que zero, é maior que o orçamento disponível para esses serviços. Portanto, constatou-se que não havia condições práticas de resolver o problema de imediato. É um problema freqüentemente enfrentado pelos órgãos responsáveis pelos serviços de manutenção. Para suprir essa dificuldade, são elaborados programas de prioridades.

A análise realizada possibilitou alocar os recursos disponíveis, beneficiando $100 \%$ das seções com índice de prioridade maior ou igual a 0,5 (na escala de 0 a 1). O modelo mostrou-se eficaz para gerar mapas com índice de prioridades, que possam ser avaliados caso a caso, desenvolvendo as mais diversas análises para determinação das verdadeiras necessidades, sem prejuízos para os administradores e desperdícios do dinheiro público.

Nesse cenário, assim como nos outros, por se tratar de rede viária na qual cada linha da rede é um trecho analisado separadamente, os mapas gerados no SIG não produzem áreas específicas de maior prioridade e sim as prioridades se espalham por toda a rede da cidade. A utilização do programa de computador ArcView GIS 3.2 possibilitou que todas as etapas de avaliação multicritério fossem realizadas sem muitas dificuldades, pois devido ao 
número de critérios envolvidos no modelo não ser muito grande, as atividades puderam ser rapidamente executadas. A escolha do SIG utilizado é um ponto importante para o sucesso do modelo. O ArcView foi adotado em função da sua disponibilidade e também por ser facilmente adaptado ao problema. Como neste trabalho utilizou-se o sistema vetorial, não se teve maiores dificuldades quanto à modelagem do problema, pois todas as informações foram incorporadas à rede viária (dividida em "Polyline") georeferenciada da cidade.

A associação das técnicas da avaliação multicritério e o uso do SIG para a questão da priorização de pavimentos, com muitas vantagens já evidenciadas em trabalhos anteriores, garantiu a boa estruturação da base do modelo. $\mathrm{O}$ modelo mostrou-se eficiente em várias etapas do processo, destacando-se a flexibilidade que se tem com o uso da metodologia de análise multicritério quando se insere ou se retira algum critério da estrutura de decisão, aliada à facilidade dos SIGs de gerar e visualizar mapas das mais diversas estratégias.

Finalmente, a proposta inicial deste trabalho era unir temas distintos na elaboração de um modelo de decisão (priorização de vias), ou seja, agregar informações da gerência de pavimentos e realizar análises utilizando a avaliação multicritério, produzindo cenários de decisão em ambiente SIG. O objetivo foi alcançado e merece consideração a definição dos critérios, que foi um ponto crucial do trabalho, pois uma vez definidos e agrupados, o modelo está com suas bases estruturadas.

Como conseqüência direta da diversidade dos temas abordados, as possibilidades de continuação e refinamento do trabalho são diversas. Cada tema pode ser estudado separadamente, no intuito de melhoria do modelo proposto. Portanto, como possibilidades para trabalhos futuros, são sugeridos:

- Melhoria dos dados para a modelagem do problema: alguns dados, como por exemplo, o volume de tráfego, foram considerados de forma subjetiva. No entanto, podem ser reavaliados e incluídos no modelo com valores que podem expressar melhor a sua participação;

- Inclusão dos critérios que foram deixados de lado pela falta de dados confiáveis: alguns critérios, importantes para a priorização de vias, como por exemplo, questões relacionadas com a segurança, podem ser incluídos no modelo, no momento em que se dispuser de dados mais consistentes. Uma base georeferenciada com informações sobre acidentes de trânsito foi desenvolvida por Santos (2006) e pode agregar informações referentes aos locais críticos de acidentes. Realizando-se um filtro em relação aos motivos dos acidentes em seções de vias da cidade de São Carlos, aqueles relacionados com a condição do pavimento poderão ser utilizados em novos estudos de prioridades, uma vez que o critério questões relacionadas à segurança teve um peso elevado nas avaliações dos especialistas. 
- Refinamento do modelo de priorização: reavaliação dos critérios relevantes e dos seus graus de importância, utilizando entrevista direta e interação com o painel de avaliadores especialistas (com uma amostra mais representativa, podendo até ser menor), uma vez que esta pesquisa contou com avaliações à distância (via correio e planilha eletrônica) de uma amostra maior de especialistas. 


\section{REFERÊNCIAS BIBLIOGRÁFICAS}

ABDELRAHIM A. M.; GEORGE, K. P. (2001). Artificial Neural Network for enhancing selection of pavement maintenance strategy. Transportation Research Record 1699. TRB. Washington, D.C.

ANTHONY, R. N. (1965). Planning and control systems: a framework for analysis. Harvard University Graduate School of Business Administration, Cambridge, MA.

BAKER, J. A.; LAMBERT, J. H. (2000). Using multiple factors to select among diverse highway improvements. Transportation Research Record. TRB. 79th Annual Meeting. National Research Council. Washington, D.C.

BANDARA, N.; GUNARATNE, M. (2001). Current and Future Pavement Maintenance Prioritization Based on Rapid Visual Condition Evaluation. Journal of Transportation Engineering. March/April, pp.116-123.

BERTOLLO, S. A. M.; FERNANDES JR., J. L. (1997). Métodos estocásticos para previsão de desempenho e sua utilização em Sistemas de Gerência de Pavimentos Urbanos. XI ANPET - Congresso Nacional de Pesquisa e Ensino em Transportes. Rio de Janeiro, Anais, p.357369.

BODI, J.; BALBO, J.T. (1998). Modelos para Priorização de Serviços de Manutenção de Pavimentos Urbanos. $31^{a}$ Reunião Anual de Pavimentação. São Paulo - SP.

BOSSARD, E.G. (1999) "Envisioning neighborhood quality of life using conditions in the neighborhood access to and from conditions in the surrounding region. In: Paola Rizzi (ed.), Computers in Urban Planning and Urban Management on the Edge of the Millenium, FrancoAngeli, Veneza, Itália.

CAFISO, S.; GRAZIANO, A.; KERALI, H.R., AND ODOKI, J.B. (2002). Multicriteria Analysis Method for Pavement Maintenance Management. Transportation Research Record 1816. TRB. Washington, D.C., pp73-84.

CÂMARA, G.; DAVIS, C.; MONTEIRO, A. M. (2001). Geoprocessamento: Teoria e Aplicações. Disponível em: <http://www.dpi.inpe.br/gilberto/livro>.Acesso em: jul/2004.

CARDOSO, S. H. (1994) Gerência de pavimentos em vias urbanas. Associação Brasileira de Pavimentação. $5^{a}$ Reunião de Pavimentação Urbana. Natal, RN.

CAREY, W. N.; IRICK, P. E. (1960). The pavement serviceability - performance concept. Highway Research Board Bulletin 250, p.40-58. 
CARVER, S. J. (1991). Integrating multi-criteria evaluation with Geographical Information Systems. International Journal of Geographic Information Systems. Vol.5(3), p.321-339.

CHAN, W.T.; FWA, T.F.; TAN, C.Y.(1994). Road Maintenance Planning Using Genetic Algorithms. I: Formulation. Journal of Transportation Engineering. Vol.120, n ${ }^{\circ} .5$, pp.693709.

CHEN, X.; WEISSMANN, J.; DOSSEY, T. e HUDSON, W. R. (1993). URMS: graphical urban roadway management system at network level. Transportation Research Record 1397. TRB. Washington, D.C., pp103-111.

COSTA, M.S.; SILVA, A.N.R.; RAMOS, R.A.R. (2004). Indicadores de mobilidade urbana sustentável para o Brasil e Portugal. In: Contribuições para o Desenvolvimento Sustentável em Cidades Portuguesas e Brasileiras. ed.Coimbra, Portugal : Almedina, 2004, v.1, p. 83-97.

COSTA, M. S. (2003). Mobilidade urbana sustentável: um estudo comparativo e as bases de um sistema de gestão para Brasil e Portugal. Dissertação (Mestrado). Escola de Engenharia de São Carlos - Universidade de São Paulo, São Carlos, SP.

DENSHAM, P. J. (1991) Spatial decision support systems. In: Maguire, D. J.; Goochild, M. F.; Rhind, D. (eds). Geographical Information Systems: principles and applications. London: Longman Scientific \& Technical, v. 1, p. 403-412.

DNER - Departamento Nacional de Estradas de Rodagem (1993). Programa de Manutenção para o Pavimento da BR-116/SP, $8^{\circ}$ Distrito Rodoviário Federal, Trecho Divisa RJ/SP, Subtrecho km 0-236,1; Relatório Final (12/93). Departamento Nacional de Estradas de Rodagem, Ministério dos Transportes, Rio de Janeiro.

DNER - Departamento Nacional de Estradas de Rodagem (1996). Manual de Pavimentação. $2^{\mathrm{a}}$.Ed. Rio de Janeiro, RJ.

DNIT - Departamento Nacional de Infra-Estrutura de transportes (2005a). Manual de Conservação Rodoviária. $2^{\mathrm{a}}$.Ed. Rio de Janeiro, RJ.

DNIT - Departamento Nacional de Infra-Estrutura de transportes (2005b). Área de Planejamento Rodoviário - O Modelo de Avaliação Econômica. (Disponível em: $<$ http://www.dnit.gov.br/apr/index.htm>. Acesso em: 21 out 2005.

DNIT - Departamento Nacional de Infra-Estrutura de transportes (2004a). Área de Planejamento Rodoviário - Gerência de pavimentos. Disponível em: $<$ http://dnit.gov.br/apr/gerencia.htm>. Acesso em: 16 nov.2004.

DNIT - Departamento Nacional de Infra-Estrutura de transportes (2004b). Avaliação de Desempenho de Pavimentos Típicos Brasileiros. Relatório Final. Enecon SA.

DNIT - Departamento Nacional de Infra-Estrutura de transportes (2003). Avaliação Objetiva da Superficie de Pavimentos Flexíveis e Semi-rígidos - Procedimentos DNIT 006/2003-PRO. Rio de Janeiro, RJ.

DNIT - Departamento Nacional de Infra-Estrutura de Transportes (2003). Levantamento visual contínuo para avaliação da superficie de pavimentos flexíveis e semi-rígidos. Procedimentos DNIT 008/2003-PRO. Rio de Janeiro, RJ. 
DNIT - Departamento Nacional de Infra-Estrutura de Transportes (2003). Avaliação Subjetiva da Superfície de Pavimentos Flexíveis e Semi-rígidos - Procedimentos DNIT 009/2003-PRO. Rio de Janeiro, RJ.

EASTMAN, J. R.; JIANG, H.; TOLEDANO, J. (1998). Multi-criteria and multi-objetive decision making for land allocation using GIS. In: Beinat, E.; Nijkamp, P. (Eds), Multicriteria Analysis for Land-Use Management. Dordrecht: Kluwer Academic Publishers. P. 227-251.

EASTMAN, J. R.; JIANG, H. (1996). Fuzzy measures in multi-criteria evaluation. Second International Symposium on Spatial Accuracy Assessment in Natural Resources and Environmental Studies. Anais... May 21-23, Fort Collins, Colorado. p.527-534.

ELDIN, N. N. e SENOUCI A. B. (1995). Use of neural networks for condition rating of joined concrete pavements. Advances in Engeneering Software 23, p.133-141.

ENSSLIN, L.; MONTIBELLER NETO, G.; ZANELLA, I. J.; NORONHA, S. M. D. (2000). Metodologias multicritério em apoio à decisão. Apostila. Universidade Federal de Santa Catarina. Dep. Eng. de Produção e Sistemas. Prog. Pós-Grad. Eng. Produção. LabMCDA Laboratório de Metodologias Multicritério em Apoio à Decisão.

ESRI, Environmental Systems Research Institute, Inc. (1996) Arc View GIS, The Geographic Information System for Everyone, Using Arc View GIS. United States of America, 1996.

FERNANDES JR., J. L.; LIMA J. P.; ZANCHETTA, F.; LOPES, S. B. (2004). Gerência de Pavimentos Urbanos com uso de um Sistema de Informações Geográficas: estudo de caso em São Carlos-SP, Brasil. In: XIII Panamerican Conference of Traffic and Transportation Engineering. Anais... New York. USA .

FERNANDES JR., J. L. (2001) Sistemas de Gerência de Pavimentos Urbanos para cidades de médio porte. Livre-Docência. Universidade de São Paulo - Escola de Engenharia de São Carlos. São Carlos, SP.

FERNANDES JR., J. L.; ODA, S.; ZERBINI, L. F. (1999). Defeitos e atividades de manutenção e reabilitação em pavimentos asfálticos. Apostila Didática. Departamento de Transportes da Escola de Engenharia de São Carlos - Universidade de São Paulo, São Carlos, SP.

FERNANDES JR., J. L.; PANTIGOSO, J. F. G. (1997). Compatibilização da gerência de pavimentos urbanos com as concessionárias de serviços públicos com o uso de SIG. In: XI ANPET - Congresso Nacional de Pesquisa e Ensino em Transportes. Anais... Rio de Janeiro, p.67-70.

FERNANDES JR, J. L.; MARGARIDO, S. A.; ZERBINI L. F. (1996). Priorização em Sistemas de Gerência de Pavimentos Urbanos. Associação Brasileira de Pavimentação. $7^{a}$ Reunião de Pavimentação Urbana. São José dos Campos, SP.

FERNANDO, E. G.; HUDSON, W. R. (1983). Development of a prioritization procedure for the network level Pavement Management System. Center for Transportation Research. University of Texas at Austin. 
FERREIRA, A., ANTUNES, A., PICADO-SANTOS, L.(2002) "Probabilistic segment-linked pavement management optimization model", ASCE - Journal of Transportation Engineering. Volume 128, Issue 6, pp. 568-577.

FERREIRA, A.; ANTUNES, A.; PICADO-SANTOS, L. (2001). A GIS-based Pavement Management System. Proceedings of the Fifth International Conference on Managing Pavements. CD Ed. Transportation Research Board, Washington DC Vol.1.

FORMAN, E.; SELLY, M. A. (2001). Decision by objectives: how to convince others that you are right. Disponível em: $<$ http://www.expertchoice.com/dbo >.Acesso em: 17 abr.2003.

FWA, T. F.; CHAN, W. T.; HOQUE, K. Z. (1998). Analysis of pavement management activities programming by Genetic Algorithms. Transportation Research Record 1643. TRB. National Research Council Washington, D.C.

GALVÃO, R.D. (2000). Sistemas de Apoio à Decisão Espacial para problemas de localização e distribuição. Projeto integrado de pesquisa, Programa de Engenharia de Produção - COPPE/UFRJ. Em:<http://www.po.ufrj.br/projeto/> Acesso em 20 mai 2003.

GAO, B. (2004). A GIS-Enabled Multi-Year Pavement Rehabilitation Needs Analysis System. Thesis (Doctor of Philosophy in Civil Engineering). Georgia Institute of Technology.

GEORGE K.P.; UDDIN, W.; FERGUSON, P.J.; CRAWLEY, A.B.; SHEKHARAN, A.R. (1994). Maintenance Planning Methodology for Statewide Pavement Management. Transportation Research Board. Washington D.C., pp.123-131.

GHARAIBEH, N. G.; DARTER, M. I. (2000). Budget allocation in infrastructure asset management using risk-based analysis. Transportation Research Record. TRB. 79th Annual Meeting. National Research Council. Washington, D.C.

GORRY, G. A.; MORTON, M. S. S. (1971). A framework for Management Information Systems. Sloan Management Review 13. pp. 50-70.

GOTHIÉ, M. (1993). Influence de L'adhérence sur la Securitié Routière. Bulletin de Liaison des Laboratoires des Ponts et Chaussés, $n^{\circ} 185$.

HAAS, R.; HUDSON, W. R.; ZANIEWSKI, J. (1994). Modern pavement management. Krieger Publishing Co. Malamar, Florida.

HALL, J. P.; KIM, T. J.; DARTER, M. I. (2000). Cost/benefit analysis os Geographic Information System implementation: case of the Illinois Department of Transportation. Transportation Research Record. TRB. 79th Annual Meeting. National Research Council. Washington, D.C.

IPEA - INSTITUTO DE PESQUISA ECONÔMICA APLICADA (1999). Caracterização e tendências da rede urbana do Brasil. Campinas. 2v.

IRRGANG F. C.; MAZE, T. H. (1993). Status of Pavement Management Systems and data analysis models at state highway agencies. Transportation Research Record 1397. TRB. National Research Council Washington, D.C., pp 1-6. 
JANKOWSKI, P.; ANDRIENKO, N.; ANDRIENKO, G. (2001). Map-centred exploratory approach to multiple criteria spatial decision making. International Journal of Geographical Information Science, v.15, n.2, p.101-127, Mar.

JOERIN, F.; THÉRIAULT, M.; MUSY, A. (2001) "Using GIS and outranking multicriteria analysis for land use suitability assessment" International Journal of Geographical Information Science, v.15, n.2, p. 153-174.

JONES, D. R.; BROWN, D. (2002). The division of labor between human and computer in the presence of Decision Support System advice. Decision Support Systems 33, pp. 375-388.

KAWAMOTO, E.; FURTADO (1997) Avaliação de projetos de transporte. Material Didático. Universidade de São Paulo, Escola de Engenharia de São Carlos. São Carlos, SP.

KENNEDY JR., J. C.; MAJIDZDEH, K.; VEDAIE, B. (1990). Pavement Management System to maximize pavement investment and minimize cost. Transportation Research Record 1272. TRB. Washington, D.C., p.65-73.

KERALI, H.G.D. MCMULLEN; ODOKI, J.B. (2000). Applications Guide - Volume 2 of Highway Development and Management Series. International Study of Highway Development and Management (ISOHDM), World Road Association PIARC, Paris, 2000.

KULKARNI, R. B.; MILLER, D.; INGRAM, R. M.; WONG, C.; LORENZ, J. (2004). Needbased project prioritization: alternative to cost-benefit analysis. Journal of Transportation Engineering. P. 150-158.

LEE, D. H.; PARK, D. (1997). An efficient algorithm for fuzzy weighted average. Fuzzy Sets and Systems. P. 39-45.

LIMA J. P.; LOPES, S. B.; ZANCHETTA, F.; ANELLI, R.L.S.; FERNANDES JR., J. L. (2004). O uso de SIG em Gerência de Infra-estrutura Urbana de Transportes: estudo de caso em São Carlos - SP. In: WORKSHOP: Planeamento Integrado: em busca de desenvolvimento sustentável para cidades de pequeno e médio portes. Universidade do Minho - Departamento de Engenharia Civil, Braga - Portugal.

LIMA, J. P.; RAMOS, R. A. R.; RODRIGUES, D. S.; MENDES, J. F. G.(2002). Avaliação multicritério da acessibilidade: um estudo de caso na sub-região do Vale do Cávado, norte de Portugal. In: XVI ANPET - Congresso da Associação Nacional de Pesquisa e Ensino em Transportes, Natal - RN, 2002. Anais... XVI ANPET - Panorama Nacional de Pesquisa em Transportes, v. 2, p. 459-470.

LIMA, R. S. (2003). Uma metodologia de apoio à decisão espacial para planejamento e gestão de serviços de educação e saúde sob a ótica dos transportes. Tese (Doutorado). 200p. Escola de Engenharia de São Carlos - Universidade de São Paulo, São Carlos, SP.

LIMA, R. S.; MENDES, J. F. G.; SILVA, A. N. R.; SILVA, A. L. M. (2000) "Uma avaliação da qualidade de vida em São Carlos - SP". Anais... IX Congresso Ibero-americano de Urbanismo, Recife, PE, (em CD-ROM)

LISBOA, M.V.; SARAGIOTTO, L.F.R. (2004). Aplicação do Analytic Hierarchy Process AHP em estudos de alternativas de traçados de rodovias: o caso do trecho norte do rodoanel 
Mário Covas. In: XVIII ANPET - Congresso da Associação Nacional de Pesquisa e Ensino em Transportes. Florianópolis - RN, 2004. Anais... Comunicações Técnicas.

MABWANA, J. R.; TURNQUIST, M. A. (1996). Optimization modeling for enhanced network-level Pavement Management System. Transportation Research Record 1524. TRB. Washington, D.C., p.76-85.

MALCZEWSKI, J. (1999). GIS and multicriteria decision analysis. New York: John Wiley \& Sons, Inc.

MAPC (1986). Pavement management - a manual for communities. U. S. Depatment of Transportation. Metropolitan Area Planning Council, Boston, MA.

MASSARO, L.C. (2005). Planejamento da execução de remendos em vias urbanas sob o enfoque da logística de serviços. Mestrado (Dissertação). São Carlos. Escola de Engenharia de São Carlos. Universidade de São Paulo. São Carlos - SP.

MASSEY, S. (2001). Caltrans` Innovative Approaches to Preventive Maintenance. Proceedings of $5^{\text {th }}$ International Conference on Pavement Management. Seattle, Washington, August 11-14.

MENDES, J.F.G.; LIMA, R.; SILVA, A.; SILVA, A.N. (2000) An evaluation of the quality of life in the city of São Carlos, SP - Brazil. Habitat International. São Carlos -SP

MENDES, J. F.G. (1999). Onde viver em Portugal - Uma análise da qualidade de vida nas capitais de distrito. Ordem dos Engenheiros, Coimbra, Portugal.

MENDES, J.F.G.; SILVA, J.; RAMETTA, F.; GIORDANO, S. (1999) Mapping urban quality of life in Portugal: a GIS approach. In: BENTO, J.; ARANTES, E.; OLIVEIRA, E.; PEREIRA, E., eds EPMESC VII: Computational Methods in Engineering and Science, Macao, Elsevier, v.2, p.1107-1115.

MENDIRATTA, P.; RAVIKUMAR, K. V. R. K. (1997) “GIS as a Decision Support System in urban planning: case study of regional park development in New Bombay." Proceedings of the 5th World Conference on Computers in Urban Planning and Urban Management. Indian Institute of Technology, Mumbai, India. v.2, p.794-801.

MISRA, A.; ROOHANIRAD, A.; SOMBOONYANON, P. (2003). Guidelines for a Roadway Management System (RMS) for Local Governments. Final Report. MTC - Midwest

Transportation Consortium. (Disponível em:

$<$ http://www.ctre.iastate.edu/mtc/reports/RMS.htm> Acesso em: 25 out 2005).

ODA, S.; SÓRIA, M. H. A.; FERNANDES JR., J. L. (1997). Seleção de atividades de manutenção e reabilitação de estradas não-pavimentadas para fins de gerência de vias. $X I$ ANPET - Congresso Nacional de Pesquisa e Ensino em Transportes, Rio de Janeiro, Anais, p.370-383.

PANTIGOSO, J. F. G. (1998). Uso dos Sistemas de Informação Geográfica para integração da gerência de pavimentos urbanos com as atividades das concessionárias de serviços públicos. Dissertação (Mestrado) - Escola de Engenharia de São Carlos - Universidade de São Paulo. São Carlos, SP. 
PEREIRA, P.; MIRANDA, V. (1999). Gestão da conservação dos pavimentos rodoviários. Braga, Portugal.

PEREIRA, P.A.A. (1988). Contribuição para um Sistema de Gestão Rodoviária - modelos de comportamento e método de avaliação da qualidade dos pavimentos rodoviários. Tese (doutorado). Universidade do Minho. Braga, Portugal.

PRAKASH, A.; SHARMA, B. N.; KAZMIEROWSKI, T. J. (1993). Management and preservation of pavements. Pavement Design, Evaluation and Management Section. Ontario.

RAMOS, R. A. R. (2000). Localização industrial - um modelo espacial para o noroeste de Portugal. Tese (Doutorado). Universidade do Minho. Braga, Portugal.

RARDIN, R.L. (2000). Optimization in Operations Research. Prentice Hall, Inc.

RODGHER, S. F.; ODA, S.; FERNANDES JR., J. L. ; FABBRI, G. T. P.; SÓRIA, M.H.A. (1998). Uso de redes neurais artificiais na seleção de atividades de manutenção e reabilitação de estradas não-pavimentadas. XII ANPET - Congresso Nacional de Pesquisa e Ensino em Transportes, Fortaleza, Anais... p.183-196.

RODRIGUES, D.S.; MENDES, J.F.G.; LIMA, J.P.; RAMOS, R.A.R. (2004). Uma abordagem multicritério para a avaliação da acessibilidade. In: Contribuições para o Desenvolvimento Sustentável em Cidades Portuguesas e Brasileiras. Almedina - Coimbra, Portugal. 2004, v.1, p. 98-117.

RODRIGUES, D.S. (2001). Avaliação multicritério de acessibilidade em ambiente SIG. Braga, Portugal, 143 p. Dissertação (Mestrado). Departamento de Engenharia Civil, Universidade do Minho.

ROSADO, M. C. (2000) "Um método de avaliação da acessibilidade a serviços públicos com o uso do SIG - Aplicação à cidade de Araranguá (SC)". Dissertação (Mestrado), 131p. Departamento de Engenharia Civil, Universidade Federal de Santa Catarina, Florianópolis, SC.

ROSE, A. (2001). Uma avaliação comparativa de alguns Sistemas de Informação Geográfica aplicados aos transportes. Dissertação (Mestrado), 135p. Escola de Engenharia de São Carlos - Universidade de São Paulo, São Carlos, SP.

ROY, B. (1996). Multicriteria methodology for decision aiding. Kluwer Academic Publishers.

SAATY, T; VARGAS, L.(1991). Método de Análise Hierárquica. São Paulo: McGraw Hill, Makron, 1991.

SAATY, T. (1980). The Analytic Hierarchy Process. New York. McGraw Hill

SANCHES, O. M. (1997). Estratégias para a implantação e gerência de sistemas de informação de apoio à tomada de decisões". Revista da Administração Pública, v. 31, n. 4, p. 68-100, jul/ago, Rio de Janeiro, FGV, RJ. 
SANTO M. A.; LOCH, C.; OLIVEIRA, F. H. (2006). Modelos de Generalização Cartográfica em SIG. COBRAC 2006 - Congresso Brasileiro de Cadastro Técnico Multifinalitário. UFSC, Florianópolis- SC.

SANTOS, L. (2006). Análise dos Acidentes de Trânsito no Município de São Carlos Utilizando SIG e Ferramentas de Análise Espacial. Dissertação (Mestrado). UFSCAR Universidade Federal de São Carlos. São Carlos - SP.

SCHWARTZ, C.W.; RADA, G.R.; WITCZAK, M.W.; RABINOW, S.D. (1991). GIS applications in airfield pavement management. Transportation Research Record 1311. TRB. National Research Council. Washington, D.C. pp.267-276.

SHIM, J. P.; WARKENTIN, M.; COURTNEY, J. F.; POWER, D. J.; SHARDA, R.; CARLSSON, C. (2002). Past, Present, and Future of Decision Support Tecnology. Decision Support Systems 33, pp. 111-126.

SHRP (1993). Distress identification manual for the long-term pavement performance studies. The Strategic Highway Research Program. National Academy of Science. Washington, D.C.

SILVESTRE, L. A. (2002). Desenvolvimento de um modelo para avaliação de sites de comércio eletrônico utilizando a Metodologia Multicritério de Apoio à Decisão - MCDA. Dissertação (Mestrado). Escola de Engenharia de São Carlos - Universidade de São Paulo. São Carlos, SP.

SIMON, H. A. (1960). The new science of management decision. Harper Brothers, New York. pp.40-43.

SMITH, R. E.; SHAHIN, M.Y.; DARTER, M. I.; CARPENTER, S. H. (1988). A comprehensive ranking system for local agency pavement management. Transportation Research Record 1123. TRB. Washington, D.C.

SPEICHER, D.; SCHWARTZ, M.; MAR, T. (2000). Prioritizing major transportation improvement projects: comparison of evaluation criteria. Transportation Research Record 1706. TRB. Washington, D.C. pp.38-45.

SPRAGUE, R. H. E; WATSON, H. J. (1996). Decision support for management. Upper Saddle River, New Jersey, Prentice Hall.

TAVAKOLI, A.; LAPIN, M.S.; FIGUEROA, J.L. (1992) PMSC: Pavement Management System for Small Communities. Journal of Transportation Engineering. Vol.118, $\mathrm{N}^{\circ} 2$, pp270-280, Cleveland, Ohio.

TRB - Transport Research Board (1990). Pavement rehabilitation and design. Transportation Research Record 1568. TRB. Washington, D.C.

ULLIDTZ, P. (1983). Management system for pavement maintenance and rehabilitation based on analytic methods of pavement evaluation. Transportation Research Record 930. TRB. Washington, D.C. 
VISCONTI, T. S. (2000). O Sistema Gerencial de Pavimentos do DNER. Departamento Nacional de Estradas de Rodagem - DNER. (Disponível em: <http://www1.dnit.gov.br/ arquivos_internet/ipr/ipr_new/manuais/pms_99.pdf $>$. Acesso em: 20 set 2006)

VISSER, A.T., QUEIROZ, C.A.V. (1979). Rougness Meassurements Systems. Empresa Brasileira de Planejamento de Transporte-GEIPOT. PICR Working Document nº 10, Brasília.

VOOGD, H. (1983). Multicriteria evaluation for urban and regional planning. London: Pion Ltd.

WANG, F.; ZHANG, Z.; MACHEMEHL, R. B. (2003). Decision making problem for managing pavement maintenance and rehabilitation projects. Transportation Research Record 2202. TRB. National Research Council Washington, D.C.

WASSERMAN, P. D. (1989). Neural computing: theory and practice. Van Nostrand Reinhold, New York.

WATANABE, E.M. (2004). O método de análise hierárquica aplicado ao desenvolvimento do produto. Dissertação (Mestrado). Faculdade de Engenharia Mecânica, Departamento de Projeto Mecânico, Universidade Estadual de Campina. Campinas - SP.

WINSTON, W.L.(1995). Introduction to Mathematical Programming - Applications and Algorithms. R. R Donneley \& Sons Company.

WISCONSIN DOT (1990). Pavement management decision support using a Geographic Information System. Wisconsin Department of Transportation. Madison, Wisconsin.

YAGER, R. R. (1988). On ordered weighted averaging aggregation operators in multicritério decision making. IEEE Transactions on Systems, Man and Cybernetics, v. 8, n. 1, p. 183-190.

ZADEH, L. A. (1965). Fuzzy Sets. Information and Control, Vol.8. pp.338-353.

ZAMBON, K.L. (2004). Localização de usinas termoelétricas utilizando sistema de informação geográfica e métodos de decisão multicritério. Tese (doutorado). Dissertação (Mestrado). Universidade de São Paulo, Escola de Engenharia de São Carlos, Departamento de Transportes. São Carlos, SP.

ZANCHETTA, F.; LIMA J. P.; LOPES, S. B.; FERNANDES JR., J. L. (2004). Considerações sobre avaliações de vias para a implantação de um Sistema de Gerência de Pavimentos Urbanos. In: XVIII ANPET - Congresso da Associação Nacional de Pesquisa e Ensino em Transportes. Florianópolis - RN, 2004. Anais... Comunicações Técnicas.

ZHANG, Z.; SMITH, S.G.; HUDSON, W. R. (2001). Geographic Information System implementation plan for Pavement Management Information System. Transportation Research Record 1769. TRB. National Research Council. Washington, D.C.

ZHANG, Z.; SINGH, N.; HUDSON, W. R. (1993). Comprehensive ranking index for flexible pavement using fuzzy sets model. Transportation Research Record 1397. TRB. National Research Council. Washington, D.C., pp 96-102. 
ZIMMERMAN, K.A.(1995) Pavement Management Methodologies to Select Projects and Recommend Preservation Treatments. Transportation Research Board. NCHRP Synthesis of Highway Practice 222. Washington, D.C.

ZOPOUNDIS, C.; DOUMPOS, M.; MATSATSINIS, N. F. (1997). On the use of knowledgebased decision support systems in financial management: a survey. Decision Support Systems, v. 20, 259-277. 
ANEXOS

ב 

ANEXO A: QUESTIONÁRIO DISTRIBUÍDO PARA AS PREFEITURAS DE CIDADES MÉDIAS BRASILEIRAS 


\section{A-1. NÚCLEOS DE CENTROS URBANOS ORDENADOS DE FORMA}

DECRESCENTE DE ACORDO COM A POPULAÇÃO URBANA EM 1996

(IPEA,1999).

\begin{tabular}{|c|c|c|c|}
\hline \multicolumn{4}{|c|}{ " CENTROS URBANOS BRASILEIROS } \\
\hline \multicolumn{4}{|c|}{ CENTROS REGIONAIS } \\
\hline $\mathbf{N}^{\mathbf{0}}$ & Cidade & UF & População em 1996 \\
\hline 1 & São Luís & MA & 780.833 \\
\hline 2 & Maceió & AL & 723.230 \\
\hline 3 & Natal & $\mathrm{RN}$ & 656.037 \\
\hline 4 & Teresina & PI & 655.473 \\
\hline 5 & Campo Grande & MS & 600.069 \\
\hline 6 & João Pessoa & PB & 549.363 \\
\hline 7 & São José dos Campos & SP & 486.467 \\
\hline 8 & Ribeirão Preto & SP & 462.351 \\
\hline 9 & Cuiabá & MT & 433.355 \\
\hline 10 & Santos & SP & 429.245 \\
\hline 11 & Aracaju & SE & 428.194 \\
\hline 12 & Londrina & PR & 421.343 \\
\hline 13 & Porto Velho & RO & 294.227 \\
\hline 14 & Florianópolis & $\mathrm{SC}$ & 271.281 \\
\hline 15 & Vitória & ES & 265.874 \\
\hline 16 & Rio Branco & $\mathrm{AC}$ & 228.857 \\
\hline \multicolumn{4}{|c|}{ CENTROS URBANOS SUB-REGIONAIS DE NÍVEL UM } \\
\hline 17 & Feira de Santana & $\mathrm{BA}$ & 450.487 \\
\hline 18 & Uberlândia & MG & 438.986 \\
\hline 19 & Sorocaba & $\mathrm{SP}$ & 431.561 \\
\hline 20 & Juiz de Fora & MG & 424.479 \\
\hline 21 & Joinville & $\mathrm{SC}$ & 397.951 \\
\hline 22 & Campos dos Goitacazes & RJ & 389.547 \\
\hline 23 & Campina Grande & PB & 344.730 \\
\hline 24 & São José do Rio Preto & SP & 326.315 \\
\hline 25 & Caxias do Sul & RS & 326.086 \\
\hline 26 & Pelotas & RS & 307.667 \\
\hline 27 & Jundiaí & SP & 293.373 \\
\hline 28 & Bauru & $\mathrm{SP}$ & 292.566 \\
\hline 29 & Imperatriz & MA & 274.104 \\
\hline 30 & Maringá & PR & 267.942 \\
\hline 31 & Anápolis & GO & 264.975 \\
\hline 32 & Ilhéus & $\mathrm{BA}$ & 242.445 \\
\hline 33 & Vitória da Conquista & BA & 242.155 \\
\hline 34 & Uberaba & MG & 237.433 \\
\hline 35 & Volta Redonda & RJ & 232.287 \\
\hline 36 & Caruaru & $\mathrm{PE}$ & 231.989 \\
\hline 37 & Blumenau & $\mathrm{SC}$ & 231.401 \\
\hline 38 & Limeira & SP & 230.348 \\
\hline 39 & Macapá & $\mathrm{AP}$ & 220.962 \\
\hline 40 & Cascavel & PR & 219.652 \\
\hline 41 & Petrolina & $\mathrm{PE}$ & 191.238 \\
\hline 42 & Juazeiro do Norte & $\mathrm{CE}$ & 189.161 \\
\hline 43 & Itabuna & $\mathrm{BA}$ & 183.403 \\
\hline 44 & Rio Grande & $\mathrm{RS}$ & 178.256 \\
\hline 45 & Presidente Prudente & SP & 177.367 \\
\hline 46 & São Carlos & SP & 175.517 \\
\hline 47 & Araraquara & SP & 172.746 \\
\hline 48 & Juazeiro do Norte & BA & 172.065 \\
\hline 49 & Barra Mansa & RJ & 166.745 \\
\hline 50 & Boa Vista & RR & 165.518 \\
\hline 51 & Dourados & MS & 153.191 \\
\hline 52 & Crato & $\mathrm{CE}$ & 95.521 \\
\hline 53 & Palmas & TO & 86.116 \\
\hline
\end{tabular}




\begin{tabular}{|c|c|c|c|}
\hline \multicolumn{4}{|c|}{ CENTROS SUB-REGIONAIS DE NÍVEL DOIS } \\
\hline $\mathbf{N}^{\mathbf{0}}$ & Cidade & UF & População em 1996 \\
\hline 54 & Piracicaba & SP & \begin{tabular}{|c|}
302.886 \\
\end{tabular} \\
\hline 55 & Montes Claros & MG & 271.608 \\
\hline 56 & Franca & SP & 267.235 \\
\hline 57 & Santarém & PA & 263.468 \\
\hline 58 & Ponta Grossa & PR & 256.302 \\
\hline 59 & Santa Maria & RS & 233.351 \\
\hline 60 & Foz do Iguaçu & PR & 231.627 \\
\hline 61 & Governador Valadares & MG & 231.242 \\
\hline 62 & Mossoró & $\mathrm{RN}$ & 205.822 \\
\hline 63 & Ipatinga & MG & 195.793 \\
\hline 64 & Marília & SP & 177.632 \\
\hline 65 & Arapiraca & $\mathrm{AL}$ & 173.339 \\
\hline 66 & Divinópolis & MG & 171.565 \\
\hline 67 & Araçatuba & SP & 169.309 \\
\hline 68 & Nova Friburgo & $\mathrm{RJ}$ & 169.246 \\
\hline 69 & Sete Lagoas & MG & 167.340 \\
\hline 70 & Jequié & BA & 165.345 \\
\hline 71 & Criciúma & $\mathrm{SC}$ & 159.101 \\
\hline 72 & Passo Fundo & RS & 156.333 \\
\hline 73 & Guarapuava & PR & 155.835 \\
\hline 74 & Cachoeiro do Itapemirim & ES & 150.359 \\
\hline 75 & Marabá & PA & 150.095 \\
\hline 76 & Lages & $\mathrm{SC}$ & 148.860 \\
\hline 77 & Caxias & MA & 146.045 \\
\hline 78 & Rondonópolis & MT & 142.524 \\
\hline 79 & Sobral & $\mathrm{CE}$ & 138.565 \\
\hline 80 & Teófilo Otoni & MG & 136.044 \\
\hline 81 & Itajaí & $\mathrm{SC}$ & 134.942 \\
\hline 82 & Parnaíba & PI & 131.885 \\
\hline 83 & Chapecó & $\mathrm{SC}$ & 131.014 \\
\hline 84 & Linhares & ES & 125.297 \\
\hline 85 & Paranaguá & PR & 124.920 \\
\hline 86 & Uruguaiana & RS & 124.881 \\
\hline 87 & Alagoinhas & BA & 122.838 \\
\hline 88 & Poços de Caldas & MG & 121.831 \\
\hline 89 & Castanhal & PA & 117.380 \\
\hline 90 & Cabo Frio & $\mathrm{RJ}$ & 115.759 \\
\hline 91 & Mogi-Guaçu & SP & 114.546 \\
\hline 92 & Barreiras & BA & 113.695 \\
\hline 93 & Garanhuns & $\mathrm{PE}$ & 110.084 \\
\hline 94 & Bragança Paulista & SP & 110.083 \\
\hline 95 & Barbacena & MG & 107.810 \\
\hline 96 & Araguaína & TO & 105.019 \\
\hline 97 & Jaú & SP & 103.601 \\
\hline 98 & Catanduva & SP & 100.942 \\
\hline 99 & Botucatu & SP & 100.876 \\
\hline 100 & Rio Verde & GO & 100.586 \\
\hline 101 & Santa Cruz do Sul & $\mathrm{RS}$ & 100.433 \\
\hline 102 & Guaratinguetá & SP & 98.265 \\
\hline 103 & Ji-Paraná & RO & 95.356 \\
\hline 104 & Itabira & MG & 95.205 \\
\hline 105 & Mogi-Mirim & SP & 75.337 \\
\hline 106 & Aparecida & SP & 34.318 \\
\hline
\end{tabular}




\title{
A-2. QUESTIONÁRIO DESTINADO AOS RESPONSÁVEIS PELOS SERVIÇOS DE
}

\author{
MANUTENÇÃO E REABILITAÇÃO DE PAVIMENTOS DAS PREFEITURAS DE
}

\section{CIDADES MÉDIAS BRASILEIRAS}

UNIVERSIDADE DE SÃO PAULO
ESCOLA DE ENGENHARIA DE SÃO CARLOS
DEPARTAMENTO DE TRANSPORTES

PESQUISA SOBRE A PRÁTICA DA GESTÃO DAS ATIVIDADES DE MANUTENÇÃO E REABILITAÇÃO DE PAVIMENTOS

Por Favor, responda as questões abaixo

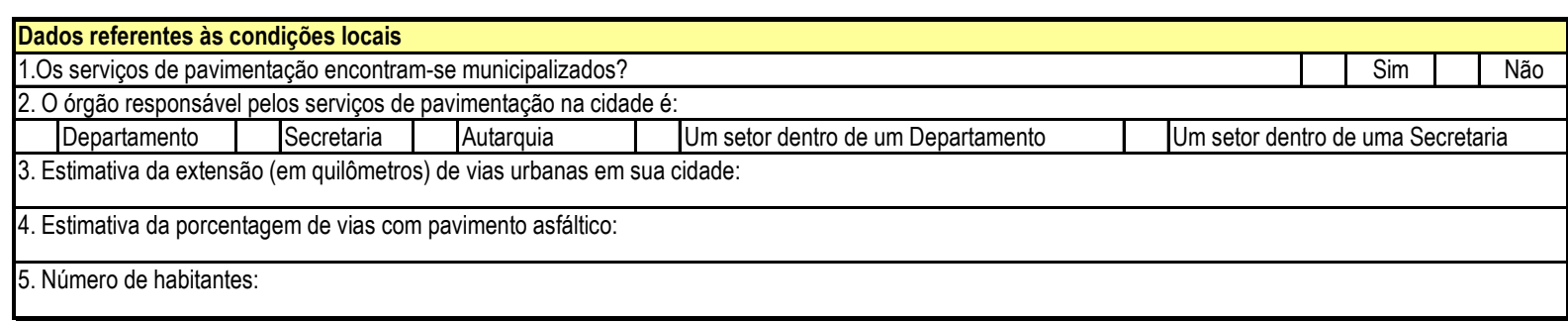

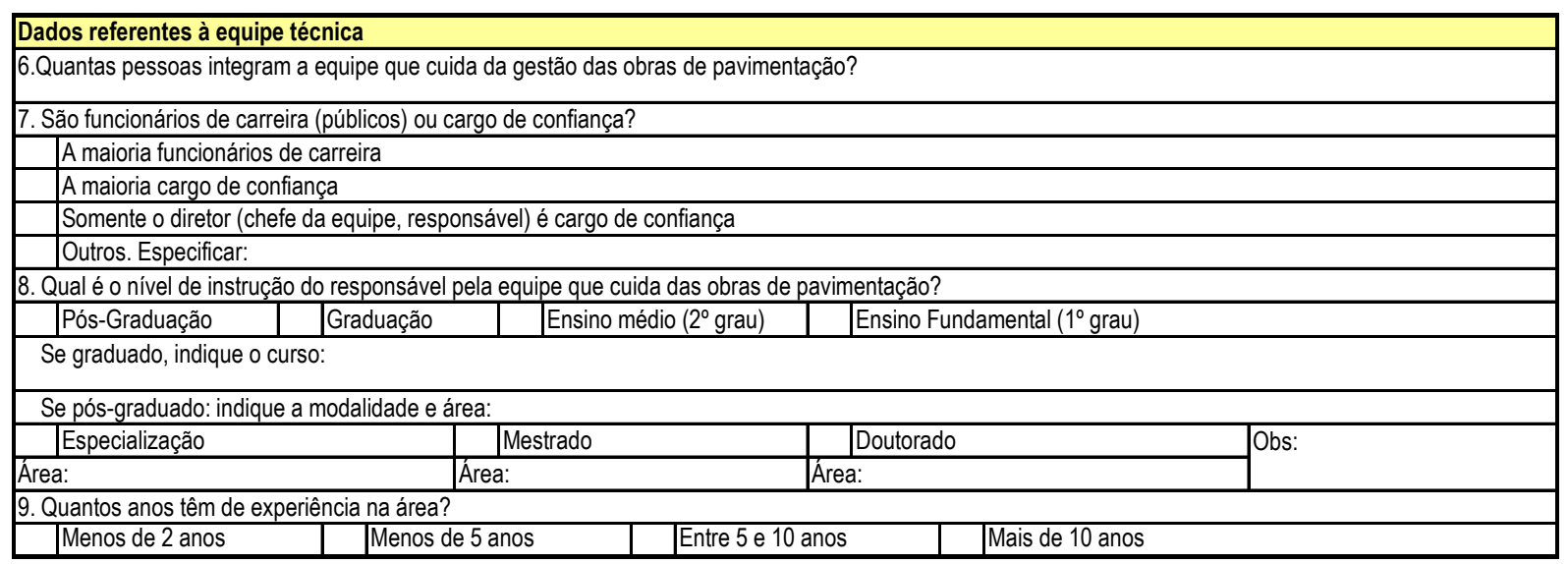

\begin{tabular}{|c|c|c|c|c|c|c|}
\hline \multicolumn{7}{|c|}{ Dados referentes à gestão das obras de manutenção dos pavimentos } \\
\hline 10. A prefeitura & i um inventário das ruas da cidade? & & Sim & Não & & \\
\hline \multicolumn{7}{|c|}{ 11. Com que freqüência são realizados levantamentos de campo e avaliação do pavimento? } \\
\hline \begin{tabular}{|l|l|} 
& Todo ano
\end{tabular} & De dois em dois anos & \multicolumn{2}{|l|}{ Quando necessário } & \multicolumn{3}{|c|}{ Outros. Especifique: } \\
\hline \multicolumn{5}{|c|}{ 12. A prefeitura conta com recursos de computador para processamento das informações sobre o pavimento? } & Sim & Não \\
\hline \multicolumn{5}{|c|}{ 13. A prefeitura possui procedimentos específicos (um sistema) para a gestão das obras de manutenção dos pavimentos? } & Sim & Não \\
\hline \multicolumn{7}{|c|}{ 14. Qual(s) o(s) objetivo(s) específico(s) deste sistema? } \\
\hline \multicolumn{7}{|c|}{ Banco de dados ou inventário } \\
\hline \multicolumn{7}{|c|}{ Histórico de construção, manutenção e reabilitação dos pavimentos } \\
\hline \multicolumn{7}{|c|}{ Atualização das avaliações dos pavimentos } \\
\hline \multicolumn{7}{|c|}{ Seleção de seções ou ruas candidatas a obras de manutenção (Priorização das seções ou ruas) } \\
\hline \multicolumn{7}{|c|}{$\begin{array}{l}\text { Seleção de estratégias de obras de manutenção (como por exemplo, não fazer nada, manutenção preventiva, manutenção corretiva, recapeamento e } \\
\text { reconstrução) }\end{array}$} \\
\hline \multicolumn{7}{|c|}{ Alocação de recursos e orçamento } \\
\hline \multicolumn{7}{|c|}{ Previsão de desempenho de pavimentos } \\
\hline \multicolumn{7}{|c|}{ Outros. Especifique: } \\
\hline
\end{tabular}




\begin{tabular}{|c|c|c|}
\hline \multicolumn{3}{|l|}{ Dados referentes aos procedimentos associados à seleção de ruas ou seções } \\
\hline 15. É estabelecido algum critério para determinar o local (a seção ou rua) onde será realizada a obra de manutenção? & Sim & Não \\
\hline \multicolumn{3}{|l|}{ 16. Diante de defeitos ou problemas encontrados, quais são os critérios para a seleção destes locais? Marque uma ou mais respostas. } \\
\hline \multicolumn{3}{|c|}{ As ruas prioritárias serão aquelas com pior condição do pavimento, ou seja, com defeitos que comprometem a segurança e o conforto do usuário. } \\
\hline \multicolumn{3}{|c|}{$\begin{array}{l}\text { As ruas prioritárias serão selecionadas conforme a sua hierarquia viária, ou seja, de acordo com a classe funcional, ruas com grande quantidade de tráfego, } \\
\text { ruas com rotas de ônibus, etc. }\end{array}$} \\
\hline \multicolumn{3}{|c|}{ As ruas prioritárias serão aquelas próximas a terminais rodoviários, ferroviários, escolas, hospitais, centro comerciais, áreas de lazer, etc. } \\
\hline \multicolumn{3}{|l|}{ As ruas prioritárias serão aquelas onde o custo da obra de manutenção for o menor para a administração e para os usuários. } \\
\hline \multicolumn{3}{|l|}{ Outros. Especifique: } \\
\hline \multirow{2}{*}{\multicolumn{3}{|c|}{ 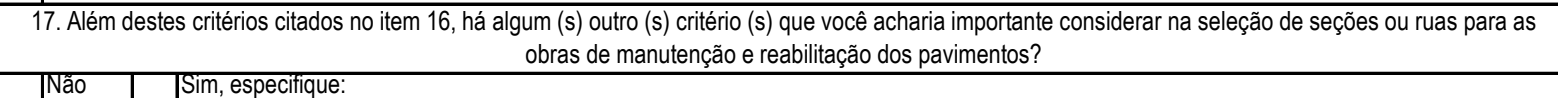 }} \\
\hline & & \\
\hline 18. A prefeitura trabalha com algum método específico para a seleção de seções ou ruas candidatas as obras de manutenção? & Sim & Não \\
\hline \multicolumn{3}{|l|}{ 19. Como é este método? } \\
\hline \multicolumn{3}{|l|}{ Através de índices de prioridades que consideram fatores específicos } \\
\hline \multicolumn{3}{|l|}{ Através de critérios pré-determinados para hierarquização de ruas ou seções pavimentadas } \\
\hline \multicolumn{3}{|l|}{ Através de análises da condição do pavimento } \\
\hline \multicolumn{3}{|l|}{ Através de modelos de priorização de projetos } \\
\hline \multicolumn{3}{|l|}{$\begin{array}{l}\text { Através de modelos de otimização de rede } \\
\text { Outros.Especifique: }\end{array}$} \\
\hline \multirow{2}{*}{\multicolumn{3}{|c|}{\begin{tabular}{l|l} 
& Outros.Especifique: \\
\end{tabular}}} \\
\hline & & \\
\hline
\end{tabular}

\section{Observações e comentários}

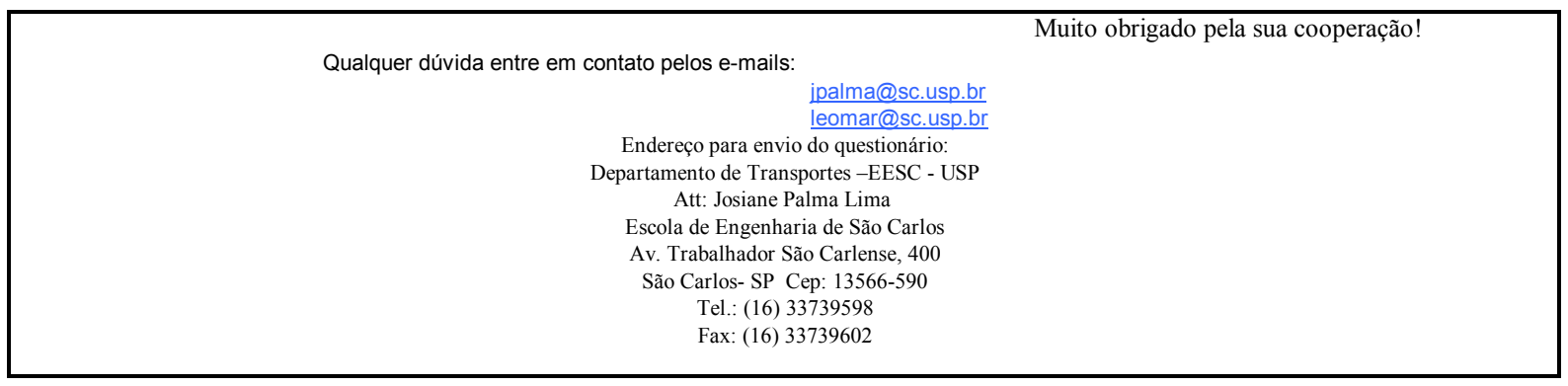



ANEXO B: CRITÉRIOS DE PRIORIZAÇÃO DE SEÇÕES

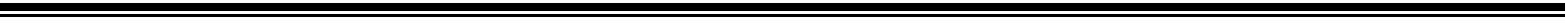




\section{B-1 LISTA DE CRITÉRIOS RELEVANTES PARA A PRIORIZAÇÃO DE SEÇÕES}

\begin{tabular}{|l|}
\hline Fatores associados à hierarquia viária \\
\hline Classificação funcional \\
Tipo de rota \\
Volume de tráfego \\
\hline Fatores associados às questões técnicas e operacionais \\
\hline Necessidade técnica por intervenção \\
Índice combinado de defeitos (avaliação objetiva) \\
Índice da condição do pavimento (avaliação subjetiva) \\
Idade do pavimento \\
Questões Ambientais \\
Questões de Segurança \\
\hline Fatores associados à localização das seções de pavimento \\
\hline Proximidade a infra-estruturas de Transportes \\
Proximidade a terminal rodoviário \\
Proximidade a terminal ferroviário \\
Proximidade a portos e aeroportos \\
Proximidade a rodovias \\
Proximidade a equipamentos ou prédios institucionais \\
Proximidade a escolas primárias e secundárias \\
Proximidade a universidades \\
Proximidade a postos de saúde \\
Proximidade a hospitais \\
Proximidade a centros administrativos \\
Proximidade a corporação de bombeiros \\
Proximidade a instalações militares \\
Preferências pessoais ou administrativas \\
Proximidade a centros comerciais \\
Proximidade a bairros com particular qualidade de vida \\
Proximidade a áreas de lazer e esportes \\
Proximidade a áreas turísticas \\
Proximidade a áreas industriais \\
\hline Fatores associados aos custos \\
\hline Custos dos Usuários \\
Custo de operação de veículos \\
Custo do tempo de viagem \\
Custo de acidentes \\
Custos da Administração \\
\hline
\end{tabular}


ANEXO C: AVALIAÇÃo DE CRITÉRIOS PELO PAINEL DE ESPECIALISTAS

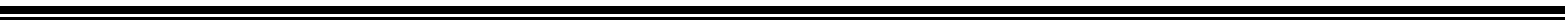




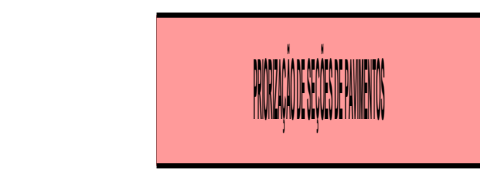

0

恼

已

$\frac{1}{4}$

$<$

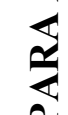

6

닐

อิ

选

通

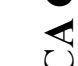

已

ชิ

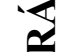

重

$\$$

ํㅗㄹ

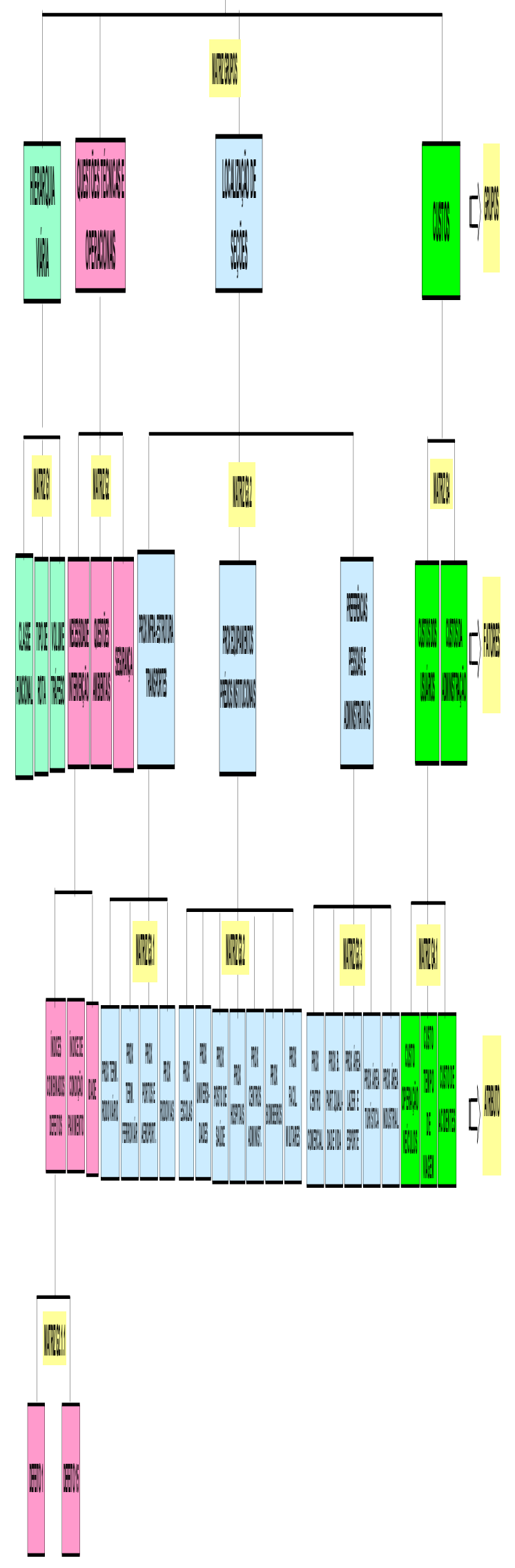




\section{C-2 MATRIZES DESENVOLVIDAS EM PLANILHA ELETRÔNICA - COMPARAÇÃO PAR A PAR DO PROCESSO DE AVALIAÇÃO $A H P$}

Qual a importância relativa dos critérios abaixo para a priorização de seções candidatas à manutenção e reabilitação(M\& $R)$ do pavimento?

\section{Somente os campos em verde devem ser preenchidos.}

Instruções detalhadas podem ser encontradas na planilha "Instruções".

Clique no link abaixo para voltar ao menu principal e acessar as demais matrizes de comparação

\section{$\underline{\text { Menu principal }}$}

\section{Escala numérica}

1 - Igual importância

3 - Linha pouco mais importante que Coluna

5 - Linha muito mais importante que Coluna

7 - Linha bastante mais importante que Coluna

9 - Linha extremamente mais importante que Coluna

$1 / 3$ - Coluna pouco mais importante que Linha

1/5 - Coluna muito mais importante que Linha

1/7 - Coluna bastante mais importante que Linha

1/9 - Coluna extremamente mais importante que Linha

Matriz Grupos - Comparação dos Grupos de Fatores

\begin{tabular}{|l|c|c|c|c|}
\hline & Hierarquia Viária & QuestõesTécOper & Localização & Custos \\
\hline Hierarquia Viária & 1 & & & \\
\hline QuestõesTécOper & \#DIV/0! & 1 & & \\
\hline Localização & \#DIV/0! & \#DIV/0! & 1 & 1 \\
\hline Custos & \#DIV/0! & \#DIV/0! & \#DIV/0! & 1 \\
\hline
\end{tabular}

\begin{tabular}{|c|c|c|}
\hline $\begin{array}{l}\text { Grau de } \\
\text { Consistência }\end{array}$ & $\begin{array}{l}\mathrm{Se}>0,1 \\
\mathrm{Se}=0,1\end{array}$ & $\begin{array}{l}\text { Revise seus julgamentos! } \\
\text { Julgamentos Consistentes! }\end{array}$ \\
\hline
\end{tabular}

Matriz G1 - Comparação dos Fatores relacionados ao Grupo Hierarquia Viária

\begin{tabular}{|r|c|c|c|}
\hline & Classe Funcional & Tipo de Rota & Volume de Tráfego \\
\hline Classe Funcional & 1 & & \\
\hline Tipo de Rota & $\# \mathrm{DIV} / 0 !$ & 1 & \\
\hline Volume de Tráfego & $\# \mathrm{DIV} / 0 !$ & $\# \mathrm{DIV} / 0 !$ & 1 \\
\hline
\end{tabular}

\begin{tabular}{|c|c|c|}
\hline $\begin{array}{c}\text { Grau de } \\
\text { Consistência }\end{array}$ & $\begin{array}{l}\mathrm{Se}>0,1 \\
\mathrm{Se}=0,1\end{array}$ & $\begin{array}{l}\text { Revise seus julgamentos! } \\
\text { Julgamentos Consistentes! }\end{array}$ \\
\hline
\end{tabular}


Matriz G2 - Comparação dos Fatores relacionados ao Grupo Questões Técnicas e Operacionais

\begin{tabular}{|r|c|c|c|}
\hline & Neces TécnicaInterv & QuestAmbientais & Segurança \\
\hline Neces TécnicaInterv & 1 & & \\
\hline QuestAmbientais & $\# \mathrm{DIV} / 0 !$ & 1 & \\
\hline Segurança & $\# \mathrm{DIV} / 0 !$ & $\# \mathrm{DIV} / 0 !$ & 1 \\
\hline
\end{tabular}

\begin{tabular}{|c|c|c|}
\hline $\begin{array}{c}\text { Grau de } \\
\text { Consistência }\end{array}$ & $\begin{array}{l}\mathrm{Se}>0,1 \\
\mathrm{Se}=0,1\end{array}$ & $\begin{array}{l}\text { Revise seus julgamentos! } \\
\text { Julgamentos Consistentes! }\end{array}$ \\
\hline
\end{tabular}

Matriz G3 - Comparação dos Fatores relacionados ao Grupo Localização de Seções de Pavimentos

\begin{tabular}{|c|c|c|c|}
\hline & ProxInfraEs trutTrans portes & ProxEquipamentos & PreferPes soais Adminis t \\
\hline ProxInfraEs trutTrans portes & 1 & & \\
\hline ProxEquipamentos & \#DIV/0! & 1 & \\
\hline PreferPessoais Administ & \#DIV/0! & \#DIV/0! & 1 \\
\hline
\end{tabular}

\begin{tabular}{|c|c|c|}
\hline $\begin{array}{c}\text { Grau de } \\
\text { Consistência }\end{array}$ & $\begin{array}{l}\mathrm{Se}>0,1 \\
\mathrm{Se}=0,1\end{array}$ & $\begin{array}{l}\text { Revise seus julgamentos! } \\
\text { Julgamentos Consistentes! }\end{array}$ \\
\hline
\end{tabular}

Matriz G4 - Comparação dos Fatores Relacionados ao Grupo Custos

\begin{tabular}{|r|c|c|}
\hline & Cus tos do us uário & Custos da adminis tração \\
\hline Custos do us uário & 1 & 1 \\
\hline
\end{tabular}

Neste caso tem-se somente dois critérios e a consistência dos julgamentos não necessita ser avaliada.

Matriz G2.1 - Comparação dos Indicadores relacionados ao Fator Necessidade Técnica de Intervenção

\begin{tabular}{|c|c|c|c|}
\hline & ÍndCombDefeitos & ÍndCondPavimento & Idade \\
\hline ÍndCombDefeitos & 1 & & \\
\hline ÍndCondPavimento & $\# \mathrm{DIV} / 0 !$ & 1 & 1 \\
\hline Idade & $\# \mathrm{DIV} / 0 !$ & $\# \mathrm{DIV} / 0 !$ & \\
\hline
\end{tabular}

\begin{tabular}{|c|c|c|}
\hline $\begin{array}{c}\text { Grau de } \\
\text { Consistência }\end{array}$ & $\begin{array}{l}\mathrm{Se}>0,1 \\
\mathrm{Se}=0,1\end{array}$ & $\begin{array}{l}\text { Revise seus julgamentos! } \\
\text { Julgamentos Consistentes! }\end{array}$ \\
\hline
\end{tabular}

Matriz G3.1 - Comparação dos Indicadores relacionados ao fator proximidade à infra-estrutura de transportes

\begin{tabular}{|r|c|c|c|c|}
\hline & ProxTermRodoviário & ProxTermFerroviario & ProxPortos Aerop & ProxRodovias \\
\hline ProxTermRodoviário & 1 & & & \\
\hline ProxTermFerroviario & \#DIV/0! & 1 & & \\
\hline ProxPortos Aerop & \#DIV/0! & \#DIV/0! & 1 & \\
\hline ProxRodovias & \#DIV/0! & \#DIV/0! & \#DIV/0! & 1 \\
\hline
\end{tabular}

\begin{tabular}{|c|c|c|}
\hline $\begin{array}{c}\text { Grau de } \\
\text { Consistência }\end{array}$ & $\begin{array}{l}\mathrm{Se}>0,1 \\
\mathrm{Se}=0,1\end{array}$ & $\begin{array}{l}\text { Revise seus julgamentos! } \\
\text { Julgamentos Consistentes! }\end{array}$ \\
\hline
\end{tabular}


Matriz G3.2 - Comparação dos Indicadores Relacionados ao Fator Proximidade à Equipamentos ou Prédios Intitucionais

\begin{tabular}{|c|c|c|c|c|c|c|c|}
\hline & ProxEscolas & ProxUniversidades & ProxPos tos Saúde & ProxHospitais & ProxCentAdminis & ProxBombeiros & ProxFacilMilitares \\
\hline ProxEscolas & 1 & & & & & & \\
\hline ProxUniversidades & \#DIV/0! & 1 & & & & & \\
\hline ProxPos tos Saúde & \#DIV/0! & \#DIV/0! & 1 & & & & \\
\hline ProxHos pitais & \#DIV/0! & \#DIV/0! & \#DIV/0! & 1 & & & \\
\hline ProxCentAdminis t & \#DIV/0! & \#DIV/0! & \#DIV/0! & \#DIV/0! & 1 & & \\
\hline ProxBombeiros & \#DIV/0! & \#DIV/0! & \#DIV/0! & \#DIV/0! & \#DIV/0! & 1 & \\
\hline ProxFacilMilitares & \#DIV/0! & \#DIV/0! & \#DIV/0! & \#DIV/0! & \#DIV/0! & \#DIV/0! & 1 \\
\hline
\end{tabular}

\begin{tabular}{|cl|}
\hline Grau de & $\mathrm{Se}>0,1$ \\
Consistência & $\mathrm{Se}=0,1$
\end{tabular}$\quad$ Revise seus julgamentos!

Matriz G3.3 - Comparação dos Indicadores Relacionados ao Fator Preferências Pessoais ou Administrativas

\begin{tabular}{|r|c|c|c|c|c|}
\hline \multicolumn{2}{|c|}{ ProxCentrComerciais } & ProxBairros PartQualVida & ProxAreaLaze rEs porte & ProxAreas Indus & ProxAreaTuris tica \\
\hline ProxCentrCome rciais & 1 & & & \\
\hline ProxBairros PartQualVida & $\# \mathrm{DIV} / 0 !$ & 1 & & \\
\hline ProxAreaLazerEsporte & $\# \mathrm{DIV} / 0 !$ & $\# \mathrm{DIV} / 0 !$ & 1 & \\
\hline ProxAreas Indust & $\# \mathrm{DIV} / 0 !$ & $\# \mathrm{DIV} / 0 !$ & $\# \mathrm{DIV} / 0 !$ & 1 \\
\hline ProxAreaTuris tica & $\# \mathrm{DIV} / 0 !$ & $\# \mathrm{DIV} / 0 !$ & \#DIV/0! & \#DIV/0! & \\
\hline
\end{tabular}

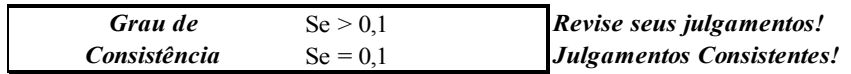

Matriz, 4.1 - Comparação dos Indicadores Relacionados ao Fator custos dos usuários

\begin{tabular}{|r|c|c|c|}
\hline & Custo Operação Veiculos & Custo Tempo Viagem & Custo Acidentes \\
\hline Custo Ope ração Veiculos & 1 & & \\
\hline Cus to Tempo Viagem & \#DIV/0! & 1 & \\
\hline Custo Acidentes & \#DIV/0! & \#DIV $/ 0 !$ & 1 \\
\hline
\end{tabular}

$\left.\begin{array}{|cl|l}\hline \text { Grau de } & \mathrm{Se}>0,1 \\ \text { Consistência } & \mathrm{Se}=0,1\end{array}\right] \begin{aligned} & \text { Revise seus julgamentos! } \\ & \text { Julgamentos Consistentes! }\end{aligned}$

Matriz G2.1.1- Comparação dos Tipos de Defeitos para Avaliação da Importância Relativa

\begin{tabular}{|c|c|c|c|c|c|c|c|c|c|c|c|c|c|c|c|}
\hline & TFadiga & TBlocos & DBordos & TLong & TRefle $x$ & TTrans & Remendo & Panela & DefPe rm & Corruga & Exuda & AgPolid & Desgaste & Desnível & Bomb \\
\hline TFadiga & 1 & & & & & & & & & & & & & & \\
\hline TBlocos & \#DIV/0! & 1 & & & & & & & & & & & & & \\
\hline DBordos & \#DIV/0! & \#DIV/0! & 1 & & & & & & & & & & & & \\
\hline TReflex & \#DIV/0! & \#DIV/0! & \#DIV/0! & \#DIV/0! & 1 & & & & & & & & & & \\
\hline TTransv & \#DIV/0! & \#DIV/0! & \#DIV/0! & \#DIV/0! & \#DIV/0! & 1 & & & & & & & & & \\
\hline Remendo & \#DIV/0! & \#DIV/0! & \#DIV/0! & \#DIV/0! & \#DIV/0! & \#DIV/0! & 1 & & & & & & & & \\
\hline Corruga & \#DIV/0! & \#DIV/0! & \#DIV/0! & \#DIV/0! & \#DIV/0! & \#DIV/0! & \#DIV/0! & \#DIV/0! & \#DIV/0! & 1 & & & & & \\
\hline Exuda & \#DIV/0! & \#DIV/0! & \#DIV/0! & \#DIV/0! & \#DIV/0! & \#DIV/0! & \#DIV/0! & \#DIV/0! & \#DIV/0! & \#DIV/0! & 1 & & & & \\
\hline AgPolid & \#DIV/0! & \#DIV/0! & \#DIV/0! & \#DIV/0! & \#DIV/0! & \#DIV/0! & \#DIV/0! & \#DIV/0! & \#DIV/0! & \#DIV/0! & \#DIV/0! & 1 & & & \\
\hline Desgaste & \#DIV/0! & \#DIV/0! & \#DIV/0! & \#DIV/0! & \#DIV/0! & \#DIV/0! & \#DIV/0! & \#DIV/0! & \#DIV/0! & \#DIV/0! & \#DIV/0! & \#DIV/0! & 1 & & \\
\hline Desnível & \#DIV/0! & \#DIV/0! & \#DIV/0! & \#DIV/0! & \#DIV/0! & \#DIV/0! & \#DIV/0! & \#DIV/0! & \#DIV/0! & \#DIV/0! & \#DIV/0! & \#DIV/0! & \#DIV/0! & 1 & \\
\hline Bomb & \#DIV/0! & \#DIV/0! & \#DIV/0! & \#DIV/0! & \#DIV/0! & \#DIV/0! & \#DIV/0! & \#DIV/0! & \#DIV/0! & \#DIV/0! & \#DIV/0! & \#DIV/0! & \#DIV/0! & \#DIV/0! & 1 \\
\hline
\end{tabular}

Graude $\quad \mathrm{Se}>0,1 \quad$ Revise seus julgamentos!

\begin{tabular}{ll|l} 
Consistência & $\mathrm{Se}=0,1$ & Rulgamentos Consistentes!
\end{tabular} 


\section{C-2 PLANILHA DE DEFINIÇÃO DAS FUNÇÕES FUZZY}

2a. Etapa: Alguns dos critérios avaliados na 1a.etapa dizem respeito à localização das seções de pavimentos, ou seja, distâncias a infra-estruturas de transportes, a prédios institucionais e locais de preferências pessoais ou administrativas. Estabelecida a importância de cada um desses critérios durante a 1a.etapa, escolha agora uma das funções sugeridas e quantifique as distâncias correspondentes ao limite máximo até o critério é considerado importante.

\section{Somente os campos em verde devem ser preenchidos}

i. Defina a área de abrangência (a distância máxima em metros) na qual considera admissível levar em conta a existência do critério num processo de priorização de seções para a manutenção dos pavimentos. (Dmax)

ii. Apoiando-se nos dois gráficos seguintes,escolha aquele que considerar o mais indicado para cada um dos locais (A e B- representam a variação da importância da distância quando o afastamento à sua origem vai aumentando até Dmax).

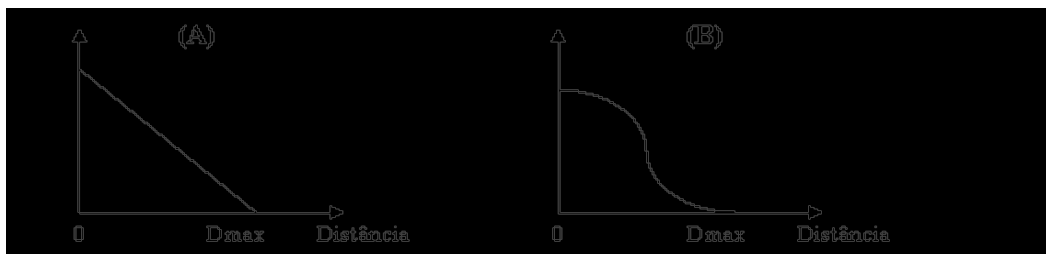

\begin{tabular}{|c|c|c|c|}
\hline \multirow{4}{*}{ 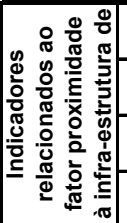 } & Proximidade a Terminal Rodoviário & Dmáx $=$ & Gráfico: \\
\hline & Proximidade a Terminal Ferroviário & Dmáx $=$ & Gráfico: \\
\hline & Proximidade a Portos e Aeroportos & Dmáx $=$ & Gráfico: \\
\hline & Proximidade a Rodovias & Dmáx $=$ & Gráfico: \\
\hline
\end{tabular}

\begin{tabular}{|c|c|c|c|}
\hline \multirow{7}{*}{ 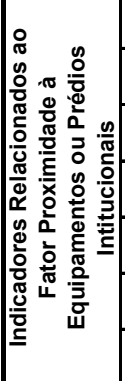 } & Proximidade a Escolas & Dmáx $=$ & Gráfico: \\
\hline & Proximidade a Universidades & Dmáx= & Gráfico: \\
\hline & Proximidade a Postos de Saúde & Dmáx $=$ & Gráfico: \\
\hline & Proximidade a Hospitais & Dmáx= & Gráfico: \\
\hline & Proximidade a Centros Administrativos & Dmáx $=$ & Gráfico: \\
\hline & Proximidade a Corporação de Bombeiros & Dmáx $=$ & Gráfico: \\
\hline & Proximidade a Facilidades Militares & Dmáx $=$ & Gráfico: \\
\hline
\end{tabular}

\begin{tabular}{|c|c|c|c|}
\hline \multirow[t]{5}{*}{ 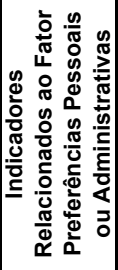 } & Proximidade a Centros Comerciais & Dmáx $=$ & Gráfico: \\
\hline & Proximidade a Bairros com Particular Qualidade de Vida & Dmáx $=$ & Gráfico: \\
\hline & Proximidade a Áreas de Lazer e Esporte & Dmáx $=$ & Gráfico: \\
\hline & Proximidade a Áreas Industriais & Dmáx $=$ & Gráfico: \\
\hline & Proximidade a Áreas Turísticas & Dmáx $=$ & Gráfico: \\
\hline
\end{tabular}


ANEXO D: MAPAS E TABELAS DE LOCALIZAÇÃO UTILIZADAS NO ESTUDO DE CASO PARA SÃO CARLOS - SP 


\section{D.1 - LOCALIZAÇÃO DE EQUIPAMENTOS PÚBLICOS E PRÉDIOS}

\section{INSTITUCIONAIS}

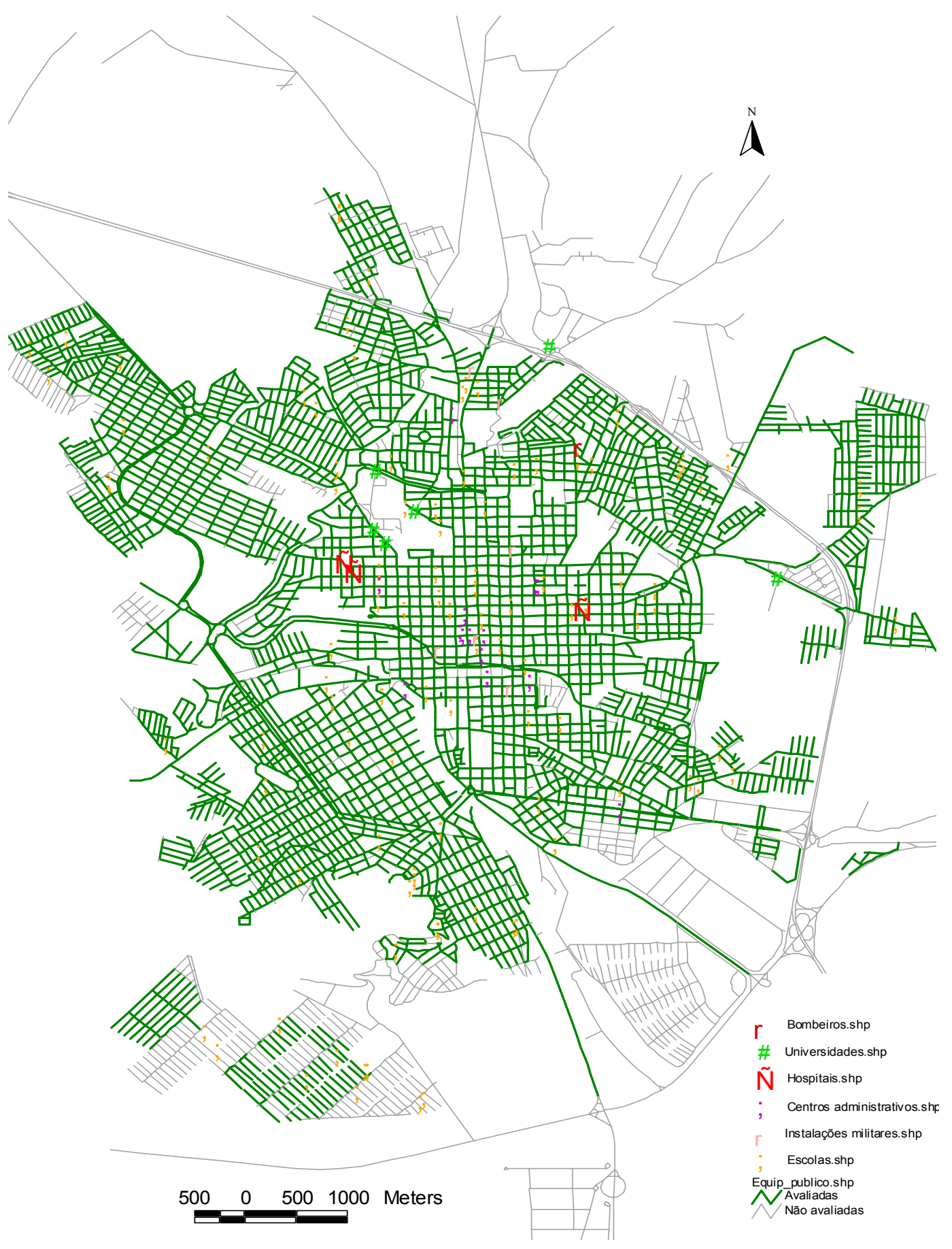

Tabela D1.1: Corporação de Bombeiros

\begin{tabular}{|c|c|c|l|}
\hline ID & $X$ & $Y$ & NOME \\
\hline 10000 & $-47,8798$ & $-21,9996$ & CORPO DE BOMBEIROS \\
\hline
\end{tabular}


Tabela D1.2: Instalações Militares

\begin{tabular}{|c|c|c|l|}
\hline ID & Longitude & Latitude & \multicolumn{1}{c|}{ NOME } \\
\hline 10001 & $-47,8922$ & $-22,0185$ & DELEGACIA DE INVESTIGAÇÕES GERAIS \\
\hline 10002 & $-47,8859$ & $-22,0220$ & POLICIA MILITAR \\
\hline 10003 & $-47,8889$ & $-22,0174$ & DELEGACIA DE POLICIA \\
\hline 10004 & $-47,8867$ & $-21,9955$ & DELEGACIA DE POLICIA \\
\hline 10005 & $-47,8892$ & $-21,9925$ & POLICIA AMBIENTAL \\
\hline 10006 & $-47,8857$ & $-22,0092$ & TIRO DE GUERRA \\
\hline
\end{tabular}

Tabela D1.3: Universidades

\begin{tabular}{|c|l|l|l|l|}
\hline ID & \multicolumn{1}{|c|}{ TIPO } & Longitude & Latitude & \multicolumn{1}{c|}{ NOME } \\
\hline 10007 & PÚBLICA & $-47,8983$ & $-22,0076$ & UNIVERSIDADE DE SÃO PAULO \\
\hline 10008 & PÚBLICA & $-47,8972$ & $-22,0088$ & UNIVERSIDADE DE SÃO PAULO \\
\hline 10009 & PÚBLICA & $-47,8981$ & $-22,0022$ & UNIVERSIDADE DE SÃO PAULO \\
\hline 10010 & PÚBLICA & $-47,8947$ & $-22,0058$ & UNIVERSIDADE DE SÃO PAULO \\
\hline 10011 & PÚBLICA & $-47,8829$ & $-21,9906$ & UNIVERSIDADE FEDERAL DE SÃO CARLOS \\
\hline 10012 & PARTICULAR & $-47,8630$ & $-22,0121$ & FADISC \\
\hline
\end{tabular}

Tabela D1.4: Postos de Saúde

\begin{tabular}{|c|l|c|l|l|}
\hline ID & \multicolumn{1}{|c|}{ TIPO } & Longitude & Latitude & \multicolumn{1}{|c|}{ NOME } \\
\hline 10013 & UBS UNIDADE BASICA DE SAUDE & $-47,8685$ & $-22,0306$ & DR ROMEU DE CRESCI \\
\hline 10014 & UBS UNIDADE BASICA DE SAUDE & $-47,8865$ & $-22,0435$ & DR DANTE ERBOLATO \\
\hline 10015 & UBS UNIDADE BASICA DE SAUDE & $-47,8563$ & $-22,0071$ & DR VIRIATO F NUNES \\
\hline 10016 & UBS UNIDADE BASICA DE SAUDE & $-47,9082$ & $-22,0363$ & DR LAURO CORSI \\
\hline 10017 & UBS UNIDADE BASICA DE SAUDE & $-47,8727$ & $-22,0125$ & DR WILSON POZZI \\
\hline 10018 & UBS UNIDADE BASICA DE SAUDE & $-47,9015$ & $-22,0029$ & DR ARSENIO AGNESINI \\
\hline 10019 & UBS UNIDADE BASICA DE SAUDE & $-47,8787$ & $-21,9994$ & DR LUIZ VALENTTE DE OLIVEIRA \\
\hline 10020 & UBS UNIDADE BASICA DE SAUDE & $-47,8985$ & $-21,9913$ & DR LUIZ MAIA \\
\hline 10021 & UBS UNIDADE BASICA DE SAUDE & $-47,9188$ & $-21,9989$ & DR BENJAMIN LOPE \\
\hline 10022 & UBS UNIDADE BASICA DE SAUDE & $-47,9040$ & $-22,0569$ & DR ERNESTO PEREIR \\
\hline 10023 & UBS UNIDADE BASICA DE SAUDE & $-47,8969$ & $-21,9785$ & EM CONSTRUÇÃO \\
\hline 10024 & UBS UNIDADE BASICA DE SAUDE & $-47,9010$ & $-21,9786$ & DR ALGEMIRO PAULO \\
\hline 10025 & PSF PROGRAMA SAUDE FAMILIAR & $-47,8993$ & $-22,0176$ & PSF DR JOAO MARIN \\
\hline 10026 & UBS UNIDADE BASICA DE SAUDE & $-47,9146$ & $-22,0265$ & VALERIA DE CASSIA \\
\hline 10027 & UBS UNIDADE BASICA DE SAUDE & $-47,8866$ & $-22,0319$ & ENF ROSANA CECATO \\
\hline 10028 & PSF PROGRAMA SAUDE FAMILIAR & $-47,8575$ & $-22,0037$ & PSF JR MUNIQUE \\
\hline 10029 & PSF PROGRAMA SAUDE FAMILIAR & $-47,9235$ & $-22,0051$ & PSF SANTA FELICIA \\
\hline 10030 & PSF PROGRAMA SAUDE FAMILIAR & $-47,9195$ & $-22,0536$ & PSF ANGENOR GARVI \\
\hline 10031 & PAD PROGRAMA ATENDIMENTO & $-47,8923$ & $-22,0149$ & PAD PROGRAMA DE ATENDIMENTO \\
\hline 10032 & UPAILILIAR & $-47,8901$ & $-22,0238$ & UPA CENTRO \\
\hline 10033 & ATENDIMENTO & $-47,9040$ & $-22,0590$ & UPA CIDADE ARACI \\
\hline 10034 & ETENDIMENTO & $-22,0317$ & ESPECEIALIDADES \\
\hline
\end{tabular}


Tabela D1.5: Hospitais

\begin{tabular}{|c|c|c|l|}
\hline ID & Longitude & Latitude & \multicolumn{1}{c|}{ NOME } \\
\hline 10035 & $-47,9000$ & $-22,0115$ & MATERNIDADE (SANTA CASA) \\
\hline 10036 & $-47,9008$ & $-22,0105$ & SANTA CASA \\
\hline 10037 & $-47,8801$ & $-22,0150$ & CASA DE SAUDE \\
\hline
\end{tabular}

Tabela D1.6: Centros Administrativos

\begin{tabular}{|c|c|c|l|}
\hline ID & Longitude & Latitude & \multicolumn{1}{c|}{ NOME_ } \\
\hline 10038 & $-47,8910$ & $-21,9970$ & SECRETARIA DA AGRICULTURA \\
\hline 10039 & $-47,8884$ & $-22,0192$ & SECRETARIA DE ASSISTENCIA SOCIAL \\
\hline 10040 & $-47,8901$ & $-22,0174$ & PREFEITURA MUNICIPAL \\
\hline 10041 & $-47,8951$ & $-22,0223$ & SECRETARIA DE EDUCACAO E CULTURA \\
\hline 10042 & $-47,8879$ & $-22,0212$ & SECRETARIA CIENCIA E TECNOLOGIA \\
\hline 10043 & $-47,8837$ & $-22,0127$ & SECRETARIA EDUCACAO E CULTURA \\
\hline 10044 & $-47,8835$ & $-22,0128$ & SECRETARIA DE ESPORTE E LAZER \\
\hline 10045 & $-47,8903$ & $-22,0170$ & SECRETARIA DA FAZENDA \\
\hline 10046 & $-47,8882$ & $-22,0174$ & SECRETARIAS DE HABITAÇÃO, OBRAS, TRANSPORTES \\
\hline 10047 & $-47,8973$ & $-22,0126$ & SECRETARIA DE SAUDE \\
\hline 10048 & $-47,8763$ & $-22,0335$ & SAAE \\
\hline 10049 & $-47,8898$ & $-22,0155$ & CAMARA MUNICIPAL \\
\hline 10050 & $-47,8895$ & $-22,0174$ & FORUM \\
\hline 10051 & $-47,8842$ & $-22,0216$ & FORUM \\
\hline
\end{tabular}

Tabela D1.7: Escolas

\begin{tabular}{|c|l|l|l|l|}
\hline ID & TIPO & Longitude & Latitude & \multicolumn{1}{|c|}{ NOME } \\
\hline 10052 & EMEI & $-47,9200$ & $-21,9920$ & VICENTE DE PAULO ROCHA KEPPE \\
\hline 10053 & EMEI & $-47,9123$ & $-22,0004$ & MARIA LUCIA AP. MARRARA \\
\hline 10054 & EMEI & $-47,9008$ & $-21,9781$ & IDA VINCIGUERRA \\
\hline 10055 & EMEI & $-47,8995$ & $-21,9910$ & MARIA LUIZA PEREZ \\
\hline 10056 & EMEI & $-47,9010$ & $-22,0019$ & JOSE ANTUNES DE OLIVEIRA E SOUZA \\
\hline 10057 & EMEI & $-47,8920$ & $-22,0073$ & ARACY LEITE PEREIRA LOPES \\
\hline 10058 & EMEI & $-47,8855$ & $-22,0020$ & JULIEN FAUVEL \\
\hline 10059 & EMEI & $-47,8788$ & $-22,0016$ & HELENA DORNFELD \\
\hline 10060 & EMEI & $-47,8712$ & $-22,0020$ & MONS. ALCINDO SIQUEIRA \\
\hline 10061 & EMEI & $-47,8553$ & $-22,0037$ & ANTONIO LOURDES RONDON \\
\hline 10062 & EMEI & $-47,9016$ & $-22,0186$ & CECILIA RODRIGUES \\
\hline 10063 & EMEI & $-47,8805$ & $-22,0150$ & CONEGO MANOEL TOBIAS \\
\hline 10064 & EMEI & $-47,8733$ & $-22,0145$ & DOM RUY SERRA \\
\hline 10065 & EMEI & $-47,9000$ & $-22,0267$ & CARMELITA ROCHA RAMALHO \\
\hline 10066 & EMEI & $-47,8815$ & $-22,0256$ & DEP. LAURO MONTEIRO DA CRUZ \\
\hline 10067 & EMEI & $-47,8676$ & $-22,0281$ & JOAO BATISTA PAINO \\
\hline 10068 & EMEI & $-47,9073$ & $-22,0313$ & OSMAR STANLEY DE MARTINI \\
\hline 10069 & EMEI & $-47,8702$ & $-22,0308$ & JOAO JORGE MARMORATO \\
\hline 10070 & EMEI & $-47,9044$ & $-22,0395$ & BENEDICTA STHAL SODRE \\
\hline 10071 & EMEI & $-47,8947$ & $-22,0406$ & VICTORIO REBUCCI \\
\hline 10072 & EMEI & $-47,8890$ & $-22,0430$ & OCTAVIO DE MOURA \\
\hline 10073 & EMEI & $-47,8984$ & $-22,0576$ & AFONSO FIOCA VITALI (CAIC) \\
\hline 10074 & CEMEI & $-47,9210$ & $-22,0031$ & WALTER BLANCO \\
\hline & & & & \\
\hline
\end{tabular}




\begin{tabular}{|c|c|c|c|c|}
\hline 10075 & EMEI & $-47,8669$ & $-22,0013$ & SANTA MARIA II \\
\hline 10076 & EMEI & $-47,9060$ & $-22,0533$ & CASA AZUL \\
\hline 10077 & EMEI & $-47,8938$ & $-22,0606$ & CASA ROSA \\
\hline 10078 & EMEI & $-47,8934$ & $-22,0602$ & CASA AMARELA \\
\hline 10079 & CEMEI & $-47,8993$ & $-22,0597$ & PROF MARIA ALICE V MACEDO \\
\hline 10080 & CEMEI & $-47,9126$ & $-22,0540$ & MARIA CONSUELO B TOLENTINO \\
\hline 10081 & CRECHE & $-47,9263$ & $-21,9932$ & GILDENEY CARRERI \\
\hline 10082 & $\mathrm{EE}$ & $-47,9279$ & $-21,9907$ & BENTO SILVA CEZAR \\
\hline 10083 & $\mathrm{EE}$ & $-47,9197$ & $-21,9979$ & ATILIA PRADO MARGARIDO \\
\hline 10084 & $\mathrm{EE}$ & $-47,9015$ & $-22,0235$ & BISPO DOM GASTAO \\
\hline 10085 & $\mathrm{EE}$ & $-47,8973$ & $-22,0364$ & PROFA MARIA RAMOS \\
\hline 10086 & $\mathrm{EE}$ & $-47,8920$ & $-22,0352$ & JESUINO DE ARRUDA \\
\hline 10087 & $\mathrm{EE}$ & $-47,8959$ & $-22,0465$ & ARACI LEITE PEREIRA LOPES \\
\hline 10088 & $\mathrm{EE}$ & $-47,8856$ & $-22,0444$ & PERICLES SOARES \\
\hline 10089 & $\mathrm{EE}$ & $-47,9037$ & $-22,0585$ & PROF ORLANDO PERES \\
\hline 10090 & $\mathrm{EE}$ & $-47,8695$ & $-22,0312$ & PROF JOAO JORGE MARMORATO \\
\hline 10091 & $\mathrm{EE}$ & $-47,8834$ & $-22,0331$ & PROF ANTONIO ADOLFO LOBBE \\
\hline 10092 & $\mathrm{EE}$ & $-47,8843$ & $-22,0249$ & PROF ARLINDO BITTENCOURT \\
\hline 10093 & $\mathrm{EE}$ & $-47,8932$ & $-22,0227$ & EUGENIO FRANCO \\
\hline 10094 & $\mathrm{EE}$ & $-47,8974$ & $-22,0143$ & PROF SEBASTIAO DE OLIVEIRA ROCHA \\
\hline 10095 & $\mathrm{EE}$ & $-47,8889$ & $-22,0129$ & DR ALVARO GUTAO \\
\hline 10096 & $\mathrm{EE}$ & $-47,8884$ & $-22,0159$ & CEL PAULINO CARLOS \\
\hline 10097 & $\mathrm{EE}$ & $-47,8762$ & $-22,0120$ & PROF ANTONIO MILITAO DE LIMA \\
\hline 10098 & $\mathrm{EE}$ & $-47,8830$ & $-22,0125$ & LUIZ AUGUSTO DE OLIVEIRA \\
\hline 10099 & $\mathrm{EE}$ & $-47,8748$ & $-22,0159$ & PROF JOS $_{\Gamma}$ JULIANO NETO \\
\hline 10100 & $\mathrm{EE}$ & $-47,8554$ & $-22,0061$ & PROF ARCHIMEDES A M CARVALHO \\
\hline 10101 & $\mathrm{EE}$ & $-47,8692$ & $-22,0033$ & MARILENE TEREZINHA LON \\
\hline 10102 & $\mathrm{EE}$ & $-47,8800$ & $-22,0011$ & ESTERINA PLACCO \\
\hline 10103 & $\mathrm{EE}$ & $-47,8836$ & $-22,0016$ & PROF ANDRELINO VIEIRA \\
\hline 10104 & $\mathrm{EE}$ & $-47,9001$ & $-21,9885$ & PROF LUDGERO BRAGA \\
\hline 10105 & $\mathrm{EE}$ & $-47,9029$ & $-21,9964$ & CEFAM \\
\hline 10106 & $\mathrm{EE}$ & $-47,9039$ & $-21,9953$ & CONDE DO PINHAL \\
\hline 10107 & EP & $-47,8888$ & $-21,9945$ & COL CECILIA MEIRELLES \\
\hline 10108 & EP & $-47,8963$ & $-22,0014$ & COL DOM BOSCO \\
\hline 10109 & EP & $-47,8899$ & $-22,0026$ & COL VIDA ATIVA \\
\hline 10110 & EP & $-47,8924$ & $-22,0057$ & ESC CATOLICA QUERIGMA \\
\hline 10111 & EP & $-47,8881$ & $-22,0055$ & COL ADVENTISTA DE SC \\
\hline 10112 & EP & $-47,8951$ & $-22,0055$ & CAASO ARMANDO SALES DE O \\
\hline 10113 & EP & $-47,8974$ & $-22,0114$ & SAPIENS CURSO E COLEGIO \\
\hline 10114 & EP & $-47,8924$ & $-22,0116$ & COL MUNDINHO NOSSO \\
\hline 10115 & EP & $-47,8921$ & $-22,0137$ & COL SAO CARLOS \\
\hline 10116 & EP & $-47,8889$ & $-22,0119$ & INST EDUCACAO DE SC OBJETIVO \\
\hline 10117 & EP & $-47,8859$ & $-22,0146$ & ALCANCE CURSO E COLEGIO \\
\hline 10118 & EP & $-47,8912$ & $-22,0150$ & INTERATIVO CURSO E COLEGIO \\
\hline 10119 & EP & $-47,8889$ & $-22,0182$ & CIFSC CENTRO INTEGRADO DE EDUCAÃAO \\
\hline 10120 & EP & $-47,8868$ & $-22,0183$ & ESC RECANTO DAS ABELHINHAS \\
\hline 10121 & EP & $-47,8846$ & $-22,0202$ & ESC TECNICA BALLET CRISTINA \\
\hline 10122 & EP & $-47,8963$ & $-22,0285$ & COL EDUCARTE \\
\hline 10123 & EP & $-47,8763$ & $-22,0314$ & COL ANGLO CIDADE DE SAO CARLOS \\
\hline 10124 & EP & $-47,8732$ & $-22,0131$ & ESC OCA DOS CURUMINS \\
\hline 10125 & EP & $-47,9019$ & $-22,0218$ & CENTRO EDUCAC DIOCESANO LA SALLE \\
\hline 10126 & EP & $-47,8766$ & $-21,9971$ & ESC CULTURAL E ARTISTICA DE SC \\
\hline
\end{tabular}




\begin{tabular}{|l|l|l|l|l|}
\hline 10127 & EMEB & $-47,9008$ & $-21,9782$ & PROFA DALILA GALLI \\
\hline 10128 & EMEB & $-47,9209$ & $-22,0034$ & ANGELINA DAGNONE DE MELO \\
\hline 10129 & EMEB & $-47,9160$ & $-22,0275$ & PROFA MARIA E C TARPANI SAO CARLOSVI \\
\hline 10130 & EMEB & $-47,9079$ & $-22,0374$ & CARMINE BOTTA \\
\hline 10131 & EMEB & $-47,8943$ & $-22,0400$ & JANETE MARIA MATINELLI LIA \\
\hline 10132 & CRECHE & $-47,8922$ & $-22,0446$ & TEREZINHA RISPOLI MASSE \\
\hline 10133 & CRECHE & $-47,9075$ & $-22,0270$ & RUTH BLOEN SOUTO \\
\hline 10134 & CRECHE & $-47,8986$ & $-22,0576$ & DARIO RODRIGUES \\
\hline 10135 & CRECHE & $-47,8922$ & $-22,0445$ & TEREZINHA RISPOLI MASSEI \\
\hline 10136 & CRECHE & $-47,8943$ & $-22,0395$ & JOAO PAULO II \\
\hline 10137 & CRECHE & $-47,8854$ & $-22,0442$ & JOAO MUNIZ \\
\hline 10138 & CRECHE & $-47,8665$ & $-22,0303$ & BRUNO PANHOCA \\
\hline 10139 & CRECHE & $-47,9011$ & $-22,0034$ & JOSE MARRARA \\
\hline 10140 & CRECHE & $-47,8983$ & $-21,9841$ & JULIANA MARIA CIARROCCHI PERES \\
\hline 10141 & CRECHE & $-47,8710$ & $-22,0017$ & PEDRO PUCCI \\
\hline 10142 & CRECHE & $-47,8708$ & $-22,0013$ & CAMINHADA COM JESUS \\
\hline 10143 & CRECHE & $-47,9247$ & $-21,9898$ & AMELIA MEIRELLES BOTTA \\
\hline 10144 & EMEB & $-47,8522$ & $-22,0163$ & ANTONIO STELLA MORUZZI \\
\hline 10145 & EMEB & $-47,9115$ & $-22,0558$ & ARTHUR NATALLINO DERIGGI \\
\hline 10146 & EMEB & $-47,9010$ & $-22,0563$ & AFONSO FIOCA VITALI \\
\hline 10147 & OUTROS & $-47,8952$ & $-22,0149$ & ESCOLA DE M SICA \\
\hline 10148 & OUTROS & $-47,8793$ & $-22,0144$ & ESCOLA INDUSTRIAL \\
\hline 10149 & OUTROS & $-47,8911$ & $-22,0239$ & SENAC \\
\hline 10150 & OUTROS & $-47,8971$ & $-22,0229$ & SENAI \\
\hline 10151 & OUTROS & $-47,8820$ & $-22,0367$ & SESI \\
\hline 10151 & OUTROS & $-47,8898$ & $-21,9940$ & SESI \\
\hline 10153 & OUTROS & $-47,8901$ & $-21,9949$ & APAE \\
\hline & & & & \\
\hline
\end{tabular}




\section{D.2 - LOCALIZAÇÃO DE INFRA-ESTRUTURA DE TRANSPORTES}

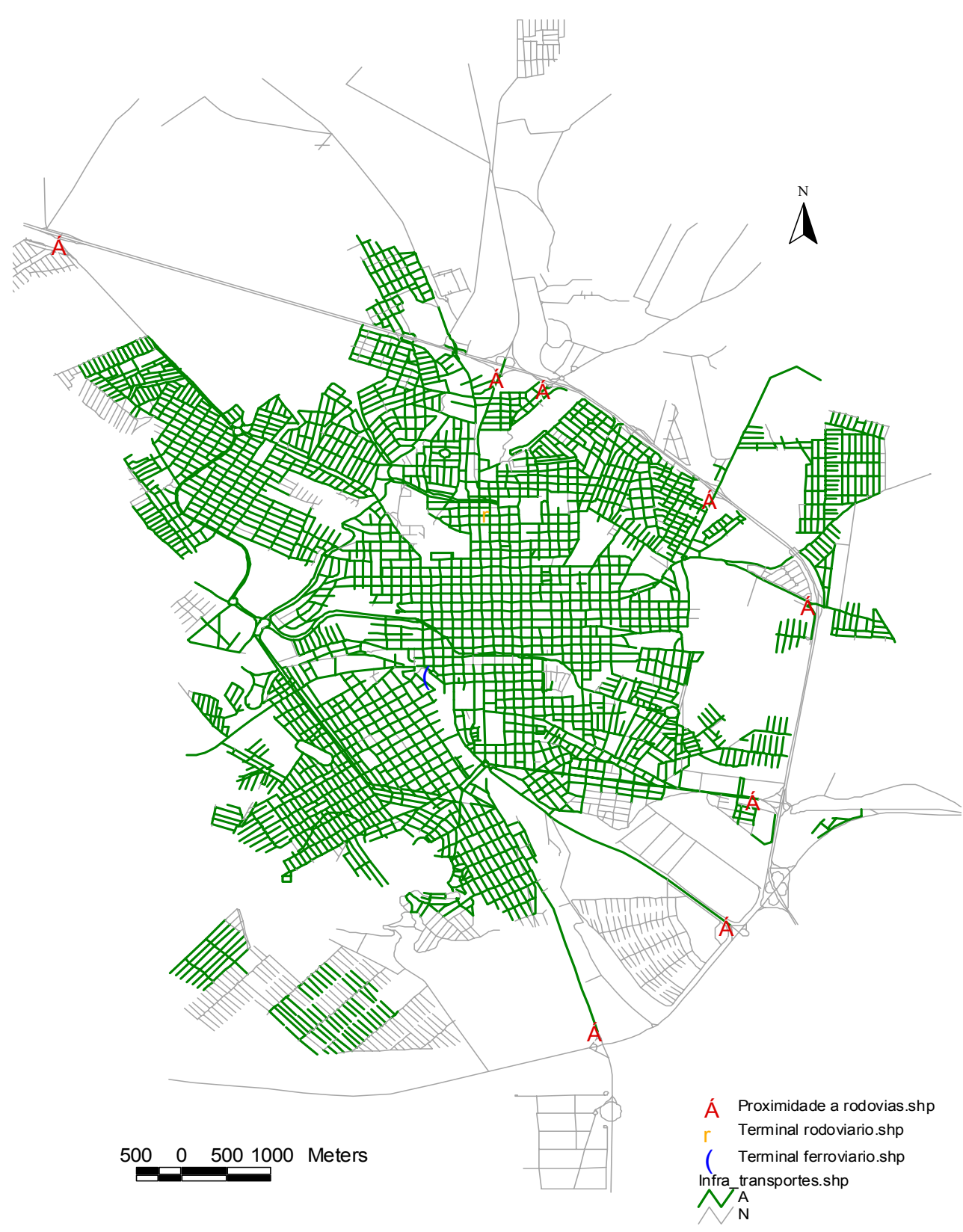

Tabela D2.1: Infra-estrutura de Transportes

\begin{tabular}{|c|c|c|l|}
\hline ID & Longitude & Latitude & \multicolumn{1}{c|}{ NOME } \\
\hline 10154 & $-47,88910$ & $-22,00497$ & Terminal rodoviário \\
\hline 10155 & $-47,89526$ & $-22,02224$ & Terminal Ferroviário \\
\hline 10156 & $-47,88861$ & $-21,99088$ & Rodovia Woshington Luiz \\
\hline 10157 & $-47,93209$ & $-21,97685$ & Rodovia Woshington Luiz \\
\hline 10158 & $-47,88394$ & $-21,99209$ & Rodovia Woshington Luiz \\
\hline 10159 & $-47,86736$ & $-22,00367$ & Rodovia Woshington Luiz \\
\hline 10160 & $-47,85763$ & $-22,01481$ & Rodovia Woshington Luiz \\
\hline 10161 & $-47,86306$ & $-22,03539$ & Rodovia Woshington Luiz \\
\hline 10162 & $-47,86578$ & $-22,04860$ & SP 215 \\
\hline 10163 & $-47,87886$ & $-22,05970$ & SP 215 \\
\hline
\end{tabular}




\section{D.3 - LOCALIZAÇÃO DE INTERESSES PESSOAIS OU ADMINISTRATIVOS}

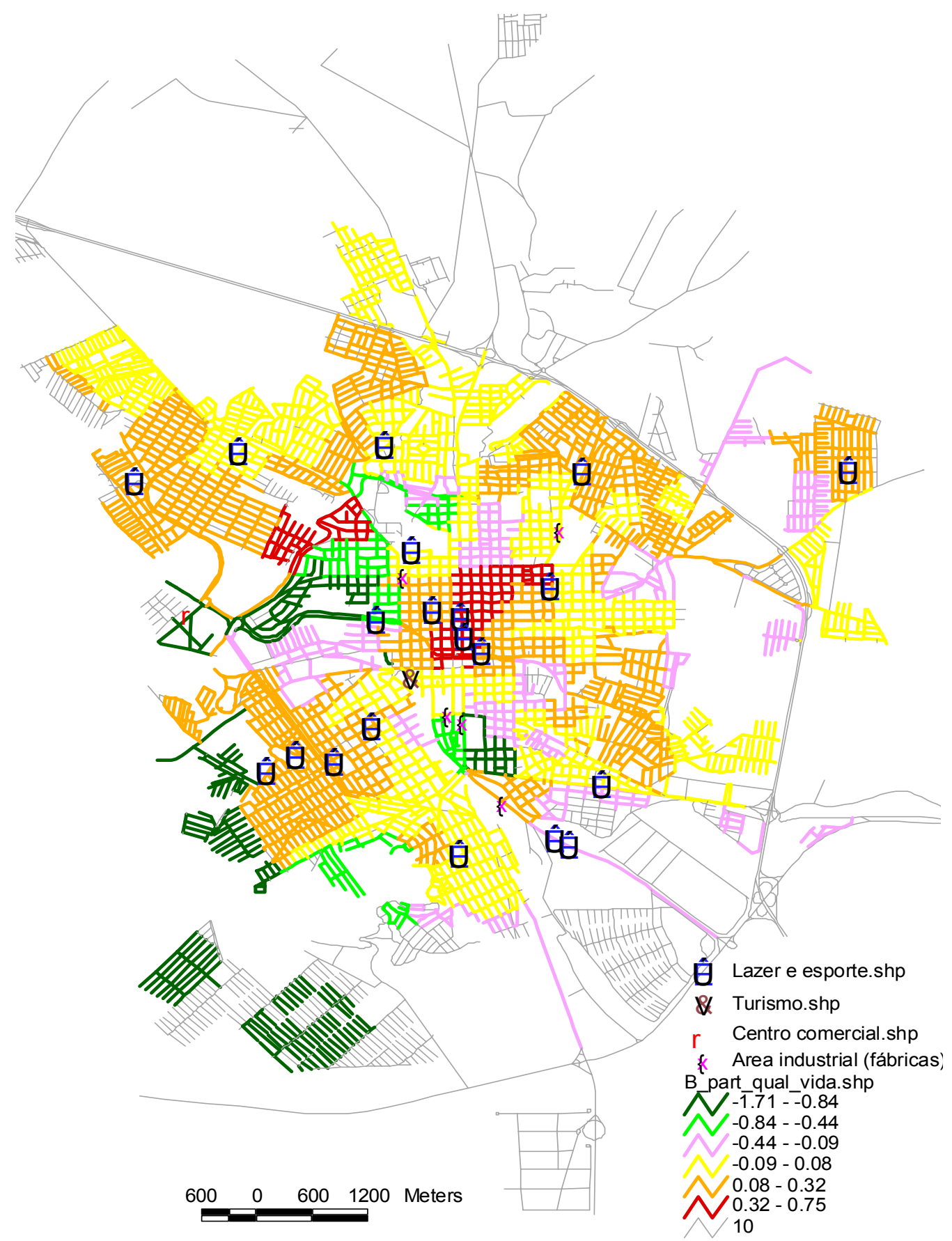

Tabela D3.1: Centro comercial

\begin{tabular}{|c|c|c|c|}
\hline ID & Longitude & Latitude & NOME \\
\hline 15872 & $-47,91603$ & $-22,01560$ & SHOPPING CENTER IGUATEMI \\
\hline
\end{tabular}


Tabela D3.2: Áreas de Esporte, Lazer e Cultura

\begin{tabular}{|c|c|c|l|}
\hline ID & Longitude & Latitude & \\
\hline 15898 & $-47,89040$ & $-22,04026$ & CAMPO DO RATTI \\
\hline 15899 & $-47,88116$ & $-22,03875$ & SESI \\
\hline 15900 & $-47,87972$ & $-22,03943$ & CLUBE FABER CASTEL \\
\hline 15901 & $-47,89836$ & $-22,01653$ & SESC \\
\hline 15902 & $-47,89502$ & $-22,00940$ & SAO CARLOS CLUBE \\
\hline 15903 & $-47,92167$ & $-22,00236$ & GINASIO DE ESPORTES JOSE FAVORETO \\
\hline 15904 & $-47,91166$ & $-21,99939$ & GINASIO DE ESPORTES JOSE EDUARDO GREGORACI \\
\hline 15905 & $-47,89756$ & $-21,99870$ & KARTODROMO MUNICIPAL \\
\hline 15906 & $-47,87851$ & $-22,00138$ & GINASIO DE ESPORTES HUGO DORNTEL ZUZAO \\
\hline 15907 & $-47,85284$ & $-22,00128$ & CENTRO DA JUVENTUDE \\
\hline 15908 & $-47,88822$ & $-22,01965$ & PISCINA MUNICIPAL SABINO DE ABREU \\
\hline 15909 & $-47,87658$ & $-22,03320$ & GINASIO MUNICIPAL MILTO O HILMO \\
\hline 15910 & $-47,88160$ & $-22,01316$ & ESTADIO MUNICIPAL RUI BARBOSA \\
\hline 15911 & $-47,90890$ & $-22,03186$ & GINASIO DE ESPORTES ARISTEU FAVORETTO \\
\hline 15912 & $-47,90611$ & $-22,03028$ & PARQUE DO BICAO \\
\hline 15913 & $-47,90243$ & $-22,03093$ & ESTADIO MUNICIPAL PROF LUIZ AUGUSTO DE SIQUEIRA LUIZAO \\
\hline 15914 & $-47,89027$ & $-22,01615$ & SAO CARLOS CLUBE SEDE SOCIAL \\
\hline 15915 & $-47,89297$ & $-22,01547$ & TEATRO MUNICIPAL ALDERICO VIEIRA PERDIGAO \\
\hline 15916 & $-47,88993$ & $-22,01814$ & BIBLIOTECA PUBLICA MUNICIPAL AMADEU AMARAL \\
\hline 15917 & $-47,89882$ & $-22,02728$ & BIBLIOTECA MUNICIPAL \\
\hline
\end{tabular}

Tabela D3.3: Turismo

\begin{tabular}{|c|c|c|c|}
\hline ID & Longitude & Latitude & NOME \\
\hline 16743 & $-47,89513$ & $-22,02232$ & MUSEU HISTORICO PEDAGOGICO CERQUEIRA CEZAR \\
\hline
\end{tabular}

Tabela D3.4: Área Industrial

\begin{tabular}{|c|c|c|l|}
\hline ID & Longitude & Latitude & NOME \\
\hline 16765 & $-47,89006$ & $-22,02674$ & TOALHAS SÃO CARLOS \\
\hline 16766 & $-47,88070$ & $-22,00722$ & TAPETES SÃO CARLOS \\
\hline 16767 & $-47,88620$ & $-22,03509$ & TECUMSEH \\
\hline 16768 & $-47,89575$ & $-22,01189$ & EMBRAPA \\
\hline 16769 & $-47,89152$ & $-22,02599$ & FABER CASTELL \\
\hline
\end{tabular}



ANEXO E: VALORES OU FUÇÕES FUZZY ADOTADAS E MAPAS DE FATORES ANTES E APÓS A NORMALIZAÇÃO, UTILIZADOS NO ESTUDO DE CASO 
E-1 VALORES ADOTADOS E MAPAS DE FATORES ENVOLVENDO VALORES LINGUÍSTICOS

\section{VALORES ADOTADOS PARA A NORMALIZAÇÃO}

\begin{tabular}{clc}
\hline \multirow{2}{*}{ Mapas } & \multicolumn{1}{c}{ Valores Lingüísticos } & $\begin{array}{c}\text { Valores adotados } \\
\text { escala de 0 a 1 }\end{array}$ \\
\hline \multirow{2}{*}{ A1 } & Via Arterial & 0,90 \\
& Via Coletora & 0,75 \\
& Via Local & 0,30 \\
& Rota de ônibus & 1,00 \\
& Rota normal (veículos de passeio) & 0,30 \\
& Tráfego Pesado & 0,90 \\
& Tráfego Médio & 0,60 \\
& Tráfego Leve & 0,30 \\
\hline
\end{tabular}


MAPAS DO FATOR A2 - TIPO DE ROTA

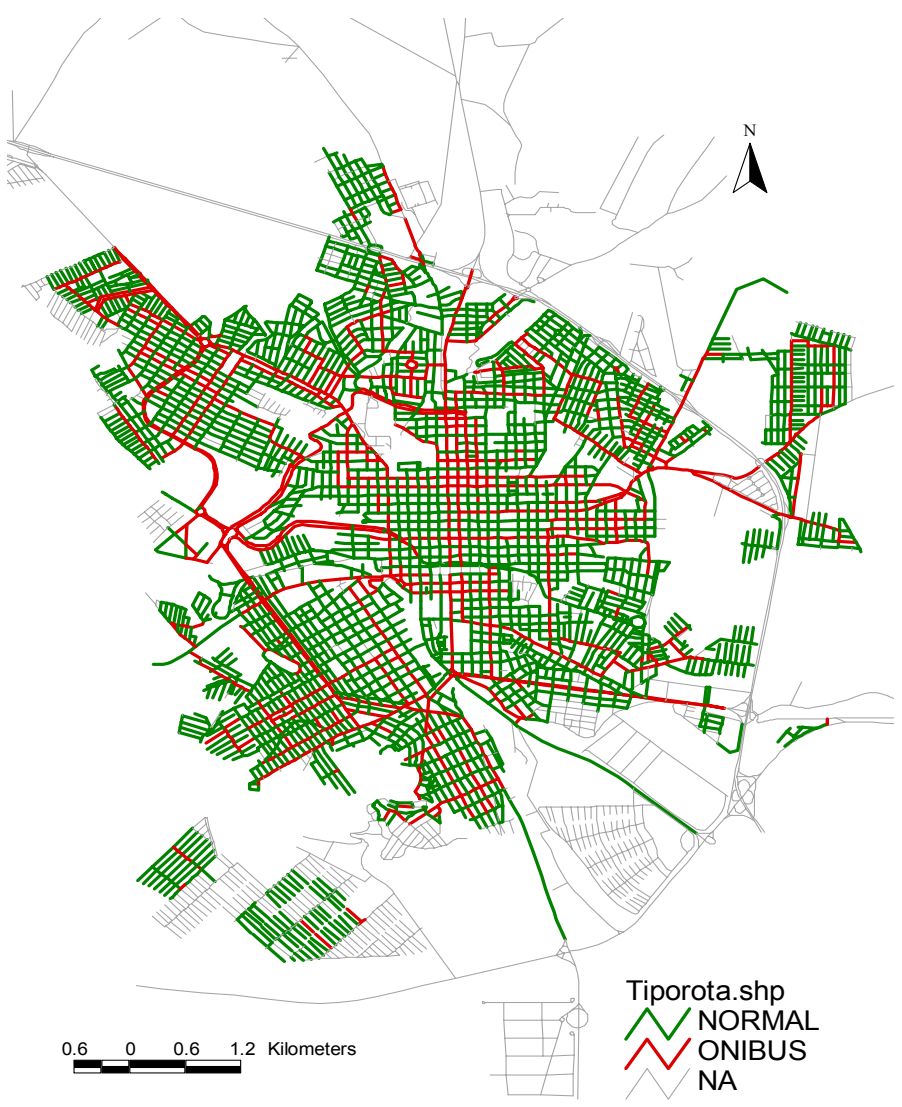

(a) Fator A2 - Não normalizado

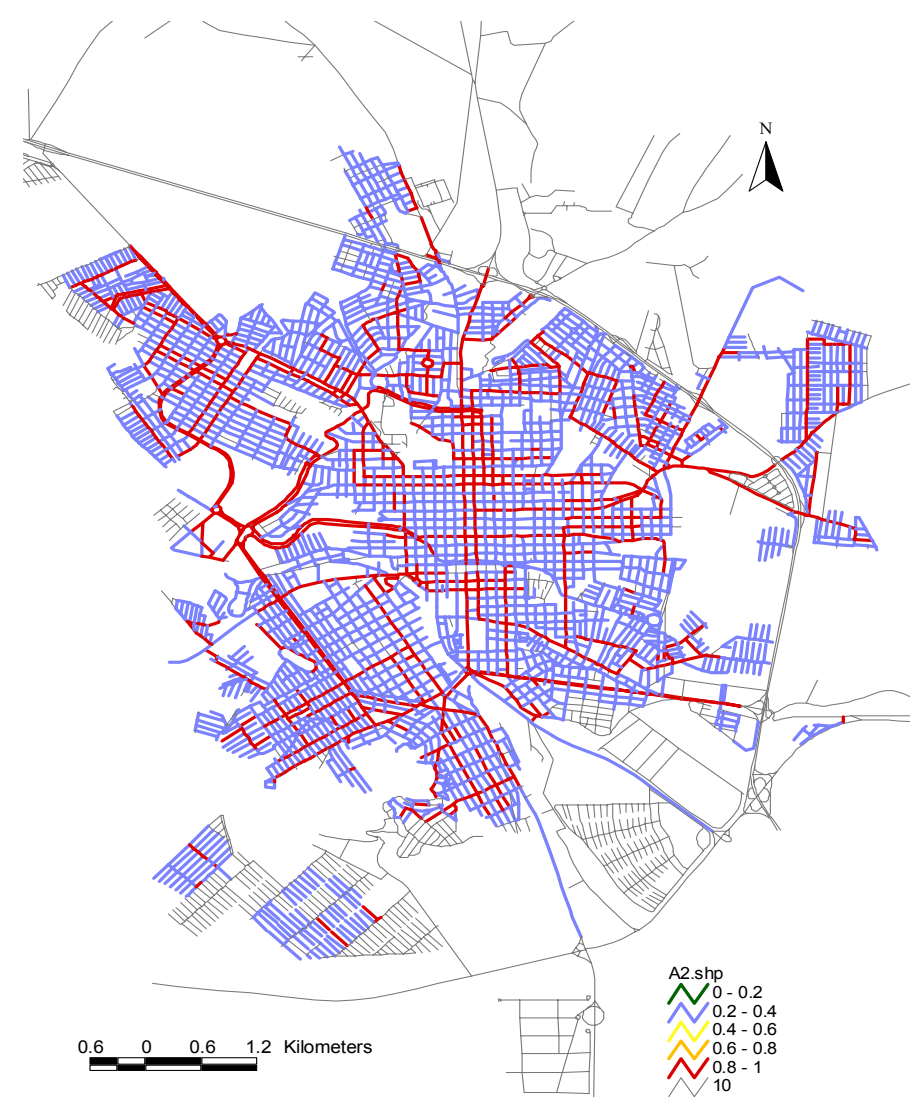

(b) Fator A2 - Normalizado 
MAPAS DO FATOR A3 - VOLUME DE TRÁFEGO

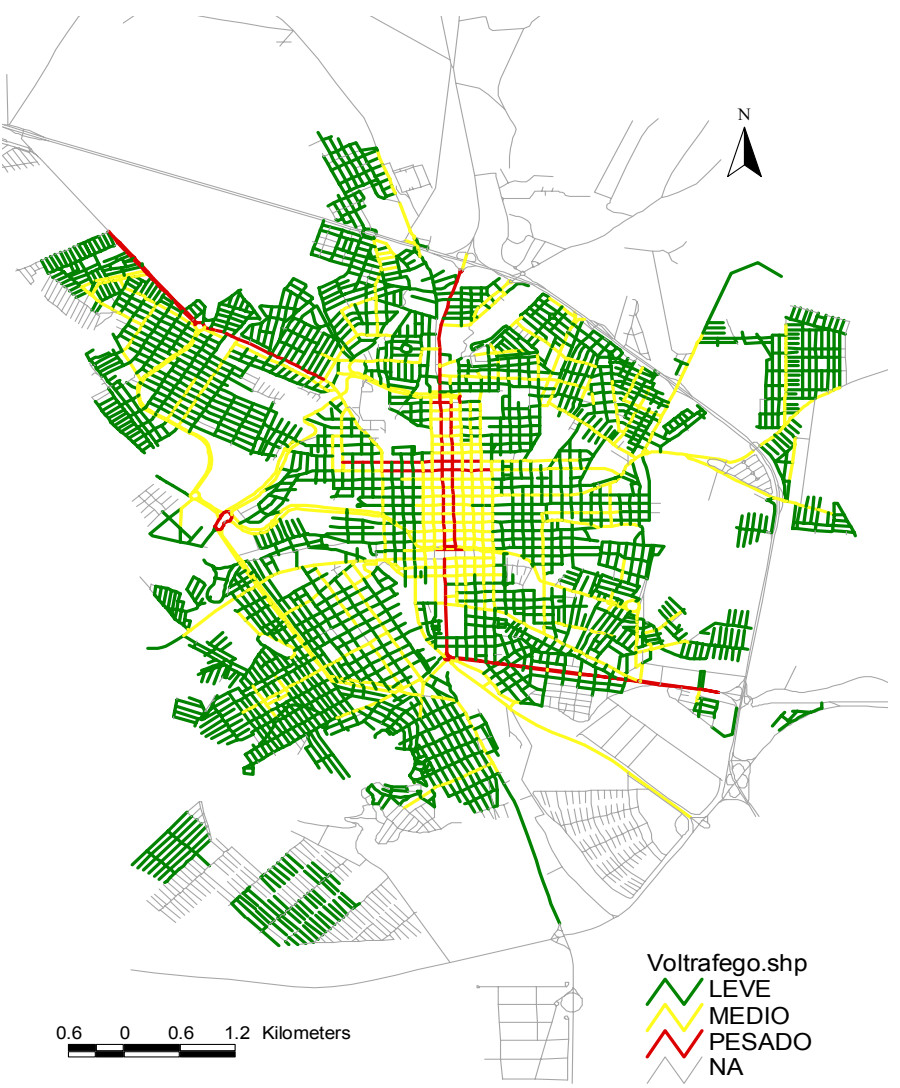

(a) Fator A3 - Não normalizado

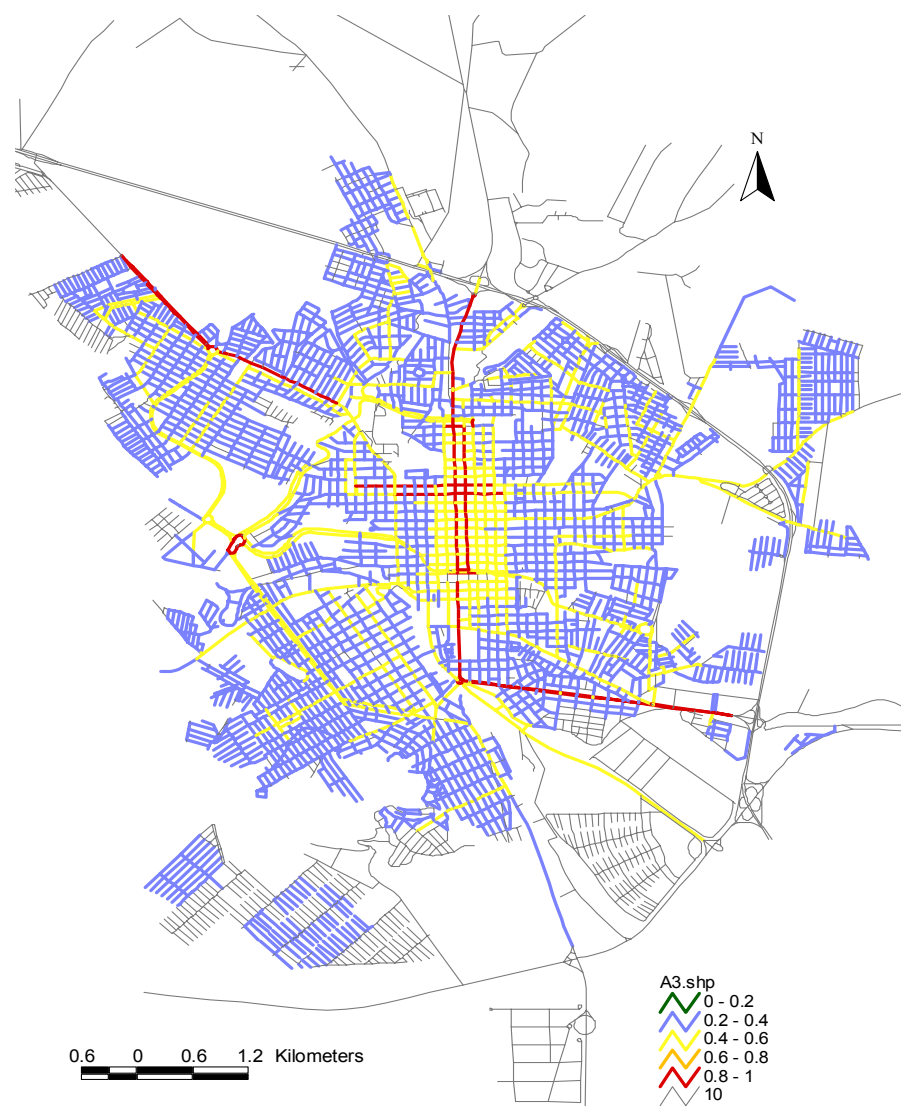

(b) Fator A3 - Normalizado 


\section{E-2 FUNÇÕES FUZZY E MAPAS DE FATORES ENVOLVENDO VALORES NUMÉRICOS}

\section{FUNÇÃO FUZZY DO FATOR B2 - ÍNDICE DA CONDIÇÃO DO PAVIMENTO}

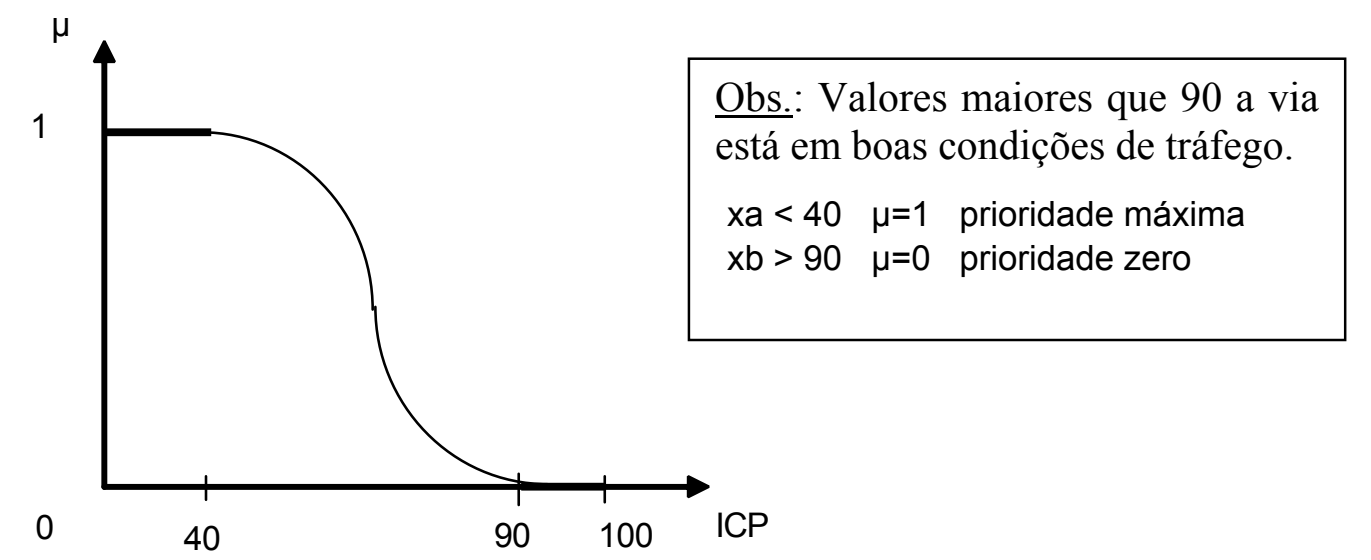

FUNÇÃO FUZZY DO FATOR C32 - ÍNDICE DE QUALIDADE DE VIDA

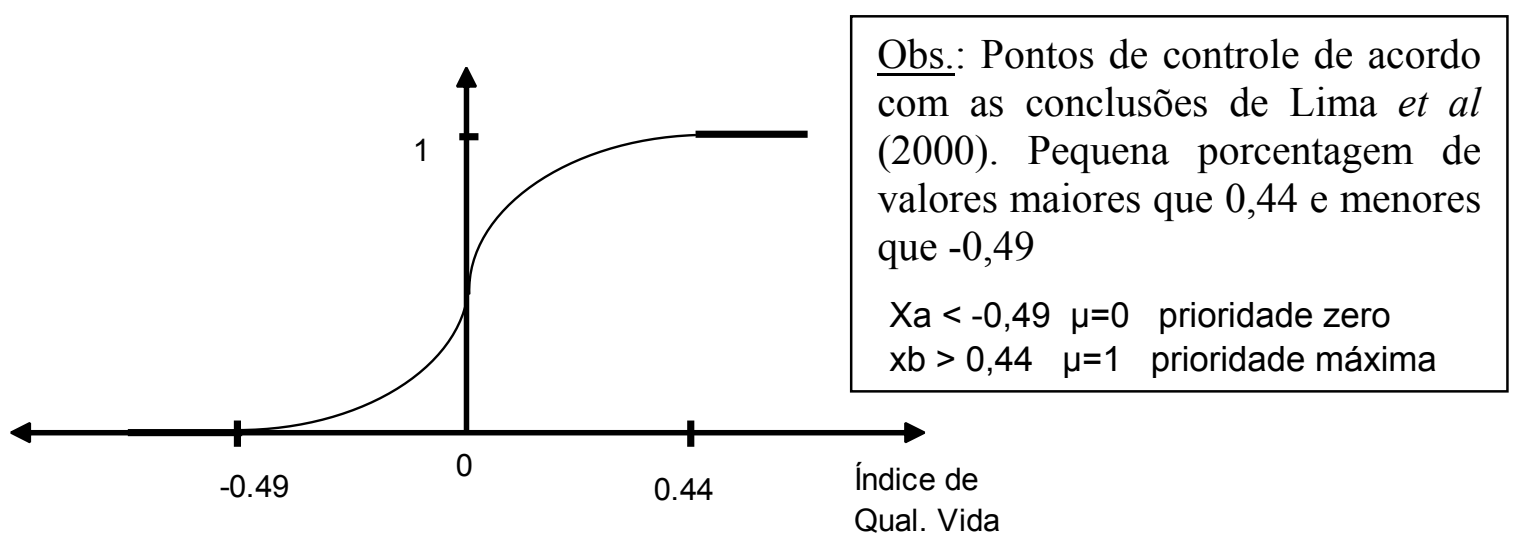

\section{FUNÇÃO FUZZY DO FATOR D - CUSTOS DE M\&R}

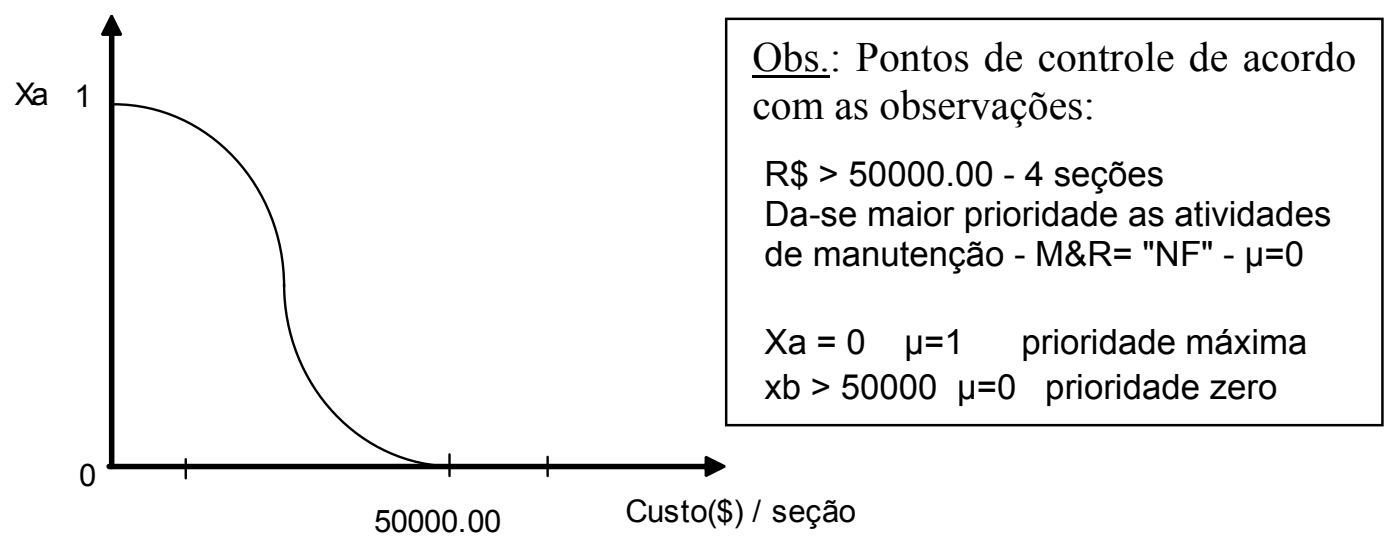


MAPAS DO FATOR C32 -QUALIDADE DE VIDA NOS BAIRROS

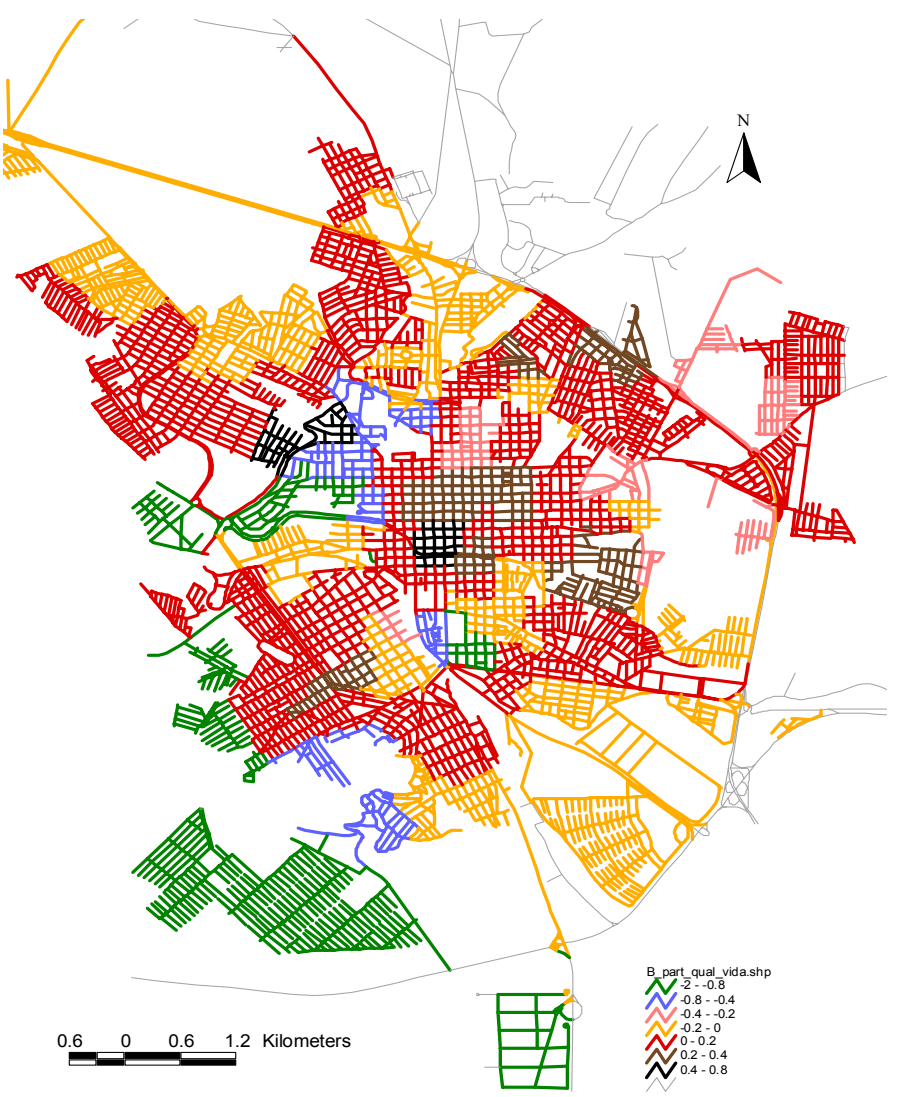

(a) Fator C32 - Não normalizado

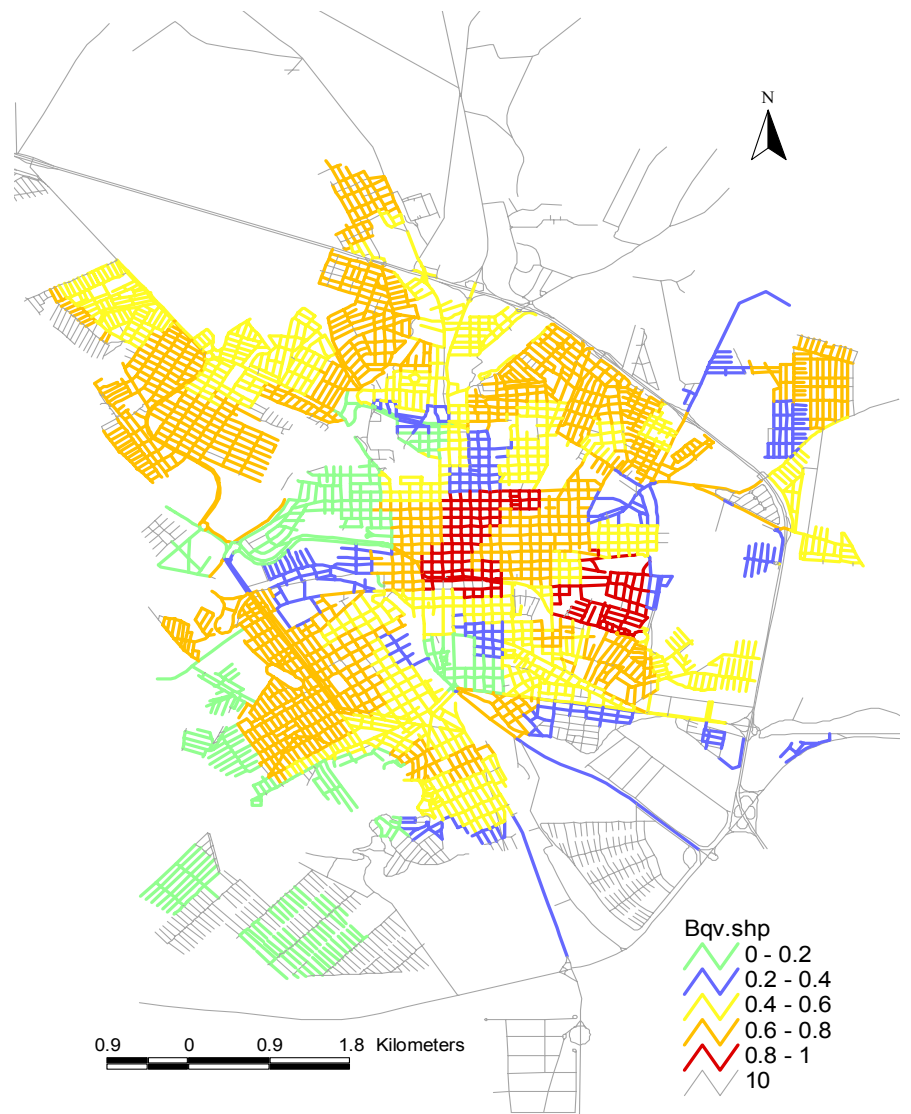

(b) Fator C32 - Normalizado 


\section{MAPA DO FATOR D - CUSTOS DA ESTRATÉGIA DE M\&R}

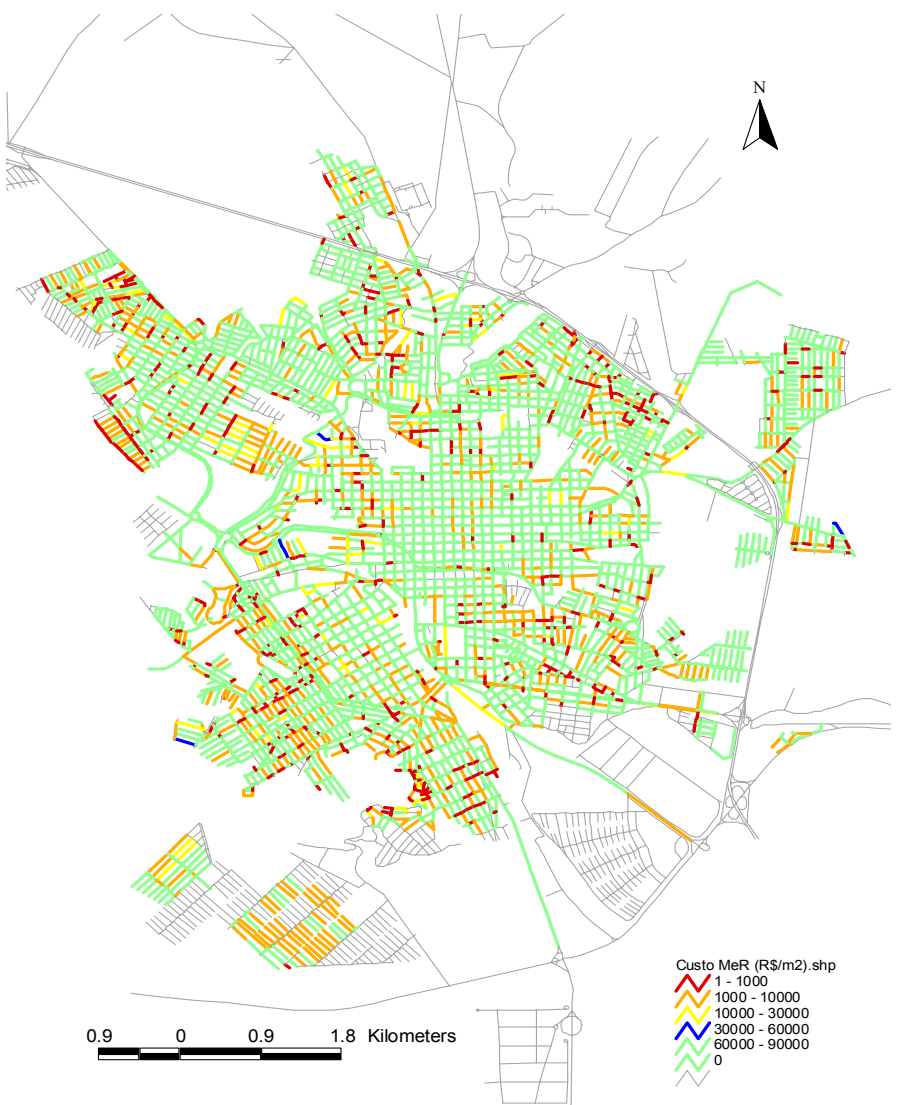

(a) Fator D - Não normalizado

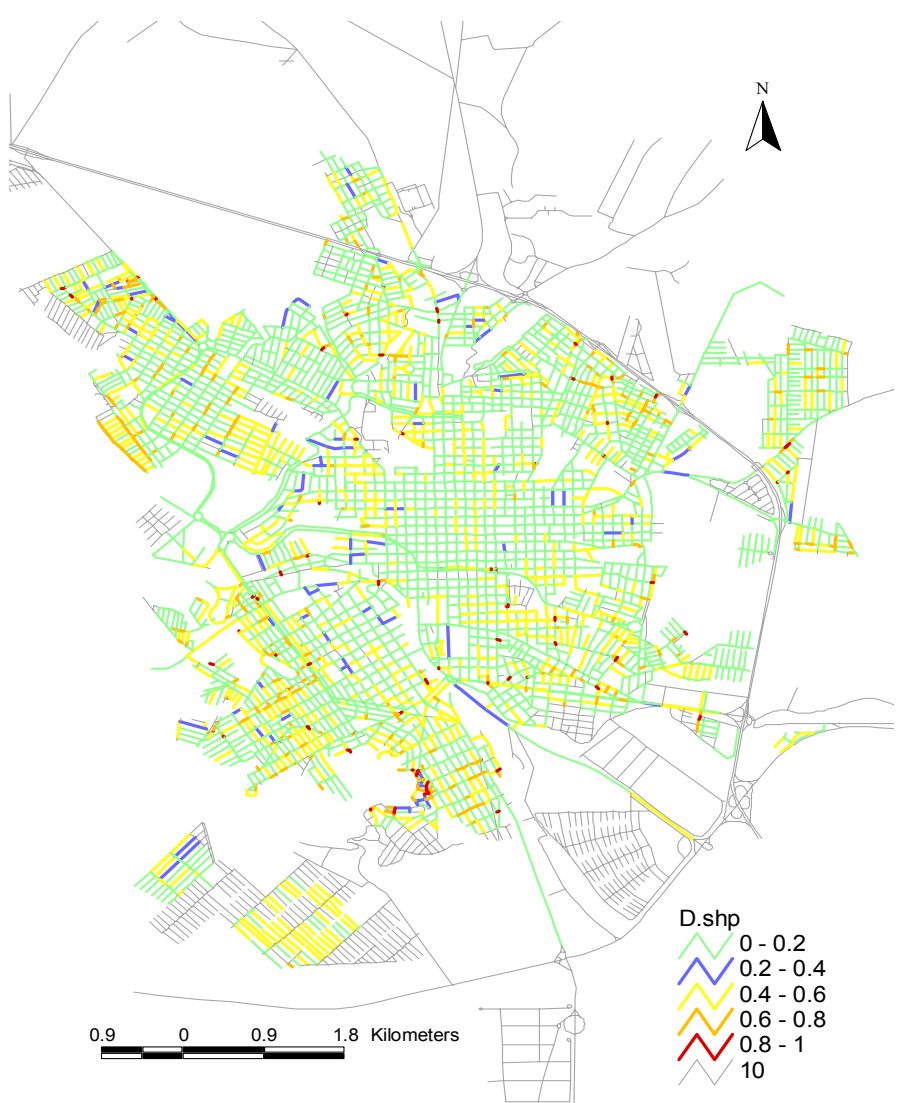

(b) Fator D - Normalizado 

ANEXO F: MAPA DE BAIRROS DA CIDADE DE SÃO CARLOS - SP 


\section{F-1. LOCALIZAÇÃO DE BAIRROS}

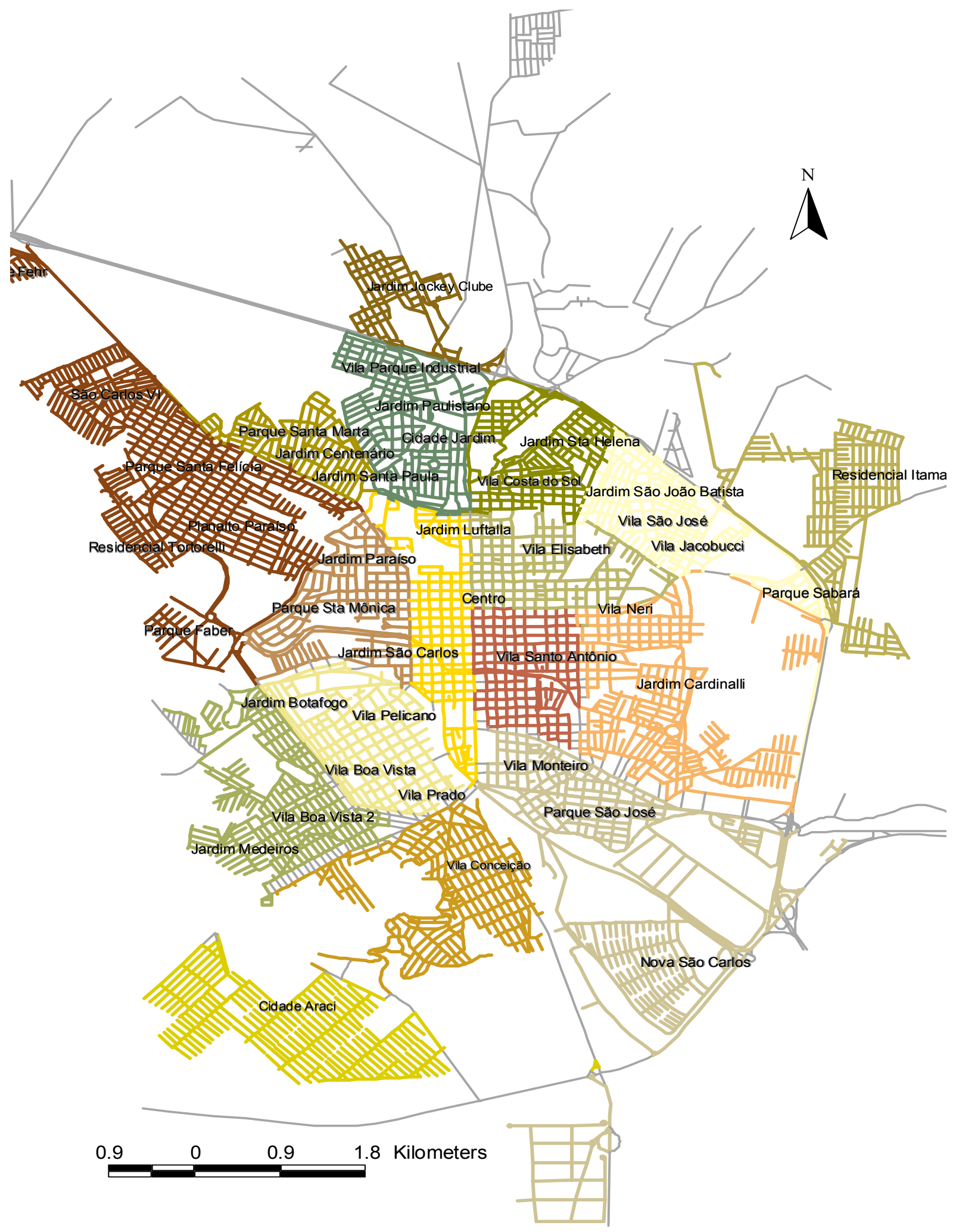

